\title{
Economic Analysis of International Law
}

\author{
Edited by \\ THOMAS EGER, STEFAN OETER \\ and STEFAN VOIGT
}

Mohr Siebeck 


\section{Economic Analysis of International Law}

Contributions to the XIIIth Travemünde Symposium on the Economic Analysis of Law

(March 29-31,2012)

\section{Edited by}

Thomas Eger, Stefan Oeter

and Stefan Voigt

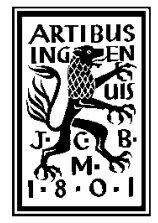

Mohr Siebeck 
Thomas Eger is professor of Law and Economics at the University of Hamburg, Faculty of Law, Vice-Dean for Research and International Affairs, director of the Institute of Law and Economics, director of the Graduate School on "The Economics of the Internationalisation of the Law" and director of the international and interdisciplinary European Master in Law and Economics Program.

Stefan Oeter is professor of Public Law and International Law and director of the Institute for International Affairs at the University of Hamburg as well as chairman of the Historical Commission of International Society for Military Law and the Laws of War and member of the Permanent Court of Arbitration, Den Haag.

Stefan Voigt is professor at the University of Hamburg and director of the Institute for Law and Economics at the University of Hamburg, fellow of the CESifo in Munich and connected to the International Centre for Economic Research (ICER) in Turin.

e-ISBN PDF 978-3-16-153512-3

ISBN 978-3-16-151894-2

The Deutsche Nationalbibliothek lists this publication in the Deutsche Nationalbibliographie; detailed bibliographic data are available on the Internet at http://dnb.dnb.de.

\section{(c) 2014 by Mohr Siebeck Tübingen. www.mohr.de}

This work is since 01/2020 licensed under the license "Attribution-NonCommercialNoDerivatives 4.0 International" (CC BY-NC-ND 4.0). A complete version of the license text can be found at: https://creativecommons.org/licenses/by-nc-nd/4.0/. An electronic version of this book is freely available, thanks to the support of libraries working with Knowledge Unlatched. KU is a collaborative initiative designed to make high quality books Open Access for the public good. More information about the initiative can be found at www.knowledgeunlatched.org.

The book was printed by Gulde-Druck in Tübingen on non-aging paper and bound by Gulde-Druck in Tübingen.

Printed in Germany. 


\section{Preface}

By now, the Travemünde Symposia have become a well-established tradition. The XIIIth Travemünde Symposium on Law and Economics took place in March 2012. Compared to previous symposia on issues of economic analysis of law, the 2012 event entered new ground. The topics traditionally dealt with at Travemünde covered a broad range of classical issues of Law and Economics, mostly linked with questions of private, commercial and economic law. The XIIth symposium in 2010 had broadened the range of topics by dealing with economic analysis of European law. This time, the symposium went further and focused upon economic analysis of international law.

The choice of topics is far from accidental. Since 2010, the faculties of law and of economics and social science at the University of Hamburg have hosted a Graduate School (Graduiertenkolleg) on "Economics of Internationalization of Law" funded by the German Research Organization DFG. Doctoral students from all over the world conduct research on a broad range of topics dealing with economic analysis of international and transnational law. At the same time, an impressive number of well-known scholars working on issues of economic analysis of international law have come to Hamburg to give lectures on recent research in the field. All this has given research on economic analysis of international law a boost. This is important since the branch of Law and Economics dealing with issues of international law is very young. The debate on economic analysis of international law did not start until the late 1990s, with a number of articles applying tools of economic analysis to questions of international economic law, but also with a number of articles of Jack Goldsmith and Eric Posner as well as Jeffrey Dunoff and Joel Trachtman on more general issues of international law. These articles took a rather critical stance on traditional international legal doctrine and were criticized by a number of authors which led to a thought provoking scholarly debate. Goldsmith and Posner consolidated their position with the 2005 monograph on "The Limits of International Law". Joel P. Trachtman and Andrew Guzman reacted in 2008 with their monographs on "The Economic Structure of International Law" and "How International Law Works. A Rational Choice Theory". These three books, together with a special issue of the University of Illinois Law Review 2008 containing the papers of a 2006 conference at Bonn on "Public International Law and Economics", have been the starting-point of a full-scale academic debate on a broad range of issues of economic analysis applied to international law. In this discourse of relatively recent origin, the Hamburg Graduate School plays an important role. 
The 2012 Travemünde Symposium was intended to map the on-going debate on Law and Economics applied to international law. The topics covered in this volume range from classics of the on-going discussion on economic analysis of international law - like the issue of "Legitimacy of Customary International Law" - to rather new topics such as internet privacy, private military contractors, combat against piracy, the International Criminal Court and the highly topical issue of 'land grabbing'.

The first contribution by Stefan Oeter deals with the Legitimacy of Customary International Law. This constitutes a classic of the Law and Economics debate on issues of international law. The debate started in the late 1990s with articles of Goldsmith and Posner dealing very critically with traditional doctrines of customary international law (CIL). Their massive onslaught on traditional doctrines provoked heavy reactions - and initiated an intense debate. It demonstrated that the standard accounts of CIL in a doctrinal perspective are not really convincing; however, ridiculing customary international law (like it was done by Goldsmith and Posner) as misleading labels for situations where there are simply significant payoffs from cooperation does not really help to understand the intricacies of CIL either. Pay-offs from cooperation are needed to stabilize certain patterns of action; without such payoffs, CIL would not exist. But the assumption that coordination always needs an immediate payoff would not do justice to the intricacies of social action in long-term relationships. The paper by Oeter tries to demonstrate the type of social dilemma underlying CIL and highlights how - in a rational choice perspective - rules of CIL evolve as a response to such dilemma structures. The paper takes recourse to recent experimental studies on the formation of custom. Customary Law mostly occurs in coordination games of a repeated nature, where states need a focal point in order to develop concerted patterns of behaviour. The emergence of behavioural regularities is the first decisive factor of gradual emergence of norms out of social practice. The expectation goes towards a calculus that a certain pattern of behaviour will continue also in future. Such an expectation facilitates transactions between states, because it reduces insecurity about future behaviour, and in the medium term also minimizes transaction costs. Such behavioural regularities, however, may only be attributed legal significance if there is a shared interpretation regarding the meaning of such usages in a given social environment. Entering into a dynamic of evolutionary creation of regular patterns of behaviour, linked shared meanings and - as a result - legitimate expectations are not as implausible as some critical rationalist authors have argued. The paper attempts to shed some new light on a number of basic theoretical questions concerning customary international law.

The second paper deals with the Economics of Informal International Law. In a strongly empirical research design, Stefan Voigt uses the US database of 'international treaties' (requiring the consent of the US Senate) 
and of 'international agreements' (of an executive agreement character) to find answers to a number of questions in the realm of informal international law-making: Has the use of 'international agreements' (as opposed to the more formal 'treaties') truly increased, as is often presumed? What are the policy areas that are primarily tackled by this less formal form of international law and are executive agreements used primarily in bilateral relations or multilaterally? Which actors use international agreements - is it primarily the traditional actors that also enter into treaties, or is this type of law-making the arena of other ministries or even independent government agencies? With regard to the US, the inquiry shows that the number of international agreements concluded did indeed increase dramatically until around 2006, but that since then their use has declined substantially. Around two-thirds of all international agreements are concerned with only three policy areas: the military, science and technology, and aid. More than $90 \%$ of all international agreements are conducted bilaterally. And around $40 \%$ of all agreements are concluded by a non-traditional actor on the US side, i.e., an actor other than the President or the Secretary of State. Unfortunately, analysing data from just one country does not allow one to draw any general conclusions, but such a systematic analysis of the practice over a 30-year period does permit to reveal some interesting insights into the pattern of informal international law-making.

In a third paper, the highly topical issue of Internet Privacy in the Evolving Technological Environments is looked at from a Law and Economics perspective by Haksoo Ko. The paper elaborates in detail on the technological evolution of the internet as a constantly changing technological environment for the issues of protection of internet privacy. Internet privacy definitively is endangered by the described technological changes, and it constitutes a difficult question of how to develop the ways and means of protecting rights of privacy under these conditions. In taking a Law and Economics perspective, the author attempts to shed some light on the chances of a sustainable protection of internet privacy. The chances of such protection are grim, but a closer look is needed why this is so - and the paper helps a lot in understanding the challenges and future prospects of endeavours to improve the protection of internet privacy.

A fourth contribution is dedicated to a topic recently discussed very heavily in the realm of international law - the issue of Private Military Contractors and its position within the normative setting of international law dealing with armed conflicts. In this paper, Thilo Marauhn describes the economic rationale that leads to the outsourcing of military capabilities. The handling of military logistics, but sometimes even the conduct of military operations by private contractors raises a number of serious legal questions. What is the status of such contractors under international law, and how does responsibility of states operate if delicate types of action are conducted at arms-length by 
private contractors? The paper states an ideological turn in security governance with a strong preference for organizational flexibility - a flexibility that is much easier to achieve if large segments of the security apparatus are outsourced to contractors. The paper analyses the applicable law to be found in the law of armed conflicts, but also in the rules of state responsibility. In particular, the rules on the prohibition of mercenaries prove to be completely inadequate to cover the situation. Additionally, the status rules of traditional humanitarian law pose problems, as well as the rules on direct participation in hostilities. Human rights law does not provide convincing answers either thus the quest for new treaty law. An economic analysis perspective, however, demonstrates that there are not sufficient incentives for the elaboration of a new treaty regime. The alternative is a recourse to new forms of 'soft law' - a track that has been pursued with the Montreux Document and the complementary International Code of Conduct for Private Security Service Providers (with its innovative Oversight Mechanism). The paper provides an in-depth analysis of these mechanisms and explores the potential of such soft law approaches, but also revisits the question whether the established legal rules are sufficient to deal with the challenges raised by the growing use of private military contractors.

In this contribution to the volume, Christopher Drahozal deals with the Economics of Comity. Whereas the first paper in this volume (implicitly) describes the difficulties in distinguishing customary law from mere comity, this paper highlights the rationale of developing concerted patterns of behaviour by comity in a Law and Economics perspective. The doctrine of comity secures a spirit of cooperation without entering in the intricacies of deep legalization. The paper reconstructs the doctrine of comity as it is used by the US Supreme court in dealing with foreign official acts. Comity involves a balancing of competing public and private interests, in order to systematically take into account conflicts between the public policies of domestic and foreign sovereigns. Thus, it constitutes a complementary tool to the doctrines of state immunity. Drawing on economic tools, the paper then highlights the dynamics of comity, oscillating between cooperation and defection. When courts refuse to defer to foreign acts, which in a choice left open under the doctrine of comity, they are deliberately defecting from the cooperative solution suggested by the concept of comity. The ensuing dynamics of recognition of foreign judgments and denial of such recognition follows clear patterns of interest. The doctrine of comity attempts to bring some structure into such opportunistic tendencies, and tries to strengthen cooperative modes of dealing with jurisdictional conflicts. A Law and Economics perspective helps in understanding not just the patterns, but also the challenges of such an approach, which is demonstrated by the subsequent remarks on the relationship between comity and more tight-knit solutions laid down in treaties of judicial coopera- 
tion. A perspective on rent-seeking and on judicial incentives gives interesting insights in this regard.

Matters of cooperation in judicial matters, in particular in criminal prosecution, form the focus of Birgit Feldtmann's paper on Fighting Maritime Piracy. The paper deals with the possible actions in fighting piracy - and the consequences of such actions, modelled in terms of economic analysis. The paper accordingly looks at the question of how the international community reacts to the problem of maritime piracy. For this purpose, it takes a brief look at the general problem of maritime piracy; specifically in the Horn of Afri$\mathrm{ca} /$ Indian Ocean region, and looks at counter-piracy activities undertaken by the international community. The impact of those activities has been very much debated. The main international legal question raised has been whether the established legal framework is sufficient or not. This controversial issue forms the background of the paper, which in its second part analyses the legal framework for counter-piracy enforcement under international law in-depth. In a third part, the article examines the question of how this legal framework is implemented into national legislation and guidelines, as well as how it is actually used in different contexts. This is illustrated by two examples, one concerning the question of prosecution (or often, rather, non-prosecution) of suspected pirates arrested by States engaging in counter-piracy operations, the other concerning the importance of Rules of Engagement for the effectiveness of counter-piracy activities. As a conclusive part, the paper moves to the question of what the consequences of the approaches chosen by the states in question might be. The perception of the stakeholders in the shipping business gradually shifted towards the impression that counter-piracy operations were somewhat ineffective and that to some extent they were left alone with the problem. As a result, the tendency to take care of ship security by hiring Privately Contracted Armed Security Personnel was growing - a trend that causes great concern in security circles. The resulting question is how this development towards extended private security provision can be conducted and controlled in a sensible way, governed by the principles of the "rule of law".

The following paper deals with the experiences from the first ten years of the International Criminal Court (ICC). Florian Jeßberger supplements a stocktaking exercise concerning the development of the recent structures of an international criminal judiciary by the attempt to apply some elements of a law and economics approach to issues of international criminal justice in general and the ICC in particular. This is done, first and foremost, in order to identify topics and themes for a future research agenda and it is warranted because, as the paper shows, there still is a significant lack of in-depth research concerning basic issues underlying and shaping the emerging system of international criminal justice. The paper is organized in three parts. The first part briefly summarizes the key characteristics of the ICC, its roots and competences, and outlines its practice. The 
second part looks into the roles and functions which may be ascribed to the ICC. The third part endeavours to identify a few issues which may deserve further scrutiny from the perspective of law and economics. While international criminal law is made by states, in contrast to traditional international law its norms do not regulate the relationship between states, but directly impose obligations on the individual. Individuals are the addressees of international criminal law. Thus, an analysis of international criminal law can either focus on the individual or on the actions of states. Reflecting this structure of international criminal law - at the intersection of individual responsibility and international/inter-state regulation - there are two natural starting points of an economic analysis. First, it is possible to think about international criminal law in terms of crime and punishment; such a micro-analysis would take on a perspective which is well known in the traditional Law and Economics literature. Second, an economic analysis of international criminal law in general and the ICC in particular could start from the perspective of states as major actors in the international arena. In such a macro-analysis, the 'sovereignty costs' connected to the surrender of states to the ICC system could be taken into consideration as well as possible benefits. A third, separate starting point for an economic analysis of international criminal law (which the paper addresses briefly) could inquire into the costs and benefits of establishing mechanisms for the determination and enforcement of individual responsibility on the international level as compared to applying (traditionally existing) inter-state mechanisms of state responsibility.

Another contribution takes up issues of the last Travemünde Symposium dealing with issues of European law and focuses upon the European Constitutional Impossibility Theorem. This theorem, developed Christian Kirchner, highlights the difficulties in constitutional change plaguing the European Union. The constitutional quests for a further deepening of integration as well as for more decentralisation both focus very much on Treaty revisions. But if Treaty revisions play a prominent role in power transfers in both directions, procedural rules for Treaty revisions are of utmost importance for either centralisation or decentralisation. In order to find out whether moves towards more (or less) integration can be undertaken within the present legal structure of the European Union, it is necessary to analyse the existing Treaty revision provisions and possible circumventions. The thesis of the paper is that, due to present legal provisions for Treaty revisions in the Lisbon Treaty, major moves in the direction of either more or less integration are impossible (European Constitutional impossibility theorem). This is the case for a revision of existing revision provisions as well. Thus, the present balance of competences between Member States and the European level is being petrified. Only slight shifts of power can be achieved within the present legal structure of the European Union. The 
in-depth analysis of the paper supports to a certain degree such theorem. It demonstrates that revisions of the European constitution are extremely costly. This fact will prevent any substantial Treaty revision in the future. The incentive for Member States to participate in a race for stricter ratification or quasi-ratification rules may lead to a situation where impediments for Treaty revisions become insurmountable. If Member States or the European Commission should not just try to circumvent the Treaty revision provisions but ignore them and take recourse to unconstitutional activities and engage in de-facto revisions of the Treaty, the price of legal uncertainty and weakening the rule of law would be tremendous and would endanger the European integration process as such.

The last paper is dedicated to an analysis of recent phenomena of Foreign Direct Investment in Agriculture - a phenomenon that is open to rather divergent evaluations, phrased in the question: Land Grabbing or Food Security Improvement? In recent years, foreign direct investments in agricultural land in Third World Countries have grown enormously. Often traditional farmers are driven from the land, instead large commercial farms are created that produce crops for export. The phenomenon has been coined in negative terms as 'land grabbing'. Christian Haeberli tries to demonstrate that land grab, where it occurs, is not only another symptom of regulatory failure at the national level but also a lack of corporate social responsibility by certain private actors. National governance is clearly the most important factor; it is submitted, however, that there is also an international dimension involving investor home states in various capacities. The implication is that land grab is not solely a question whether a particular investment contract is legal or not. Since about 2008, advocacy groups have drawn attention to numerous cases of what they consider as land acquisitions with a doubtful legal basis, especially in socalled weak states. Economic studies as far back as 1989 had shown the advantages and the intrinsic distortions of agricultural FDI in a food security perspective. Since then, numerous impact modelling and assessment studies have been conducted, often with the World Bank economic research programme. Legal scholars and policy makers lag far behind. Legal studies, especially of the international issues of agricultural FDI, are still virtually nonexistent. The numerous new proposals for codes of conduct, voluntary guidelines and principles for responsible agricultural investment are typically less than three years old, and they tend to focus on the national dimension of land grab. The paper deals with legal issues which seem to have largely escaped the attention of both human rights lawyers and, especially, of investment lawyers. It addresses this fragmentation between different legal disciplines, rules, and policies, by asking two basic questions: Do governments and parliaments in investor home countries have any responsibility with respect to the behaviour of their investors abroad? And what should they and international regulators do? There are still no valid answers to these questions, although the paper 
outlines various lines of action that might make sense. Investment law and investment treaties have so far not been seriously scrutinised in this context. Since their principal objective is investment promotion and protection, most of them still fail to take on board other considerations and interests such as human rights and food security. The food security impact of agricultural FDI is far from clear, and an overall impact assessment would hardly be feasible. But there are enough allegations and some serious evidence of land grab to warrant a re-examination of the relevant regulatory framework by home states and in the competent intergovernmental organisations.

This volume does not only contain the papers just described but also the comments presented by a commentator at the Symposium as well as a brief summary of the subsequent discussions. The reader of this volume will, hopefully, be able to grasp the lively and stimulating atmosphere that has become one of the trademarks of the Travemünde Symposium. Organizing such a symposium requires the help of many. First of all, the organizers would like to thank the German Research Foundation (DFG) for the financial support of the conference. We also wish to thank Christiane NeySchönig for doing all the necessary preparatory work to make the conference a success; José Guilherme Moreno Caiado, Jan Engelmann, Elif Erdemoglu, Joseb Gudiashvili, Jerg Gutmann, Christoph Kimmerle, Viola Prifti and Johannes Schwarze, who summarized the discussions; and, last but not least, David Börn and Kevin West for their invaluable help in formatting this volume. Finally, we are truly grateful for the - as usual - excellent and professional cooperation with the people working at Mohr Siebeck, our publisher, for all their assistance in the publication of this book.

Hamburg, im März 2014

Thomas Eger

Stefan Oeter Stefan Voigt 


\section{Table of Contents}

Stefan Oeter

The Legitimacy of Customary International Law

Georg von Wangenheim

Comment on Stefan Oeter.

Discussion on Stefan Oeter

summarized by José Caiado

Stefan Voigt

The Economics of Informal International Law -

An Empirical Assessment

Peter Lewisch

Comment on Stefan Voigt

Discussion on Stefan Voigt

summarized by Christoph Kimmerle.

Haksoo Ko

Law and Technology of Data Privacy:

A Case for International Harmonization.

Michael Fehling

Comment on Haksoo Ko.....

Discussion on Haskoo Ko

summarized by José Caiado

Thilo Marauhn

Private Military Contractors -

Mercenaries Outside the Scope of Law?

Discussion on Thilo Marauhn

summarized by Jerg Gutmann. 
Christopher R. Drahozal

Some Observations on the Economics of Comity

Dieter Schmidtchen

Comment on Christopher R. Drahozal ...

Discussion on Christopher R. Drahozal

summarized by Jan Engelmann....

Birgit Feldtmann

Fighting Maritime Piracy -

On Possible Actions and Consequences

Max Gössler

Comment on Birgit Feldtmann

Discussion on Birgit Feldtmann

summarized by Viola Prifti.

Florian Jeßberger/Julia Geneuss

A Success?

Reflections on the First Ten Years

of the International Criminal Court....

Eyal Benvenisti

Comment on Florian Jeßberger/Julia Geneuss

Discussion on Florian Jeßberger/Julia Geneuss

summarized by Joseb Gudiashvili...

Christian Kirchner

The European Constitutional Impossibility Theorem

Thomas Eger

Comment on Christian Kirchner...

Discussion on Christian Kirchner

summarized by Elif Erdemoglu...

Christian Häberli

Foreign Direct Investment in Agriculture:

Land Grab or Food Security Improvement? 
Laarni Escresa

Comment on Christian Häberli......................................... 305

Discussion on Christian Häberli

summarized by Johannes Schwarze................................. 321

Short Biographies................................................ 327

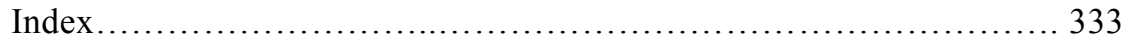





\title{
The Legitimacy of Customary International Law
}

\author{
by \\ Stefan Oeter ${ }^{*}$
}

\begin{abstract}
:
Customary International Law has experienced massive onslaughts; authors like Goldsmith and Posner have negated the relevance of customary international law altogether. At the same time, a renewed interest in scholarship on customary international law could be seen during the last years. The paper tries to use the existing scholarly studies to reconstruct and model the operation of customary international law in an economic analysis perspective. A key element in such a reconstruction is the role legitimate expectations (and the stabilization of legitimate expectations) play in the workings of international relations. Customary Law mostly occurs in coordination games of a repeated nature, where states need a focal point in order to develop concerted patterns of behavior in order to overcome social dilemma situations. The emergence of behavioral regularities is the first decisive factor of gradual emergence of norms out of social practice. The expectation goes towards a calculus that a certain pattern of behavior will continue also in future. Such an expectation facilitates transactions between states, because it reduces insecurity about future behavior, and in the medium term also minimizes transaction costs. Such behavioral regularities, however, may only be attributed legal significance if there is a shared meaning of such usages in a given social environment. Entering into a dynamic of evolutionary creation of regular patterns of behavior, linked shared meanings and - as a result - legitimate expectations is not as implausible as some critical rationalist authors have argued. The paper cannot purport to answer most of the open questions, but attempts to shed some new light on a number of basic theoretical questions concerning customary international law and to deal with some intricate operational questions of how to model certain details of the practice of customary international law.
\end{abstract}

${ }^{*}$ Chair of Comparative Public Law and Public International Law, Faculty of Law, University of Hamburg, and Director, Institute of International Affairs, University of Hamburg. 


\section{A. Why Bother about Customary International Law?}

Customary International Law (CIL) until now has found only limited attention as a topic of law and economics scholarship. A reason for such neglect might be the two mega-trends that Goldsmith and Posner highlight in their book of $2005 .{ }^{1}$ They point to the fact that political scientists as well as international lawyers strongly emphasize two trends which are in their view characteristic for the late twentieth century - the 'legalization' of international relations and the rise of multilateral institutions. ${ }^{2}$ Both trends rest on the assumption that what counts in international law are formal international organizations and multilateral treaties. This view - Goldsmith and Posner argue - betrays a lack of historical perspective. ${ }^{3}$ Customary international law has always served as a kind of backbone of public international law, with the same legal force as treaty law - and still today CIL regulates important elements of international relations in a structure which is equally as multilateral as modern treaty law. Despite the rise of multilateral treaties and organizations, they stress, "customary international law remains an important component of international law and an important object of study for international lawyers". ${ }^{4}$

The following paper argues that there are good arguments for making such claim: Most of the foundational principles of international law (such as territorial sovereignty and sovereign equality), together with the fundamental institutions of international law deriving from such principles, such as sovereign immunity of states, rules of recognition of states and governments, the detailed norms of non-intervention, as well as state responsibility, are still governed by CIL. ${ }^{5}$ And even in areas where treaties have proliferated, such as the law of treaties, the laws of war, international criminal law and the law of human rights, international law continues to play an important role, since it offers a fallback regime in cases where treaty rules do not apply (due to nonratification of important treaties by major states) and provides interpretive presumptions and guidelines for treaty norms as well. " "For these reasons, no comprehensive theory of international law can ignore it", Goldsmith and Posner formulate, only to continue with the blunt statement: "And yet, we have a poor understanding of customary international law."

Such a statement of 'poor understanding', the paper admits, may be true even the most fundamental issues linked with the doctrine of customary inter-

\footnotetext{
${ }^{1}$ Goldsmith and Posner (2005), 21.

${ }^{2}$ See e.g. Abbot and Snidall (1998).

${ }^{3}$ Goldsmith and Posner (2005), 21.

${ }^{4}$ Goldsmith and Posner (2005), 21.

${ }^{5}$ Guzman (2008), 184.

${ }^{6}$ See also Goldsmith and Posner (1998).

${ }^{7}$ Goldsmith and Posner (2005), 21.
} 
national law remain very much in dispute until today. ${ }^{8}$ Writings on international law always have argued rather diverse positions on what constitutes CIL, which elements are needed to form it and what indicators should be looked at in order to identify its rules. ${ }^{9}$ Such diversity of views is inextricably linked to a lack of understanding of what might constitute the binding element in customary law. Why should states obey rules that are not written down, in the formation of which they might not have participated and which do not possess any formal institutions of compliance management and enforcement? The idea that such a kind of informal rules should exert any constraining force on the behavior of states - collective actors usually modeled as rational actors seeking to maximize their interests - is difficult to understand for many authors working with rational choice paradigms. ${ }^{10}$

The work of Goldsmith and Posner is exemplary for such epistemic difficulties. Their treatment of issues of customary international law is more a symptom of the described problem of "poor understanding" of CIL than an attempt to deliver any kind of productive answer to improve the understanding of CIL. ${ }^{11}$ In the approach they take, they show exactly the same lack of historical perspective that they complain about when approaching the issue of CIL. In trying to model the workings of CIL rules, they tend to approach the segments of international relations that are regulated by CIL as if they constituted simple forms of a one-shot-game - an assumption that by definition cannot do justice to the interactive arrangements that states are caught into. That one cannot do justice to the intrinsic problems of CIL by simply ignoring their character as (nearly endless) repeated games has already been highlighted by Andrew Guzman. ${ }^{12}$ It is to be admitted that the typical standard accounts of CIL in a doctrinal perspective are not really convincing - but ridiculing customary international law as misleading labels for situations where there are simply significant payoffs from cooperation does not really help us to understand the intricacies of CIL either. To be open: Pay-offs from cooperation are needed to stabilize certain patterns of action; without such payoffs, CIL would not come into existence. But the assumption that coordination always needs an immediate payoff would not do justice to the intricacies of

\footnotetext{
${ }^{8}$ As a recent restatement of the conceptual as well as practical enigmas of CIL see Lepard (2010), 3-44.

${ }^{9}$ See only - as some more recent contributions - Mendelson (1998); Byers (1999); Tomuschat (1999); Kelly (2000); Goldsmith and Posner (2000); Roberts (2001); Chinen (2001); Stern (2001); Estreicher and Stephan (2003); Kolb (2003); Vagts (2004); Mofidi (2005); Guzman (2005); Hannikainen (2006); Golove (2006); Ochoa (2007); Petersen (2007); Norman and Trachtman (2008); Orakhelashvili (2008); Treves (2009); Stephan (2010); Lepard (2010); Baker (2010); Kammerhofer (2011); Scharf (2013).

${ }^{10}$ See also Engel and Kurschilgen (2011), 6.

${ }^{11}$ As critics of Goldsmith and Posner's position on CIL, see only Chinen (2001); Norman and Trachtman (2005); Golove (2006); Guzman (2008).

${ }^{12}$ Guzman (2008).
} 
social action in long-term interactive relationships. In the background there is always a dilemma of social action - cooperation as such brings payoffs, but the biggest gains might be earned when one is successfully taking the position of a free-rider. But not all actors can be free-riders - since then no cooperation (and no pay-offs) would occur. In such a social dilemma, individual and social rationality fall apart: "What would be best for society is not in the best interest of the individual." ${ }^{13}$ Such a dilemma is quite common in social interaction and can be easily modeled and made testable in terms of game theory. ${ }^{14}$

In order to understand the radical onslaught on traditional doctrines of CIL that was launched by Goldsmith and Posner, one should read the decisive passage of their argumentation in full: "Although most international law scholars acknowledge that states are more likely to violate customary international law as the costs of compliance increase, they insist that the sense of legal obligation puts some drag on such deviations. Our theory, by contrast, insists that the payoffs from cooperation or deviation are the sole determinants of whether states engage in the cooperative behaviors that are labeled customary international law. This is why we deny the claim that customary international law is an exogenous influence on states' behavior. And because we are skeptical about the possibility of cooperation by custom in multiplayer prisoner's dilemmas, we are skeptical that customary international law fosters true multilateral cooperation." 15

The following paragraph of their critical assessment goes even further by contending: "Similarly, pairwise coordination may emerge spontaneously, or evolve into a behavioral regularity. Multilateral coordination is, for reasons explained earlier, unlikely to evolve by custom, but if it were to evolve, states would not act as they do out of a sense of legal obligation, but to further their interests. ${ }^{16}$ Only as a side-remark: The last formulation is a truism if we model state practice in rational-choice terms - law only works in these terms if it embodies an enlightened self-interest of states, i.e., helps states to further their interests, be it short-term, or long-term interests. We gain a first insight here: the time perspective is of utmost importance - it makes quite a difference whether we model the games as one-shot games or as repeated games, whether states pursue short-term gains limited to the concrete interaction or long-term gains linked to the repeated coordination game as such.

The approach of Goldsmith and Poser might be reformulated in the following words: States as actors of international relations might sometimes behave as if they were induced by rules that public international law doctrine describes as customary international law - but these are mere coincidences,

\footnotetext{
${ }^{13}$ Engel (2010), 4.

${ }^{14}$ For applications of game theory to international relations see Holzinger (2003); Sandler

${ }^{15}$ Goldsmith and Posner (2005), 39.

${ }^{16}$ Goldsmith and Posner (2005), 39.
} (2004). 
since states are not compelled to behave in the way they do by an exogenous influence of law, but merely by their own calculus of interest in the concrete situation, more or less converging with the proclaimed rules of CIL. And that such convergence happens seems plausible for Goldsmith and Posner only in the context of bilateral relations, and not in multilateral relations - but CIL is always about multilateral rules, and not bilateral ones. In bilateral exchanges, there usually will be an immediate coordination gain - but not in multilateral interactions. Put in blunt terms: CIL does not exist in the perspective of Goldsmith and Posner, but is a misnomer for certain types of converging interests where states show coordinated behavior due to a parallel calculus of interest.

Are international lawyers a herd of fools that believe in a form of law that never existed? Or are they a band of manipulators that pretend to guide state practice by a set of inherited rules that are sacred to any member of the caste of international lawyers, but which now are proving as the 'emperors' new clothes' if analyzed under the stringent categories of economic analysis? My hypothesis is that both questions are to be answered in the negative. CIL does indeed exist, and it is possible to reconstruct and model such a type of law in terms of a rationalist analysis of collective behavior of states. ${ }^{17}$ The following paragraphs will try to deliver a first sketch of the arguments that might help to prove that a category like CIL makes sense and rules of such a customary international law are capable to exert exogenous influence on states to abide by certain rules. "There is no reason in theory, or in data adduced by others, to believe CIL to be generally epiphenomenal."18

\section{B. Defining the Key Terms}

Customary law is not explicitly and intentionally created by individual authors but constitutes a consequence of social practice, emerges in an evolutionary fashion. ${ }^{19}$ The International Law Commission has even spoken of "the 'spontaneous' nature of the customary process". ${ }^{20}$ Customary law is not a new phenomenon in the long history of law, but probably the most ancient type of law that came into existence already at a very early stage of the history of mankind. ${ }^{21}$ Legal anthropology has found varieties of customary law all over the world, in practically all types of human society. ${ }^{22}$ In order to form socie-

\footnotetext{
${ }^{17}$ See also Trachtman (2008), 72-117.

${ }^{18}$ Trachtman (2008), 72.

${ }^{19}$ Engel (2010), 18.

${ }^{20}$ See the ILC's 2012 Report, para. 171 - International Law Commission, Report on the work of its sixty-fourth session (7 May to 1 June and 2 July to 3 August 2012), GAOR 67th Session, Suppl. No. 10 (UNGA Doc. A/67/10); see in addition Ago (1957), 727-730.

${ }^{21}$ Engel and Kurschilgen (2011), 2, and Mendelson (1998), 166-168.

${ }^{22}$ See only Fikentscher (2009); Donovan and Anderson (2003); Pospisil (1982).
} 
ties with a certain division of labor, human beings must build up basic institutions that stabilize expectations. Without stable expectations on what your fellows (on which you have to rely) will do with you, a societal development is more or less impossible. Cooperation and coordination of behavior in early societies probably developed in a long evolutionary process, driven to a certain degree by trial and error. But as soon as clans, tribes, peoples, expanding to ever larger societal set-ups, had developed certain behavioral regularities, they tended to trust in these regularities - not only because they seemed to repeat forever in terms of practical experience, but also because the members of the relevant society perceived their co-fellows to be obliged to behave in such a way because already the forefathers had behaved in such a way. Customs and mores were perceived as immutable, inherited from time immemori$\mathrm{al}-$ and men were obliged to respect such customs inherited from the forefathers. ${ }^{23}$

Factual regularity of social practices thus transforms - from a social science perspective - at a certain point in a prescriptive 'ought'. The other members of society (and transaction partners) trust in the regularity, develop a 'legitimate expectation'. ${ }^{24} \mathrm{Lab}$ experiments in the context of studies of behavioral economics have demonstrated that such 'legitimate expectations', based on regularities in behavioral patterns, develop quite easily in repeated game structures and help to overcome social dilemma situations where individual and social rationality fall apart. ${ }^{25}$ If somebody disappoints these legitimate expectations, the actor is perceived not only as showing an exceptional, perhaps even eccentric pattern of behavior, but - if the counterpart relied on the behavioral regularity for his own patterns of activity - is perceived to destroy the 'harmony' of society, by violating an iron rule that 'must' be respected. Typically, such rules of customary law in pre-modern societies are not seen as man-made, but as perennial, as inherited from time immemorial and the violation of such rules cries for sanctions, in order to restore 'harmony', an intuition which is even visible in lab experiments when test persons opt for sanctioning rule breakers even if these sanctions are costly for them. ${ }^{26}$

Modern times have not gotten completely rid of all forms of customary law - but they have lost their faith in rules of customary law as something perennial and immutable. We are aware that even customary law is a creation of man and changes over time. The evolution of behavioral regularities in specific societal constellations is not difficult to reconstruct - but how such regularities mute into something we could describe as law is much more difficult to model, in particular for a legal academia so much accustomed to authorita-

${ }^{23}$ Pospisil (1982), 53.

${ }^{24}$ As to the role of 'legitimate expectations' in the customary process see very much in detail Byers (1999), 106-126.

${ }^{25}$ Engel (2010), Engel and Kurschilgen (2011).

${ }^{26}$ Engel (2010), 10. 
tively enacted, written codes of law. ${ }^{27}$ But also rational choice theorists "have a hard time with customary law", as Engel and Kurschilgen have put it, "since it seems unclear why self-interested actors should contribute to the formation of a rule that will prevent them from acts of selfishness". ${ }^{28}$

When natural law concepts that had dominated international legal thinking until early $19^{\text {th }}$ century muted into concepts of customary international law, it was still easy to accept the rules concerned as law proper. Because the rules had been perceived before as 'law' deriving from the iron prescriptions of human reason, they had for a long time been practiced as a normative prescription - and that what had been practiced as law for a time immemorial clearly constituted customary law in the perspective of lawyers. ${ }^{29}$ But with the changing dynamics of societies (and the international system) even such customary law became a historical category. In traditional terms it was difficult to explain why something practiced for a long time should suddenly convert into a legal 'ought'. These epistemic difficulties explain why international legal doctrine remained to a certain degree in a relatively crude state, linking the existence of a rule of customary law to the proof of two determinant factors: 'consuetudo' and 'opinio juris sive necessitatis', i.e., 'custom' (in the sense of a behavioral regularity) and a 'sense of legal obligation', the belief that one is bound to behave in the same way as one has one has usually behaved.. The need of the first element is indisputable - without a pattern of behavioral regularity, there can never be any trait of customary law. The relevance of the second element, however, is very much disputed - and it has proven difficult to define more specifically what 'opinio juris' really might mean in operational terms.

It is obvious that behavioral regularity alone cannot provide a foundation for a prescriptive legal rule. Some other element must be added, a kind of shared belief that a regular pattern of behavior is something to be relied on when shaping one's own patterns of action, a kind of regularity that deserves legitimate trust - and if that trust is disappointed, constitutes a violation of legitimate expectations. ${ }^{30}$

\section{Some Theory: On the Incentive Structure of Customary International Law}

At the outset of the following arguments on the incentive structure of CIL, I would like to start with some basic observations grounded on theoretical re-

\footnotetext{
${ }^{27}$ See also Guzman (2008), 184.

${ }^{28}$ Engel and Kurscilgen (2011), 6.

${ }^{29}$ See only Treves (2009), 1; as well as Ochoa (2007), 129.

${ }^{30}$ See also Byers (1999), 106-107.
} 
flection of the experiences of international legal practice. CIL in most cases deals with coordination problems of a social dilemma nature. ${ }^{31}$ In some cases it might also help to stabilize relatively easy types of cooperation. But setting up and stabilizing complex patterns of cooperation necessitates an elaborate treaty regime with written codes and formal institutions. The types of coordination problems dealt with by CIL are definitely not of a 'one-shot-game' character - customary law is based upon a long trajectory of social practice, developing over time certain behavioral regularities. ${ }^{32}$ This conforms to the findings of economic literature dealing with the possibility to reach mutual cooperation in social dilemma situations - situations where individual and social rationality diverge and where a centralized authority with the power to enforce promises about behavior previously made is lacking. ${ }^{33}$ Availability of information regarding the past behavior of actors is key here, which presupposes a whole sequence of repeated games.

Customary law thus is by definition embedded in a pattern of repeated games. Lab experiments in the context of the nascent experimental law and economics literature have demonstrated that the traditional positivist as well as more recent rational choice conceptualisations of customary law miss a key ingredient. ${ }^{34}$ In the words of Engel and Kurschilgen: "Practice turns into law since behaviour and normative expectations coevolve. If nearly everybody behaves in a certain way, this not only shapes beliefs about others' future behaviour. If the pattern has been repeated for a while, the behavioural belief turns into a normative expectation. It no longer is purely cognitive. A motivational component is added to it. If one actor deviates from established practice, she violates others' normative expectations: others regard such behaviour as not only anti-social but illegitimate." ${ }^{35}$

Such custom turned into legitimate expectations (and thus law) has a strong beneficial effect on the interaction of experimental participants in social dilemma situations. "It helps experimental participants overcome a social dilemma." ${ }^{36}$ If there are no sanctions, the lab experiments of Engel and Kurschilgen demonstrate, the effect "basically coincides with the behavioural effect of what public international law calls comity." ${ }^{37}$ But since normative expectations and regularities of behaviour often coevolve (as again lab experiments demonstrate), comity tends to mute into rules of customary law. These rules tend to remain epiphenomenal as no sanctions are involved. "Whether the rule invokes the authority of the law is at best immaterial, if not detri-

\footnotetext{
${ }^{31}$ See Engel (2010), 4.

${ }^{32}$ Guzman (2008), 191; Trachtman (2008), 83.

${ }^{33}$ See e.g., Axelrod (1984); Milgrom, North, and Weingast (1990); Guzman (2008).

${ }^{34}$ See also Engel and Kurschilgen (2011), 6.

${ }^{35}$ Engel and Kurschilgen (2011), 6.

${ }^{36}$ Engel and Kurschilgen (2011), 18.

${ }^{37}$ Engel and Kurschilgen (2011), 18.
} 
mental. Yet the authority of the law becomes instrumental as soon as there are sanctions. If combined with comity, sanctions crowd out some of the beneficial effect. If the rule originates in law, however, the authority of the law and the threat of sanctions reinforce each other." ${ }^{38}$

These findings from decontextualized laboratory experiments gain even more force in real life contexts. The community of states is a close-knit community characterized by a relatively small number of members with intense interactions. There is practically no one-shot game in international relations. You always meet at least twice - a fact which is easily explainable by the stable structure of the community of states where a limited number of collective actors is caught in a network of repeated interactions which cannot be avoided. This means that the actors will have to interact with each other again and again, in a social set-up where acculturation and the evolution of shared 'social constructions of reality' in close-knit 'epistemic communities' play an enormous role. There are plenty of studies on normativity in international relations now that explore these issues. ${ }^{39}$

The critics of customary law use, it is suggested, "an overly narrow and therefore inappropriate concept of normativity" ${ }^{40}$ Normativity does not exhaust itself in guiding actors to patterns of behaviour the violation of which would be the addressee's self-interest, thus compelling them to forms of action running against their own interests. At the same time, however, in a social science perspective it is beyond doubt that the (moral or normative) duty to abide by the law is not the exclusive motivating force either. "Norms matter because they provide guidance. Most actors are most of the time willing to follow the norms prevailing in their context, or at least to be not too far off the mark, and most actors expect other actors to be thus guided." ${ }^{41}$ In terms of customary law: As far as normative expectations and behavioural patterns coevolve, behaviour is guided into the normatively desired direction, thus helping actors to develop stable patterns of behavioural coordination. ${ }^{42}$ In a more enlightened sense, actors have a self-interest in such stable patterns enabling structured coordination, since this makes their world more calculable and helps to further their interests in a stable social environment, thereby allowing investments in cooperation. This goes in line with studies over an "expressive" function of law. Law serves as a focal point for patterns of coordination. ${ }^{43}$ It informs people about behaviour others will approve, and thus

\footnotetext{
${ }^{38}$ Engel and Kurschilgen (2011), 18.

${ }^{39}$ See only Risse (1999); Risse (2000).

${ }^{40}$ Engel and Kurschilgen (2011), 3.

${ }^{41}$ Engel and Kurschilgen (2011), 3.

${ }^{42}$ Engel and Kurschilgen (2011), 3.

${ }^{43}$ McAdams (2000), McAdams and Nadler (2005).
} 
might inform also about the consequences associated with a specific type of action, minimizing collateral damage to social capital. ${ }^{44}$

In addition, the nature of the social environment plays a strong role. The number of collective actors qualified as states is limited and the bilateral interactions between them might have significant repercussions for others. Accordingly, states closely observe the interactions which happen even between third states. In taking a specific course of action vis-à-vis another state, they usually know which behavioral pattern is commonly preferred by the partner of their transaction, and they also tend to know what will be the pattern of action of the majority of the states in the field concerned. Mutual observation, the distilling of such observation into expectations of future behavioral patterns of interaction partners, and finally formal reactions if the expectations are not fulfilled explain how behavioral patterns develop - behavioural patterns that go much beyond mere bilateral relations ${ }^{45}$ Behavioral patterns thus not only consolidate into behavioral regularities on a temporal axis, but also spread among states that imitate successful patterns of interaction from others, thus at the end forming a more and more general pattern of action amongst a whole group of states (or even the entire state community).

With such generalization of behavioral patterns not only over time, but also in terms of participating states, rational expectations on the behavioral patterns of the interaction partners develop - rational expectations which facilitate interactions and lower transaction costs. ${ }^{46}$ With a behavioral regularity that might be trusted to continue in future, cumbersome calculations (and speculations) on what might be the future behavioral pattern of the partner become superfluous - information costs as well as the costs of decisionmaking go down, fewer securities are needed to invest in a fruitful cooperation with the other. A working pattern of behavioral regularities (in the sense of customary legal rules) thus improves efficiency of international coordination and cooperation.

But how does it work? There are no explicit institutions of compliance management, few possibilities to adjudicate, and 'tit for tat' sanctions after a violation also do not work very well in traditional international law (although they play a certain role in expressing the discontent of the others disappointed in their legitimate expectations). Nevertheless, the experience of international legal practice demonstrates that customary international law works well to an astonishing degree. Why do states rely on these behavioral regularities although there are few options really to enforce the rules? Reputation comes into play here as a key factor. ${ }^{47}$ States are well aware that others rely on their be-

\footnotetext{
${ }^{44}$ See McAdams (2000); Geisinger (2002).

${ }^{45}$ Byers (1999), 106-110.

${ }^{46}$ As far as the category of transaction costs is concerned, see only the ground-breaking work of Williamson (1985).

${ }^{47}$ See in particular Guzman (2008), 191.
} 
havioral regularities, have legitimate expectations that these regularities will continue - and that they can build their course of action on these regularities, including some kind of investment in enhanced coordination and cooperation. In inter-state communication signals are sent that certain regularities of behavior are trustworthy and can be relied upon, while others are still open and might change in future. But if it has been signaled that expectations of a continued behavioral regularity are legitimate, an aberration from that course, by taking a different path of action, clearly will violate these legitimate expectations. The state concerned thus finds itself under a constant pressure of such legitimate expectations, and perceives itself bound to comply with these expectations, because any other course of action would deny the commitment taken.

Like in other cases of legal obligation, the reputation of the acting state as a 'reliable', as a 'trustworthy' partner in interactions is at stake. States may still choose otherwise, may take another course of action that does not conform to the legitimate expectations - but the state then has to pay the price for such a decision that - it knows - will disappoint legitimate expectations of others. ${ }^{48}$ Like with other categories of international law, states are not exogenously compelled to abide by certain rules, but they have invested a lot of social capital in their reputation as a reliable partner of interaction, a partner others can rely upon, and they tend to avoid - at least if there are no stringent reasons for doing so - types of action that would too obviously damage such reputation and thus devalue the underlying investment in social capital. ${ }^{49}$ This implicit tendency towards preserving reputation gives the other partners in interaction a certain guarantee that the state concerned will abide by its legal commitments and will try not to disappoint the legitimate expectations of others, at least as long as costs of compliance do not become too excessive.

Bringing this arrangement of stabilization of rational expectations in the form of legal obligations makes sense. It is too cumbersome to rehearse any time you have to deal with another state its complete record of past interactions. Transforming legitimate expectations into some kind of legal obligations minimizes transaction costs. The legal code allows an abbreviated form of decision-making calculus. As a result of the transformation, not every decision in a sequence of repeated games requires a new calculus whether and to what degree the expectations on the behavioral patterns of the interaction partner are justified; a brief (and very abbreviated) assessment suffices of what the legal rule is in the constellation concerned, and perhaps also whether the interaction partner has a reputation to abide by the law in general. The generalization of behavioral regularities into universal rules of customary law thus helps to minimize transaction costs, because it leads to a standardization

\footnotetext{
${ }^{48}$ Guzman (2008), 192.

${ }^{49}$ Guzman (2008), 71-117.
} 
of the decisional calculus. Decision-makers can more or less abstract from the individual profile of the interaction partner and can simply look to the content of the rules at stake. The legal arrangement becomes even more stable if "repeated compliance gradually becomes habitual obedience" as international law "penetrates into a domestic legal system, thus becoming part of that nation's internal value set" ${ }^{\circ 0}$ and if, finally, obedience to the law constitutes an issue of morality, relying on the "habit and inertia of continued compliance". ${ }^{51}$

\section{Some Practical Issues: Operational Details of Customary International Law}

The theoretical observations made above should now allow us to dive more in detail into some of the intricate problems of the construction of CIL. These more practical issues concern, first, the scope and extent of state practice relevant for the formation of CIL; second, the problems around the question what role 'opinio juris' really plays in the formation of customary law, and how to find and model this 'subjective element' of CIL; and, third, the delicate question how CIL might change over time, despite the stabilization of expectations.

The position argued in the following pages resembles very much the position taken by some authors like Maurice Mendelson who opines that 'opinio juris' plays a negligible role in the formation of customary law (if any) and that what really counts is state practice. Such construction goes very much in parallel to the findings of the lab experiments undertaken by Christoph Engel. ${ }^{52}$ Mendelson argues that the international legal order is embryonic, and in a deep way incomplete. Therefore, a 'formalistic approach' is misplaced. ${ }^{53}$ There are no stringent formal conditions that must be fulfilled in order for a new rule to become a rule of customary law - the "customary process is in fact a continuous one, which does not stop when the rule has emerged." ${ }^{54}$ Every act of compliance later on will strengthen the rule, and "every violation, if acquiesced in, will help to undermine it". ${ }^{55}$ Customary law thus must be modeled as a result of the legitimate expectations of the other partners in the international community. Such legitimate expectations that states will continue to

\footnotetext{
${ }^{50} \operatorname{Koh}(1997), 2603$.

${ }^{51}$ Henkin (1997), 49.

${ }^{52}$ See Engel and Kurschilgen (2011), 6.

${ }^{53}$ Mendelson (1998), 168.

${ }^{54}$ Mendelson (1998), 175, see also the formulation by Sir Michael Wood, Special Rapporteur of the ILC for the topic "Formation and evidence of customary international law", in his introductory note for the 2012 session of the ILC:, speaking of "the very essence of custom, its flexibility and constant evolution" - UN Doc. A/CN.4/653 of 30 May 2012, para. 3.

${ }^{55}$ Mendelson (1998), 175.
} 
behave in the way they have done in the past arise "if the generality of states has regularly behaved in certain ways". ${ }^{56}$ Phrased differently: "If, within a social group, people habitually behave in a certain way, then, particularly if others rely on the continuation of this conduct, the sentiment may develop within that society that one is obliged to continue so to act. In other words, a norm emerges from what is normal." 57

\section{State Practice}

Customary international law, we have learnt from experimental studies as well as from theoretical debate, emerges in an evolutionary fashion from the social practice of subjects of international law, mostly states. Because the actors forming such practice are usually states, it is also called 'state practice'. ${ }^{58}$ This does not preclude, however, that international organizations also develop patterns of action which might be relevant for the formation of CIL. With the growing importance and rising decisional autonomy of international organizations (IOs) in international relations, actions taken by IOs are of high relevance for states concerned (and the international system in general). Also IOs may thus develop behavioral regularities that give rise to legitimate expectations. ${ }^{59}$ The practice we are dealing with consists in principle mostly of communicative acts. Nearly all acts of international relations are not physical acts that pursue a certain end on its own, but are acts of communication that try to influence the position and course of action of other international actors. To give only one example: Even a military intervention commonly does not bring about a changed situation in itself, but constitutes mainly (at least in a political perspective) a communicative act trying to force the other side into obedience with the declared will of the intervening power.

The types of communicative acts that are of relevance in international relations vary a lot. ${ }^{60}$ Most typical forms are diplomatic notes, public declarations, documents submitted in the framework of treaty negotiations or in the context of international organizations, signatures and ratifications of treaties, decisions in voting upon resolutions of international organizations (and declarations explaining such votes), even - under certain circumstances - cases of a qualified form of omission. ${ }^{61}$ But relevant acts may also be legal acts originally stemming from the internal, national legal order, such as national statutes, judicial decisions, parliamentary declarations. ${ }^{62}$ Authors generally must be a

\footnotetext{
${ }^{56}$ Mendelson (1998), 185.

${ }^{57}$ Mendelson (1998), 185.

${ }^{58}$ See Brownlie (2004), but also Byers (1999), 133-136 and Tomuschat (1999), 330-333.

${ }^{59}$ See Mendelson (1998), 201-202, as well as Lepard (2010), 277-282.

${ }^{60}$ See Byers (1999), 133-136, and Guzman (2008), 185 as well as 201-204.

${ }^{61}$ See Mendelson (1998), 204-209.

${ }^{62}$ See Mendelson (1998), 199-200.
} 
state organ, ${ }^{63}$ and the content of the act must have a relevance for a specific issue of international relations. ${ }^{64}$ Whether a certain act really has relevance for the legal relationship between states, however, is regulated by the perception that others have of the act, which leads to a strong linkage between the practice element and the 'subjective' element linked to the social meaning of the act. ${ }^{65}$ A series of communicative acts, extended and stable enough to be called a behavioral regularity, becomes only relevant 'custom' when a certain meaning can be attributed to such behavioral regularity. ${ }^{66}$ The 'meaning' will be the expectation of the others that the state concerned will continue with the behavioral regularity, and this behavioral regularity is of such importance for them that they rely on it for their own patterns of action.

A specific problem consists with the requirement of "general and consistent practice" (or "constant and uniform usage") ${ }^{67}$ There are again two elements in this requirement, a time element and a participation element. The element of 'consistency' points to the need of repetition of behavioral patterns over time - and these patterns must be more or less identical over time ${ }^{68}$ But how much time is required? Do you need decades to form a reliable custom, or might that happen rather quickly? It is difficult to give an abstract answer to these questions, since the answer probably will depend on the intensity and frequency of interactions. ${ }^{69}$ In a field of social practice where - on a more or less daily basis - routinely interactions take place, a relatively short span of time will suffice to produce an impressive pattern of behavioral regularities. ${ }^{70}$ In another sector, however, where states interact only in considerable intervals, a rather long passage of time might be needed to come to some indication of behavioral regularity. And how about isolated acts inconsistent with the proclaimed custom? A single inconsistent act probably is not really relevant, but if the number of acts following a completely different line of action becomes sizeable, 'consistency' definitively suffers. ${ }^{71}$

The other element of 'generality' refers to the number of states that must participate in a specific kind of behavioral regularity in order to qualify it as 'general custom'. ${ }^{72}$ There exists a consensus that not all nearly 200 states of the world must actively participate in such practice. ${ }^{73}$ (Most problems dealt

\footnotetext{
${ }^{63}$ There is, however, a debate whether also other actors should be taken into account - see pars pro toto Ochoa (2007).

${ }^{64}$ See Mendelson (1998), 198-203.

${ }^{65}$ See also Byers (1999), 139-141.

${ }^{66}$ See Byers (1999), 148.

${ }^{67}$ See Mendelson (1998), 209-227.

${ }^{68}$ Mendelson (1998), 209-211, as well as Lepard (2010), 218-228.

${ }^{69}$ See Byers (1999), 160-162.

${ }^{70}$ As to so-called 'instant customary law', see only Mendelson (1998), 370-382.

${ }^{71}$ See Guzman (2008), 185.

${ }^{72}$ See in detail Mendelson (1998), 218-227.

${ }^{73}$ See Guzman (2008), 185-186.
} 
with by international law are rather specific in nature, which implies that many states will have no relevant practice at all. ${ }^{74}$ Others might have some practice, but their standards of documentation and record-keeping might be so low that practice is difficult to learn from the outside. And even in the cases where relevant documentation exists, issues of language and culture might prevent the mainstream of international legal scholars of taking into consideration such practice, since it is too difficult to extract it from sources and to process it for the discussion on relevant practice. ${ }^{75}$ As a result, international legal doctrine usually takes only a relatively small number of states into account when analyzing 'relevant' practice ${ }^{76}$ - and if there is a conformity of behavioral patterns amongst these states, 'generality' of the custom is commonly declared.

For international lawyers taking a third-world perspective, there is a problem with such definition of 'generality' ${ }^{77}$ By practically limiting the amount of practice really to be taken into consideration when evaluating the 'uniformity' of usage to a small number of Western powers, plus Russia, China and some other BRICS states, the 'eurocentrism' (or 'West-centrism') of traditional international law continues to dominate international legal thinking. ${ }^{78}$ As a result, authors decidedly taking a 'Third-World Approach to International Law' are very skeptical towards traditional concepts of customary law. ${ }^{79}$ 'Custom' really counts - but 'custom' should be the practice of all the states of the world. That is why deliberations in the UN General Assembly need to be taken much more into account when assessing the uniformity of certain types of 'usage' - and not only by looking to the statements of great powers with a privileged position in the Security Council, but in particular as a tool to reconstruct the reactions of third world countries to certain types of 'usage'. ${ }^{80}$ Acquiescence can lead to limited usage transforming into 'custom' (and further on into customary law). The counter-positions taken by smaller states, however, should be taken into consideration when evaluating the 'generality' of certain types of usage.

\section{Opinio Juris}

Traditional accounts of what the 'subjective element' in CIL - the so-called 'opinio juris' - means, and how we can reconstruct whether such a conviction

\footnotetext{
${ }^{74}$ Mendelson (1998), 219.

${ }^{75}$ See Mendelson (1998), 225-226, as well as Guzman (2008), 186.

${ }^{76}$ See Byers (1999), 156, and Mendelson (1998), 225-227.

${ }^{77}$ See also Mendelson (1998), 226-227.

${ }^{78} \mathrm{See}$ - pars pro toto - Onuma (2009), 236-240.

${ }^{79} \mathrm{See}$ - as an example - Onuma (2009), 220-249.

${ }^{80}$ See Onuma (2009), 245-249.
} 
of a legal relationship really exists, are far too simplistic. ${ }^{81}$ But it is possible to reconstruct in rationalist terms the role 'opinio juris' plays in the operation of CIL. As Joel Trachtman has formulated it: "Opinio juris should be understood as a way of referring to the intent of states to propose or accept a rule of law that will serve as the focal point of behavior, implicate an important set of default rules applicable to law but not to other types of social order, and bring into play an important set of linkages among legal rules." ${ }^{82}$

Opinio juris thus is not a simple belief of state actors to be bound by law, but an acceptance of a specific rule, brought about by continued social practice. Basis is the consistent practice, i.e., the behavioral regularity "in circumstances which give rise to a legitimate expectation of similar conduct in the future". ${ }^{83}$ With other words: the acting state knows that its behavioral pattern showing a strong degree of regularity has given rise (or will give rise) to legitimate expectations, and being conscious of such expectations the state continues with that pattern, thus strengthening the expectations of the other states relying on his signal to accept the proclaimed rule. ${ }^{84}$ In other words: the process of formation of customary law is a process of dynamic exchange of signals to accept a certain rule and the expectations going along with such a rule, in exchange for the expectation that also the others will follow the same rule and thus will make their behavioral patterns calculable to the acting state. ${ }^{85}$ As a result, what matters here "is more a question of the positions taken by the organs of States about international law, in their internal processes and in their interaction with other States, than of their beliefs" ${ }^{86}$

Accordingly, there is a 'subjective' element - one could also say: a normative consideration - involved in such creation of legitimate expectations in social interaction. ${ }^{87}$ The usage as such does not contain legal relevance embedded as a practice category. The legal significance arises from the engrained structures of 'shared meaning' that accompany any act of social practice - a 'shared meaning' that is inextricably linked to the 'cognitive patterns', the shared 'social construction of reality' that characterizes a specific social system. ${ }^{88}$ In performing a certain act of social practice, actors know that the

${ }^{81}$ As a critical account of traditional doctrine, see Mendelson (1998), 245-293; see also as some of the most recent contributions to the debate on 'opinio juris' - Yee (2000); Tasioulas (2007); Taki (2008); Dahlman (2012).

${ }^{82}$ Trachtman (2008), 73.

${ }^{83}$ International Law Association (2000), § 1 (i).

${ }^{84}$ This does not imply a position of rigid 'consensualism' where positive consent of states to rules of customary law is required; see - as a recent restatement of such 'consensualist' constructions - Orakhelashvili (2008), 80-89.

${ }^{85}$ See also Mendelson (1998), 269-270.

${ }^{86}$ Mendelson (1998), 270.

${ }^{87}$ As an attempt to elucidate the place of normative considerations in the analysis of CIL see Voyiakis (2010), as well as Lepard (2010), 112-121.

${ }^{88}$ See more in detail Wiener (2008). 
others in the social system will ascribe a certain meaning to it - and in international relations this will often be a legal meaning. ${ }^{89}$ The knowledge about the social meaning of the practice will not always be explicit. A mere implicit knowledge often suffices to bind actors to the legitimate expectations that they create by their practices. ${ }^{90}$ In a sense, normative meaning is thus 'ascribed' to practices - but such attribution of meaning is not a wanton act, but is embedded in the meaning structures of social practice, thus constitutes a category open to empirical study. ${ }^{91}$ As a consequence, actors knowing that their acts will raise expectations of a certain legal meaning must complement the act with a disclaimer if they want to avoid such legal significance - thus the relevance of acquiescence and omissions in the formation of customary law. ${ }^{92}$

If a state disappoints the expectations of other states and changes its pattern of action, the other will feel betrayed in its (seemingly legitimate) expectations and will sanction the 'breach of law' with reputational sanctions, adjusting their assessments about the reliability of the acting state. ${ }^{93}$ Being conscious of the implicit threat of such sanctions, states are stabilized in their respect for the rules of CIL. If the overwhelming majority of states has accepted such a rule of CIL, it also becomes difficult to negate the existence of the rule. There exists a possibility to object against the coming into force of a rule of CIL $a b$ initio, by consistently taking a position of so-called 'persistent objector' ${ }^{94}$ The option is not available, however, if the formation of the rule has already happened - and even in the situations where it applies in principle, the institution of 'persistent objector' is extremely difficult in its practical application, making it nearly impossible for individual states to fulfill its requirements. $^{95}$

\section{Changes in Customary International Law}

In a traditional, pre-modern perspective it was difficult to perceive that customary law might change at all. Modernity, with all its archives and its institutionalized historical memory, is well aware - at least in principle - that customary law is a product of history, subject to historical change. But a theoretical conundrum remains: How can expectations be stabilized by per-

\footnotetext{
${ }^{89}$ See in this direction also Byers (1999), 148-151.

${ }^{90}$ See also Orakhelashvili (2008), 91.

${ }^{91}$ See Wiener (2009).

${ }^{92}$ See also Orakhelashvili (2008), 97-101, and Byers (1999), 106-107.

${ }^{93}$ Guzman (2008), 194.

${ }^{94}$ See Guzman (2008), 197-198, and very much in detail Mendelson (1998), 227-244; see in addition Byers (1999), 180-183; Trachtman (2010); Dumberry (2010); Lepard (2010), 229-242.

${ }^{95}$ See also Guzman (2008), 197-198.
} 
ceiving a particular pattern of behavior as legally required, while keeping the whole set of rules dynamic and flexible? Must not a state that deliberately departs from his past behavioral pattern perceive such a type of action as a violation of law? In principle - yes! As long as the acting state still shares the wide-spread perception that the past pattern of behavior should be continued in future, it will perceive its own departure from the rule as a violation of a legal commitment, even if trying to blur that violation by arguing with the imprecision and the loopholes of common rules of customary law. But what happens if social and political circumstances have changed so much that the traditional behavioral norm does not qualify as efficient anymore? If an acting state perceives a traditional norm as inefficient and outdated, and wants to propose a new norm, as focal point for behavioral coordination, the state has the option of not trying to hide its departure from the old rule; if the state is willing to take the leadership, it can also discard the old norm as not serving its purpose any more, and try to propose openly a new norm, thus becoming a kind of 'norm entrepreneur' ${ }^{96}$ For the traditionalists, the acting state will still be a 'law-breaker', but if there are good grounds to be argued in favor of the new norm, other states will join the acting state, and - with more and more states changing side - a new norm might emerge. ${ }^{97}$ In that sense, CIL combines in an interesting way the primary purpose of stabilizing expectations with a certain flexibility and openness to change.

\section{E. Concluding Remarks}

The argumentation led above had the purpose of demonstrating that the frontal assault of some rationalist authors on the traditional institution of CIL is erroneous, is based on wrong assumptions. Even inside the rationalist paradigm of economic analysis, it is possible to reconstruct and model how CIL operates - in a way that makes sense also under more traditional understandings of international law. CIL (if rightly modeled) is not a crude ideology, but a well-operating legal institution. CIL makes sense in coordination games with a repeated game character - and most problems of international relations are of that character. It is easily explainable that states have a mutual interest to agree on a series of coordinating rules even outside the formation of complex treaty regimes. The emergence of behavioral regularities is the first decisive factor of such gradual emergence of norms out of social practice - behavioral regularities that from a certain moment start to create legitimate expectations of other states. The expectation goes towards a calculus that a certain pattern of behavior will continue also in future. Such an expectation

\footnotetext{
96 See Trachtman (2008), 114.

${ }^{97}$ See Mendelson (1998), 270-271, 284-291, as well as Byers (1999), 157-160.
} 
facilitates enormously transactions between states, because it reduces insecurity about future behavior, and in the medium term also minimizes transaction costs. Such behavioral regularities only may be attributed legal significance if there is a shared meaning of such usages in a given social environment - but the international community in its diplomatic networks constitutes a relatively close-knit society with a strong degree of shared understanding. Entering into the described dynamic of evolutionary creation of regular patterns of behavior, linked shared meanings and - as a result - legitimate expectations is not as implausible as some critical rationalist authors have argued. Just to the contrary, it is rather plausible under certain conditions of social dilemma situations where productive coordination games are needed. If states accept the expectations raised by their practices and confirm them by relevant communicative acts, they inevitably become entangled in a web of mutual expectations that then transforms practice into legal obligations.

The paper has attempted to demonstrate the dynamics of such processes of building converging expectations and of hardening the mutual expectations to legal obligations. At the same time, it has tried to shed some light on decisive issues of the doctrine of CIL that have been left unresolved in traditional international legal doctrine. The author does not claim to know all the answers to the questions formulated. There is still a lot to do in order to understand the incentive structures that make CIL work. But such work is worthy of being done, since CIL is a relevant category, far from being epiphenomenal in international relations. Our understanding of the operation of CIL could still profit a lot from further studies in terms of economic analysis.

\section{Bibliography}

Abbott, K. and D. Snidal (1998), Why States Act Through Formal International Organizations, International Organization 42(1) 3-32.

Ago, R. (1957), Positive Law and International Law, American Journal of International Law 51 (4) 691-733.

Axelrod, R. (1984), The Evolution of Cooperation, New York: Basic Books.

Baker, R. B. (2010), Customary International Law in the $21^{\text {st }}$ Century: Old Challenges and New Debates, European Journal of International Law 21 (1) 173-210.

Brownlie, I. (2004), Some Problems in the Evaluation of the Practice of States as an Element of Custom, in: Studi di diritto internazionale in onore di Gaetano Arangio-Ruiz, Napoli: Editoriale Scientifica, 313-318.

Byers, M. (1999), Custom, Power and the Power of Rules. International Relations and Customary International Law, Cambridge: CUP.

Chinen, M. A. (2001), Game Theory and Customary International Law, Michigan Journal of International Law 23 (1) 143-189.

Dahlman, C. (2012), The Doctrine of Opinio Juris in Customary International Law, Nordic Journal of International Law 81 (3) 327-339.

Donaghue, S. (1995), Normative Habits, Genuine Beliefs and Evolving Law, The Australian Yearbook of International Law 16: 327-344. 
Donovan, J. M. and H. E. Anderson (2003), Anthropology \& Law, New York. Berghahn.

Dumberry, P. (2010), Incoherent and Ineffective: the Concept of Persistent Objector Revisited, International \& Comparative Law Quarterly 59 (3) 779-802.

Engel, C. (2010), An Experimental Contribution to the Theory of Customary International Law, Bonn: Preprints of the Max Planck Institute for Research on Collective Goods 2010/13.

Engel, C. and M. Kurschilgen (2011), The Coevolution of Behavior and Normative Expectations. Customary Law in the Lab, Bonn: Preprints of the Max Planck Institute for Research on Collective Goods 2011/32.

Estreicher, S. and P. B. Stephan (2003), Rethinking the Binding Effect of Customary International Law, Virginia Journal of International Law 44 (1) 5-17.

Fikentscher, W. (2009), Law and Anthropology. Outlines, Issues, and Suggestions, München: Verlag der Bayerischen Akademie der Wissenschaften.

Geisinger, A. (2002), A Belief-Change Theory of Expressive Law, Iowa Law Review 88 (1) $35-73$.

Goldsmith, J. L. and E. A. Posner (1999), A Theory of Customary International Law, Univ. of Chicago Law Rev. 66 (4) 1113-1177.

Goldsmith, J. L. and E. A. Posner (2000), Understanding the Resemblance between Modern and Traditional Customary International Law, Virginia Journal of International Law 40 (2) 639-672.

Goldsmith, J. L. and E. A. Posner (2005), The Limits of International Law, Oxford: OUP.

Golove, D. M. (2006), Leaving Customary International Law Where It Is, Georgia Journal of International \& Comparative Law 34 (2) 333-377.

Guzman, A. T. (2005), Saving Customary International Law, Michigan Journal of International Law 27 (1) 115.

Guzman, A. T. (2008), How International Law Works - A Rational Choice Theory, Oxford: OUP.

Guzman, A. T. and T. J. Meyer (2008), Customary International Law in the $21^{\text {st }}$ Century, in: R.A. Miller (ed.), Progress in International Law, Leiden: Nijhoff, 197.

Hannikainen, L. (2006), The Collective Factor as a Promoter of Customary International Law, Baltic Yearbook of International Law 6: 125-141.

Henkin, L. B. (1997), How Nations Behave, $2^{\text {nd }}$ ed. New York: Columbia Univ. Press.

Holzinger, K. (2003), Transnational Common Goods. Strategic Constellations, Collective action Problems, and Multi-Level Provision.

International Law Association (2000), Final report of the Commission on Formation of Customary (General) International Law: Statement of Principles Applicable to the Formation of General Customary International Law, available at: http://www.ilahq.o $\mathrm{rg} / \mathrm{pdf} /$ CustomaryLaw.pdf

Kammerhofer, J. (2011), Uncertainty in International Law: A Kelsenian Perspective, London: Routledge.

Kelly, J. P. (2000), The Twilight of Customary International Law, Virginia Journal of International Law 40 (2) 449-543.

Koh, H. H. (1997), Why Do Nations Obey International Law?, Yale Law Journal 106: 2599.

Kolb, R. (2003), Selected Problems in the Theory of Customary International Law, Netherlands International Law Review 50 (2) 119-150.

Lepard, B. D. (2010), Customary International Law: A New Theory with Practical Applications, Cambridge: CUP.

McAdams, R. H. (2000), A Focal Point Theory of Expressive Law, Virginia Law Review 86 (4) 1649-1729.

McAdams, R. H. and J. Nadler (2005), Testing the Focal Point Theory of Legal Compliance. The Effect of Third-Party Expression in an Experimental Hawk/Dove Game, Journal of Empirical Legal Studies 2 (1) 87-123. 
Mendelson, M. (1995), The Subjective Element in Customary International Law, The British Yearbook of International Law 66: 177.

Mendelson, M. (1999), The Formation of Customary International Law, Recueil des Cours de l'Académie de Droit International de la Haye 272: 155-410.

Milgrom, P. R., D. C. North, and B. R. Weingast (1990), The Role of Institutions in the Revival of Trade: The Law Merchant, Private Judges, and the Champagne Fairs, Economics and Politics, 2(1): 1-23.

Mofidi, M. (2005), Applying Rational Choice Theory to Customary International Law, Ann Arbor: UMI.

Norman, G. and J. P. Trachtman (2005), The Customary International Law Game, American Journal of International Law 99 (3) 541.

Norman, G. and J. P. Trachtman (2008), Measuring the Shadow of the Future. An Introduction to the Game Theory of International Law, University of Illinois Law Review 60 (1) $127-153$.

Ochoa, C. (2007), The Individual and Customary International Law Formation, Virginia Journal of International Law 48 (19) 119-186.

Onuma, Y. (2009), A Transcivilizational Perspective on International Law, Recueil des Cours / Collected Courses of the Hague Academy of International Law 342: 77-418.

Orakhelashvili, A. (2008), Natural Law and Customary Law, Zeitschrift für ausländisches öffentliches Recht und Völkerrecht 68 (1) 69-110.

Petersen, N. (2007), Customary Law Without Custom? Rules, Principles, and the Role of State Practice in International Norm Creation, American University International Law Review 23 (2007), 275-310.

Petersen, N. (2008), Rational Choice or Deliberation? Customary International Law between Coordination and Constitutionalization, Bonn: Preprints of the Max Planck Institute for Research on Collective Goods 2008: 28.

Pospisil, L. (1982), Anthropologie des Rechts: Recht und Gesellschaft in archaischen und modernen Kulturen, München: C.H. Beck.

Risse, T. (1999), International Norms and Domestic Change. Arguing and Communicative Behaviour in the Human Rights Area, Politics \& Society 27 (5) 529-559.

Risse, T. (2000), Let's Argue. Communicative Action in World Politics, International Organization 54 (1) 1-39.

Roberts, A. E. (2001), Traditional and Modern Approaches to Customary International Law, American Journal of International Law 95 (4) 757-791.

Sandler, T. (2004), Global Collective Action, Cambridge: CUP.

Scharf, M. P. (2013), Customary International Law in Times of Fundamental Change, Cambridge: CUP.

Stephan, P. B. (2010), Disaggregating Customary International Law, Duke Journal of Comparative \& International Law 21 (1) 191-205.

Stern, B. (2001), Custom at the Heart of International Law, Duke Journal of International \& Comparative Law 11 (1) 89-108.

Taki, Hiroshi (2008), Opinio Juris and the Formation of Customary International Law, German Yearbook of International Law 51: 447-466.

Tasioulas, J. (2007), Opinio Juris and the Genesis of Custom, The Australian Yearbook of International Law 26: 199-205.

Tomuschat, C. (1999), International Law: Ensuring the Survival of Mankind on the Eve of a New Century. Recueil des Cours de l'Académie de Droit International de la Haye 281: 9.

Trachtman, J. P. (2008), The Economic Structure of International Law, Cambridge, Mass.: Harvard Univ. Press.

Trachtman, J. P. (2010), Persistent Objectors, Cooperation, and the Utility of Customary International Law, Duke Journal of Comparative \& International Law 21 (1) 221-233. 
Treves, T. (2009), Customary International Law, in: Max Planck Encyclopedia of Public International Law, ed. by R. Wolfrum, Oxford: OUP (Online edition).

Vagts, D. F. (2004), International Relations Looks at Customary International Law: A Traditionalist's Perspective, European Journal of International Law 15 (5) 1031-1040.

Voyiakis, E. (2010), Customary International Law and the Place of Normative Considerations, American Journal of Jurisprudence 55 (1) 163-200.

Williamson, O. E. (1985), The Economic Institutions of Capitalism, New York: Free Press.

Wiener, A. (2008), The Invisible Constitution of Politics. Contested Norms and International Encounters, Cambridge: CUP.

Wiener, A. (2009), Enacting Meaning-in-Use: Qualitative Research on Norms and International Relations, Review of International Studies 35 (1) 175-193.

Yee, S. (2000), The News that Opinio Juris "is not a Necessary Element of Customary International Law" is Greatly Exaggerated, German Yearbook of International Law 43: 227238. 


\section{Comment on Stefan Oeter}

\section{Customary International Law, Coordination and Dilemmas}

by

Georg von Wangenheim

\section{A. Coordination and Dilemma?}

The contribution of Stefan Oeter to the conference and the present volume presents an important starting point for the discussion of customary international law (CIL). With good reasons, he argues that simplifying approaches to CIL based on one-shot coordination or dilemma games are inapt to reflect the underlying ideas of CIL. Neither can one-shot games describe consuetudo (behavioural regularity) nor is it possible to frame the idea of opinio iuris sive necessitates (opinion of law or necessity) in a simple game-theoretic setting of a coordination or of a dilemma problem.

From this observation, Stefan Oeter does not infer that game theory and rational choice is the wrong methodology to understand CIL but rather that more sophisticated game-theoretic approaches are required. In particular, he calls for relying on repeated coordination games to describe the social dilemma situation in which CIL may emerge and for being very explicit about the meaning of opinio iuris in this framework. However, he only sketches the basic ideas of a model and does not always make clear whether such a model should be based on a repeated coordination game or on a repeated social-dilemma game, two games which are clearly distinct and mutually exclusive in game theory. In the following paragraphs I therefore endeavour to present an explicit and more precise model of CIL which aims at representing Stefan Oeter's ideas as much as possible. This may alter some of his intermediate arguments, but the results are the same, if I understand them correctly. 
I start by arguing that neither a repeated coordination game nor a repeated social-dilemma game may capture the central ideas of CIL, even if one assumes random matching of players at each stage game. Adding random perturbations to the repeated coordination game will, however, allow me to describe a situation in which CIL may become relevant. Looking at the choice between strategies according to which countries may behave in such a game, I will show that the game has elements of a social dilemma. This social-dilemma structure of the game will make it possible to express the idea that deviating behaviour should be forbidden in a consistent way. Hence, by adding random perturbations to the coordination stage-games, it becomes possible to describe both the emergence of a behavioural regularity (consuetudo) in the coordination game and the dilemma situation required for the need for legal intervention (opinion iuris) within one model. All modelling will neglect public-choice theory and assume that the preferences of the countries' politicians, who actually make decisions, are perfectly aligned with the countries preferences.

\section{B. Unperturbed Stage Games}

A common starting point for modelling social norms in general and CIL in particular are (infinitely) repeated games with random matching of players at each stage and common knowledge about the proportions of behaviours chosen in the previous stage. The stage game is a coordination game when the spontaneous evolution of coordinated behaviour is the core interest, and a prisoners' dilemma (or more general: a social dilemma) when the enforcement of cooperation by the threat of long-run defection is the main topic. At each stage, exactly one game is played after the players for this game are randomly selected from the population.

This set of models is not capable of modelling CIL, independently of whether the stage game is a coordination game or a dilemma game. Let us start with repeated coordination games, as defined by Payoff Matrix 1 on the following page, and take a brief look at the well-known model of evolving coordination. Assume that such a game is played repeatedly by two countries randomly selected from the population of countries in each period. Every country knows the frequencies by which countries have chosen actions $a$ and $b$ in the past (information may even be given about the specific countries, but this is not necessary). If all countries assume that other countries' choice of action exhibits some inertia, then the information about past behaviour is a good predictor of future behaviour. Thus, as soon as there happens to be a clear majority of countries choosing action $a$, for example, all countries will prefer to choose the majority action, $a$ in 
the example. The choice of this action will become unanimous; no country will ever want to deviate. ${ }^{1}$

The very simplicity of the convergence to, and the stability of cooperation described in the previous paragraph is the source of its inapplicability to CIL: since no country will ever deviate from the coordination equilibri$\mathrm{um}$, the question of whether any deviation would be a violation of CIL will never arise. We get consuetudo, but we cannot get anything like opinio iuris.

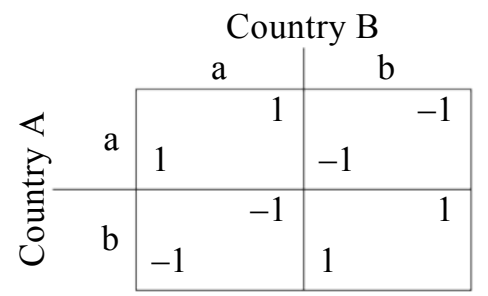

Payoff Matrix 1: coordination game

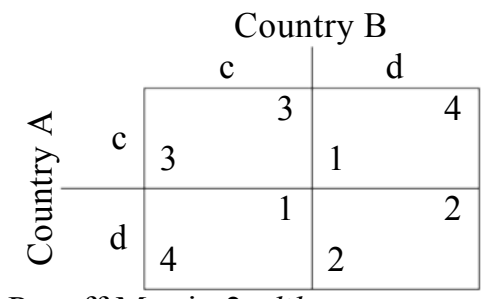

Payoff Matrix 2: dilemma game

Turning to social dilemma games such as the Prisoners' Dilemma in Matrix 2 above, we get the reverse result: the Kaldor-Hicks-optimum reached when both countries play action $c$ (which we will call "cooperation") is Pareto-superior to the Nash-equilibrium at mutual choice of action $d$ (which we will call "defection") but all players have incentives to deviate. One could thus imagine a rule "you should not deviate from mutual cooperation" and reasonably ask whether its violation would be in contempt of law, i.e. whether it is a legal rule, which by definition allows sanctioning its violation and implies that this sanctioning itself is not a violation of law. ${ }^{2}$ Opinio iuris could thus exist. However, with this payoff matrix at each stage game, no country would ever start cooperation, to an even lesser extent could a behavioural regularity evolve - we lack consuetudo.

One might of course argue that the total number of countries is so small, that the model of evolutionary game theory, as we used it in the previous paragraphs, is inappropriate because random matching is not incompatible with repeated play of the stage game amongst the same two players. Recall is large enough to allow for more complex strategies than "best response against expected behaviour at the current stage". As a consequence, any pair of countries can enter into mutual, complete or partial, cooperation. Unfortunately, as it is well known from the Folk Theorem, there is an

\footnotetext{
${ }^{1}$ As presented here, the model is based on a number of simplifications, such as symmetry of the game and restriction to $2 \times 2$ games. Obviously, such simplifications could easily be replaced by more complex assumptions, but this would not provide any further insights.

${ }^{2}$ See Norman and Trachtman (2005), 574 for a similar decisive criterion for turning a rule legal.
} 
abundance of strategies enforcing such cooperation. And not all strategies correspond to each other so that coordination of strategies is required. The dilemma game thus turns into a coordination meta-game about choosing strategies for the dilemma game. ${ }^{3}$

By allowing for repeated interaction among stable pairs of countries and by thus allowing the Folk Theorem to work in our model, we have turned the game into an $n$-strategy coordination game. This brings us back to the problems discussed at the beginning of this section. However, there is one problem more: one of the many possible strategies is unconditional defection and general obedience to this strategy is one of the many coordination equilibria. Unless cooperative strategies start to be chosen in the first instances of the stage game already, there will be a majority of countries defecting and thus all countries will coordinate on defection. Again, we lack consuetudo. And if we don't, we are back to the coordination equilibrium which does not allow for opinio iuris.

As a last twist in the discussion of the evolution of cooperation in international dilemma games, we should consider the possibility of agreeing explicitly on a specific set of corresponding strategies entailing selfenforcing cooperation. For example, two countries could agree to act cooperatively in every stage of the game and if one deviates, the other should also deviate for a predetermined number of stages and return to cooperation if the first country did not again deviate in the meantime. Like many other strategies starting with cooperation (e.g., grim trigger, tit-for-tat) such penance strategies would induce mutual and continuous cooperation. However, when the two countries agree to continuously cooperate and even agree on the sanctions in case of deviation, then most lawyers would call this a treaty and not CIL. We therefore neglect this possibility in the remainder of this comment.

\section{Random Perturbations in Coordination Games}

In the previous section, we have argued that repeated coordination games fail to allow for deviation from the equilibrium and hence law cannot become relevant. This changes, if we introduce random perturbations to the model. For simplicity, suppose that only for one-sided deviation from an equilibrium, payoffs are random numbers and the payoffs in the offdiagonal cells of Payoff Matrix 1 are only their expected values. The coordination game then turns into the randomized coordination game presented in Payoff Matrix 3 on the following page, where $T_{\mathrm{iJ}}^{t}$ stands for the (randomized) temptation of country $\mathrm{J} \in\{\mathrm{A}, \mathrm{B}\}$ to deviate from general play of

\footnotetext{
${ }^{3}$ Cf. Norman and Trachtman (2005) on this point.
} 
action $\mathrm{i} \in\{\mathrm{a}, \mathrm{b}\}$ at stage $t$. A simplifying example which we will use in what follows due to its ability to present the central elements of our argument is that all these random numbers are stochastically independent of each other, binary and take value 2 with probability $p=1 / 10$ and value $-4 / 3$ with probability $1-p=9 / 10$. This implies an expected value of $\mathrm{E}\left(T_{\mathrm{iJ}}^{t}\right)=-1$ for all $\mathrm{i}$ and $\mathrm{J}$.

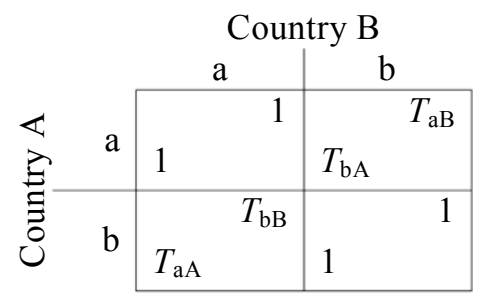

Payoff Matrix 3: randomized coordination game

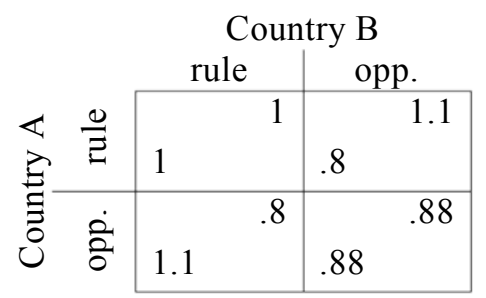

Payoff Matrix 4: expected stage payoffs from following the general behaviour as a rule or opportunistically

Obviously, this randomization may only become relevant for the countries' decisions, if the countries know the realizations of at least their own payoffs. We therefore assume that at each stage $t$ the realizations of $T_{\mathrm{aA}}^{t}$ and $T_{\mathrm{bA}}^{t}$ are known to Country $\mathrm{A}$, and $T_{\mathrm{aB}}^{t}$ and $T_{\mathrm{bB}}^{t}$ are known to Country $\mathrm{B}$ before they make their respective choices. We assume that this knowledge is private information. ${ }^{4}$

Again, the game evolves towards either of two equilibria: Either all countries most often (namely when their own temptation to deviate is negative, $T_{\mathrm{a}}^{t}=-4 / 3$, i.e., in 90 per cent of all instances) play strategy a, and only rarely (namely when their own temptation to deviate is positive, $T_{\mathrm{a} .}^{t}=2$, i.e., in 10 per cent of all instances) play strategy $\mathrm{b}$, or vice versa. The careful reader may easily prove that these two are Nash equilibria ${ }^{5}$ and

\footnotetext{
${ }^{4}$ If the other country also knew the realizations each country would be able to adapt to the other country's temptation and thus guarantee itself a payoff of 1 . Only when onesided deviation happened to be beneficial to both countries, both countries would get a payoff of 2. As a consequence, expected stage payoffs would be slightly less than 1.02 and thus larger than under perfect coordination. To exclude this possibility from the further discussion, we could assume that collection of information about the other country's realizations of random variables is too costly, i.e., it costs at least 0.02 or 2 percent of the net temptation.

${ }^{5}$ To see that this is a Nash equilibrium, one should take brief look at a country's expected payoffs in the stage game assuming that the other country deviates from the generally played action if and only if its temptation to deviate is positive. The country's
} 
that they are evolutionarily stable due to their strictness. When 90 per cent of all choices are for one of the actions, one may well be tempted to say that this is what countries generally do, or one could even say that choosing this action is the rule. Whether it also becomes a legal rule, i.e., a rule of CIL will be discussed in the following paragraphs.

\section{Behavioural Regularity or Legal Rule?}

As a preliminary, we note that with this perturbation, the overall expected stage payoffs for every country are $.81 \cdot 1+.09 \cdot 2-.09 \cdot 4 / 3+.01 \cdot 1=.88$, where the $.81, .09, .09$, and .01 are the probabilities that the temptation to deviate is $T_{i J}^{t}=2$ for neither country, only for the country we are looking at, only for the other country, and for both countries, respectively, and where $1,2,-4 / 3$, and 1 are the respective payoffs. Obviously, the perturbation has reduced the expected equilibrium stage payoffs. In addition, if all countries always followed the general rule, the stage payoff would always be 1 .

It is at this point of the argument that the interference of a social dilemma with the coordination problem, which Stefan Oeter refers to in his article several times, becomes relevant: If all countries always acted according to the general rule, all were better off in expectations than if all violate the rule whenever it is beneficial for them in the short run. Even worse, we do not only have this Pareto-superiority of the non-equilibrium strategy combination, but every country is tempted to deviate from the general rule even if some or all others follow it, because violating the rule against a rule follower increases a country's own expected payoffs from 1 to $.9 \cdot 1+.1 \cdot 2=1.1$ and violating the rule against a rule violator increases a country's own payoff from $.9 \cdot 1+.1 \cdot(.9 \cdot(-4 / 3)+.1 \cdot 2)=.8$ to $.88 .{ }^{6}$ Payoff

expected payoff from playing the more frequently played action is then $.9 \cdot 1-.1 \cdot 4 / 3=$ .766 or $.9 \cdot 1+.1 \cdot 2=1.1$, depending on its temptation to deviate from the other strategy. Its payoff from deviating is $-.9 \cdot 4 / 3+.1 \cdot 1=-1.1$ if the country's own temptation is negative and $.9 \cdot 2+.1 \cdot 1=1.9$ if it is positive. Deviation from the generally played action is thus worthwhile if and only if the country's temptation to deviate is positive.

${ }^{6}$ Expected payoffs from violating against a rule follower are given by the payoff from jointly following the rule when the temptation to violate the rule is negative and the payoff from being the only violator when the temptation is positive. Expected payoffs from following the rule against a violator are given by the payoff from jointly following the rule when the temptation of the other country to violate the rule is negative and by the expected payoff from being the sole follower of the rule when the other country's 
Matrix 4 summarizes these expected payoffs and elucidates that the choice between following the rule as a rule or only when it is opportune exhibits the structure of a Prisoners' Dilemma.

If not only the author and the reader of these lines but also the involved countries understand that the constantly positive probability of temptations to deviate from the general rule adds a dilemma problem to the cooperation game, then these countries may realize that the general rule of behaviour should be a legal rule, i.e., one whose violation may be punished by retaliation, possibly in a completely different policy field, without any threat of sanctions against the retaliatory act, although the retaliatory act would otherwise be seen as illegal. ${ }^{7}$

As a consequence, we may have both consuetudo and opinio iuris sive necessitates: A behavioural regularity may evolve spontaneously and before countries think about the behaviour being legal or necessary. Of course, such regularity fails to comprise each and every action, as would be the case with an unperturbed coordination game. But this broader understanding of behavioural regularity as a behaviour which countries exhibit most often, but not always is exactly what we need for understanding CIL: Only when a regularity is imperfect, we can reasonably ask and answer whether the regularity has turned into law, viz. customary international law.

Unfortunately, the last step of the coming about of CIL and of customary law in general still seems to be hardly studies in law and economics, so far. It is still unclear, how and why individuals or countries adopt the opinion that a regularity exhibited by a large majority is not only a regularity but required by law. A nice experiment by Engel and Kurschilgen (2013), to which Stefan Oeter refers extensively, elicits that such adoption occurs but does not always occur. However, the process of the adoption proper seems to be still unresearched and would go beyond the scope of a comment.

Once opinio iuris sive necessitates has been adopted, the now legal rule will be enforced and stabilized in the same way as most of international law: sanctioning of violations and toleration of these sanctions by third countries. Such enforcement may and probably will be incomplete, but still there would be consuetudo and opinio iuris, so that we can reasonably speak of customary international law.

temptation to violate is positive. Expected payoffs from violation against a violator have been derived at the beginning of this section.

${ }^{7} \mathrm{Cf}$. the argument supra at footnote 2 and Norman and Trachtman (2005), 574. 


\section{E. Conclusions}

Stefan Oeter stresses in his article that one should understand CIL within the framework of evolutionary game theory while taking care of the complexities inherent to CIL: repeated interaction, spontaneous evolution of cooperation and a social dilemma in enforcing such cooperation. In this comment, I developed a framework to embrace all these complexities which clearly separates the cooperation game underlying spontaneous evolution of cooperation and the social dilemma resulting from randomized temptations to deviate from cooperation. What is still open to further research, however, is the adoption of opinio iuris both by early adopters and by imitators.

\section{Bibliography}

Engel, C. and M. Kurschilgen (2013), The Coevolution of Behavior and Normative Expectations: An Experiment, American Law and Economics Review, Advance Access published June 21, 2013, doi: 10.1093/aler/aht010.

Norman, G. and J. P. Trachtman (2005), The Customary International Law Game, American Journal of International Law, 99 (3) 541-580. 


\title{
Discussion on Stefan Oeter
}

\author{
summarized by
}

\section{José Caiado}

The presentation is an attempt to bring economic analysis to the study of international customary law (CIL). It conjectures that CIL deals basically with coordination problems, in which cooperation is only possible if information regarding past behavior is available, and argues that CIL provides for such information, as each actor in the international community can observe and register the behavior of other actors. Important concepts at this point are (i) mutual observation, and (ii) its transformation in expectation of behavior.

These elements lead to reductions in information and decision costs, and fewer securities are needed to invest in cooperation, thereby improving efficiency in international coordination. But still, how does that work? There is no clear compliance, there is tit for tat retaliation, and there must be something else behind this. One could argue, following Guzman, that reputation fulfills this role. If a state invests in building social capital, you have a trend to avoid actions that affect this social capital represented by reputation. To investigate every past behavior of a state would be absurdly expensive, so the legal rule provides a cheaper tool to represent those patterns. As a consequence, CIL facilitates coordination between states. This is the general outset.

Discussions followed on the issue of whether the evolution of CIL should be understood as a result of passive state interaction, or of "premeditated" action by some states trying to impose a certain law over others. It was argued that states interested in having their idea prevail over others could use two strategies - one is by signing a treaty with a subset of states, like the EU and USA signing an agreement and pragmatically forcing others to adopt the same standards; the other way is through the use of courts, as states respect courts because they know the courts will reach decisions that are not fully based on CIL; these elements might explain why strong states initially accepted the idea of CIL.

As a conclusion, the author stressed that it is possible to explain CIL as coordination game of long-term interaction. Interaction leads to behavior 
regularities that in a certain moment lead to expectations, which then facilitate transaction by reducing uncertainties about behavior and also lower transaction costs. If states accept these expectations, and communicate to others, CIL might emerge. 


\title{
The Economics of Informal International Law - An Empirical Assessment
}

by

Stefan Voigt ${ }^{*},+$

\begin{abstract}
A. Motivation
Informal international lawmaking is becoming more prevalent. To the extent it overlaps with the notion of soft law, it has been the subject of numerous debates concerning its effects, its effectiveness, and its legitimacy. Soft law and the related move from parliaments to the executive when it comes to international cooperation are not new; they have been around for a long time. It has also been a problem for a long time. Decades ago, thenchairman of the United States (US) Senate Foreign Relations Committee J. William Fulbright (D-Arkansas) complained: 'The Senate is asked to convene solemnly to approve by a two-thirds vote a treaty to preserve cultural artefacts in a friendly neighboring country. At the same time, the chief executive is moving military men and material around the globe like so many pawns in a chess game'. ${ }^{1}$ Similarly, the US Foreign Relations Committee complained in a formal report in 1969: 'We have come close to reversing the traditional distinction between the treaty as an instrument of a
\end{abstract}

${ }^{*}$ Extract from 'The Economics of Informal International Lawmaking: An Empirical Assessment' by $S$. Voigt from "Informal International Lawmaking" edited by Pauwelyn, J., Wessel, R. \& Wouters, J. (2012), 81-105, by permission of Oxford University Press.

$\dagger$ Director, Institute of Law \& Economics, University of Hamburg, Johnsallee 35, D20148 Hamburg, E-mail: stefan.voigt@uni-hamburg.de. The author thanks Matthias Dauner, Nora El Bialy, Sina Imhof, Ram Singh, Agnes Strauß, and, in particular, Jerg Gutmann, who coordinated the group of research assistants that coded all agreements, for critical comments on a first draft of this paper, and Julian Boakye-Nyarko, Birthe Brandes, Xufeng Jia, Denis Maciel, Rune Weltz, and Norma Widulle for invaluable research assistance. Paper originally prepared. The author thanks all participants of the HiiL Workshop on Informal International Lawmaking (March 2011) as well as the Travemünde conference (2012) for stimulating comments, in particular Eyal Benvenisti, Peter Lewisch and Joost Pauwelyn.

${ }^{1}$ See L. Johnson and J. Mc Cormick (1977). 
major commitment and the executive agreement as the instrument of a minor one'. ${ }^{2}$

Members of the legislature are thus concerned about potential misuse of international agreements by the executive. They fear that international agreements could shift power in favour of the executive, and to their own detriment. 'Treaties' in the sense of Article II of the US Constitution must be adopted by a two-thirds majority in the US Senate; 'international agreements', in contrast, are either adopted by simple majority in both houses of the US Congress (both the House of Representatives and the Senate, e.g., in the case of congressional-executive agreements) or, in the case of pure executive agreements, by the US executive alone. ${ }^{3}$ Although 'treaties' and 'international agreements' are, thereby, different for internal, US law purposes, public international law does not distinguish between them: both are legally binding under international law. In 1972, the CaseZablocki Act was passed, which stipulates that the State Department must publish the text of any 'international agreement' other than a 'treaty' (as defined under US law) to which the US is a party no later than 60 days after having entered into force. All agreements covered by the Act and entered into since 1981 are readily available on the Internet, creating a very valuable database that covers all international agreements entered into by one very powerful country. This chapter analyses all 2,289 agreements entered into over the 30 -year period, thus making it possible to evaluate the use of international agreements in a more systematic fashion than previously undertaken.

The dataset enables answering a number of important questions in the realm of informal international lawmaking: (1) Has the use of 'international agreements' (as opposed to the more formal 'treaties') truly increased, as is often presumed? (2) What are the policy areas that are primarily tackled by this less formal form of international law? (3) Are international agreements used primarily between two States (bilaterally) or by more States (multilaterally)? (4)Which actors use international agreements? Is it primarily the traditional actors that also enter into treaties, i.e., heads of State and/or the foreign ministries, or is this type of lawmaking the arena of other ministries or even independent government agencies?

With regard to the US, our results show that (1) the number of international agreements concluded did indeed increase dramatically until around 2006. Since then, its use has declined almost as dramatically. (2) Around two-thirds of all international agreements are concerned with only three policy areas: the military, science and technology, and aid. (3) More than $90 \%$ of all international agreements are conducted bilaterally. (4) Around

\footnotetext{
${ }^{2}$ Ibid.

${ }^{3}$ See O. Hathaway (2008).
} 
$40 \%$ of all agreements are concluded by a non-traditional actor on the US side, i.e., an actor other than the President or the Secretary of State. Studying data from just one country (the US) does not allow generalisation of conclusions, of course, but such a systematic analysis of the practice over a 30 -year period does permit to reveal some interesting insights. A follow-up paper comparing the use of international agreements on a cross-country basis and explicitly taking potentially relevant institutional factors into account that might be causing the cross-country variance is an obvious next step.

The remainder of this chapter is structured as follows. Section B introduces the key terms used in this study. Section $C$ develops a number of conjectures concerning the use of informal instruments, which deal with the circumstances under which governments prefer, in this particular case, international agreements to more formal international lawmaking. Tools developed in the field of institutional economics are employed to find an answer. Section D describes the practices of the US regarding international agreements over the last 30 years. Section E previews possible future research by presenting several conjectures regarding variance in the use of informal instruments among nation-States. Section F concludes.

\section{B. Defining the key terms}

Some governments see the main difference between formal and informal international lawmaking as the consequent obligations: formal lawmaking creates legal obligations; informal lawmaking results only in 'moral or political commitments' ${ }^{4}$ From an economic point of view, this distinction is of limited value as it is unclear, at least ex ante, whether there are systematic differences in the costs of non-compliance with these different kinds of obligation.

Pauwelyn identifies three possible dimensions of informality: the actors participating in its creation, the process by which informal law is generated, and the outcome or output of such process. ${ }^{5}$ To qualify as informal international law (IN-LAW), informality in any of these three dimensions is sufficient. He proposes the following definition: 'Cross-border cooperation between public authorities, with or without the participation of private actors and/or international organisations, in a forum other than a traditional international organisation (process informality), and/or as between actors other than traditional diplomatic actors (such as regulators or agencies)

\footnotetext{
${ }^{4}$ See Canada Treaty Information (2011); For a near identical formulation, see also: US Department of State (2011).

${ }^{5}$ See J. Pauwelyn (2012).
} 
(actor informality), and/or which does not result in a formal treaty or legally enforceable commitment (output informality). ${ }^{6}$

In the empirical section below (Section D), the international agreements concluded between the US and its partners are analysed. Following Pauwelyn $^{7}$, at least some of these agreements can be classified as informal international law due to actor informality (around $40 \%$ of all agreements are concluded by a non-traditional actor on the US side). Giving the term process informality a domestic rather than international twist, slightly different from how it was intended by Pauwelyn, ${ }^{8}$ process informality is also present because domestic legislatures do not need to consent to the creation of certain international agreements, namely so-called executive agreements which are adopted by the US executive alone. Moreover, as indicated earlier, all international agreements also escape the two-thirds majority requirement for treaties (as referred to in Article II of the US Constitution), thereby avoiding a formal requirement under domestic law and making international agreements also in this sense less formal as compared to treaties. In this chapter, the criterion separating formal from informal international law is, in other words, focused on the domestic process used to generate and adopt or ratify these respective kinds of law (rather than on whether the instrument is legally binding under international law; as pointed out earlier, both 'treaties' and 'international agreements' are legally binding under international law).

I propose to think of various forms of international cooperation in terms of governance structures, as proposed by Williamson. Williamson points out that exchange cannot only be accomplished by the market (short-term on-the-spot cash for goods exchanges contracts) and the firm (i.e., hierarchical organisations) but also by an infinite number of hybrids such as long-term contracts, joint ventures, and franchise agreements. ${ }^{9}$ Similarly, one can rank-order various forms of international cooperation by their degree of formality. For example, comity, defined as gestures or courtesies exchanged between governments of sovereign nation-States, is less formal than international lawmaking; indeed, comity does not appear to have anything to do with law at all, and yet its presence can have far-reaching consequences for international relations. The formal ratification of treaties, on the other hand, is perceived as the formal creation of international law. The

\footnotetext{
${ }^{6}$ In an early contribution on the topic, Lipson (1991) suggests thinking of informality as a matter of degree and along two principal dimensions: (1) the government level involved in its creation and (2) the form used to generate informal international law (mentioning written documents, the exchange of notes, joint communiqués, oral bargains, and tacit bargains).

${ }^{7}$ See J. Pauwelyn (2012).

${ }^{8}$ Ibid.

${ }^{9}$ See O.E. Williamson (1985).
} 
creation of an international organisation (IO) is even more formal yet if one thinks of an organisation as a treaty endowed with permanent staff who can monitor compliance with its terms and have at least some enforcement power.

To this point, the governance structures discussed are ones that can deliberately be created (or, in the case of comity, at least carried out). Customary international law (CIL), however, is different: it is never explicitly or intentionally created but is instead the consequence of State practice. In other words, informal international law can be created purposefully; CIL tends to evolve.

\section{Some theory: on the benefits and costs of informal international law}

This section discusses the costs and benefits of informal international law. More specifically, we are interested in identifying the conditions under which governments prefer informal international law over formal international law (i.e., formal treaties that need to be ratified domestically) and vice versa. Governments are assumed to be rational utility-maximisers. Based on insights from the new institutional economics, we deduce a number of concrete cost-benefit considerations comparing the making of informal international law with more formal treaty making. But first, we briefly review Lipson's work on this topic. ${ }^{10}$

Lipson states that informal agreements are more flexible than formal ones, make fewer informational demands on the parties, and can be concluded and implemented more quickly than formal ones. Moreover, they are less public and less prominent than formal agreements. Consequently, they should also be less subject to slack because they can be controlled by the (executive) agency that created them, which is equivalent to having a shorter principal-agent chain. As a cost, Lipson mentions that they can also be more easily abandoned. ${ }^{11}$ In summarizing his conclusions, Lipson writes: "These costs and benefits suggest the basic reasons for choosing informal agreements: (1) the desire to avoid formal and visible pledges, (2) the desire to avoid ratification, (3) the ability to renegotiate or modify as circumstances change, or (4) the need to reach agreements quickly.' ${ }^{12}$

\footnotetext{
${ }^{10}$ See C. Lipson (1991).

${ }^{11}$ Ibid., 501.

${ }^{12}$ Ibid.
} 


\section{Differences in transaction costs}

Coase $^{13}$ was interested in the economic rationale behind the existence of firms. Many economists are convinced that markets are the best available allocation mechanism, so why are firms founded and why do they survive? Coase introduced a cost category known as transaction costs. These are the costs of using the market, i.e., the costs incurred in finding interaction partners, negotiating contract details with them, and monitoring compliance with the contract. If transaction costs are high but the cost of organising some activities within a hierarchy are relatively low, then a firm could be more cost effective than the market. Transaction costs are also incurred in both informal and formal international lawmaking. However, the cost differentials between these two forms of cooperation might differ. I propose a number of relevant transaction cost categories here and combine them with a conjecture concerning their relative importance. Analysing cost differences between hard and soft law will enable us to make predictions concerning government choices.

Relevant transaction cost categories include the following:

Negotiation costs: Given that formal law constrains governments more than informal law, governments can be expected to invest more time into the precise wording of formal law. We, hence, assume that $\mathrm{cf}>\mathrm{ci} .{ }^{14}$

Ratification costs: Formal law needs to be formally ratified domestically. Often, many actors need to consent, quite frequently with supermajorities. None of this applies to informal law, implying that $\mathrm{cf}>\mathrm{ci}$.

Monitoring costs: International agreements are concluded to induce a specific behaviour by the contracting parties. ${ }^{15}$ Monitoring is needed to ascertain whether parties comply with the agreements they have concluded. Formal treaties are often accompanied by the creation of IOs, one of the main tasks of which is to collect information on the behaviour of ratifying States. Monitoring is often centralised and its costs shared among States. This is, however, usually not the case with informal international law. This implies that $\mathrm{cf}<\mathrm{ci}$.

Enforcement costs: The possibility of appealing to a third party in case of a conflict over the appropriate interpretation of an agreement is unusual

\footnotetext{
${ }^{13}$ See R. Coase (1937).

${ }^{14}$ Given that there is no difference between formal and informal law as to their benefits, rational utility-maximisers would opt in favour of informal law. Yet, there might be substantial differences in benefits, and these need to be taken explicitly into account before a rational decision can be made. It is not excluded that bureaucrats will take the same level of care in negotiating agreements no matter whether formal or informal. The cost advantage of informal law in terms of negotiation costs might, hence, only be miniscule.

${ }^{15}$ Or, in the event they are already behaving in accordance with an agreement even before it is put in place, to make their behaviour more certain.
} 
in case of informal international law. Such procedures, however, are often a part of formal law. The availability of such procedures implies that $\mathrm{cf}<$ ci.

Modification costs: Sometimes agreements have unintended effects and at least one partner will want to modify the original agreement. Given the higher degree of formality under formal law making, informal law making should be less costly in such a case, such that $\mathrm{cf}>\mathrm{ci}$.

Exit costs: If the results attained by an international agreement are completely unsatisfactory, the parties may desire to abandon the agreement altogether. Informal international law would seem to have a cost advantage over formal law is such a case, hence cf $>$ ci.

It is noteworthy that formal lawmaking is conjectured to have cost advantages regarding both monitoring and enforcement, leading to a hypothesis regarding the choice of lawmaking: ceteris paribus, i.e., under given benefits, rational law-makers will prefer informal international law to more formal law if neither monitoring nor enforcement cause substantial problems. This could be the case, for example, if an agreement is selfenforcing, i.e., there are no incentives for unilateral defection. ${ }^{16}$

\section{The choice of law as the choice of governance structure}

According to Williamson, the choice of governance structures should be determined by (1) the frequency with which partners interact, (2) the asset specificity necessary for carrying out the agreement, and (3) the degree of uncertainty present. ${ }^{17}$ Low frequency combined with a low degree of asset specificity would lead to choosing market exchange, whereas high frequency combined with a high degree of asset specificity would lead to unified governance. The third dimension, uncertainty, becomes relevant only when there is a high degree of asset specificity, in which case higher degrees of uncertainty would lead to more unified forms of governance. ${ }^{18}$ Is it possible to meaningfully apply these dimensions to the choice of governance structures in international lawmaking?

Regarding frequency, Williamson makes a distinction between 'sometimes' and 'regularly'. One could argue that almost all States interact sometimes, e.g., at the UN General Assembly and similar meetings. More

${ }^{16}$ See K. Abbott and D. Snidal (2000). They conjecture that formal law reduces the transaction costs of subsequent interactions more than informal law. In conjunction with our considerations, their argument implies a trade-off: the higher costs of formal lawmaking must be weighed against the lower costs of structuring interactions under it. Hence, to identify the optimal choice for a given government, its time preference needs to be taken into account.

${ }^{17}$ (n. 9).

${ }^{18}$ (n. 9), 79. 
regular interaction could be the consequence of geography; externalities could result in higher frequency. It is not obvious how to translate asset specificity to agreements between nation-States. One way to think about it, though, is to ask whether specific investments by private actors residing in the States that agree on some interaction are likely to follow suit. Agreeing on a certain standard could be followed by investments that pay off only given that the standard will be used. Asset specificity implies a hold-up risk, and this risk would be borne by private law subjects residing in the interacting States, not by the States themselves. Given that agreements are reciprocal, the hold-up problem does not seem that severe, though.

Given a mixed degree of asset specificity, Williamson argues that for partners who interact only 'sometimes' trilateral governance would be best, whereas for partners who interact 'regularly', bilateral governance, in the sense of relational contracts, would be optimal. Trilateral governance implies drawing on some arbitration or mediation mechanism in case of conflict, whereas relational contracts are based on the idea that the relationship is ongoing and that the net advantages of an ongoing relationship do not need to be perfectly balanced at each point in time.

Figure 1: $\quad$ Efficient governance structures according to Williamson

\begin{tabular}{|c|c|c|c|c|}
\hline & \multicolumn{3}{|c|}{ Characteristics of Investment Good } \\
\hline & & Non-specific & Mixed & Idiosyncratic \\
\hline \multirow{2}{*}{ Frequency } & Sometimes & \multirow[t]{2}{*}{ 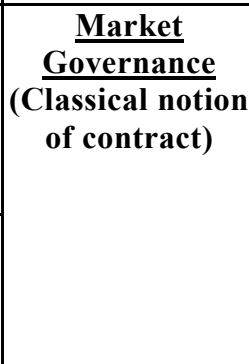 } & 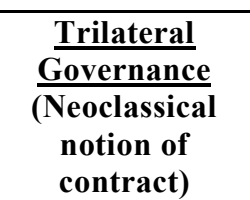 & \multirow[b]{2}{*}{$\underline{\begin{array}{c}\text { Unified } \\
\text { Governance }\end{array}}$} \\
\hline & Regularly & & 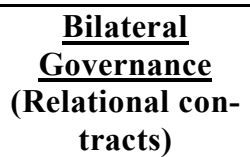 & \\
\hline
\end{tabular}

Analogising from the choice of firm structures to the choice of international law, one could argue that the equivalent of bilateral governance is informal international law, whereas the equivalent of trilateral governance is formal law. The choice of either form is primarily determined by the frequency of interaction. Thus, in attempting to explain government choices, it might be helpful to take frequency of interaction explicitly into account. Comparison of various transaction cost categories as well as comparison of factors determining choice of governance structures are both based on a 
decision-theoretic framework: the acting government assumes its environment to be exogenously given; hence, strategic interaction is assumed to be absent.

This is somewhat unsatisfactory, however, as international law, both formal and informal, is the outcome of an exchange between government representatives of at least two countries. Game theory provides an appropriate framework for dealing with strategic interactions, and is discussed next.

\section{Mutual cooperation in the prisoners' dilemma}

There is an important body of literature that deals with the possibility of reaching mutual cooperation in the prisoners' dilemma (PD) in the absence of a centralised authority with the power to enforce previously made promises. ${ }^{19}$ Information about past behaviour of actors is a crucial factor: given that an actor has always behaved as previously promised, they enjoy a good reputation that allows them to find partners for interaction in the future. ${ }^{20}$ However, if they have not behaved as promised and provided that this is common knowledge, finding partners to interact with will be much more difficult. In other words, reaching mutual cooperation in PDs without centralised enforcement depends, amongst others, on the availability of information regarding the past behaviour of all actors involved. Past behaviour can be evaluated only if the agreements the relevant actors have entered into are also known.

\section{Hypotheses}

I now translate the insights drawn from Coase, Williamson, and the PD into several hypotheses. Drawing on Coase, I conjecture that informal law is more likely to be used in interaction situations when monitoring and enforcement are not a huge problem.

$\mathrm{H} 1$ : informal international law will be primarily used in coordination games, whereas formal law will be used to deal with games involving a higher amount of conflict.

Assume that all games can be ranked by the degree of conflict inherent in them (i.e., from pure coordination to zero-sum games). To solve pure

${ }^{19}$ See e.g., R. Axelrod (1984); A. Greif (2006); P. Milgrom, D. North and B. Weingast (1990); A. Guzman (2008).

${ }^{20}$ Other factors determining the likelihood of managing mutual cooperation are (1) the likelihood of meeting again and (2) the time-discount rates of the parties. 
coordination games, creation of a focal point or a salient solution ${ }^{21}$ is sufficient as no single actor can benefit from unilateral defection. The incentive to defect increases as the conflict element increases; to guard oneself against being taken advantage of, States might try to insure themselves via more formal deals.

According to Williamson, regular interaction is a precondition for relational contracts. Translated into the realm of international law, I conjecture:

H2: The more regularly the relevant countries interact, the more likely are they to resort to informal law to structure their interactions. ${ }^{22}$

This hypothesis takes into account that repetition is key to maintaining the mutually cooperative solution. The central insight regarding the mutually cooperative solution in PDs played in the absence of a central authority is that common knowledge of previous behaviour of the actors is crucial. A low degree of publicness, however, is the norm in informal international law. Some of the agreements are not even in writing, which limits the degree to which they can be publicly known. This observation is the basis of a third hypothesis:

H3: Due to its limited publicness, informal international law is unlikely to structure interaction situations that are characterised by the PD; it is more likely to structure coordination games in which there are no incentives for unilateral defection.

Sometimes, governments have an interest in making their (domestic) policy promises more credible: for example, governments trying to attract foreign direct investment have a substantial interest in making credible their promise to protect private property rights. It is argued that governments use international agreements to enhance the credibility of their promises. ${ }^{23}$ If that is indeed the government's goal, then formal lawmaking will be more beneficial than informal law as its binding quality is much stronger. Credibility can also be signalled by securing the support of many domestic veto players in favour of a piece of specific legislation; this can be interpreted as a signal of the earnestness of the government's intentions. Since it is less costly to pass informal than formal law, the signal produced by informal international law is less valuable than that produced by passing formal law.

${ }^{21}$ See T. Schelling (1960).

${ }^{22}$ Abbott and Snidal (n. 16), 448, formulate a similar hypothesis, but based on of a different argument. They argue that powerful States are most concerned with delegation as it can entail considerable sovereignty costs, which they would prefer not to incur. From this it would seem to follow that powerful States prefer soft law (inter se but also with less powerful ones; since they are powerful, they should be able to secure their most preferred form of legalisation) but powerless States would agree on hard law inter se.

${ }^{23}$ See B. Levy and P. Spiller (1994); A. Dreher and S. Voigt (2011). 
From this observation, it seems reasonable to expect that States that do not enjoy a good reputation - and that thus could be searching for a way of making credible commitments - will prefer formal over informal agreements because only the former will build credibility. We would hence expect that informal law is primarily used as an instrument for coordinating behaviour between parties that have long-established ties and whose relationship can be characterised as well-functioning.

H4: Governments prefer formal law over informal law if they are interested in improving their credibility.

This is a very general hypothesis. I propose to narrow it by highlighting specific country types that might have an interest in more formal agreements: law. ${ }^{24}$

H4a: Young States are expected to prefer formal lawmaking to informal

$\mathrm{H} 4 \mathrm{~b}$ : States undergoing extensive transitions are expected to prefer formal to informal law.

Alternatively:

H4c: informal law will be primarily used by States already enjoying a good reputation.

These hypotheses put a high premium on credibility, but there are situations making it more likely that young countries will prefer informal law. For example, given that highly qualified diplomats are scarce, the lower costs incurred by informal international law could well lead some (likely younger) governments to prefer informal over more formal law.

One way to enforce contracts in the absence of a central enforcement authority is by the exchange of collateral or hostages. ${ }^{25}$ Compliance with the agreement is secured because the other party has in its possession something valued by the first party. In case of non-compliance with the agreement, the other party could threaten to destroy the hostage, sell it to a third party, etc. Given that the secrecy of informal law is one of its chief attractions, revealing its existence could pose such a credible threat. In other words: the secret is the hostage. It would be very interesting to discover whether, and if so, the consequence of such a threat has ever been made a reality. ${ }^{26}$

International agreements can be concluded between just two States or involve a great many States. Generally speaking, the more States partici-

\footnotetext{
${ }^{24}$ Note that this does not necessarily imply that young States will indeed rely more on formal law than older countries. The actual choice is determined by all partners. If the hypothesis is correct, however, we should observe an above-average reliance on formal law when young countries enter into agreements inter se.

${ }^{25}$ See A. Kronman (1985).

${ }^{26}$ Given that the US regularly publishes its informal agreements, we will not be able to test this conjecture with our dataset.
} 
pate in an agreement, the higher the monitoring costs. Substantial monitoring costs may make it very desirable to set up an international secretariat to perform that task. Establishing such secretariats, however, entails a certain degree of formality. We thus conjecture:

H5: Due to increasing monitoring costs, informal law is likely to be agreed upon among a limited number of participants, most likely only two. ${ }^{27}$

This hypothesis may need to be more precise. Both negotiation and monitoring costs increase with the number of participants. Thus, the optimal governance structure also depends on which transaction cost category grows faster. If negotiation costs grow faster than monitoring costs, it could well be that informal law is agreed upon by a number of States larger than two.

International lawmaking can be unpopular with the general public, for example, if it is viewed as reducing domestic sovereignty. If this is the case, politicians might prefer informal law as long as they think they can hide it. ${ }^{28}$ Similarly, if politicians are interested in not being too strictly bound, they might prefer informal over formal law. This might be the case if one party had a strong interest in an international agreement, but its partner would prefer no agreement at all. ${ }^{29}$

H6: Politicians will prefer informal over more formal law if the agreement is unpopular among their constituents.

Another reason international lawmaking could be unpopular among large parts of the population is because it privileges a limited few. If it is lobbied for by interest groups that make large donations or confer other advantages on politicians, politicians might try to square the circle - i.e., staying popular with the voters whilst maintaining the support of specific interest groups - by passing agreements that are largely hidden from the

${ }^{27}$ Abbott and Snidal (n. 16), 445, argue the exact opposite. They construct a trade-off between many participants and soft law on the one hand, and a small number of participants and harder law on the other. Empirical analysis is needed to ascertain which hypothesis is supported by the facts.

${ }^{28}$ If this does indeed describe politicians' preferences, the above argument according to which publication of a hitherto hidden agreement constitutes a credible threat is applicable. This sort of action can be described as something such as: this is highly unpopular, we only do it because nobody knows, whereas the well-known scapegoat function of international agreements works in an almost opposite way: this is highly unpopular, we do it because some IO forces us to. The scapegoat tactic is unlikely to be effective in bilateral relationships, however. It is more likely to be effective in very firmly established multilateral settings such as the EU.

${ }^{29}$ Indeed, power differences between countries could be a determinant of informal law. Assume a weak state is being forced to accept a solution largely unfavourable to it. It might only be willing to agree informally, for the very purpose of preventing domestic opposition. 
public. In such a case, informal law will be preferred over more formal agreements. ${ }^{30}$

The cost of non-compliance could be higher under formal law. Breaking a legal obligation is likely to harm one's reputation more than breaking political and/or moral obligations.

We now turn to situations in which formal lawmaking would seem to be more beneficial than informal law. Governments that expect to lose upcoming elections are assumed to implement measures that may protect their own policies against future policy reversals. ${ }^{31}$ This argument has been applied to independent domestic players such as the judiciary: that is, when a government expects to lose power, it might increase judicial independence to reduce the likelihood that the successor government can implement far-reaching policy reversals. ${ }^{32}$ Entering into international agreements might also be a way of binding successor governments. Since the binding quality of formal law exceeds that of informal law, governments on their way out are expected to prefer the former over the latter.

H7: Governments prefer formal over informal law if they expect to lose the next election and they aim at constraining the successor government.

The political or moral obligation produced by informal law might bind only those politicians (governments) that entered into it. Subsequent governments might not feel bound by it. This implies that uncertainty regarding the behavioural effects of informal law is higher than under formal law. If the reduction of uncertainty in a specific policy area is of paramount importance, governments are expected to prefer formal over informal lawmaking.

Drawing largely on tools used in institutional economics, this section has developed a number of hypotheses regarding the use of informal law. In the interests of simplicity, we have assumed throughout that the choice is binary: either informal or formal law. However, Abbott and Snidal show that the choice can be perceived on a continuum, with obligation, precision, and delegation as three dimensions. ${ }^{33}$

Furthermore, I implicitly assumed that the choice between hard and soft law is a choice of substitutes. Kiwit and Voigt show and discuss at consid-

\footnotetext{
${ }^{30}$ Thus, informal law can be conceptualised as the result of successful rent-seeking by lobbying groups. This leads directly to the next question: Under what conditions will lobby groups opt in favour of informal law and under what conditions will they prefer more formal agreements? Answering this question is beyond the scope of this paper, but one step in that direction might be to look at an analogous choice in the domestic realm: Under what conditions do such groups prefer constitutional law over ordinary law? For a treatment of this issue, see D. Boudreaux and A.C. Pritchard (1993).

${ }^{31}$ See e.g., T. Moe (1990); T. Persson, and L. Svensson (1989); A. Alesina and G. Tabellini (1990); G. Tabellini and A. Alesina (1990).

${ }^{32}$ See M. Ramseyer (1994); T. Ginsburg (2002).

${ }^{33}$ (n. 16).
} 
erable length four possible relationships between institutions. ${ }^{34}$ They can have a not only a substitutive relationship, but also complement each other, be neutral, or conflict. Shaffer and Pollack have recently focused on this last relationship, which they call antagonistic. ${ }^{35}$ They expect conflicting relationships under fragmented legal systems and when important distributive issues are at stake.

Finally, we have been relying primarily on a decision-theoretic rationale, i.e., a single government deciding in isolation about its optimal behaviour, and assuming that the decisions of all other actors are exogenously given. In reality, of course, at least two governments need to agree on the form of cooperation. In future work, it might be appropriate to give more attention to bargaining theory. However, given that the US is a very powerful actor, relying primarily on decision theory seems justified here.

\section{Taking Stock}

In Annex $\mathrm{C}$ of its Policy on Tabling of Treaties in Parliament, the Canadian government states: "If a matter is of a routine or technical nature, or appears to fall entirely within the existing mandate and responsibility of a department or agency, and if it does not contain substantive matter which should be legally binding in public international law, it is often preferable to deal with the matter through the use of a non-legally binding instrument. [...] Memoranda of Understanding and similar arrangements can be between Canada and another sovereign state, but much more commonly are between a Canadian Government department, an agency, or a province, or other sub-national government, or para-statal organisation, and a similar body in another country." ${ }^{36}$

Are these statements indications that informal law has become more relevant relative to formal international law over time? Which actors use it most? Is it used more in structuring bilateral or multilateral relationships? What are the main policy areas covered by informal law? These are some of the questions that will be answered in this section. Ideally, we would like to base our answers on the complete stock of informal law in the world today. Unfortunately, there is no central database that collects all such agreements. Often, informal law is not even systematically collected at the country level. ${ }^{37}$ A systematic analysis of informal law runs into several other obstacles, too. Informal law might not be in writing and thus will not

\footnotetext{
${ }^{34}$ See D. Kiwit and S. Voigt (1998).

${ }^{35}$ See G. Schaffer and M. Pollack (2010).

${ }^{36}$ See Canada Treaty Information (n. 4).

${ }^{37}$ For example, the Foreign \& Commonwealth Office (2004) stipulates that memoranda of understanding are usually not published.
} 
show up in any statistic. There is no established convention in terminology. Even countries using the same official language might use different words to describe it. For example, in English, informal law is variously known as a gentlemen's agreement, an executive agreement, or a memorandum of understanding, to name but a few of many descriptions. What is more, informal law does not occur only between nation-State governments, so even if all these governments had complete databases, we still could miss informal law produced by other actors, such as IOs or even nongovernmental organisations (NGOs).

Given the numerous barriers to analyzing the stock of informal law across countries, we decided to conduct a detailed analysis of certain informal international lawmaking activities (as we re-defined above) of one single country. We chose the US for a number of reasons. The US passed the Case-Zablocki Act in 1972, which requires the Department of State to report international agreements to Congress no later than 60 days after they enter into force ${ }^{38}$ All agreements entered since 1981 are available online, making systematic analysis convenient. ${ }^{39}$ Additionally, our conjecture that young States that have recently undergone fundamental change and have not been able to build up a reputation as promise-keepers, are less likely to draw on informal international law makes the United States a good choice because it holds the record for the world's longest established, uninterrupted democracy, and it enjoys an excellent overall reputation. On the one hand, this might bias the results in favour of informal international law (redefined and narrowed down here to 'international agreements' as opposed to 'treaties'); on the other hand, this is likely to give us an unusually broad database for analysis.

There are some drawbacks, of course, to confining an analysis of informal international lawmaking to a single country. The most serious of these is that conjectures as to certain country characteristics cannot be tested (e.g., the US is neither young nor has it undergone a substantial transition recently, so hypotheses as to those characteristics cannot be tested). Further, the Case-Zablocki Act explicitly exempts a number of agreements from publication. Among these are 'specified military exercises' and agreements 'that have been given a national security classification', as well as a number of coordination agreements (between postal administrations and aviation agencies), and agreements involving bilateral assistance for

38 The text of the Act is available online http://ecfr.gpoaccess.gov/cgi/t/text/textidx? $=$ ecfr\&tpl=/ecfrbrowse/Title22/22cfr181_main_02.tpl accessed 19 October 2011.

${ }^{39}$ The 2,289 items covering the period from 1981 until 2010 do not only include many kinds of agreements but also Memoranda of Understanding, agreements, Memoranda of Agreements, letters of agreement, arrangements, technical exchanges, protocols, and the like. 
counter-narcotics and other anti-crime purposes ${ }^{40}$ Most importantly, it includes only 'international agreements' that are legally binding under international law, thereby excluding all informal international lawmaking that is not legally binding under international law (such as non-binding guidelines or standards).

The first aspect analysed is the number of international agreements produced annually over the last 30 years. The absolute numbers provide a first indication of whether informal lawmaking (in the sense of a shift from formal 'treaties' to less formal 'international agreements') has really so dramatically increased as sometimes insinuated. A dramatic increase in international agreements did occur following the first half of the 1990s. In 1995 , six international agreements were reported. This number rose to 86 in 1999 and to 318 in 2006 , but fell to only 113 agreements in $2010 .{ }^{41}$

This simple series allows us to answer a number of additional questions. For example, are Republican administrations more (or less) likely to rely on informal law than Democratic-led ones? Since both the rise and fall in international agreements occurred during the presidency of George W. Bush, no such preference seems identifiable: informal law dramatically increased during his first term; most of its decline took place during his second term. Between 2003 and 2006, the Republicans had a majority in both houses. During this time, passing formal law should have been relatively easy, implying that informal law should have been relatively less attractive. But this is not what happened: during the period in which the Republicans enjoyed a majority in both houses, as well as there being a Republican president, they used more informal law than ever before. ${ }^{42}$

\footnotetext{
${ }^{40}$ The last type of agreement could be motivated by a desire not to make the partner government unpopular domestically; hence, its revelation would be a credible threat in the hands of the US government.

${ }^{41}$ Frequently, agreements are not posted within the mandated 60 -day period. At times, the delay can be months or even years. This implies that numbers for the last couple of years might need a minor upward adjustment; however, this is unlikely to lead to any changes in the trends observed here.

The absolute numbers might be misleading: if other kinds of international agreements have increased at an even faster rate, the relative importance of informal law would actually have decreased. But comparing the number of informal international agreements reported under Case-Zablocki to the number of formal treaties ratified by the US might result in a skewed picture as the number of newly-ratified treaties is very low (it ranges between two in both 2007 and 2008 and six in both 2004 and 2005). This is also true for the number of IOs to which the US belonged in the respective year. Moreover, the IO membership data reports a net effect (entry minus exit), whereas our data on informal describe raw events. (Data on both treaties and IO membership are taken from A. Dreher, (2006).)

${ }^{42}$ Eyal Benvenisti who commented upon this chapter at a workshop suspects that the US National Security Strategy of 2006 is the reason for the turning point. In its report on strategy, the US government explains that it seeks partnerships with countries in Latin America and the former Soviet Union but also with non-State actors. To be convincing,
} 
Figure 2: $\quad$ Publicly documented 'international agreements' by the US between 1981 and 2010

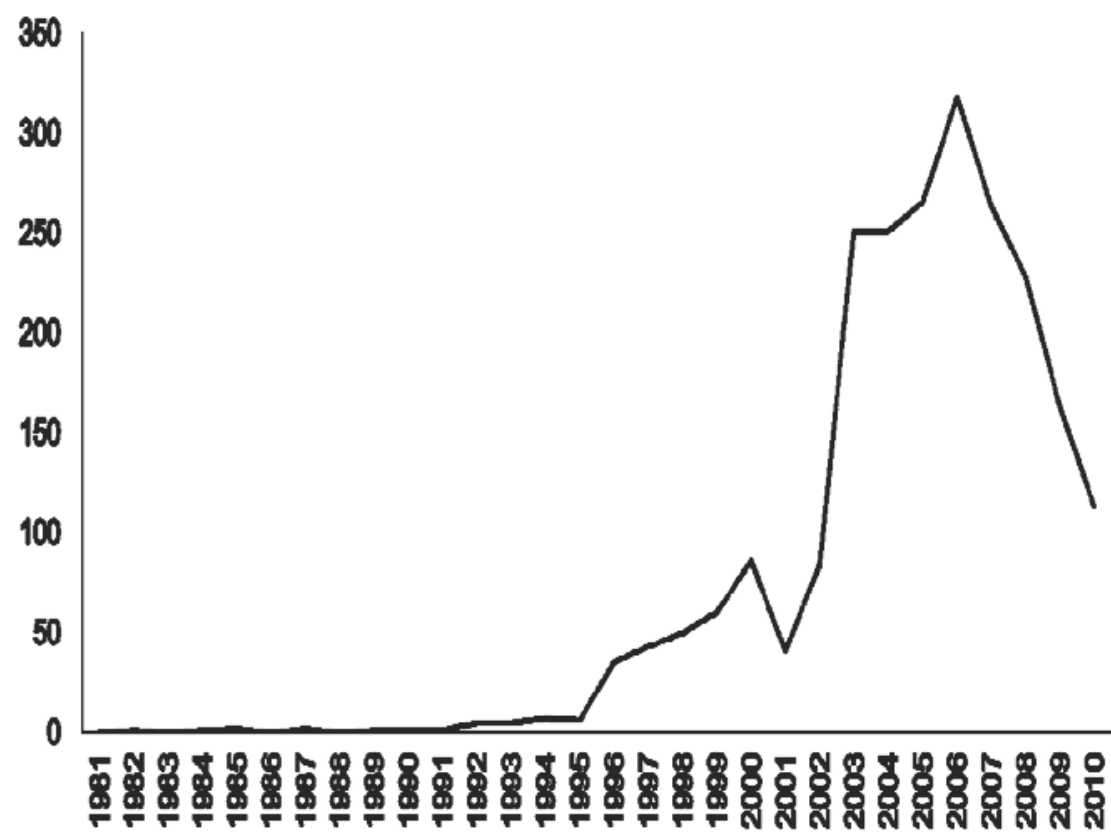

Source: Own calculations based on U.S. Department of State (2011).

If governments attempt to use international agreements as a means of binding successor governments and formal lawmaking is better suited to achieve this purpose than informal international law (as hypothesised above), informal international law should be relatively less frequent in the years immediately preceding elections than in other years. ${ }^{43}$ The Republicans lost both houses in 2007 , so we should have observed relatively less informal international law in 2006. Again, this conjecture finds no support in the data and Hypothesis 7 is refuted with regard to the US.

Informal international law could be especially appealing to the administration during periods when the legislative majority and the president belong to different parties. Ratification of formal treaties will be particularly difficult for the administration and it thus might resort to informal

the composition of countries entering into agreements before 2006 should be markedly different from that after 2006. This is, however, not the case.

${ }^{43}$ Given the highly debatable assumption that politicians have perfect foresight and know who will win future elections. 
international law. Again, however, the data show no support for this conjecture.

International agreements might be used by the administration not only as a tool to circumvent the legislature; it might also be employed to change the balance of power within the administration itself. Enactment of formal law requires the explicit consent of the minister of foreign affairs; in the US, this is the Secretary of State. No such consent is needed in the case of informal law. Thus, it is of interest to ascertain what percentage of informal law is concluded by actors other than the state department. These need not be other government departments; they could be independent agencies. Our results show that more than $40 \%$ of all international agreements are signed by an actor other than the traditional ones (namely, the head of government and/or the department of state). In the US, about half of these agreements are signed by other departments, another half by others such as independent agencies. In other countries, this share is less than oneseventh of all agreements (13.9\%), a difference possibly due to the relatively large number of independent agencies in the US, or because other countries have mechanisms making it more difficult for independent agencies to conclude informal law on their own.

Table 1: $\quad$ Identity of actors signing informal law ${ }^{44}$

\begin{tabular}{|l|c|c|}
\hline Informal law signed by & US & Partner \\
\hline Head of Executive & $38.1 \%$ & $40.8 \%$ \\
\hline Department of State/Embassy & $19.9 \%$ & $15.4 \%$ \\
\hline Other Ministries & $21.7 \%$ & $29.9 \%$ \\
\hline Others & $20.3 \%$ & $13.9 \%$ \\
\hline
\end{tabular}

Source: Own calculations based on U.S. Department of State (2011).

Evaluating these numbers is subject to ambivalence: delegation of competence is always subject to drift. ${ }^{45}$ The longer the relevant principal-agent chain, the more severe the drift. If independent agencies enter into agreements with their foreign counterparts, they have an interest in the terms of the agreement being kept, and drift could thus be expected to be low. On the other hand, agreements entered into by independent agencies are far from the supreme democratic principals - the citizen-voters.

${ }^{44}$ In the event the agreement involved more than one partner, the first partner was coded (less than $3 \%$ of all international agreements are concluded between more than two parties).

${ }^{45}$ See e.g., D.R. Kiewiet and M. McCubbins, (1991). 
Above, it was argued that informal international law is expected to be primarily bilateral, not multilateral. The Case-Zablocki data allow us to test this hypothesis on the basis of the agreements entered into by the US. Figure 3 shows that the overwhelming number of international agreements is concluded with just one other party. ${ }^{46}$

We are also interested in the geographic distribution of the US partners in international agreements. In the theoretical section, it is argued that frequent interactions are likely to be highly correlated with informal law. There are many interactions with one's direct neighbours. There will be many issues concerning border-crossing externalities. Therefore, it would be less than surprising to find that geographic proximity is correlated with a high number of international agreements.

Figure 3: $\quad$ Number of countries involved in US international agreements' (including the US)

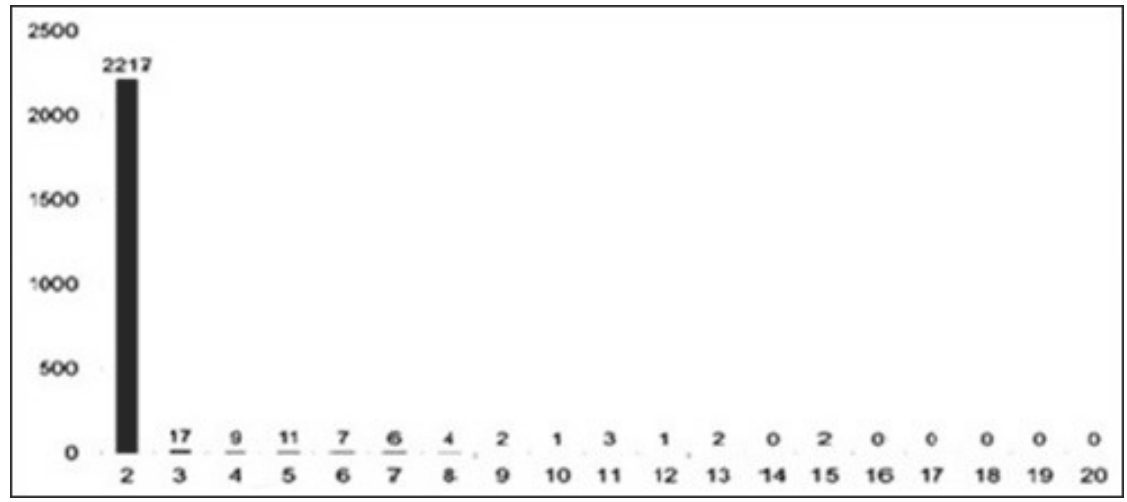

Source: Own calculations based on U.S. Department of State (2011).

Based on a delineation that distinguishes between ten geographic regions, the region that the US has the most agreements with is composed of Western Europe and North America (including Australia and New Zealand), namely, 20.5\%. Latin America (including Cuba, Haiti, and the Dominican Republic) is a close runner-up with $20.4 \%$, followed by Eastern Europe and the post-Soviet Union countries (including Central Asia) with 17.1\%.

${ }^{46}$ Simple comparisons between the number of bilateral and multilateral agreements might lead to a bias picture as a single multilateral agreement could weigh as little as two bilateral agreements (if an agreement is concluded between the US and two other countries) or as much as 200 bilateral agreements (if the agreement is concluded amongst 201 countries). Weighing multilateral agreements with the number of participants, however, does not lead to dramatic changes in the results: the non-weighted percentage of multilateral agreements is $3.15 \%$, whereas the weighted one amounts to $12.68 \%$. 
One of the hypotheses developed in Section $\mathrm{C}$ is that frequent interactions will increase the propensity to resort to informal international law. Interactions should be most frequent with those countries that share a border with the United States: Canada and Mexico. In our dataset, we identified 93 such agreements with Canada (i.e., $3.7 \%$ of the entire sample) and 43 with Mexico (1.7\% of the whole sample). If we compare these numbers with the number of agreements between the United States and two of its major trading partners - China and Japan - our conjecture seems to find at least some support: there are only 35 recorded agreements with China (i.e., $1.4 \%$ of the entire sample) and 63 with Japan (2.5\%).

Table 2

\begin{tabular}{|l|l|}
\hline Region & Share in\% \\
\hline $\begin{array}{l}\text { Western Europe and North America (including Australia and } \\
\text { New Zealand) }\end{array}$ & 20.5 \\
\hline $\begin{array}{l}\text { Latin America (including Cuba, Haiti, and the Dominican } \\
\text { Republic) }\end{array}$ & 20.4 \\
\hline $\begin{array}{l}\text { Eastern Europe and post Soviet Union (including Central } \\
\text { Asia) }\end{array}$ & 17.1 \\
\hline Sub-Saharan Africa & 10.6 \\
\hline $\begin{array}{l}\text { North Africa \& the Middle East (including Israel, Turkey, } \\
\text { and Cyprus) }\end{array}$ & 8.2 \\
\hline East Asia (including Japan and Mongolia) & 7.3 \\
\hline South Asia & 6.5 \\
\hline Southeast Asia & 5.7 \\
\hline The Pacific (excluding Australia and New Zealand) & 1.9 \\
\hline $\begin{array}{l}\text { The Caribbean (including Belize, Guyana, and Suriname, but } \\
\text { excluding Cuba, Haiti, and the Dominican Republic) }\end{array}$ & 1.8 \\
\hline
\end{tabular}

Source: Own calculations based on U.S. Department of State (2011).

It is also interesting to see in which policy areas most informal international law falls. Interestingly, Brummer compares the propensity to enter into soft law regarding trade issues with that involving finance and develops the following claims. (1) Trade liberalisation is fragile; to safeguard it, hard law is needed. (2) Financial markets evolve very quickly. Adequate regulation of these markets thus also needs to be able to adapt quickly, implying that international law on financial issues ought to be soft rather than hard. (3) Finance markets are often regulated by independent bodies 
such as central banks and supervisory authorities; however, these bodies can only create soft law. ${ }^{47}$

Table 3

\begin{tabular}{|l|c|}
\hline Policy Area & Share in \% \\
\hline Military & 30.5 \\
\hline Science and technology & 19.9 \\
\hline Aid & 14.7 \\
\hline Crime prevention and anti-terrorism & 7.2 \\
\hline Economic (goods and services) & 6.1 \\
\hline Foreign relations & 5.3 \\
\hline Transportation & 5.3 \\
\hline Agriculture and environment & 3.8 \\
\hline Culture and education & 3.2 \\
\hline Economic (financial capital) & 2.3 \\
\hline Other & 1.9 \\
\hline
\end{tabular}

Source: Own calculations based on U.S. Department of State (2011).

With regard to the US, we find that almost two-thirds of all international agreements falls into three policy areas: military agreements $(30.5 \%)$, agreements regarding science and technology (19.9\%), and agreements on aid (14.7\%). To get a more concrete picture of whether the US uses international agreements based on a more formal framework (such as NATO) or on a more ad hoc basis, comparing the agreements concluded with NATO members and non-member countries might be illuminating: only $8.3 \%$ of all military agreements have been concluded with NATO partners. If informal lawmaking by U.S. authorities is taken as the basis, then Brummer's conjecture is not confirmed by the data ${ }^{48}$ : according to our count, $6.1 \%$ of all agreements deal with goods and services; only $2.3 \%$ involve financial capital. ${ }^{49}$

A number of papers show that temporary membership on the UN Security Council can be very valuable because the US is willing to support a

${ }^{47}$ See C. Brummer (2010).

${ }^{48} \mathrm{Ibid}$.

${ }^{49}$ On the other hand, these are absolute numbers and to really test the Brummer hypothesis, we would need to analyse the ratio between soft and hard law in both policy areas. 
member country in exchange for voting in line with it on Security Council matters. ${ }^{50}$ Given that informal agreements are rather opaque, we propose to discover whether countries receiving any kind of support from the US belonged to the Security Council at the time the informal agreements were concluded. ${ }^{51}$

\section{E. Comparing the stock across countries: domestic institutions as determinants of the choice between formal and informal law}

Section D provided an overview of all types of international agreements entered into by the US over the last 30 years. However, the US is only one of many countries, and decisions about entering into either formal or informal law might vary markedly among countries. In this chapter, I only develop conjectures on this issue; empirical tests will have to wait for a sequel.

Compare the way two major West European countries deal with informal law. In Germany, the federal ministries have joint by-laws (gemeinsame Geschäftsordnung ${ }^{52}$ ), which in \$72(1) stipulate: 'Before international law treaties (interstate treaties, memoranda of understanding, agreements between ministers, exchange of notes and letters) are elaborated on and concluded, the ministry in charge must check whether a binding contract under international law is irrefutable or whether the same goal may also be attained through other means, especially through understandings which are below the threshold of an international agreement. ${ }^{53}$ In France, a 1997 Circular of the Prime Minister emphasises that arrangements administratifs should be resorted to only in exceptional circumstances given their uncertain effects. Moreover, arrangements administratifs are not even registered by the French Ministry of Foreign Affairs, which not only makes monitoring of them by the French legislature very difficult but also prevents empirical research into their use in France. Thus,

\footnotetext{
${ }^{50}$ See I. Kuziemko and E. Werker (2006).

${ }^{51}$ Note, however, that at least two possible areas of support are exempt from the reporting requirement: rescheduling of intergovernmental debt payments and some agreements concluded with USAID.

${ }_{53}^{52}$ See Bundesregierung (2009).

${ }^{53}$ Author's translation. The original text reads: 'Vor der Ausarbeitung und dem Abschluss völkerrechtlicher Verträge (Staatsverträge, Regierungsübereinkünfte, Ressortabkommen, Noten- und Briefwechsel) hat das federführende Bundesministerium stets zu prüfen, ob eine völkervertragliche Regelung unabweisbar ist oder ob der verfolgte Zweck auch mit anderen Mitteln erreicht werden kann, insbesondere auch mit Absprachen unterhalb der Schwelle eines völkerrechtlichen Vertrags.'
} 
the approaches to informal law taken in Germany and France seem to be completely opposite. Why? This section develops a number of conjectures that make these choices - and those taken by other States - understandable.

Given that a government desires to enter into an international agreement, its choice regarding formality will depend on the relative costs of informal versus formal agreements. Procedures for ratifying formal law vary widely among countries. One important cost component is therefore determined by the institutional prerequisites for passing formal law. Two hypotheses can be derived:

H1: The higher the number of players that need to consent to ratify formal international law domestically, the higher the proportion of informal law.

Additionally, the majorities required within the respective houses are conjectured to have an effect:

H2: The higher the required majorities needed to ratify formal international law domestically, the higher the proportion of informal law.

The first two hypotheses focus on the institutional structure of a country. The bliss points of the actors enjoying a majority in the various houses are also conjectured to play a role. A higher degree of ideological heterogeneity will make it more difficult to reach the required majorities. Hence:

H3: The higher the degree of ideological heterogeneity among the veto players, the higher the proportion of informal law.

Above, it was mentioned that an advantage of informal law is that it is relatively cheap to amend or even abolish. In contrast, amending or abolishing formal international treaties can be very costly. Forward-looking politicians might take this into account. Formulated as a hypothesis:

H4: The more costly it is to abolish formal treaty law (in terms of the number of players who have to consent and/or the required majorities), the higher the proportion of informal law. ${ }^{54}$

States have developed different approaches for dealing with the relationship between national and international law. In some, both types of law are assumed to form a uniform legal order (monism); in others, it is assumed that the two create two different legal orders (dualism). The chosen approach could be relevant to the form of international agreements chosen depending on whether national or international law commands supremacy in case the two types of law conflict. Agreeing on formal international agreements is more costly in countries in which international law assumes supremacy over domestic law. The corresponding hypothesis reads:

${ }^{54}$ If one assumes that all relevant actors discount the future, the costs of exiting should be less important than the costs of ratification. 
H5: Countries in which formal international law assumes supremacy over domestic law will pass relatively less formal international law than countries in which the inverse holds, ceteris paribus.

Passing formal international law can also strengthen a domestic veto player, namely, the judiciary. Given that the domestic judiciary has the power to apply international law directly, this can imply additional constraints for domestic governments. Given that governments do not like to be constrained, this would mean that:

H6: If the domestic judiciary has the power to apply formal international law directly, a higher proportion of informal law will be used than in countries in which the direct application is not possible.

In the last couple of hypotheses, we implicitly assumed that governments prefer not to be bound by international constraints. However, this assumption might be wrong. Hence, it is important to control for whether governments are afraid of losing upcoming elections and thus attempt to bind successor governments (see Section C).

The form of government might also be an important determinant of the choice between formal and informal law. In parliamentary systems, the executive's survival depends on maintaining the confidence of the legislature. This is not the case in presidential systems. This institutional difference has a number of implications. First, the number of veto players is higher under presidential systems than under parliamentary ones. In line with the above hypotheses, this implies that we should expect less formal lawmaking under presidential systems than under parliamentary ones. Formulated differently:

H7: Cp, presidential systems will resort to informal law more often than parliamentary systems.

If the executive passes a great deal of informal law, i.e., legislates without the legislature's approval and sometimes without the legislature even being informed of it (either before international agreements are concluded or even after), the legislature may have an incentive to change this state of affairs. Under presidential systems, the executive's survival does not depend on retaining the confidence of the legislature. Therefore, the executive can be expected to implement informal law that is not entirely in line with the preferences of the legislature. Consequently, the legislature has an incentive to create legislation aimed at somehow monitoring the executive. Under parliamentary systems, the executive's survival does depend on the continued confidence of the legislature. Therefore, the executive has an incentive to take the legislature's preferences into account when agreeing upon informal international law. This leads us to the following hypothesis:

H8: Cp, legislatures under presidential systems are more likely to pass legislation aimed at monitoring informal law-making than are legislatures under parliamentary systems. 
Minnich argues that the type of electoral system can have an influence on the propensity of nation-State governments to enter international agreements. He argues that governments under proportional rule systems are more likely to enter into such agreements than are governments under firstpast-the-post systems because under the latter, it is unlikely that international agreements deliver benefits to specific constituents. ${ }^{55}$ Assuming that this argument is correct, the following hypothesis is offered:

H9: Governments under MR systems are more likely than governments under PR systems to draw on informal law because agreements are less visible.

Above, it was argued that recent transitions of a political system are more likely to make its government seek formal, rather than informal, international agreements. Various hypotheses can be derived from this:

H1Oa: The longer a country has been sovereign, the higher the propensity of its government to resort to informal law.

H10b: The longer a country has been democratic without interruption, the higher the propensity of its government to resort to informal law.

\section{F. Open questions: possible next steps}

This is the first paper to empirically analyse the choice of informal international law. Based on all publicly available international agreements entered into by the US since 1981, the main findings are as follows: (1) Informal international lawmaking (defined here as the conclusion of 'international agreements' rather than more formal 'treaties' in the sense of the US Constitution) did increase dramatically until around 2006. Since then, its use has declined almost as dramatically. (2) Around two-thirds of all international agreements are concerned with only three policy areas: the military, science and technology, and aid. (3) More than $90 \%$ of all international agreements are conducted bilaterally. (4) More than $40 \%$ of all agreements are concluded by a non-traditional actor on the US side, i.e., an actor other than the President or the Secretary of State.

This chapter has answered some questions and given rise to others. There are at least five issues waiting in the wings for their chance at centre stage. Some of the central characteristics of informal law could be described in more detail. Is informal law primarily created to order one-shot interactions, or is it created as the foundation for a multitude of single interactions in later periods? Does informal law contain sunset clauses? Does it contain rules on how to renegotiate if necessary? Does it contain explicit

\footnotetext{
${ }^{55}$ See D. Minnich (2005).
} 
sanctions in the event of non-compliance? Does it involve reliance on third parties for its enforcement? How frequently is it abolished?

What do we know about compliance with informal law? Are all agreements equally likely to be complied with or are there systematic differences?

(1) Can we discern any systematic pattern in the development of informal law over time? Under what circumstances does informal law constitute a first step toward formal law? Under what circumstances does it complement hard law?

(2) Section E contains hypotheses that can be tested only on a crosscountry basis, which will entail considerable effort in collecting and coding data. Two levels can be distinguished here: the first one deals with the kind and frequency of informal law being chosen under various institutional constraints. The second one deals with attempts to set up institutions to monitor informal law in a systematic fashion.

(3) In this chapter, choice of informal law has been described from a decision-theoretic angle. However, informal law is not chosen in isolation by any single government; at least two governments have to come to an agreement on the issue. Which government will prevail if their preferences on soft versus hard law conflict? (For example, in the case of Germany and France, who have such opposite views of informal law, which government will prevail?). What role do power differences play? If one wants to model this as a bargaining game, it might make sense to distinguish between two dimensions, namely, content and form. Is soft law a likely compromise if one government wants hard law whereas the other would prefer no agreement at all?

(4) Finally, it is well-known that IOs play an important role in the creation of international law. (Shanks et al. estimate that IOs are involved in some way in two-thirds of all newly-created international law. ${ }^{56}$ ) It would be interesting to learn more about the ways that IOs are involved in the creation of informal law. For example, have IOs established monitoring mechanisms to alleviate their own principal-agent problems? Pari passu, the same questions could be asked with regard to (International) NGOs.

Both the analysis contained in this chapter and the proposed next steps have been primarily positive. Obviously, important normative issues need to be dealt with concerning informal law. These include both the legitimacy of informal law, as well as the accountability of those who create it. The Case-Zablocki Act can be perceived as one way to increase accountability. If a distinction is made between ex ante and ex post accountability, which one is more effective? Is ex post accountability sufficient or is there also a

\footnotetext{
${ }^{56}$ See C. Shanks, H. Jacobson and J. Kaplan (1996).
} 
need for ex ante accountability, according to which parliament would need to be informed before informal law is created?

These questions can be answered only after a number of other issues have been dealt with adequately. Among them are the costs and benefits of non-accountability, and the delineation of policy areas that should be subject to a high degree of accountability and those for which a low degree is deemed sufficient. A very fundamental question is whether a combination of a high degree of accountability and informal law even makes sense: Could it be that precisely that characteristic of informal law which makes it attractive is that its creators are somewhat less accountable?

There is much to be learned, much to be done. It is hoped that this chapter will provide the point of departure.

\section{Bibliography}

Abbott, K. and D. Snidal (1998); Why States Act Through Formal International Organizations, International Organization 42(1):3-32.

Abbott, K. and D. Snidal (2000); Hard and Soft Law in International Governance, International Organization 54(3):421-456.

Alesina, A. and G. Tabellini (1990); A Positive Theory of Fiscal Deficits and Government Debt, Review of Economic Studies 57(3):403-414.

Axelrod, R. (1984); The Evolution of Cooperation, New York: Basic Books.

Boudreaux, D. and A. C. Pritchard (1993); Rewriting the Constitution: An Economic Analysis of the Constitutional Amendment Process, Fordham Law Review, 62:111162.

Brummer, C. (2010); Why Soft Law Dominates International Finance - and Not Trade, Journal of International Economic Law, 13(3):623-643.

Bundesregierung (2009); Gemeinsame Geschäftsordnung der Bundesministerien, available at: http://www.bmi.bund.de/cae/servlet/contentblob/139852/publicationFile /55730/ggo.pdf.

Canada Treaty Information (2011); Policy on Tabling of Treaties in Parliament, available at: www.treaty-accord.gc.ca/procedure.asp.

Coase, R. (1937); The Nature of the Firm, Economica 4:386-405.

Dreher, A. (2006); Does Globalization Affect Growth? Evidence from a New Index of Globalization, Applied Economics, 38(10):1091-1110. Updated data available at: http://globalization.kof.ethz.ch./.

Dreher, A. and S. Voigt (2011); Does Membership in International Organizations Increase Governments' Credibility?, Journal of Comparative Economics 39:326-348.

Foreign and Commonwealth Office (2004); Guidance on Practice and Procedures for Treaties and Memoranda of Understanding, available at: http://www.fco.gov.uk/en/ publications-and-documents/treaties/practice-procedures/glossary-treaty-terms.

Ginsburg, T. (2002); Economic Analysis and the Design of Constitutional Courts, Theoretical Inquiries in Law 3(1):49-85.

Grant, R. and R. Keohane (2005); Accountability and Abuses of Power in World Politics, American Political Science Review 99(1):29-43.

Greif, A. (2006); Institutions and the Path to the Modern Economy - Lessons from Medieval Trade, Cambridge: CUP. 
Guzman, A. (2008); How International Law Works - A Rational Choice Theory, Oxford: OUP.

Hathaway, O. (2008); Treaties' End: The Past, Present, and Future of International Lawmaking in the United States, Yale Law Journal 117:1237.

Johnson, L. and J. McCormick (1977); Foreign Policy by Executive Fiat, Foreign Policy 28:117-138.

Kiewiet, D. R. and M. McCubins (1991); The Logic of Delegation: Congressional Parties and the Appropriation Process, Chicago: University of Chicago Press.

Kiwit, D. and S. Voigt (1998); The Role of Evolution of Beliefs, Habits, Moral Norms, and Institutions. In: Giersch, H. (ed.): The Merits of Markets - Critical Issues of the Open Society, Berlin: Springer, 83-108.

Kronman, A. (1985); Contract Law and the State of Nature, Journal of Law, Economics, and Organization, 1(1):5-32.

Kuziemko, I. and E. Werker (2006); How Much is a Seat on the Security Council Worth? Foreign Aid and Bribery at the United Nations; Journal of Political Economy 114(5):905-930.

Levy, B. and P. Spiller (1994); The Institutional Foundations of Regulatory Commitment: A Comparative Analysis of Telecommunications Regulation, Journal of Law, Economics, and Organization, 10(2):201-246.

Lipson, C. (1991); Why Are Some International Agreements Informal? International Organization 45(4):495-538.

Milgrom, P., D. North, and B. Weingast (1990); The Role of Institutions in the Revival of Trade: The Law Merchant, Private Judges, and the Champagne Fairs, Economics and Politics, 2(1):1-23.

Minnich, D. (2005); Veto Players, Electoral Incentives and International Commitments: The Impact of Domestic Institutions on Intergovernmental Organization Membership, European Journal of Political Research 44(2):295-325.

Moe, T. (1990); Political Institutions: The Neglected Side of the Story, Journal of Law, Economics, and Organization, 6:213-253.

Papadopoulos, Y. (2007); Problems of Democratic Accountability in Network and Multilevel Governance, European Law Journal, 13(4):469-486.

Pauwelyn, J. (2012); Informal International Lawmaking: Framing the Concept and Research Questions. In: Pauwelyn, J., Wessel, R., and Wouters, J. (eds.), Informal International Lawmaking. Oxford. OUP, 13-34.

Persson, T. and L. Svensson (1989); Why a Stubborn Conservative Would Run a Deficit: Policy with Time-Inconsistent Preferences, Quarterly Journal of Economics 104(2):325-345.

Ramseyer, M. (1994); The Puzzling (In)dependence of Courts: A Comparative Approach, Journal of Legal Studies, 23(2):721-747.

Schelling, T. (1960); The Strategy of Conflict, Cambridge, MA: Harvard University Press.

Shaffer, G. and M. Pollack (2010); Hard vs. Soft Law: Alternatives, Complements, and Antagonists in International Governance, Minnesota Law Review 94:706-799.

Shanks, C., H. Jacobson and J. Kaplan (1996). Inertia and change in the constellation of international governmental organizations, 1981-1992. International Organization 50: 593-627.

Tabellini, G. and A. Alesina (1990); Voting on the Budget Deficit, American Economic Review 80(1):37-49.

U.S. Department of State (2011); Guidance on Non-Binding Documents, available at: www.state.gov/s/1/treaty/guidance/.

Williamson, O. E. (1985); The Economic Institutions of Capitalism, New York: Free Press. 


\section{Comment on Stefan Voigt}

\section{The Economics of Informal International Law - An Empirical Assessment}

by

\section{Peter Lewisch}

\section{A. Introduction}

The paper by Stefan Voigt provides both an analytical and an empirical account of informal international law - with regard to its empirical nature. It is the first article on the subject. Chapeau for this achievement!

The paper defines "informal international law" (avoiding the connotations of "soft law") by reference to the domestic process employed to generate, adopt or modify the respective legal instruments. An agreement is thus deemed informal if it does not require the consent of domestic legislators. Although this definition is not without its problems (see infra II.), it may serve as a starting point for further analysis.

The first part of the paper provides an analytical explanation of informal international law and it does so through the "lens" of transaction costs and new institutional economics. The starting point for this analysis is quite straightforward: if (political) actors may choose between different instruments of international law (formal and informal) and if these choice patterns differ (either over time or depending on the subject matter involved), the economist will explain these shifts in terms of the differences in the underlying costs and benefits. The paper goes beyond a mere (i) transaction cost perspective, employing the tools of (ii) governance structure analysis in the Williamson sense and also looking to the (iii) substantive characteristics of the underlying choice settings, namely their prisoners' 
dilemma or coordination game structure. Whereas the legal literature ${ }^{1}$ has also explained the growing importance of "soft law" with reference to the transaction costs involved, to adaptability, to flexibility and to the potential for confidence building, all this has been done in very general terms. The paper by Professor Voigt goes far beyond such conceptual reasoning and formulates, in the light of this analytical approach, a whole set of concrete, testable hypotheses.

The empirical part of the paper is not immediately connected to these hypotheses. It addresses the issue from the somewhat different angle of the data set of (informal) US international agreements ${ }^{2}$, as published under the Case-Sablocki Act of 1972. Despite the obvious limitations of any such analysis (one country, one institutional background, limited time period, etc.), the data set allows for some informative, perhaps even puzzling results. Among those is the finding that the production of informal international law per annum rose between 2002 and 2006, peaked in 2006 and declined sharply thereafter. These figures are intriguing all the more since both the sharp increase and decrease of newly approved international informal commitments occurred during the George W. Bush administration. The paper also shows that the largest portion of these informal international instruments falls within three categories only (military, science and technology, and aid). The paper also presents a breakdown of these agreements by region of the contracting partner, showing the "western countries" in the lead, closely followed by Latin America, and the Asian countries lagging far behind.

The paper promises to pursue and refine its pioneering analysis in subsequent follow-up work.

\section{B. Key Features from Voigt}

The paper tackles an important legal phenomenon and deserves credit for its attempt to systematically study the underlying costs and benefits and to provide a first empirical assessment. Let me consider a few aspects that may deserve further reflection; first to the legal questions involved, second to the analytics, and third to the empirical findings.

\footnotetext{
${ }^{1}$ See, e.g., Hafner, The Effect of Soft Law on International Economic Relations, in: Griller (ed.), International Economic Governance and Non-Economic Concerns (2002) 149 , at 160 et seq.

${ }^{2}$ As to be distinguished from "treaties".
} 


\section{Legal Questions}

First, with regard to the distinction between formal treaties and informal agreements, the paper relies on the involvement of the legislator in the law production process. It seems, however, that this criterion is not ideally chosen.

Historically, the "treaty-making power" was perceived as an essential part of the executive branch of government (in earlier times, the king's monarchic powers), and as such it did not require any parliamentarian involvement. Most of the pertinent constitutional developments of the last 150 years revolve around the constitutional "taming" of these executive powers. The bottom line of this development was to require parliamentarian approval if the respective international acts, in substance, amount to law-making in the material sense. ${ }^{3}$ In that regard, one can also speak of an elimination of a "democratic deficit". This constitutional development overlaps with a further - albeit distinct - conceptual development, namely that of "dualism". This concept sees international law and "inner-state law" as two separate bodies of law, such that provisions of international agreement require some (not necessarily step-by-step) translation into national law to become mandatory on this level as well.

Having said that, international agreements conceptually require the involvement of the lawmaker only to the extent that they, in substance, touch upon lawmakers' issues. The paper makes it clear that international agreements may be concluded by the executive branch alone in two different cases. On the one hand, "executive agreements" do not require the legislator's involvement if they remain "underneath" the level of the lawmaker (covering only issues of an "administrative nature"). On the other hand, legislators' consent may not be needed because the respective covenants are, in substance, too soft to be considered law. ${ }^{4}$ Note that in the first case these international agreements can be very detailed and technical, as is the case with many of the so-called "administrative agreements/acts". It is perhaps not obvious why these agreements are also considered "informal" for the purposes of the paper.

The above question is not only a terminological one, but the constitutional checks and balances at issue reflect the underlying "principal-agent"

\footnotetext{
${ }^{3}$ It shall therefore not come as a surprise that also historically the early cases of parliamentarian involvement in the conclusion of treaties has concerned those instances, where the treaties were likely to affect basic constitutional liberties of the constituency (liberty, property). This idea was more generalised in the French constitutions of the French revolution and the Belgian constitution of 1831 that required consent by the parliament, if the international treaty imposes burdens either on the state or on any of its citizens.

${ }^{4}$ Still, the legislator may decide to enact provisions under national law to comply with the non-binding rules of soft law agreements, as is de facto very often the case.
} 
relationship between the parliament and the executive branch. In particular, it has been stressed in the literature on the subject that soft law provides a tool for the executive to escape the otherwise required internal procedures of seeking legislators' consent ${ }^{5}$.

Moreover, the exact borderline between formal and informal agreements may be questionable to the extent that the constitutional framework provides for different degrees of legislators' involvement. The paper itself refers to Article II of the US Constitution whereby a "treaty" in the formal sense requires a 2/3 majority of the Senate. However, this does not mean that for all other "international agreements" there would be no involvement by the legislator. American constitutional law knows a further category of international agreements that (albeit seemingly counted as "informal" in the paper) require a simple majority of both the Senate and House of Representatives.

A further, albeit distinct, aspect of these constitutional checks and balances concerns the question of whether the executive branch is empowered to sign constitution-amending agreements (which would, of course, require the approval of the lawmaker). Austrian constitutional law has changed in this respect (in 2008) and has shifted material powers to the legislator. Whereas under the previous constitution, the (here: constitutional) lawmaker was reduced to a veto-role after the conclusion of the treaty (namely, to approve or not to approve), the amended rules provide for prior constitutional change by the lawmaker. On the basis of the thus amended constitution, the international agreement (no longer constitution changing in itself) may well be concluded.

\section{Analytics}

Second, to the analytical part. Whereas it seems straightforward to develop the hypotheses, as presented in the paper, based on a broadly-conceived transaction cost perspective, it seems less obvious whether a "market versus hierarchy" view can add too much. With regard to international informal law, hardly any agreement concerns a "spot market exchange" in the sense of an immediate one shot interaction. Both formal and informal agreements typically concern ongoing interaction and obligations ("Dauerschuldverhältnisse"). Moreover, it seems unclear whether the primary research question should be whether states with a higher frequency of interaction shift to informal instruments of international law, but rather why the same states (with a given frequency of interaction) choose formal in-

\footnotetext{
${ }^{5}$ See, e.g., Schreuer, Die innerstaatliche Anwendung von internationalem "soft law" aus rechtsvergleichender Sicht, Österreichische Zeitschrift für öffentliches Recht und Völkerrecht 34 (1983) 243.
} 
struments to govern certain international topics on some occasions and informal instruments on others.

\section{Empirical Findings}

As for the empirical part, the most puzzling result is seemingly the sharp increase and sharp decline of newly approved informal agreements under the Bush administration. Of course, it would be interesting to compare these figures with those for formal agreements to check for a similarity of movements. Even considered in themselves, however, the figures appear ambiguous. It seems as if the respective numbers reflect the newly concluded agreements, not the aggregate figures. In this light, it is certainly possible (depending on whether some agreements had expired) that the number of informal agreements increased through the entire period and that figures simply show a decline in the growth rate, not a decline in the absolute number. Such a flattening out of the growth rate would not come as a surprise in a second presidential term. The new government may have entered office with new priorities and may have concluded most of the envisaged agreements already during its first term; in this respect, the second term may basically cover follow-up agreements and a certain number of new issues, altogether being of minor quantitative importance.

A further point: multilateral agreements and decisions by international associations/organisations are, at least to some extent, functional substitutes. The same countries may, for example, deal with a certain issue, under regular international law by multilateral agreement or on the European institutional level by the respective (formal or informal) instruments. The number of (formal and informal) international agreements may, therefore, depend on the availability of institutional alternatives under the respective association or organisational structure.

\section{Conclusion}

Finally, a word on the paper's focus on bilateral agreements. This focus is, at least from a lawyer's perspective, somewhat surprising. Informal international law is predominantly a phenomenon of multilateral agreements and international organisations, not so much of bilateral agreements. Soft law instruments cover a huge spectrum of acts/documents, inter alia resolutions of international organisations (or even international conferences), declarations, statements, conclusions, and recommendations. ${ }^{6}$ One may only think of the various recommendations in the framework of the OSCE

\footnotetext{
${ }^{6}$ See, e.g., Hafner ibid, also for possible reasons for soft law; and Schreuer ibid.
} 
or the framework of the WTO dispute settlement procedures. The reasons for the adoption of informal rules ("soft law") in multilateral environments are manifold, but they have to do with the specific functional task of international law between politics and power. Soft law instruments are therefore, for example, used to direct the international communities' attention to new problems, to express concern about them, to change certain basic rules of international relations, to test the acceptance of certain rules, to demonstrate opinio iuris or even to specify pre-normative rules with the prospect of development into binding rules.

It seems worthwhile to extend the analysis developed in this paper to these phenomena as well, since the organisational features of these instruments allow for an even more immediate application of the respective transaction cost-based and governance structure-based analysis. A pursuit of the paper with a particular focus on the soft law of international organizations is, therefore, not only welcome, but highly promising. 


\title{
Discussion on Stefan Voigt
}

\section{The Economics of Informal International Law - An Empirical Assessment}

\author{
by \\ Christoph Kimmerle
}

The discussion of "The economic analysis of international law making - an empirical assessment" mainly involved comments on the following issues: the conceptualization of the term "soft law" in the paper, the empirical data set chosen, the overall relevance of soft law in the international sphere, and the use of transaction cost theory.

During the discussion, several participants described alternative options for defining the term soft law and argued that the definition proposed in the paper could be improved in terms of conceptual clarity. Contrary to the author's argument that most (US) soft law works on a bilateral basis, some participants argued that soft law is mainly employed in multilateral cooperation. Accordingly, soft law was seen as an instrument mainly used by international organizations. The international organizations turn to soft law in the form of written standards to overcome the coordination problem while allowing them to benefit from the flexibility and changeability offered by these softer agreements. Generally, the question arose which kind of agreements could be qualified as belonging to the category of soft law. Some participants argued that, in their view, the US Executive Agreements, in the paper defined as falling into the realm of soft law, actually classify as hard law. They came to this contrary assessment because these agreements were seen to be binding international treaties from an international law perspective.

In the course of the discussion, attention focused on the empirical basis of the paper. The participants asked whether the three policy areas in which executive agreements were mainly employed had something in common. In addition, one participant found that the present incentives would also merit closer attention: he wondered whether the tendency of the 
US executive agreements between 2000 and 2006 could also be explained by other surrounding conditions specific to this time span. The participants then asked whether soft law in contrast to hard law might be an instrument predominantly used by developed democracies as opposed to dictatorships. They reasoned that this could be due to the fact that the legal foundations of longstanding democracies such as the US are more developed, so that soft law might be perceived as a tool to fill the remaining gaps. Moreover, a country-by-country comparison was suggested to identify the actual relevance of soft law in the US compared to other countries.

One attendee then addressed the question of whether soft law really could be seen as less politically relevant. It was argued that at least for some soft law, for instance in case of particular technical standards, this is not the case. These soft laws, although non-binding, usually have a great impact on state behavior. (The author replied that his paper asks why the term soft law has become so popular recently and does not analyze the political impact of different types of soft law or of soft vs. hard law). Another attendee argued that the mentioned principal-agent relationship between the legislative and executive branch only holds if treaty making were to lie within the powers of the former. However, in his point of view, this is not the case as international treaty making actually falls within the realm of the executive branch.

The discussion then turned to the application of transaction cost theory in hypothesizing the employment of international soft law. One participant asked for the meaning of modification costs. His understanding of modification costs was in terms of the difficulties in changing softer law. The author's reply was that the category of modification costs in the paper addresses the procedure of ratification, i.e., if ratification is needed, modification becomes relatively costly. Another attendee was interested in the actual relevance of the different categories of soft law in more general terms. He questioned the explanation of diverging degrees of legal impact due to the classification into different categories of law. Additionally, he was interested in existing empirical evidence of the explained phenomena. Moreover, he discussed the interaction of the different types of transaction cost. In particular, he wondered whether cases exist in which a relative decrease (or increase) in one specific category of transaction cost had led to an increase (or decrease) in the use of informal cooperation. Additionally, this participant suggested thinking of law-making as a specific investment. He also concluded that the more specific such an investment, the greater the likelihood of the relevant actors to turn to relatively harder law. 


\title{
Law and Technology of Data Privacy: A Case for International Harmonization
}

by

\author{
Haksoo Ko ${ }^{*}$
}

\section{A. Introduction}

With technological advancements, the frequency of global data processing has increased dramatically in recent years and the amount of personal data that crosses national borders has increased significantly as well. As technology advances, there is a growing concern related to the collection and use of personal data and there also is a growing need to provide adequate protection to personal data and privacy. ${ }^{1}$ Addressing issues on data privacy requires a multi-disciplinary approach involving various stakeholders with divergent interests.

Perhaps reflecting the growing need to address data privacy issues, a growing number of countries have recently enacted or amended their laws and, in some other countries, active debates are taking place with proposed legislative bills. ${ }^{2}$ Indeed, considering the pace of innovations and techno-

${ }^{*}$ Professor, Seoul National University School of Law, Korea. The author is grateful for the helpful comments received from the participants at the Travemünde Symposium on the Economic Analysis of Law, at Hamburg Lecture, and at ETH Zurich seminar, and in particular from Prof. Dr. Michael Fehling. The author is also thankful to Alan Lee and Sangmin Lee for their valuable research assistance. A slightly revised version will appear in the Asian Journal of Law and Economics. This research was supported by the National Research Foundation of Korea Grant funded by the Korean Government (NRF-2012S1A5A2A0-1016128).

${ }^{1}$ Several terms are used to refer to similar issues. 'Data protection' is the term that tends to be used more commonly in Europe, while 'privacy' tends to be used more frequently outside Europe. Some other terms are also used such as 'data privacy' and 'information privacy'. 'Data protection' and 'privacy' do not necessarily have the same meaning, although there is a significant overlap. See, for comparison of these terms, Kuner (2011), 10; Bygrave (2010), 166. For the purposes of this article, there is no need to distinguish these terms. In this article, the term 'data privacy' is used.

${ }^{2}$ Kuner (2009), 301, estimates that there are approximately 50 to 60 countries with laws on data privacy issues. This estimate is regarding the situation around 2008, and the number would be considerably higher today. 
logical developments, it is perhaps inevitable and indeed necessary not only to promulgate laws and regulations in relevant areas but also to revise them on a regular basis. Significantly, in early 2012, regulators in both the E.U. and the U.S. announced major reform proposals to streamline and overhaul existing laws and regulations in their respective jurisdictions.

These legislative and reform activities obviously reflect the recognition on the significance of issues related to data privacy in many countries and jurisdictions. A natural ramification of these legislative and reform efforts would be the vulcanization of laws and regulations on data privacy. Vulcanization would be problematic in many areas of law but it could be especially problematic in the area related to data privacy due to the interconnected and open-ended nature of the Internet. With the increasing use of cloud computing, which requires using data and other resources located in many different parts of the world, the problem would become even more serious, as data processing and computing activities would constantly and simultaneously take place in multiple jurisdictions. ${ }^{3}$

At the same time, it is not clear if most of these laws and reform proposals were prepared based on a thorough and careful examination of the actual behaviour of Internet users and data subjects. There is also a lack of systematic understanding as to how data controllers acquire data and how they use or analyze the data. This article thus calls for careful review and examination regarding the behaviour of data subjects and also about data controllers' use of data. It is argued that information asymmetry and uncertainty surrounding data subjects and their information is a main cause for the problem and that a systematic understanding of the 'life-cycle' of the information gathered from data subjects should take place before serious discussions are made about various reform efforts.

More fundamentally, it is noted that the fragmented nature of legislative, administrative, and enforcement activities on data privacy could hinder the free flow of legitimate information and that an enforcement activity could easily have far-reaching repercussions beyond a jurisdiction's boundary. Thus, over-regulation could be a problem in certain situations, while under-regulation or the lack of regulation could be a problem in certain other situations. This article therefore argues for international cooperation and harmonization on data privacy. A simple analytic framework is

\footnotetext{
${ }^{3}$ Using resources located in multiple jurisdictions would raise a difficult legal and regulatory issue. A more difficult problem, however, would be that it may not even be possible to delineate the location of specific data. This is because a cloud service provider may make decisions instantaneously and, if and when needed, may move information instantly among different pieces of equipment located in different jurisdictions. Under this environment, identifying specific locations or jurisdictions which carried out different tasks as part of a specific data processing work could be an overly strenuous and burdensome process. On cloud computing and data privacy in general, see Gellman (2009).
} 
presented and it is shown that the fragmented enforcement mechanism would result in regulators' failure to recognize all relevant costs and benefits.

A first step toward international harmonization and cooperation could be to establish a coordinated mechanism for gathering facts and for conducting analyses regarding data subjects and the information gathered about them. Given the significance of issues, however, it would be more important to establish a mechanism for more substantive harmonization. Thus, the article examines and discusses possible options for international cooperation and harmonization. These options would range from a simple mechanism for information sharing to a significant cooperation to develop a substantive international norm or standard.

The article proceeds as follows. In Section B, tracking technologies that are currently used by companies are introduced, with brief discussions on the use of the information gathered through tracking. In Section C, regulatory responses regarding data privacy issues are summarized, focusing on the responses in the E.U. and the U.S. Then, in Section D, it is discussed why international cooperation and harmonization would be needed. In Section $\mathrm{E}$, possible options for international cooperation and harmonization are reviewed. Section F provides conclusive remarks.

\section{B. Online Tracking}

There are various ways through which companies acquire information on their customers and their website users. ${ }^{4}$ Among these, tracking technologies used on the Internet are some of the most rapidly changing technology areas and are subject to constant controversy. As such, it is helpful to understand how tracking works and what companies do with the information that they acquire through tracking. ${ }^{5}$ Below, some of the currently used tracking technologies are introduced, including cookies, which is one of the most commonly used tracking technologies. Then, companies' use of the information is discussed. ${ }^{6}$

\footnotetext{
${ }^{4}$ Different issues arise when companies and individuals involuntarily lose and transfer their information through illicit or even illegal means such as hacking and other data security breaches. This article does not explicitly deal with these security-related issues.

${ }^{5} \mathrm{~A}$ main focus of this article is on websites serving as portals and providing services including search, e-mail, e-commerce and social network services. Data privacy could of course be an important issue in other contexts as well. For example, see Schwartz (2009) for a case study of data privacy issues at several different types of large international companies.

${ }^{6}$ See Tene (2010) for discussions of current technologies which have data privacy implications. Tene and Polonetsky (2012), 288-307, discuss tracking technologies more specifically. For an account of the actual technological methodology employed by
} 


\section{Tracking Technologies}

In this section, illustrative explanations are made about certain tracking technologies that are often used in practice. The technologies mentioned in this section are not exhaustive in any sense. It is important to remember that technologies change constantly and new tracking methods become available on a regular basis.

\section{Cookies}

Cookies are the codes which command users' computers to send certain user information. Cookies, stored in users' computers in a text file format, improve user experience and play a crucial role in making online transactions possible. ${ }^{7}$ For instance, in online transactions, cookies store shopping carts and log-in information. Cookies may, however, also store many other types of information that a user may not want to divulge. Doing so is possible because cookies can easily store a user's information related to his/her visit to a particular website, including, among others, the time of the visit, user's IP (Internet protocol) address, specific pages visited in a website, and search queries, if any.

There are several categories of cookies. 'First-party cookies' are the cookies which send cookie information exclusively to the server that has initially sent the cookies. On the other hand, 'third-party cookies' or 'tracking cookies' may send cookie information to the servers that have not sent the cookies. In the case of third-party cookies, all websites affiliated with a network (e.g., an advertisement network) would share certain part of the information that they obtained through their cookies. More broadly, several networks could share cookie information together, and doing so is called 'cookie synching'. Obviously, as more companies share users' information, it will be increasingly difficult for users or other outsiders to control dissemination and use of the collected information.

Use of cookies is fairly widespread and cookies are a commonly used tracking technique. Compared to other tracking techniques, however, users can also easily control whether to allow the use of cookies, usually through a simple manipulation of the settings on their Internet browsers. By doing

Google, see Google's letter to French regulator, Commission nationale de l'informatique et des libertés (CNIL), dated April 20, 2012, which was sent in relation to Google's proposed amendment of its privacy policy, available at https://docs.google.com/file/d/0B8sy aai6SSfiSUhFMHVpMmhFUG8/edit?pli=1.

${ }^{7}$ These cookies are more precisely called HTTP cookies. They are different from Flash cookies (discussed below). See Debusseré (2005), 73-79 for legal issues related to HTTP cookies in the E.U. 
so, users can delete the information stored in cookies, or can delete or disable cookies altogether. This can often be done by a few clicks. However, not many users do change their browser settings. ${ }^{8}$

The following diagram illustrates how cookies work. First, using an Internet browser, a user makes a HTTP request for a website. Then, when the website's server sends the contents of the requested website in response to the request, cookie information is sent together in the set-cookie field of the HTTP response message. Third, the Internet browser, recognizing the information in the set-cookie field, stores the cookie in the user's computer. Fourth, in the event that there are subsequent requests, additional cookie information, with revisions if needed, is also sent together.

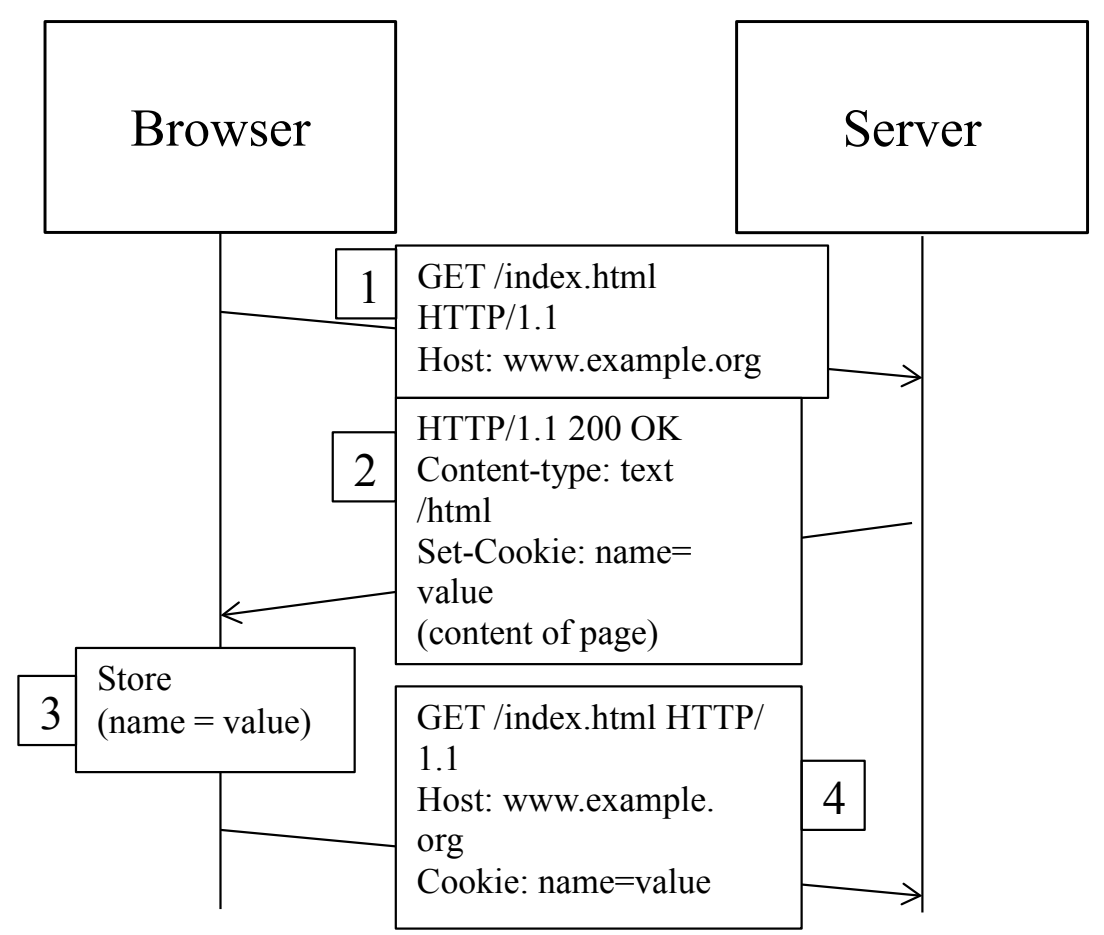

\footnotetext{
${ }^{8}$ See, for instance, McDonald and Cranor (2010), 11-15. It is not clear why there are not many users who control the use of cookies. Part of the reason would include the inconvenience that would be incurred by deleting the cookies since user name(s) and other useful and convenient information could also be deleted when cookies are deleted. On the other hand, users' lack of information or behavioural inertia could be at work as well. If the latter is an important reason, then how to set the default on the use of cookies for Internet browsers also becomes an important issue.
} 


\section{Other Tracking Methods}

While cookies are commonly used for tracking, there are other tracking methods, of course. Some of these methods are summarized below.

(a) Flash Cookies. Flash cookies, which are also called as 'local shared objects', refer to cookies that utilize the Flash Player. In functionality, they are similar to HTTP cookies and store user preferences and other information. These cookies, however, are capable of carrying much more user information than HTTP cookies. Further, they are in general more resilient and are harder to delete. ${ }^{9}$

(b) Browser Fingerprinting. Browser fingerprinting is a technique which is used to enable identifying and tracking a user through a combination of various elements of user information such as operating system, browser type and version, plug-ins, and languages. Small pieces of information about users may be trivial and may have little value by themselves, commercial or otherwise. With a combination of these small pieces of information, however, users may be identified and tracked. From users' perspective, there could be additional concerns since it is in general very difficult to detect and control browser fingerprinting.

(c) Deep Packet Inspection. Deep packet inspection is a method of inspecting contents of Internet usage of a user. Initially this method was used by Internet service providers for security and maintenance reasons and for the management of Internet traffic. If access is granted, however, advertisers could obtain extremely detailed information through this method about a user's activities on the Internet.

(d) Web Bugs. A web bug is an object embedded in a website or e-mail, which allows monitoring of user behaviour such as whether a user viewed the website or checked his/her e-mail. Using a web bug, certain information on computer usage can be gathered, including, among others, the date and time of access to a particular website, the information as to whether a particular webpage or e-mail was accessed, the IP address of the computer, and the type of the web browser.

(e) Tracking for Mobile Devices. Compared to the 'desk-top' or 'notebook' environment, widespread use of mobile devices, in particular so-

\footnotetext{
${ }^{9}$ Flash cookies will not be erased by erasing HTTP cookies, and their whereabouts may not be obvious to a casual computer user. There were even allegations that Flash cookies could sometimes restore deleted HTTP cookies. See Ayenson et al. (2012) for a survey regarding the current tracking use of Flash cookies as well as certain other local storage devices such as ETags and HTML5. A data privacy concern regarding the development of new local storage devices and other technologies is that they in general collect and store a large amount of information and that, moreover, there may be little transparency and control granted to users in the process of collecting and storing information. In response to user complaints and lawsuits related to this resilience and intrusiveness, Adobe Systems has made some changes to the functionality of Flash cookies.
} 
called 'smart phones', presents a new set of additional issues related to tracking. First, users typically carry mobile devices at all times and the users' whereabouts could constantly be located. Location-based services provide various benefits to users which were previously not available but, at the same time, location tracking raises a new layer of privacy concerns. Second, mobile devices usually contain extensive personal information such as the user's personal contacts. Thus, unwanted disclosure of personal information contained in a mobile device could have even more serious ramifications. Third, use of mobile application software (so-called 'app') does not require Internet browsers and, for general users, it is more difficult to make an informed consent about privacy policy when downloading an app. More generally, considering the technical, physical and other environments that a user would be in when using a mobile device, it would often be very difficult for a user to read a notice on data privacy policy and to give a genuine informed consent. These additional issues make tracking of mobile devices a more delicate and sensitive problem. When it comes to tracking and data privacy, it can be said that, with mobile devices, the level of transparency is in general fairly low, and that user control is very difficult and limited.

\section{Use of Tracked Information}

Information gathered through tracking is extremely valuable for companies. In particular, for marketing and advertisement purposes, it provides a rich source of information regarding their current and prospective customers. After analyzing the user information, companies could send targeted and tailored advertisements, which would result in heightened effectiveness. ${ }^{10}$ Companies can also easily conduct experiments on different advertisement methods and can measure their effectiveness. Tracking, in essence, functions as a key pillar for the advertisement-based Internet social network and portal ecosystem. ${ }^{11}$

${ }^{10}$ See Goldfarb and Tucker (2011) for an analysis of the impact of the E.U. e-Privacy Directive on advertising performance, showing that companies' ability to send targeted advertisements can enhance their effectiveness dramatically.

${ }^{11}$ A related concern is that, with the information on customers' purchase history, companies may engage in dynamic or discriminatory pricing behaviour, which can be referred to as a form of ex post opportunistic behaviour. For instance, in a well-known notorious example, Amazon.com was criticized for charging different prices for a same item between a known visitor and an anonymous visitor, a practice which the company swore that it would discontinue. D. Streitfeld, 'On the Web, Price Tags Blur: What You Pay Could Depend on Who You Are', Washington Post (September 27, 2000). Today, certain online retailers take advantage of the software which enables them to offer different prices to different customers based on their analysis of prospective customers' online activi- 


\section{Tracking and Analytics}

Tracking is used by companies to enable and/or to facilitate their provision of services. To a certain extent, tracking is necessary and often desirable in the context of Internet transactions. This is so because tracking allows retention of the information that is necessary for transactions to take place such as the information on log-in, shopping carts, and billing. Tracking also makes it possible to provide personalized services such as making product recommendations based on users' professed preferences and/or on past browsing and purchase history.

In order to provide personalized services, companies engage in traffic analytics. Through this, companies analyze a user's activities on the Internet. The information to be analyzed would include general information such as the visit frequency of a particular website, frequently viewed web pages within a website, domains and countries of origin, and the operating system and browser used. Further, the information that is gathered and analyzed may often contain much more detailed user information. ${ }^{12}$

\section{Advertisement}

With tracking and analytics, advertisement can become much more effective. A main reason why, relative to conventional methods of advertisement, Internet advertisement could be more effective is because detailed targeting and measurement is possible when advertisement is done through the Internet. In turn, in order for targeting and measurement to be possible, advertisers should be able to conduct tracking and analytics.

With targeting, first, advertisers can specify a select group of potential customers and show online advertisements only to them. For instance, advertisers can analyse Facebook user profiles and activity history, and send advertisements only to targeted individuals in a targeted and tailored manner, possibly using different platforms. With abundant data on actual and potential customers, companies would engage in extensive data mining and try to identify patterns that they can utilize usefully. For instance, a large retail chain could analyze their customers' purchasing behaviour and try to

ties. 'How deep are your pockets? Businesses are offered software that spots which customers will pay more', The Economist (June 30, 2012).

${ }^{12}$ For instance, a major U.S. data company was reported to be maintaining large data bases which contain about 1,500 data points per person for about 500 million people and which include, among others, information on an individual's age, race, sex, weight, height, marital status, education level, politics, buying habits, household health worries, and vacation dreams. See N. Singer, 'You for Sale: Mapping, and Sharing, the Consumer Genome', New York Times (June 16, 2012). 
identify pregnant female customers at an early stage, with a view to wooing them with promotional materials specifically targeted to them. ${ }^{13}$ This type of data analytics is often conducted without the knowledge of users. That is, while users would have the general knowledge that certain information on them would be collected, they would not know precisely what type of information is collected and, once collected, how the information is analysed. ${ }^{14}$

Data availability is a major contributor which has made targeting possible. That is, advertisers can now collect a huge amount of detailed data without having to incur much cost. And with targeting, advertisers can not only send tailored advertisements to a specified group of individuals but also, even for the same group of individuals, deliver different versions of advertisements, depending on device, time, location and other factors.

While tracking can be used to deliver targeted and tailored advertisements, it can also be used to measure the effectiveness of such advertisements. Through tracking, companies can measure how many consumers purchased a particular product after seeing advertisements for the product. Companies can also measure and analyze broader categories of information on consumers, including page views, number of unique visitors, entry pages and exit pages, referral pages, and clickthrough rates. Further, various tests and experiments can be conducted about consumer behaviour and advertisement effectiveness. For instance, using tracking technologies, randomized field tests, known as a/b tests, can be conducted. ${ }^{15}$ Through all this, advertisers can obtain detailed information as to what types of users

${ }^{13}$ This was in fact a case that took place with Target, a large U.S. retail chain. In an incident, this retail chain learned about a teenager's pregnancy even before her parent realized. This was made possible through the detailed predictive analytics that the company conducted based on the information on purchasing behaviour of its customers. See C. Duhigg, 'How Companies Learn Your Secrets', New York Times (February 16, 2012).

${ }^{14}$ Thus, for instance, in Target's case, noted above, a customer would not know that the information on her purchase history would collectively enable Target to learn about her pregnancy. That is, while purchasing a large quantity of unscented lotion (beginning of $2^{\text {nd }}$ trimester), nutrition supplements (such as calcium, magnesium, and zinc; middle of $2^{\text {nd }}$ trimester), and/or a large quantity of unscented soap, hand sanitizers and/or cotton balls (close to delivery), such a customer might have thought that she was making the purchase at the whim of the moment or that no one would carefully examine her purchase history to conduct an in-depth analysis. However, the company in fact put together different pieces of information and conducted predictive analytics in order to draw conclusions on her characteristics as a customer.

${ }^{15} \mathrm{a} / \mathrm{b}$ tests refer to tests commonly conducted in marketing by which a baseline control group is compared to a variety of test groups in order to obtain improved responses and to test various marketing strategies. As potential testing groups become larger, conducting these tests would in general become easier and the results would become more accurate. 
are interested in their products and the circumstances under which their products draw attention and lead to actual purchasing behaviour.

\section{Other Uses}

Tracking technologies can be used for other purposes, including noncommercial purposes. First of all, tracking may be needed to ensure network security. That is, websites and Internet service providers may need to track Internet traffic in order to prevent malicious activities such as hackers' attacks and efforts to spread viruses. More broadly, tracking may be sometimes needed and justified for law enforcement reasons. Thus, laws and regulations may allow or, under certain circumstances, may even require tracking for law enforcement purposes in order to prevent criminal activities such as activities related to frauds or money-laundering, or in order to prevent activities that could be a threat to national security.

\section{Regulatory Responses}

\section{Concerns over Data Privacy}

The above discussions on tracking technologies suggest that the use of tracking devices, in whichever form, is widespread and will continue to be so. This is partly because tracking is inevitable in order to maintain the current Internet infrastructure and ecosystem, which tend not to charge individual users for their use of e-mail, search, and other services. At the same time, general users show continuous concerns and anxieties over data privacy. ${ }^{16}$ If these concerns and anxieties are genuine, then policy measures would need to be taken in order to deal with the problem. To do so, however, it is necessary to investigate and identify what the problem is and what the sources of the problem are.

From the perspective of general users, information asymmetry and uncertainty are two of the main issues at work regarding the data privacy problem related to tracking. First, there is a serious information asymmetry between users and data controllers. Since intrusions on data privacy are usually invisible and ubiquitous, users may not know how their information is collected. More seriously, users also do not know, once information is collected, how the information will be analyzed and utilized. Further, users do not know how long the information will be stored and

\footnotetext{
${ }^{16}$ See, for example, Hoofnagle et al. (2010) for a survey result in the U.S.
} 
how it will be used not just in the primary market but also, if any, in the secondary market.

Second, there is a great deal of uncertainty as to the usage of personal data and information. Users do not know and often cannot predict in any systematic way how their information will be used by data controllers. In fact, it may well be that data controllers are themselves in a difficult position to make a reasoned prediction. This is because data controllers may only have general ideas as to the future use of the information that they gather and they may engage in various phases of trials and errors of data mining and analytics in order to extract useful information. Thus, there is always a possibility that the information could be used in a completely unexpected and unwanted manner. ${ }^{17}$ The problem could be exacerbated since data controllers, who often possess users' information for an indefinite period of time, may periodically and repeatedly try to engage in analytics as technologies develop and new methodologies become available. Overall, information asymmetry combined with uncertainty would conflate and exacerbate users' concerns and anxieties, which could justify legal intervention on related issues.

\section{Current Regulations}

A significant number of countries and jurisdictions currently have laws on data privacy and, considering active legislative discussions taking place in many jurisdictions, the number is likely to increase continuously in the near future. ${ }^{18}$ Among these, jurisdictions with relatively long history of legislation and rigorous enforcement experience include the E.U. and the U.S., in addition to certain individual countries in Europe. In Europe, individual countries began enacting laws as early as $1970 \mathrm{~s},{ }^{19}$ and the E.U. level directive on data protection, commonly called the Data Protection Directive, was announced in $1995 .{ }^{20}$

Outside the U.S. and Europe, activities in Asia Pacific are noteworthy. The APEC (Asia-Pacific Economic Cooperation) Privacy Framework was adopted in 2004, and subsequently a considerable number of countries in the region enacted or amended laws on data privacy. In Asia, however,

\footnotetext{
${ }^{17}$ For instance, in the Target's case, noted above, while the retail chain realized the significant value of identifying pregnant women at an early stage, actually identifying them through predictive analytics took many phases of internal trials and errors.

${ }^{18}$ See Bygrave (2010); OECD (2011b).

${ }^{19}$ For instance, at a local government level within a country, in Germany, the Hesse Parliament adopted the Data Protection Act in 1970 and, at a national level, Sweden enacted the Data Act in 1973. OECD (2011b), 8.

${ }^{20}$ Directive 95/46/EC on the Protection of Individuals with Regards to the Processing of Personal Data and on the Free Movement of such Data.
} 
laws were enacted only recently in many cases and the related enforcement experience is thus limited. Due to the lack of legislative and enforcement history, implications that can generally be drawn from the experience in Asia are limited as yet. ${ }^{21}$ Other than the countries and jurisdictions already mentioned, some countries in North America, South America, and Oceania are also relatively active, and all regions of the world now have at least one country with data privacy law. Brief discussion below on legal issues is mostly about the E.U. and the U.S., which have distinctive traditions and unique characteristics.

\section{The E.U.: Data Protection Directive and Other Directives}

In the E.U., the European Commission is given a general mandate to regulate data privacy issues, while most of the relevant legislative and enforcement activities are carried out by authorities in individual countries. The E.U. adopted several directives on data privacy, and among these, the most significant is the Data Protection Directive of 1995. The Data Protection Directive has a binding effect on E.U. member states and also on certain non-member states that are parties to the Agreement on the European Economic Area (E.E.A.), with several qualifications. It provides a regulatory framework on the collection, processing, storage, and transfer of personal data. The Data Protection Directive has also exerted a considerable influence over third-party countries. This is not only due to its history of rigorous enforcement but also due to its extraterritorial effect. That is, under the Data Protection Directive, it is not allowed to transfer personal data to a third country unless such third country provides 'adequate' levels of data protection..$^{22}$

While the Data Protection Directive serves as an overarching directive on general data privacy issues, there are other directives which deal with narrower, sector-specific issues. Regarding data privacy issues, certain directives on electronic communications are most relevant, including in particular the Directive 2002/58/EC Concerning the Processing of Personal Data and the Protection of Privacy in the Electronic Communications Sector (the "e-Privacy Directive"). ${ }^{23}$ The e-Privacy Directive regulates data

${ }^{21}$ See Bygrave (2010), 199-200; Kuner (2011), 17.

${ }^{22}$ E.U. Data Protection Directive, Articles 25-26.

${ }^{23}$ This Directive was preceded by Directive 97/66/EC Concerning the Processing of Personal Data and the Protection of Privacy in the Telecommunications Sector. The ePrivacy Directive was subsequently partly amended by Directive 2006/24/EC on the Retention of Data Generated or Processed in Connection with the Provision of Publicly Available Electronic Communications Services or of Public Communications Networks and Amending Directive 2002/58/EC. The e-Privacy Directive was further partly amended by Directive 2009/136/EC amending Directive 2002/22/EC on universal service and 
privacy on communication networks concerning, among others, confidentiality of communication, regulation of spam, use of cookies, and treatment of traffic data.

\section{The U.S. Regulatory Framework}

Contrary to the E.U., in the U.S., there is no uniform regulatory framework or omnibus legislation which comprehensively deals with data privacy issues. Instead, different industries or sectors are subject to different regulations and, as a general matter, online behavioural tracking is largely selfregulated. And, while the Federal Trade Commission (FTC) serves as a major regulator, it does not have a specified mandate on data privacy issues. ${ }^{24}$

About gathering user information online, the FTC has so far mostly relied on a self-regulatory 'notice and choice' model. Under this model, companies are expected to provide a clear and detailed online privacy policy to users and ask them to make an informed choice. ${ }^{25}$ After the FTC made it clear that it would rely on a self-regulatory notice-and-choice model, several proposals for professional codes of conducts and online guidelines have been made by professional associations from advertising and other industries. ${ }^{26}$

\section{Reform Proposals: the E.U. and the U.S.}

Active discussions are currently taking place in the E.U., the U.S., and many parts of the world regarding data privacy issues. As part of these active discussions, competing reform proposals have been made by authorities in both the E.U. and the U.S. in early 2012.

users' rights relating to electronic communications networks and services, Directive 2002/58/EC concerning the processing of personal data and the protection of privacy in the electronic communications sector and Regulation (EC) No 2006/2004 on cooperation between national authorities responsible for the enforcement of consumer protection laws.

${ }^{24}$ The FTC's mandate is based on a broad authority to regulate 'unfair and deceptive trade practices' that is granted to the FTC pursuant to Section 5 of the Federal Trade Commission Act, 15 U.S.C. § 45(a).

${ }^{25}$ The E.U. also employs a model similar to a notice and choice model.

${ }^{26}$ For instance, proposals were announced by, among others, Network Advertising Initiative (NAI), Interactive Advertising Bureau (IAB), and European Advertising Standards Alliance (EASA). 
In the E.U., a major reform proposal was announced in January 2012 by the European Commission. ${ }^{27}$ Through this proposed reform, the European Commission is seeking to overhaul the existing regulatory framework. In order to do so, it recommends establishing a new European Data Protection Board, which would oversee the overall data privacy issues in the E.U. At the same time, the reform proposal proposes reinforcing protective measures by granting users such rights as the right to be forgotten, the right to access users' own data, and the right to data portability. Also, data controllers would have to comply with strengthened regulatory measures including a duty to report breach within 24 hours.

Different from this, in the U.S., while various reports were issued and reform measures have been proposed, a sector-specific and self-regulatory approach is still the prevailing norm. Significantly among the reform efforts, in February 2012, the White House announced a reform proposal. ${ }^{28}$ While the White House report generally maintained the existing policy stance of the U.S. government, the report was noted for proposing what is called the 'Consumer Privacy Bill of Rights', which proclaimed basic principles of better consumer control of data, increased transparency, secure and accountable handling of data, and flexibility.

Separately, the FTC also released a report with a reform proposal in March 2012 after a long period of study on privacy issues and after releasing a preliminary report in December 2010. ${ }^{29}$ The FTC placed an emphasis on such concepts as privacy by design, simplified choice, and increased transparency. It maintained its general support for industry-led efforts, including the development and implementation of the 'Do-Not-Track' (DNT) mechanism. ${ }^{30}$ At the same time, recognizing the limits of selfregulation, it made an arduous effort arguing for the legislation of a baseline privacy law.

\footnotetext{
${ }^{27}$ See the European Commission press release entitled 'Commission proposes a comprehensive reform of data protection rules to increase users' control of their data and to cut costs for businesses' (January 25, 2012) and other related materials available at http://ec.europa.eu/justice/newsroom/data-protection/news/120125_en.htm.

${ }^{28}$ See White House, Consumer Data Privacy in a Networked World: A Framework for Protecting Privacy and Promoting Innovation in the Global Digital Economy (February 2012).

${ }^{29}$ See Federal Trade Commission, Protecting Consumer Privacy in an Era of Rapid Change: Recommendations for Businesses and Policymakers (March 2012).

${ }^{30}$ The Do-Not-Track mechanism is a mechanism that is proposed to protect users' right to choose whether to allow tracking by websites. There is no consensus yet as to what this mechanism precisely means in practicality or how this mechanism could be implemented. See Tene and Polonetsky (2012), 320-27, for discussions on this mechanism.
} 


\section{International Harmonization}

\section{Divergent Interests}

Brief discussions on legislative and reform activities in various jurisdictions above, most notably in the E.U. and the U.S., indicate that there are divergent regulatory approaches currently under way. There are also possibilities of overlapping and conflicting jurisdictions. Thus, from companies' perspectives, doing business in multiple jurisdictions means being subject to multiple and possibly conflicting laws and regulations in different jurisdictions. Regulation by individual authorities in different jurisdictions could also be problematic from a global welfare point of view in part because, in their assessments of regulatory impact, they would not normally consider ramifications of their decisions that would fall outside their jurisdictional boundaries. This is, in a nutshell, a failure to internalize all relevant costs and benefits in the regulatory decision-making process. This failure to internalize would be particularly problematic for many technology companies because their businesses often show network externalities and their business models are developed to make use of resources at multiple locations for the efficient and effective provision of data processing and computation services.

From the perspective of individual regulators, however, it is inevitable and indeed only natural that they do not consider all international effects since doing so is normally not part of their mandates. Below, we try to delineate the problem arising from this failure to internalize through a simple analytic framework. ${ }^{31}$ For expositional simplicity, it is assumed that individual regulators do not consider costs and benefits outside their jurisdictions.

When policymakers and regulators consider specific rules to regulate data privacy, they would weigh the merits of such rules against potential costs. Merits would mostly come from enhanced protection of data privacy of data subjects in their jurisdictions, and related costs would include lost opportunities for the provision of innovative and efficient services. For instance, while imposing restrictions on companies' capability to use cookies to track Internet users would give rise to a certain level of psychological and other comforts to Internet users, it would at the same time reduce companies' capability to analyze users' behaviour and to provide useful services tailored to users' needs. Regulators would then try to find a bal-

\footnotetext{
${ }^{31}$ What appears below in this section is an extension from a standard international economic theory. In particular, Guzman (1998), albeit on antitrust issues, provides a useful framework, which is employed in this section as well.
} 
ance and allow only those activities which show net benefits. Thus, if there is a hypothetical global regulator, such a regulator would weigh the expected ramifications to all companies (data controllers) and also to all users (data subjects) in making its decisions. ${ }^{32}$

Now, in order to see how fragmented regulation by individual regulators can distort policy decisions, consider countries with different economic structures. First, suppose a case where a country (Country 1) has multiple technology companies which generate most of their revenues from their international operations. If these companies engage in activities that can be considered harmful to general users, most of the harm would fall on users located in foreign countries, while these companies would reap most of the associated benefits. And, in this context, domestic regulators, having only to look to domestic costs and benefits when making a policy assessment, would thus ignore the interests of foreign users and would show favourable attitude towards the interests of companies over the interests of users. ${ }^{33}$

On the other hand, if a country (Country 2) does not have many domestic technology companies and instead users employ services provided by mostly foreign companies, such importation of services could generate analogous but opposite distortions. That is, domestic regulators would make an assessment based on domestic costs and benefits, thus ignoring much of companies' interests as a whole. The result would be favourable attitude towards the interests of users over the interests of companies. ${ }^{34}$

\footnotetext{
${ }^{32}$ An implicit assumption in the argument here is that, in making decisions, regulators consider benefits to the companies (in the form of producer surplus) and to the general users (in the form of consumer surplus) only. Other possible policy objectives are not considered. An implication that will be drawn is that, even if regulators across different jurisdictions pursue common policy objectives, their decisions will vary and could be sub-optimal. In arithmetic form, if we use the notations of 'PS' for the expected producer surplus and ' $\mathrm{CS}$ ' for the expected consumer surplus, regulators will allow companies' activities if and only if $\Delta \mathrm{PS}+\Delta \mathrm{CS}>0$. This would be, in economics terms, the decision of the 'social planner'.

${ }^{33}$ This is based on the assumption that regulators cannot impose different regulations depending on whether a company is domestic or foreign based. About the situation described in the text, in an extreme case, if the impact on domestic consumers is negligible and thus can be ignored by the regulator, companies' activities will be allowed in this country if and only if $\Delta \mathrm{PS}_{1}>0$, where $\mathrm{PS}_{1}$ is the expected producer surplus in Country 1. Now suppose that a situation arises where $\Delta \mathrm{PS}_{1}>0$ and $\Delta \mathrm{PS}+\Delta \mathrm{CS}<0$. That would be a situation where proposed business activities will enhance the producer surplus in Country 1 but, at the same time, reduce the overall producer surplus and consumer surplus globally. While the regulator in this country would allow these activities, the (global) social planner would not.

${ }^{34}$ In an extreme case, if the companies' interest can be ignored in making policy decisions, companies' activities will be allowed if and only if $\Delta \mathrm{CS}_{2}>0$, where $\mathrm{CS}_{2}$ is the expected consumer surplus in Country 2. If a situation arises such that $\Delta \mathrm{CS}_{2}<0$ and $\Delta \mathrm{PS}+\Delta \mathrm{CS}>0$, then a proposed activity will not be permitted even if it would generate overall net benefits on a global level.
} 
More generally, assume that the companies in a country (Country 3) account for $\alpha$ percent of the global market and that they explain $\alpha$ percent of the global producer surplus. At the same time, suppose that the same country's users account for $\beta$ percent of the relevant global market and the same $\beta$ percent of the global consumer surplus. Then, the regulator in that country will naturally consider the impact on the $\alpha$ percent of the global producer surplus and $\beta$ percent of the global consumer surplus when it contemplates introducing new regulations or revising existing regulations. The net impact of a country's regulation will then depend on the country's share in the global provision of services and the country's share in the global consumption. ${ }^{35}$ If the country is a net exporter (i.e., $\alpha>\beta$ ), then the country's regulator would give a relatively high weight on the impact on producer surplus in devising regulatory measures ${ }^{36}$ This would mean that, compared to a closed-economy situation, the country's regulator would give a favourable consideration to the interests of its companies. If the country is a net importer (i.e., $\alpha<\beta$ ), on the other hand, the opposite will be true. Thus, in that case, relatively stricter rules on data privacy against companies' interests will be applied compared to the closed-economy situation.

This simple exposition illustrates how policymaking would be different if we consider the open-ended and inter-connected nature of the Internet. Compared to the closed-economy case, a rational regulator's decisionmaking would take into account only a part of the interests of all stakeholders, while the resulting regulatory measures would show an extraterritorial effect. Both the regulator in a net exporter country and the regulator in a net importer country would have biased assessment criteria and fail to consider the impact of their decisions on third country data controllers and data subjects. These deviations of regulatory measures from the optimal situation would reflect the degree of externalities caused by partial consideration of all relevant costs and benefits.

\section{Divergent Regulatory Approaches}

In light of the divergent interests of different regulators in different countries, it is hardly surprising that the current level of international cooperation and harmonization is only very modest. The E.U. and the U.S., two of the most significant jurisdictions with active enforcement activities and with possibly overlapping jurisdictions on many issues, averted the prob-

35 In such a case, companies' activities will be allowed if and only if $\alpha \Delta \mathrm{PS}_{3}+\beta \Delta \mathrm{CS}_{3}>0$, where $\mathrm{PS}_{3}$ and $\mathrm{CS}_{3}$ are the expected producer surplus and expected consumer surplus in Country 3 , respectively.

${ }^{36}$ Assessment will also change depending on the size of $\mathrm{PS}_{3}$ and $\mathrm{CS}_{3}$. 
lem of regulatory divergence by establishing and maintaining a 'Safe Harbor' framework. ${ }^{37}$ Although the Safe Harbor framework may not be able to provide a permanent solution to the current and future differences in regulations between the two jurisdictions, it at least provides an ad hoc solution for the time being.

From a global perspective, perhaps more troublesome are cases of smaller jurisdictions. That is, companies in smaller jurisdictions are not given opportunities to avail themselves of a safe harbor or similar framework. Rather, they would have to comply with the applicable regulations in all the jurisdictions where they do their business or, if not, they would eventually have to withdraw their business in some jurisdictions. In addition, in the case of the E.U., there is a third alternative. That is, the European Commission can issue findings regarding adequate protection of data privacy in foreign jurisdictions and, if a country is deemed to provide adequate protection, then the companies from such a country can do business without worrying about violating EU-specific data privacy regulations. However, the fact that not too many countries have so far been able to take advantage of this mechanism suggests that adopting such a mechanism may not provide a practicable solution for many countries, which they can utilize in an expeditious and effective manner. ${ }^{38}$ An end result from this fragmented enforcement mechanism would be a mixture of over-regulation in some situations and under-regulation in some other situations. ${ }^{39}$

Over-regulation may take place when multiple regulators exercise jurisdictions over inherently the same business activities. For instance, consider a proposed change of privacy policy by a major social network service provider which does business in many jurisdictions around the world, including the U.S., the E.U., and certain other smaller jurisdictions. If any of the regulators in major jurisdictions such as the U.S. and the E.U. prohibits the proposed change, it is unlikely that the change of privacy policy would in fact take place as proposed..$^{40}$ Alternatively, if a regulator requests cer-

${ }^{37}$ The Safe Harbor framework is a streamlined framework for U.S. organisations, which allows them to comply with the E.U. Data Protection Directive without having to deal with European regulators directly. U.S. organisations are given a choice to opt in to the framework through the U.S. government, certifying their adherence to the Directive's principles.

${ }^{38}$ See Bygrave (2010), 200.

${ }^{39}$ Over-regulation may mean overlapping regulation or overly stringent regulation, while under-regulation may mean the opposite. No clear distinction needs to be made for purposes of this article.

${ }^{40}$ This is based on the assumption that the privacy policy of this social network service provider is the same or substantially similar across different jurisdictions. This appears to be the case in reality with many technology companies. If different terms of use are offered in different countries, some users may try to find technological means to bypass what is deemed to be overly restrictive, while some other users may determine not to use the service any more. For instance, when the Korean government introduced a 
tain modifications in the proposed change of privacy policy and if the service provider accommodates such a request from the regulator, then these modifications will be globally applied. More generally, considering that legal rules vary across jurisdictions, application of different rules in different jurisdictions would result in the application of the most stringent elements among different sets of rules.

On the other hand, if the proposed change is blocked in less significant smaller jurisdictions, then the social network service provider would consider whether to comply with the regulatory requirements in such jurisdictions or otherwise whether to withdraw from the market in these jurisdictions ${ }^{41}$ Seen from the perspective of the regulators in these jurisdictions, if they realize that the service provider may discontinue its service, in whole or in part, in response to stringent and rigorous enforcement activities, then they may be pressured not to exercise their regulatory power or simply adopt less stringent rules. Further, in these jurisdictions, if companies actively provide their services in foreign markets, as discussed in the above section, existing rules may in any event favour companies' interests relative to the interests of users without regard to the size of the domestic market and practical enforceability of their domestic rules against large international companies.

The above discussions indicate that, on the whole, small open economies will tend to have less stringent data privacy regulations. This is in part due to their internal policy consideration giving a relatively heavy weight to the interests of companies and, at the same, due to the reality that, even if they apply stringent rules, large international companies may choose to ignore and may even shun the provision of their services in these markets.

In contrast, large open economies may simply impose stringent regulations, depending on their economic structures and the resulting policy considerations. Currently, among major jurisdictions, the E.U. is in particular

regulation requiring Internet users to use their real names when uploading and adding comments, Google declined to comply and instead disenabled the uploading and commenting features on its Korean YouTube site. Some Korean users, however, bypassed the regulation by changing their country settings. See M. Williams, 'Google Disables Uploads, Comments on YouTube Korea', PC World (April 13, 2009).

${ }^{41}$ Although a multitude of complex issues appear to be involved including data privacy issues, there have been reports regarding Google's difficulties in dealing with Chinese authorities and regarding possibilities of Google's withdrawal from the Chinese market, at least in part. About the accessibility of Google's products in China, see Google's 'Transparency Report' on China, available at http://www.google.com/transparencyreport/ traffic/? $\mathrm{r}=\mathrm{CN}$. Of course, the Chinese market is by no means insignificant but, nonetheless, an implicit threat of withdrawal may have been a serious option that Google considered. 
noteworthy for its relatively stringent rules and well-established enforcement mechanism. Also, in the U.S., rigorous regulations could be in place, depending on specific industry sectors and other circumstances. Thus, companies with active business operations in the E.U. and in the U.S. perhaps most of large international technology companies - are subject to the regulatory jurisdictions of the E.U. and the U.S. and, as such, regulatory rules in these jurisdictions practically shape the general contour of the global regulatory regime.

Overall, however, it is not clear if regulations in major jurisdictions such as the E.U. and the U.S. are overly stringent and if regulations in smaller jurisdictions are overly lenient. What is clear nonetheless is that regulators in all jurisdictions, whether in major jurisdictions or not, consider only what is at stake within their respective jurisdictions and do not necessarily consider third-party ramifications outside their jurisdictions. The resulting mixture of different attitudes is obviously suboptimal from a global perspective. ${ }^{42}$

\section{E. Options for Cooperation and Harmonization}

While the externality argument provides a strong and clear case for international harmonization, in reality, it is hard to witness a palpable sign of major progress on international harmonization. This suggests that there may be serious impediments to international harmonization, other than different economic structures and different assessment criteria applied in different jurisdictions, as discussed above. Among these impediments, different policy goals pursued in different jurisdictions may be a particularly important factor.

The differences in policy goals would reflect different legal and cultural traditions as well as different policy priorities in different jurisdictions. When it comes to the differences between the E.U. and the U.S., one of the most commonly observed differences lies in defining and understanding the concept of data protection and privacy itself. While privacy is often explained as liberty in the U.S., dignity of individuals is considered a key underlying attribute in the E.U. when considering data protection. ${ }^{43}$ Thus,

\footnotetext{
${ }^{42}$ Further, as noted above, since net exporting countries tend to have lenient rules, while net importing countries stringent rules, there will be difficulties when these different types of countries negotiate in order to achieve international harmonization. This is because a harmonised rule may well mean a less stringent rule compared to the then de facto prevailing rule, which net exporting countries would prefer and which net importing countries would not. On the other hand, in the absence of international harmonization, stringent rules would prevail.

${ }^{43}$ See Whitman (2004).
} 
different from the U.S., data protection is perceived to constitute a fundamental human right in the E.U. There may also be other notable differences between the E.U. and the U.S. (and among different jurisdictions). ${ }^{44}$ These differences would include different attitudes toward market's selfcorrection capabilities, which can be summarized as the emphasis on regulation and paternalism, as opposed to the emphasis on self-regulation, innovation, and entrepreneurship. With this backdrop, we now consider what kind of international cooperation and harmonization would be possible.

On a broad conceptual level, there could be three categories of international cooperation and harmonization that can be considered. First is generally about soft law aspects such as sharing information and establishing international guidelines. The second category is on procedural aspects and would include international cooperation establishing choice of law rules and coordinating on the enforcement front. And, the third category would encompass various efforts to build substantive rules with binding effects. Effective regulation of data privacy issues on a global level will after all require serious efforts for harmonization of substantive rules, although harmonization of substantive rules could be a cumbersome process. It should be noted that, while these categories can be distinguished conceptually and may serve useful analytic purposes, their boundaries may not be clear and that there would be overlaps among different categories.

\section{I. 'Soft' Cooperation}

With the continuing increase in international data flows, individual domestic regulators are pressured to adopt measures for international cooperation for practical reasons. At a minimum, without establishing a mechanism to share information among regulators, it could sometimes be difficult to build the requisite know-how and skills for effective regulatory enforcement and investigation. Sharing information in this context does not have to be specifically about on-going cases or investigations. Instead, sharing of non-case specific information such as sharing information on technical expertise and investigative methods would be helpful for many regulators. In the Internet arena, in particular, once a service becomes available in a jurisdiction, such a service often becomes available in many other jurisdictions as well, using the same or similar technologies and invoking similar data privacy issues across various jurisdictions. This implies that once a legal problem on data privacy arises in a jurisdiction, similar legal problems may well arise in other jurisdictions in due course. For instance, legal

\footnotetext{
${ }^{44}$ For an example of a regulatory paradigm that appears to be at least partially outside the paradigms dominated by the perspectives from Europe and the U.S., see Chesterman (2012), which discusses the experience of Singapore.
} 
issues surrounding Google's Street View project would be a case in point, as we witness similar legal issues developing in multiple jurisdictions regarding similar factual and technological issues. ${ }^{45}$

A serious limitation of soft cooperation in general is that cooperation typically takes place on a voluntary basis and that the level of cooperation could vary depending on the participants' good-will and self-interest. Also, no penalties can usually be imposed for a breach of duties, other than the harm on the breaching party's reputation. Nonetheless, soft cooperation could make a significant contribution under certain circumstances, enhancing common understanding of relevant issues and providing a shared or standardized regulatory platform. In that respect, two specific areas for collaborative efforts are worth mentioning. One is about exerting collective research efforts in order to better understand in a systematic way the decision-making process of individuals in choosing to hide or divulge their personal information. The other area is regarding enhancing the collective understanding about companies' behaviour, that is, as to how companies gather information from individuals, what the specific substance and nature of the collected information is, and how the companies analyze and use the information.

First, one area which collective research efforts could yield useful results is the one concerning individuals' choices whether to divulge or withdraw personal information. In particular, it has been reported that individuals' choices on data privacy may not be rational at all times and that instead individuals' choices are context-dependent. That is, individuals tend to make different decisions, depending on the context under which data privacy issues are presented and on various other factors. These factors include: whether the personal information at issue is presented in a

\footnotetext{
${ }^{45}$ Google Street View is a feature available for Google Map and other Google products, which provides panoramic photo images of streets. Data privacy issues were raised mainly on two fronts: first, about the process of taking the photographs and about using the photographs themselves and, second and more recently, about collecting and storing what is called payload data while taking these photographs. These data privacy issues were raised by regulators in several counties, although factual and technological circumstances were generally similar. The U.S. Federal Communications Commission (FCC) issued a report in April 2012 about Google's conduct in relation to the collection of payload data and also in relation to FCC's investigation of the related data privacy issues. See Federal Communications Commission, Notice of Apparent Liability for Forfeiture, In the Matter of Google Inc. (April 13, 2012). Issuance of the FCC report prompted renewed interests about the case among certain third country regulators. See D. Streitfeld and K.J. O'Brien, 'Google Privacy Inquiries Get Little Cooperation', New York Times (May 22, 2012); K.J. O'Brien, 'European Regulators May Reopen Street View Inquires', New York Times (May 2, 2012); E. Wyatt, 'Denials Over Google Street View', New York Times (June 12, 2012). It is, however, unclear if regulators in these jurisdictions have any formal mechanism to share information on this case or any other specific cases.
} 
loss frame or a gain frame; ${ }^{46}$ whether the website looks professional or unprofessional $;{ }^{47}$ whether and how confidentiality assurance is presented $;{ }^{48}$ how reasons for obtaining personal information are presented; and the order that the requests for information is presented.

In addition to these, there is also a phenomenon called the paradox of control. It refers to the phenomenon which shows that the perception of more user control over disclosure of private information increases revelation, while the perception of less control reduces revelation. ${ }^{49}$ Further, there is a problem called privacy paradox, which is about the discrepancy between individuals' professed preferences and values and their actual decision-making regarding data privacy ${ }^{50}$ Thus, while individuals say that they want privacy, they may not want to pay to protect their privacy and may even be willing to disclose sensitive personal information for a very small reward.

Overall, what is summarized above about the behaviour of users is currently an active area of research, and efforts are being made in order to understand the actual behaviour of users in a systematic manner. Thus, while this line of research has shed an invaluable light in advancing our understanding of individuals' privacy choices, no general conclusions on related issues have been reached. At the same time, problems arise because regulators are forced to make rules and pronounce guidelines regardless of whether they have sufficient information and systematic understanding on individuals' decision-making processes. For instance, a notice and choice regime may have been employed in many jurisdictions without a concrete understanding on the effectiveness of such a regime or without analyzing sufficiently as to how to make it more effective. ${ }^{51}$

Second, the level of the current understanding about the way companies collect personal information and analyze the collected information is very limited, and there is a need to enhance collective understanding in this area. This is related to the recognition that one of the most difficult problems in

${ }^{46}$ See Acquisti et al. (2010).

${ }^{47}$ See John et al. (2011).

${ }^{48}$ Ibid.

${ }^{49}$ See Tucker (2011); Brandimarte et al. (2010).

${ }^{50} \mathrm{See}$, for instance, Acquisti and Grossklags (2005).

${ }^{51}$ For an example of a critical account in this regard, see Barocas and Nissenbaum (2009). This implies that the notice and consent regime, which is used in many jurisdictions, may have serious limitations. First of all, not many users read notice. Second, even if efforts are made to enhance readability, such efforts may not be successful in increasing the instances of genuine informed consents. For instance, while a notice can be given prominence, prominence itself could have little effect on readership. Further, even those who read notice may well consent regardless of the substance or one-sidedness. MarottaWurgler (2012) provides interesting insights on these issues in the context of executing software license agreement. 
assessing current regulatory frameworks and reform proposals lies in the fact that there is a general lack of knowledge regarding how personal information is collected and used. Psychological and subjective costs of information disclosure would mainly arise due to users' anxiety over the possibility of embarrassing disclosure or unanticipated use of their information and also due to the concern coming from the perception that they are being observed and analyzed. In this context, current reform proposals will not be much helpful in alleviating users' concerns. Efforts for factgathering should be done first prior to putting forth serious reform proposals. Specifically, there is a need to gather facts as to the life-cycle of the user information.

While underlying studies in this context would need to be conducted through individual research efforts, their results should be discussed and shared among various stakeholders. This undertaking - discussing and sharing - is crucial considering its policy ramifications at an international level, and efforts made in this context could signal the embarkation of a major step toward international cooperation and harmonization. This could also entail discussions of certain key terms and concepts that often appear in data privacy laws (sometimes with variations) such as 'personal data' and 'data controller'. Discussions in this context could eventually lead to a uniform and harmonized understanding of these terms and concepts across jurisdictions and, that way, common understanding and common platform could be established. In all, the final results of these studies and other soft cooperation could be influential. For instance, the OECD Privacy Guidelines on the Protection of Privacy and Transborder Flows of Personal Data of 1980 , although not legally binding, has served as a model for legislations in many countries and still remains highly influential.

\section{Procedural Cooperation}

While information sharing and other soft cooperation has its own merits, it also has clear limitations, including the lack of binding effect and enforceability. A step further in the direction of tightening cooperation would be to establish rules for choice-of-law decisions and for enforcement cooperation..$^{52}$ First of all, facilitating international cooperation at the enforcement level would have obvious benefits since many of the business activities with data privacy implications easily cross jurisdictional boundaries and

\footnotetext{
${ }^{52}$ In a related context, Kuner notes an increasing tension between the geographycased regulatory approach and the organisationally-based regulatory approach. Kuner (2011), 20-21.
} 
cooperation among enforcement authorities could often be tremendously helpful or even be required for the effective enforcement of laws. ${ }^{53}$

This has indeed been an area with relatively active discussions. For instance, there are repeated calls made for international cooperation at the annual International Conferences of Data Protection and Privacy Commissioners, and often these calls are focused on enforcement issues. ${ }^{54}$ Organisation for Economic Co-operation and Development (OECD), which has led early efforts on data privacy issues and is continuing to lead related discussions, is also actively promoting cooperation on enforcement. ${ }^{55}$

About choice-of-law issues, adopting coherent and standard rules would enhance efficiency by reducing incidences of conflicting, overlapping, or sometimes confusing jurisdictions and by reducing conflicts over governing-law decisions. ${ }^{56}$ This will in turn enhance clarity and transparency about jurisdiction and applicable law, and thus raise predictability of legal ramifications of various activities which have data privacy connotations. ${ }^{57}$

${ }^{53}$ There is a duty to cooperate within the E.U., although how cooperation is conducted in practice is unclear. 'The supervisory authorities shall cooperate with one another to the extent necessary for the performance of their duties, in particular by exchanging all useful information.' E.U. Data Protection Directive, Article 28(6).

${ }^{54}$ As an example, after the 2011 International Conferences of Data Protection and Privacy Commissioners, which was held in Mexico, a working group was formed in order to discuss possibilities for enforcement cooperation. See S. Paluck-Bastien, 'Think locally, act globally: Data protection authorities from around the globe meet in Montreal to discuss enforcement co-operation', The Privacy Advisor (May 24, 2012), available at https://www.privacyassociation.org/publications/2012_05_24_think_locally_act_globally.

${ }^{55}$ The OECD Council adopted a formal recommendation in $200 \overline{7}$, calling for international enforcement cooperation. See OECD (2007). Subsequently, the OECD published a report on the implementation of the 2007 recommendation. The report provides detailed information regarding what has been accomplished during the previous several years such as building a website, establishing national contact points and networks, and developing a form for assistance request. However, the report admits that, about handling specific cases, cross-border cooperation appears to be more the exception than the rule. See OECD (2011a).

${ }^{56}$ Rules on applicable law and jurisdiction about data privacy issues are 'notoriously unclear'. Kuner (2011), 25. Further, the problem can become even murkier since "[s] tates seem more concerned about protecting their citizens, residents and companies against improper data processing carried out abroad than about avoiding jurisdictional conflicts with other States". Kuner (2010), 246.

${ }^{57}$ For instance, in the E.U., a Member State law would be applied to a data controller not established in the E.U., if such data controller makes use of the 'equipment' located in the Member State in order to process personal data. E.U. Data Protection Directive, Article 4(1)(c). There are debates as to whether this provision grants an exorbitant jurisdiction to an E.U. Member State and also as to what this provision, including the word equipment, means precisely. See Kuner (2010), 228-229; 239-240. Also, the influential Article 29 Working Group, composed of members from national data protection authorities in the E.U. established pursuant to Article 29 of the Data Protection Directive, is of the opinion that a Member State law would be applicable if data processing took place based on the information gathered through cookies sent from a non-Member State to 
Establishing these rules, however, does not mean that, once relevant rules are adopted, there would no longer be over-regulation or under-regulation. Also, in reality, assigning jurisdiction to a single state would simply not be feasible, unless a consensus is reached over other related issues, including applicable substantive and procedural laws.

On the other hand, for regulators in small open economies, achieving international cooperation on procedural issues could enhance their capability to enforce laws and could give better opportunities for them to bring cases. This is so because, with international procedural cooperation, obtaining evidence and other useful information could become easier for these regulators. Also, large international companies may become less inclined to ignore regulators in smaller jurisdiction in light of the cross-jurisdictional ramifications of an enforcement case.

International cooperation on a procedural level, however, would inevitably have limitations. With procedural cooperation, laws will be better enforced and there will be savings in the enforcement costs. However, the inherent problem of the failure to internalize, discussed above, will not be cured.

\section{Substantive Harmonization}

Given the desirability of international harmonization and the limits of weaker level cooperation, it would only be natural to consider harmonization at a more substantive level. Substantive level cooperation is indeed what would be required in order to eliminate the externality problem arising from fragmented legal regimes. That way, different interests among different regulators and the resulting different considerations will be handled adequately and the failure to internalize will be prevented. Also, through substantive cooperation, existing problems arising from the lack of legislation or from inadequate legislation could be cured, while the problem of overlapping jurisdictions could be avoided at the same time.

In this context, we consider possible options for substantive cooperation. In broad terms, possible regulatory instruments can be grouped into two categories, that is, first, measures to reach a multilateral consensus and to prepare an international convention involving many countries and, second, measures to harmonize domestic laws and regulations themselves.

First, reaching an agreement through an international convention would bring in a great degree of harmonization. This is simply because adopting an international convention would mean that the same legal principles will

computers in Member States. Article 29 Working Party, 'Privacy on the Internet: A Comprehensive EU Approach to Online Data Protection' (WP 37, November 21, 2000). 
be applied across all signatory states. However, even among international conventions, there are many possibilities in terms of the degree of enforceability and binding effect. For instance, Council of Europe Convention for the Protection of Individuals with regard to Automatic Processing of Personal Data of 1981 ("Council of Europe Convention 108"), which is one of the few and earliest international conventions on data privacy, explicitly permits derogations and does not have a strong binding effect. ${ }^{58}$

One major difficulty with the efforts to adopt an international convention is that it usually takes a long period of time to reach a consensus, if a consensus can be reached at all. At the same time, once an international convention is adopted, it is difficult to make an amendment. Difficulty of making a timely amendment could be especially problematic considering the current pace of technological changes related to data privacy.

There have been some suggestions calling for the adoption of an international convention. ${ }^{59}$ There have also been efforts made at regional levels. A notable example is the legislation at the E.U. level, including the Council of Europe Convention 108. There are other initiatives such as the APEC Privacy Framework. However, except for the E.U., attempts in other regions have shown only limited results. Also, a regional approach has a risk of facilitating the formation of regional blocs and making consensusbuilding at an international level even more difficult. If so, regional conventions could possibly lead to the slivering of world jurisdictions into several geographic areas, instead of promoting global harmonization. In the case of the E.U. Data Protection Directive, the European Commission is given authority to regulate the transfer of personal data to countries outside the E.U. and is asked to make decisions as to whether such third countries are providing 'adequate level of data protection'. If regulators in other major jurisdictions are given similar authorities, a result could be a complicated web of decision-making processes across jurisdictions about the adequacy of data privacy regulation in other jurisdictions. ${ }^{60}$

Additionally, although not harmonization per se, adopting and promoting a model law could also be considered. This could in effect be similar to adopting an international standard in the realm of data privacy regulation. Establishing a model law could be in particular useful considering that so

${ }^{58}$ For example, see Article 13(3). Although this is a European convention, it is open to ratification by non-European states.

${ }^{59}$ In particular noteworthy would be the efforts made so far at the annual International Conferences of Data Protection and Privacy Commissioners, where proposals are made periodically for international harmonization and adoption of an international convention. 'The Madrid Resolution' of 2009 is an example, which proposed rules on 'international standards on the protection of personal data and privacy'.

${ }^{60}$ At the extreme, the resulting effect would be similar to the one commonly observed in a trading bloc, where there is non-discrimination among members of a bloc, while nonmembers are subject to a high degree of discrimination. 
far only a limited number of countries have laws dealing with data privacy issues and that, for these countries contemplating enactment, such a model law could serve as a template. Having a model law would enhance awareness and could encourage legislation, which could in turn prompt efforts for international harmonization. ${ }^{61}$ Related to this, adopting and disseminating technical and regulatory standards through international standard setting organizations such as International Telecommunication Union (ITU), International Organization for Standardization (ISO) and World Wide Web Consortium (W3C) could show similar effects. Standards established at such standard setting organizations normally are not given legally binding effect as such but, nonetheless, they are often extremely influential in practice and set prevailing rules.

\section{F. Conclusion}

Data crosses national borders routinely. And any regulation by a national authority could easily have ramifications beyond its jurisdictional boundary. This article laid out some of the relevant issues and provided an argument for international efforts for coordination and harmonization of rules on data privacy.

On a broad level, different countries and jurisdictions have very different rules. The E.U. and the U.S. would be notable examples showing markedly different attitudes. When different rules are applied on data privacy issues in different jurisdictions, an end result would be that the most stringent elements of such rules would become de facto prevailing global rules. In that respect, the current controversy involving reform proposals made both in the E.U. and in the U.S. deserves a close attention. This is partly because strict elements of the resulting reforms in both jurisdictions are likely to reverberate and define the contour of regulations not just in these jurisdictions but also around the world.

Other than the E.U. and the U.S., many 'small open economies' have problems with extraterritorial enforceability of their rules. At least regarding data privacy issues, these economies do not have many choices other than adopting similar rules that are applied in 'large open economies'. The problem, however, is that, without international harmonization, rules adopted in individual jurisdictions would fail to consider ramifications outside their jurisdictional borders. This is particularly problematic in data privacy and other Internet-related areas. Therefore, there is a great and urgent need for discussions on international cooperation and harmonization.

${ }^{61}$ For instance, in the case of arbitration, adopting a model law was influential in making many countries to adopt new laws or revise existing laws modelled after the model law. 


\section{Bibliography}

Acquisti, A., and Grossklags, J., 2005, Privacy and rationality in individual decision making, IEEE Security \& Privacy, 3(1), pp. 26-33.

Alessandro, A. John L. and Loewenstein, G., 2010, What is Privacy Worth? (manuscript). Ayenson, M., Wambach, D.J., Soltani, A., Good, N. and Hoofnagle, C.J., 2012, Behavioral Advertising: the Offer You Cannot Refuse, Harvard Law \& Policy Review (2012).

Barocas S. and Nissenbaum H., 2009, On Notice: The Trouble with Notice and Consent, Proceedings of the Engaging Data Forum: The First International Forum on the Application and Management of Personal Electronic Information.

Brandimarte, L., Acquisti, A. and Loewenstein G., 2010, Misplaced Confidences: Privacy and the Control Paradox, Proceedings of the Tenth Workshop on the Economics of Information Security (WEIS).

Bygrave, L.A., 2010, Privacy and Data Protection in an International Perspective, Scandinavian Studies in Law, 56, pp. 165-200.

Chesterman, S., 2012, After Privacy: The Rise of Facebook, the Fall of WikiLeaks, and the Future of Data Protection (manuscript).

Debusseré, F., 2005, The EU E-Privacy Directive: A Monstrous Attempt to Starve the Cookie Monster?, International Journal of Law and Information Technology, 13(1), pp. 70-97.

Gellman, R., 2009, Privacy in the Clouds: Risks to Privacy and Confidentiality from Cloud Computing, World Privacy Forum (manuscript).

Goldfarb, A. and Tucker, C., 2011, Privacy Regulation and Online Advertising, Management Science, 57(1), pp. 57-71.

Guzman, A., 1998, Is International Antitrust Possible?, New York University Law Review, 73, pp. 1501-1548.

Hoofnagle, C.J., King, J., Li, S. and Turow, J., 2010, How Different are Young Adults from Older Adults When it Comes to Information Privacy Attitudes and Policies?

John, L.K, Acquisti, A. and Loewenstein, G., 2011, Strangers on a Plane: ContextDependent Willingness to Divulge Sensitive Information, Journal of Consumer Research, 37, pp. 858-873.

Kuner, C., 2011, Regulation of Transborder Data Flows under Data Protection and Privacy Law: Past, Present and Future, OECD Digital Economy Papers, No. 187, OECD Publishing.

Kuner, C., 2010, Data Protection Law and International Jurisdiction on the Internet (Part 2), International Journal of Law and Information Technology, 18(3), pp. 227-247.

Kuner, C., 2009, An International Legal Framework for Data Protection: Issues and Prospects, Computer Law \& Security Review, 25, pp. 307-317.

Marotta-Wurgler, F., 2012, Does Contract Disclosure Matter?, Journal of Institutional and Theoretical Economics, 168, pp. 94-119.

McDonald, A.M., and Cranor, L.F., 2010, Beliefs and Behaviors: Internet Users' Understanding of Behavioral Advertising (manuscript).

OECD, 2011a, Report on the Implementation of the OECD Recommendation on Crossborder Co-operation in the Enforcement of Laws Protecting Privacy, OECD Digital Economy Papers, No. 178, OECD Publishing.

$O E C D, 2011 \mathrm{~b}$, The Evolving Privacy Landscape: 30 Years After the OECD Privacy Guidelines, OECD Digital Economy Papers, No. 176, OECD Publishing.

$O E C D, 2007$, Recommendation of the Council on Cross-border Co-operation in the Enforcement of Laws Protecting Privacy, C(2007)67/Final.

Schwartz, P.M., 2009, Managing Global Data Privacy: Cross-Border Information Flows in a Networked Environment. 
Tene, O., 2010, Privacy: The New Generations, International Data Privacy Law, 1(1), pp. $15-27$.

Tene, O. and Polonetsky, J., 2012, To Track or "Do Not Track": Advancing Transparency and Individual Control in Online Behavioral Advertising, Minnesota Journal of Law, Science and Technology, 13(1), pp. 281-357.

Tucker, C., 2011, Social Networks, Personalized Advertising, and Perceptions of Privacy Control, Proceedings of the Tenth Workshop on the Economics of Information Security (WEIS).

Whitman, J.Q., 2004, The Two Western Cultures of Privacy: Dignity Versus Liberty, Yale Law Journal, 113, pp. 1151-1221. 


\title{
Comment on Haksoo Ko
}

\section{Evolving Law and Economics of Internet Privacy in the Evolving Technological Environment}

\author{
by \\ Michael Fehling*
}

\section{A. Introduction}

My colleague Haksoo Ko has presented to us a really enlightening overview. I fully agree with him that there is a strong case for international harmonization concerning internet privacy. But I will stress the point that strategies of regulated self-regulation play a prominent role in the international coordination of data protection regimes. In part I share Professor Ko's view on the lack of knowledge as a major obstacle to an appropriate legal regime. However, stricter legal rules to enhance transparency of data usage might help to narrow both the information asymmetry and the uncertainty. Simultaneously, such rules might enhance the rationality of individuals' choices whether to divulge or withdraw personal information. Under the current legal regime the rationality of such decisions of the consumers must be doubted as Professor Ko has convincingly explained in detail.

In this short comment I can pick up only a few issues. I will concentrate more on the substantive law as it is and as it should be from a law-andeconomics point of view. In doing so, I will argue that informed consent to the usage of data is the cornerstone of internet privacy both in an economic and a legal context.

First, I will deal with the conceptional background of economic analysis and examine how it might be linked to the legal rationale of data protection on the internet. I will concentrate on European and on German law with only some short remarks on the differences to the U.S.

${ }^{*}$ Special thanks to my research assistant Manuel Waldmann for his valuable support, especially with the references. 
Second, I will argue for the best strategy for consumer protection with regard to data transfer on the internet. From an economic perspective, a sort of libertarian paternalism might be preferable, and I will try to show that this idea is helpful to understand and to further develop the legal instruments as well.

Third and last, I will take up the harmonization issue and look at the interdependency of the international, the European and the national level of regulation to protect privacy on the internet. On these different levels a different mixture of regulatory strategies might be appropriate, ranging from self-regulation to command and control.

\section{B. Economic and Legal Foundations of Internet Privacy}

\section{In search for a rationale of data protection on the internet}

According to Professor Ko, privacy is often explained as liberty in the U.S. while in the EU dignity of the individual is considered a key underlying attribute. ${ }^{1}$ This comparison might be a bit simplified because this contrast is not absolute and both rationales are often closely linked. Furthermore, we find different approaches in Europe as well. They are very much discussed in the German context but can be identified on the European level, too.

The first approach looks at privacy - and on personal data in particular - as a form of property rights. This seems to be the predominant point of view in economics. ${ }^{2}$ Therefore, the consumer can (and should) deal with his data as with other economic goods in the most efficient way to maximize his individual welfare. The jurisprudence of the German Constitutional Court and relating legal literature on the fundamental right of informational self-determination as a part of the personality-right, Art. 2 (1), Art. 1 (1) of the German Constitution (Grundgesetz - GG), arguably point in a similar direction. The Court identifies a constitutional right to a free decision about sharing his or her own data with others and about the way others may use his or her data. ${ }^{3}$ This also includes that everybody is entitled to sell his or her data (but not the personality-right itself) to commercial enterprises. ${ }^{4}$ The right to a free decision on the use of personal data is not

\footnotetext{
${ }^{1}$ Drawing on Whitman (2004), 1161.

${ }^{2}$ Prominently Posner (1978); compare more recently Murphy (1996); Varian (1996).

${ }^{3}$ Decisions of the German Federal Constitutional Court, Official Documentation (BVerfGE) vol. 65, 1, 42, 43; excerpts in English in Kommers (1997), 323-326. This is not a genuine German innovation, for a similar approach see already Westin (1967), 7.

${ }^{4}$ For details see Weichert (2001), 1467, who, however, simultaneously warns against undue commercialisation of the right of informational self-determination, ibid., 1469;
} 
meant as a property right in the more narrow sense of the fundamental right of property (Art. $14 \mathrm{GG}$ ), but it might be understood as a property right in a broader economic meaning. In the U.S., the right to privacy in general (not relating to personal data) is even seen as a Fourth Amendment matter which closely links this right to the sanctity of the home. ${ }^{5}$

The second approach might be labeled dignitarian because it points to the roots of informational self-determination in human dignity. This linkage is rarely mentioned in the U.S. ${ }^{6}$ but becomes clear already in the legal foundation the Constitutional Court gives for this fundamental right: Art. 1 (1) GG explicitly names human dignity as the basis of the constitutional legal order. ${ }^{7}$ The legal discussion has refined this rationale by pointing out that data protection is not a virtue in itself but a necessary precondition for individual freedom in many contexts in a social environment. If a person does not know what others know about him or her, this might have a chilling effect on free interaction with others. The protection of an area of privacy - which is, at least in part, self-defined - is a precondition for enhancing his or her own personality. This dignitarian approach focuses much more on the social context of information than the property rightsapproach does. ${ }^{8}$ It is important to note, however, that in social interaction not only protecting private data from others but also sharing privacy relevant information with others is an essential prerequisite of personal freedom. This double-sidedness becomes especially clear within Art. 16 TFEU which both mentions the right to data protection and the free flow of data within the European Union. ${ }^{9}$

In an economic analysis this double rationale could be reflected in the analytical framework of optimizing central constitutional values. ${ }^{10}$ The "capability approach" developed by Nobel laureate Amartya Sen might be even better suited for the analysis because this approach draws on substantial freedoms to realize alternative combinations of different so called

Britz (2010), 587, even argues for Art. 14 GG as the appropriate constitutional foundation of this right to self-commercialisation of one's personal data.

${ }^{5}$ For an overview see Whitman (2004), 1211-1216; compare Slobogin (2011), 467, who shows the limitations of this approach if there is no physical intrusion but only a technological one.

${ }^{6}$ The famous starting point was Warren/Brandeis (1890), see on the reception of this article Whitman (2004), 1204-1208; in the Supreme Court jurisprudence Schmerber v. California, 384 U.S. 757, 767 (1966), describes the Fourth Amendment as protecting "privacy and dignity against unwarranted intrusion by the State"; furthermore cf. Lawrence v. Texas, $123 \mathrm{~S}$. Ct. 2472 (2003) on homosexuality.

${ }^{7}$ BVerfGE 65, 1, 42-43; BVerfGE 120, 351, 359-360.

${ }^{8}$ Compare Britz (2010), 568-569, 573, who looks at informational self-determination as a means to secure freedom in various contexts rather than an end in itself.

${ }^{9}$ Short remarks by Schneider (2011), 519 .

${ }^{10}$ According to van Aaken (2003), 315-333. 
"functionings". ${ }^{11}$ In this framework the right to informational selfdetermination should be construed in such a way that the individual can interact most freely with others, taking into account both his or her interest in privacy as a requisite of freedom and his or her interest in sharing information in social networks or business contacts on the internet. This perspective does not exempt from the necessity to weigh the benefits (merits) of enhanced data protection against the related costs of lost private and business opportunities. But it shifts the point of view of his analysis from economic efficiency (as in the neoclassical approach) to the maximisation of capabilities. While most aspects of efficiency can be implemented in the capability approach as well, this approach helps to broaden the perspective in cost-benefit analysis. ${ }^{12}$

\section{The right of privacy between private parties}

Taking fundamental rights as the starting point of our analysis leads us to the question whether such rights are applicable in (business) contacts of private parties on the internet. In the U.S. the constitutional right to privacy, deriving from the Fourth Amendment, is protected only - at least in general - against state action. ${ }^{13}$ This might explain why data protection in the private sector seems to be so much weaker in the U.S., based primarily on tort law ${ }^{14}$, than in Germany and the European Union.

In German doctrine, constitutional rights do not only serve as individual rights against the state but - as a reaction to Nazism - also as an objective order of values which influence the whole legal order including the relationship between private individuals themselves. ${ }^{15}$ Therefore, the state (in particular the legislator) has a constitutional duty to protect the individual's fundamental rights against other private parties so far as the individual

${ }^{11}$ Theoretical foundations by Sen (1985); contrasted with traditional cost-benefitanalysis by Sen (1999), 54-86; in the context on human rights Sen (2004), 332-338; for an critical discussion see e.g., Alkire (2005); Robeyns (2005); used in practice for example in the Report to the French President by Stiglitz/Sen/Fitoussi (2009), 15 - Recommendation 6.

${ }^{12}$ For an more detailed discussion see Fehling (2011), 49-51; intimated in a different context (environmental protection) in passing by Kaplow (2007), 116; Kysar (2010), 106.

${ }^{13}$ Whitman (2004), 1161, 1213-1216. The leading case on informational privacy is Whalen v. Roe, 429 U.S. 589 (1977).

${ }^{14}$ Tene/Polonetsky (2012), 337, pointing to Restatement (second) of Torts, §652D (1977).

${ }^{15}$ BVerfGE 7, 195, 205-207; published in English in Mitglieder des Bundesverfassungsgericht (1998), 1, 5-6; excerpts in English in Kommers (1997), 361-368, for the concept of a "radiating effect" of basic rights on third parties see ibid., 48-49; in the context of informational self-determination (concerning a renting contract) BVerfGE 84, 192, 194-195; Kühling/Seidel/Sivridis (2011), 54. 
is not able to protect himself or herself. Such inability might be caused by overwhelming market power of the opponent or by severe information asymmetry. In our context, this means that legal institutions must be established and guaranteed to empower the individual (quite often, but not necessarily in the role of the consumer) in such a way that he or she can freely choose his or her appropriate level of privacy and openness on the internet. ${ }^{16} \mathrm{I}$ think that a similar conclusion should be possible in the analytical framework of institutional economics. Such a duty to protect - and correspondingly: such an individual right to get protection - is recognized for the right to privacy under Art. 8 ECHR, too. ${ }^{17}$ There is less doctrinal certainty about the interpretation of the new Art. 8 of the European Charter of Fundamental Rights (and the similar Art. 16 TFEU), but it seems fair to say that there is such a right to privacy protection on the internet on the level of the European Union as well. At least, the European Directive on Privacy and Electronic Communications, ${ }^{18}$ which draws on Art. 7 and 8 of the Charter, addresses these issues in internet communications between private parties.

\section{Necessary level of protection}

In a rational choice model the consumer is seen as a completely rational actor maximizing his or her individual welfare in internet transactions. From such a point of view, more information about each other helps private parties to create contracts on the internet which serve both parties best. If this were true, the protection of privacy might - according to Posner and others - even be a source of inefficiency. ${ }^{19}$ There would be no need for time consuming and costly legal barriers against an easy flow of information.

${ }^{16}$ From a constitutional law point of view compare Bäcker (2012), 99-111; Albers (2005), 562-582.

${ }^{17}$ See Meyer-Ladewig (2011), Art. 8 para. 2, 4, 8; O'Boyle/Harris (2009), pp. 362, 369, 382; Ehlers (2007), § 2 para. 16, § 3 para. 26.

${ }^{18}$ Directive 2009/136/EC of the European Parliament and of the Council of 25 November 2009 Amending Directive 2002/22/EC on Universal Service and Users' Rights Relating to Electronic Communications Networks and Services, Directive 2002/58/EC Concerning the Processing of Personal data and the Protection of Privacy in the Electronic Communications Sector and Regulation (EC) No. 2006/2004 on Cooperation Between National Authorities Responsible for the Enforcement of Consumer Protection Laws, O.J. L 337 of 18 December 2009, 11.

${ }^{19}$ Posner (1978), 397-401; similarly Stigler (1980), especially at 628-633; Calzolari/Pavan (2006); more nuanced Murphy (1996), 2385-2388, who endorses Posner's view regarding claims for the protection of a mere reputation but differs regarding privacy claims based on subjective privacy preferences other than manipulating reputation. 
But even from a rational choice point of view, one might reach a different conclusion when taking into account transaction costs: Because it takes too much time to read and trying to understand the privacy policy of undertakings on the internet, it might be rational to ignore the more or less hypothetical risks to privacy in internet communication. Regulation should then enhance the information companies are obliged to give to consumers about the processing of their data, in particular making the statements more comprehensive and better understandable.

Professor Ko showed us that the context (framing effect), the paradox of control and the privacy paradox influence consumers' privacy decisions. ${ }^{20}$ Therefore, behavioural law and economics might give us a more realistic picture of such decisions in internet communication. Consumers might overvalue short term benefits of information disclosure to less visible long term risks. Because of peer group pressure this might be even more the case in social networks than in pure business contacts. In this model, regulation should not only reduce information asymmetries on the usage of personal data but must also help the consumers to properly weigh the pro and cons of giving away parts of their privacy.

Although European and German law on data protection do not completely endorse the idea of bounded rationality, ${ }^{21}$ the law at least recognizes that there are severe information asymmetries which might cause severe problems to reach a truly informed consent: ${ }^{22}$ On the one hand, the lack of knowledge about the further processing of one's data might result in consumers' annoyance or overconfidence in dealing with personal data. ${ }^{23}$ But the perception of less control over the usage of private data might also the other way round - have a chilling effect on the enhancement of one's personality. Unlike Posner, the fundamental right to informational selfdetermination recognizes the psychological costs - that is, the possibly chilling effect which unknown risks to privacy may have on personal and business relationships ${ }^{24}$ - as a completely rational motive for rules of data protection. As risks to privacy are part of a social context even the presumption of such severe risks endangers the level of freedom in social relationships not only on an individual level but also in society as a whole. ${ }^{25}$

${ }^{20}$ For example, John/Acquisti/Loewenstein (2011), 868; also compare Tene/ Polonetsky (2012), 333, noting that consumers often express a strong interest in privacy and aversion towards online behavioural tracking but refrain from taking any step, no matter how trivial and costless, to prevent tracking.

${ }^{21}$ Compare Britz (2010), 587-588, drawing on BVerfGE 9, 353, 358, noting that in the first place everybody has to protect himself by making informed decisions about privacy relevant information.

${ }^{22}$ This has already been noted by Simitis (1987), 736-737, compare ibid., 733-734.

${ }^{23}$ Compare Tene/Polonetsky (2012), 335, 338; more sceptical Britz (2010), 592.

${ }^{24}$ BVerfGE 65, 1, 42-43; compare Britz (2010), 569-570.

${ }^{25}$ Weichert (2001), 1469, emphatically endorses this view. 
Therefore, legislation has to build trust in the protection of privacy in the electronic information infrastructure even if losses in freedom according to reduced privacy cannot be completely tracked down to quantified and monetized individual costs. ${ }^{26}$

\section{Strategies of consumer protection of privacy in internet communication}

\section{The appropriate scope of paternalism in the law}

From a rational choice perspective, it would be easy to dismiss every sort of paternalism concerning the disclosure of personal data. But the picture changes if we take into account bounded rationality, framing effects and context dependency, hyperbolic discounting and other behavioural biases ${ }^{27}$ which hinder rational decision making regarding privacy. To overcome such tendencies, regulatory measures against information asymmetry are necessary but not sufficient. This is even more the case considering external effects on freedom in social interaction in general (as mentioned above); such effects can be accelerated by peer pressure or even herd behavior in social networks like Facebook, etc. The problem further increases when dealing not with adults but with young people.

Because the protection of privacy is a necessary prerequisite of the free enhancement of one's personality, it would be wrong to label every paternalistic approach from the outright as "anti-freedom". Certainly, a strong form of paternalism would neglect that it is an essential part of liberty to individually and freely balance costs and benefits of disclosure of private information. But a weaker "libertarian paternalism" 28 , which only frames the balancing process to enhance rationality, is in accordance both with the insights of bounded rationality and the doctrine of the fundamental right to privacy. ${ }^{29}$

\footnotetext{
${ }^{26}$ For a discussion of the means to ascertain the "value of privacy" to individuals, see Acquisti et al. (2009).

${ }^{27}$ See in general, in the context of cost-benefit-analysis, Sunstein (2005), 65-69; Adler/E. Posner (2006), 124-153.

${ }^{28}$ Sunstein/Thaler (2003); Thaler/Sunstein (2008), similar Camerer et al. (2003); more sceptical because of the difficulties to distinguish this approach from "stronger" paternalism Schäfer/Ott (2010), chapter 4.3.1.

${ }^{29}$ Compare Acquisti (2009), describing the benefits of a soft paternalistic approach of "nudging" privacy; Tene/Polonetsky (2012), 347, citing Thaler/Sunstein (2008), 1-4.
} 


\section{Judging legislation on internet privacy from this perspective}

Legislative measures must - first of all - reduce transaction costs for protecting private information taking into account the framing effect and other features of consumers' bounded rationality. In accordance with libertarian paternalism there should be a strict regime of data protection in general with the opportunity to waive this protection by positive action. Therefore, the opportunity for opting-out might not be sufficient. Prior consent in data processing as a form of opting-in is necessary, if data processing is more than minimally intrusive and not clearly socially desirable. ${ }^{30}$ In addition, measures have to be taken to overcome the information asymmetry so that an informed consent is really possible. Too much information is not enough information. Therefore, the information about storage and usage of personal data should be accompanied by a short and easy-to-read summary, preferably using standardized symbols. ${ }^{31}$ The last proposal has been broadly discussed - but unfortunately not realized - for disclosing nutritional values of food $;{ }^{32}$ the arguments are nearly the same. In more general terms: If the way notice is given takes into account cognitive limitations then transparency can be both a means for achieving consent and an independent policy goal which serves personal autonomy and dignity. ${ }^{33}$

Second, specific legislative safeguards are necessary to limit the scope of data processing even after collecting data on the basis of an informed consent. Thus, there should always be a right to revoke consent for the future (not for the past). The legislator should even think about a general time limitation for such a consent, ${ }^{34}$ so that, unless the consumer has explicitly allowed otherwise (libertarian paternalism!), information in social networks must be deleted after a certain period ${ }^{35}$ - which of course might not hinder the fact that such information might be still accessible somewhere else on the internet. A change of purpose for using and processing of data must be forbidden without a special (second) consent for this.

${ }^{30}$ See Tene/Polonetsky (2012), 341; compare furthermore ibid., 334, noting that the decision between opt-in or opt-out, which requires a value judgement, determines the level of privacy protection as well as the fate of entire business models.

${ }^{31}$ For a detailed discussion of "non-linguistic notice", "privacy nutrition labels" and "behavioural tracking icons" see Tene/Polonetsky (2012), 344-346 with further references.

${ }^{32}$ For some aspects of the discussion see Behnsen (2009); Sosnitza (2010); in the U.S. compare Kelley et al. (2010); Hill (2011).

${ }^{33}$ Tene/Polonetsky (2012), 343, citing Calo (2012).

${ }^{34}$ The German Bundesrat proposed such a time limitation in its comment on the EUproposal for a new General Data Protection Regulation, see BR-Drucks. 52/12 (2) of 30 March 2012, no. 23.

${ }^{35}$ Similar, Tene/Polonetsky (2012), 354, argue for a "regular deletion period". 
Third, in principle a company should not be allowed to refuse a business contract (or the participation in a social network) simply for the reason that the user does not agree with the usage of his or her data for purposes not directly linked to the contract. Instead, the company could charge an (adequate) small compensation fee if using and selling privacy-relevant information is part of its business calculation.

Fourth and last, legal remedies must be construed in a way to reduce transaction costs as well. There must be an adequate mixture of private enforcement and state control.

\section{The legal framework on data protection}

European and German law on data protection have implemented some but not all of these features.

In general - there are exemptions - a prior consent of the data subject is needed for collecting and processing his or her personal data (Art. 7 lit. a of the current EU-Data Protection Directive $[D P D]^{36}$; $\S \S 4,4$ a Federal Data Protection Act - Bundesdatenschutzgesetz [BDSG]). But the wording does not tell us exactly what is necessary for a legally valuable consent (compare the definition in Art. 2 lit. h DPD "freely given, specific and informed"; § 4a Sec. 1 S. 1 BDSG: "freie Entscheidung" - free decision). In the proposal for a new European General Data Protection Regulation ${ }^{37}$ a bit more can be found - but still only general terms open for judicial interpretation. In particular, Art. 7 Sec. 4 of the draft regulation states that "consent shall not provide a legal basis for the processing, where there is a significant imbalance between the position of the data subject and the controller". Taken literally, this would be regularly true in internet commerce and in social networks due to the information asymmetries between the private party and the multinational company. This can hardly be intended. $^{38}$

${ }^{36}$ Directive 95/46/EC of the European Parliament and the Council of 24 October 1995 on the protection of individuals with regard to the processing of personal data and on the free movement of such data, O.J. L 281 of 23 November 1995, 3111, amended by Regulation (EC) No. 1882/2003 of the European Parliament and the Council of 29 September 2003, O.J. L 284, 1; for an overview see Charlesworth (2003).

${ }^{37}$ Proposal for a Regulation of the European Parliament and the Council on the protection of individuals with regard to the processing of personal data and on the free movement of such data (General Data Protection Regulation), $\operatorname{COM}(2012) 11$ final; for an analysis see Härting (2012).

${ }^{38}$ In fact, recital 34 of the proposal itself states that a "clear imbalance" is namely given in circumstances "where the data subject is in a situation of dependence from the controller", as can be the case "in the employment context", or, "where the controller is a public authority, (...) where [it] can impose an obligation by virtue of its relevant public powers $(\ldots)$ ". 
Even more problematic is the legal provision dealing with the information necessary for an informed consent. According to Art. 11 of the current Directive (similar $\S 4$ Sec. 3 BDSG) a data subject must be provided with the purpose for which the data are intended and the recipients of the data. In addition, "any information" has to be given in so far as it is necessary, with regard to the specific circumstances. Art. 11 of the proposed regulation tells us much more but is in itself very difficult to read. The information given according to this article might not be easier to understand.

Up to now, there is no explicit right to revoke the consent - this may not be confused with the data subject's right to object on compelling legitimate ground to a particular processing of data for which a consent is not needed (Art. 14 DPD). But at least the German doctrine recognizes such a right if executed in good faith. ${ }^{39}$ A time limitation (limited period of validity) for the consent does not exist at all. In this regard, the proposed European Regulation would - as already mentioned by Professor Ko - bring some progress with a "right to be forgotten and erasure" (Art. 15 of the draft); it is explicitly mentioned that the storage of data might be consented for a fixed period of time and that the data subject is entitled to withdraw consent on which the processing is based (both Sec. 1 lit. b). But there is still no time limitation in general.

According to German law ( $\$ 28 \mathrm{Sec} .3 \mathrm{~b}$ S. 1 BDSG), a company may not refuse a contract only for the reason that the consumer does not agree to the usage of his or her data, if there is no feasible alternative for the consumer, for example contracting with a competing company. But this obligation to contract has been construed narrowly. ${ }^{40}$ In particular, the consumer has no right to pay a modest fee instead of giving away private information.

Closely related to the necessity of an informed consent, there is a second cornerstone of data protection law. Personal data must only be used and processed for the specified purposes on which the data subject has given his or her consent and must not be further processed in a way incompatible with these purposes (Art. 6 Sec. 1 lit. a DPD; compare for the public sector $\S 14$ BDSG - "Zweckbindungsgrundsatz", for the private sector compare in particular $\S 28$ and $\S 31$ BDSG). But this is only a very weak protection against the abuse of personal data on the internet, because - as pointed out by Professor Ko - the person affected typically will not know about the exact processing of his or her data due to the technical complexity.

Of course, every person has the right to obtain "confirmation as to whether or not data relating to him are being processed" and to know "the

\footnotetext{
${ }^{39}$ For details see Kühling/Seidel/Sivridis (2011), 126-127.

${ }^{40}$ For a detailed discussion see Kühling/Seidel/Sivridis (2011), 117-121.
} 
purposes of the processing, the categories of data concerned and the recipients to whom the data are disclosed" (Art. 12 lit. a DPD). But few people will bear the transaction costs without probable cause or even strong suspicion. And very few will be able to estimate whether they have been informed correctly or not.

There are many provisions for building trust in the technical information infrastructure ${ }^{41}$ to make sure that manipulations do not take place on the technical level. This is the major subject of the Directive on Privacy and Electronic Communications, which in Art. 5 Sec. 3 also deals with cookies, calling in principle for opt-in consent but with several unclear exceptions. ${ }^{42}$ But again safeguards against technical manipulations do not help much against the abuse and unlawful transmission of data which a company got lawfully in the first place.

\section{Protecting privacy in a multi-level regulatory network}

\section{Transnational problems, national law}

In data protection there again is the well-known problem that we have to deal with trans-border affairs predominantly within national law.

Although the World Wide Web does not stay within national borders, there is no general and concise legal regime of data protection on the international level. We only find a few international treaties on data transfer and data protection in special areas of the law - probably most well-known on data retention in air traffic between the European Union and the U.S. ${ }^{43}$ There are negotiations between the EU and the U.S. about common minimal standards, ${ }^{44}$ and already some safe-harbour rules based on regulated self-regulation, ${ }^{45}$ but it is doubtful whether Professor Ko's proposals for more international harmonization, although convincing in theory, will find sufficient political support, taking into account the different cultures on privacy.

\footnotetext{
${ }^{41}$ The underlying rationale has been discussed in detail by Britz (2010), 588-591.

${ }^{42}$ Detailed discussion by Tene/Polonetsky (2012), 307-313; concerning the flaws of the earlier version of 2002 compare Debusseré (2005), 80-97.

${ }^{43}$ Agreement between the United States of America and the European Union on the use and transfer of Passenger Name Records to the United States Department of Homeland Security, $\operatorname{COM}(2011) 807$ final (initial legislative proposal; the legislative procedure is already completed, but the legislation is, as of July 2012, awaiting publication).

${ }^{44}$ Explicitly supported by the German Bundesrat, BR-Drucks. 52/12 (2) of 30 March 2012 , no. 6 .

${ }^{45}$ See for more details infra II. with infra note 52.
} 
Even the European Union has unchallenged power to create a legal regime directly applicable for data processing only for its own European affairs and agencies. For data protection between private parties within the member states the Union has issued a directive which has to be transformed into national law. This applies even with regard to data transfer to third countries outside of the European Union (compare Art. 25, 26 DSD). In the future, the directive should be replaced by the already mentioned ${ }^{46}$ new regulation (for the data transfer to third parties see Art. 37-44 of the draft) but it is doubtful whether the European Union has power to do so based on Art. 16 Sec. 2 TFEU. ${ }^{47}$ The regulation shall apply even if a company has no seat in the EU but sells its products or delivers its services on the European market. ${ }^{48}$

So in the end, at least today, the major burden is on national law to deal with the data flow in e-commerce and in social networks on the internet. In accordance with the current European Directive, $\S 4 \mathrm{~b} \mathrm{Sec.} \mathrm{2,} 3$ BDSG provide that the data transfer can principally take place only if the third country ensures an adequate level of protection; this shall be assessed in the light of all the circumstances surrounding a data transfer operation. But this would be completely unrealistic in the World Wide Web; even in the U.S. it is doubtful whether there is a level of protection similar to the one in the European Union concerning the data. So European (Art. 26 DPD) as well as German law ( $\S 4 \mathrm{c}$ BDSG) derogates from this principle in several variations: First, if the data subject has given his consent to the proposed transfer (Sec. 1 lit. a respectively Sec. 1 no. 1). Second and even more important - because often there will be no consent which unambiguously covers the data transfer in such a "risky" third country, too - where the controller adduces adequate safeguards for the protection of privacy; such safeguards may in particular result from appropriate contract clauses (Sec. 2). This opens up the way for Codes of Conduct, Codes of Privacy and similar Global Privacy Policies which a multinational company can use to secure a worldwide similar level of protection. ${ }^{49}$ The new draft for an EUregulation has similar, in part even more far reaching ${ }^{50}$ provisions.

\footnotetext{
${ }^{46}$ See supra note 37.

${ }^{47}$ The German Bundesrat issued a subsidiarity complaint according to Art. 12 lit. b TFEU, BR-Drucks. 52/12 and BR-Drucks 52/12 (2), both of 30 March 2012.

${ }^{48}$ The German Bundesrat has explicitly welcomed this, se BR-Drucks. 52/12 (2) of 30 March 2012, no. 7.

${ }^{49}$ See Kühling/Seidel/Sivridis (2011), 132.

${ }^{50}$ Compare the complaints of the German Bundesrat against Art. 44 of the proposed regulation, BR-Drucks. 52/12 (2) of 30 March 2012, no. 45.
} 


\section{The legal solution: "Regulated Self-Regulation"}

Regulated self-regulation is a mixture between self-regulation of the companies and State regulation..$^{51}$ Companies offer a sort of privacy governance, perhaps even combined with an audit procedure. The European authorities supervise the companies' Codes of Privacy and issue "safeharbour" principles which are most important in relationship to the U.S. ${ }^{52}$ If the standards are inadequate, the Member States will block transnational data transfer or at least would not enforce contracts on the basis of inadequate privacy standards. Ideally, this should combine the advantages of both regulatory strategies. On the one hand, self-regulation ensures flexibility and makes up to the fact that on the international level a legal authority is more or less lacking. On the other hand, State control should assure that the companies set up adequate privacy policies and adhere to them in practice, too.

But the catastrophe on the financial markets teaches us that more or less informal international standards might be much to lax, if there is not enough pressure from the people and the governments. The risk seems to be high in particular because of the lack of transparency and the information asymmetry which tends to render the State control toothless.

Global Privacy Policies might hopefully induce a sort of international harmonization of privacy standards at least within the private sector. The alternative to harmonization would be a more active role of some countries, hoping for the - in economic terms - "California Effect" ${ }^{33}$. But even the European Union with its large Common Market today seems too weak to force other countries to comply with the Union's own - far from perfect - privacy standards. ${ }^{54}$

\section{The problem of enforcement}

So the lack of effective enforcement-mechanisms is the major obstacle to an adequate protection of privacy in internet commerce and in social networks.

${ }^{51}$ Hoffmann-Riem (1996), 300-303; Schmidt-Aßmann (2001), 254-255; Schulz/Held (2001), 5-6.

${ }^{52}$ Decision of the EU-Commission 2000/520/EG and its appendices I and II, O.J. L 215, 7. For a short overview see Debusseré (2005), 95-96; Kühling/Seidel/Sivridis (2011), 31-32.

${ }^{53}$ Named after the state that has often been on the cunning edge of environmental regulation, see Vogel (1995), 6; for a critical discussion of this phenomenon see Swire (1996), 80-87.

${ }^{54}$ Schneider (2011), 522 points in the same direction. 
Data protection law relies to a great extent on private enforcement. Every data subject has the right to, as appropriate, the rectification, erasure or blocking of data the processing of which does not comply with the law (see $\S \S 6,34,35$ BDSG, Art. 12 lit. b DPD). But this does not help much because of the lack of transparency and the transaction costs which are typically too high to bear for individual claimants - even more, if the company is located in a different country. In addition, tort claims (compare \& 7 BDSG) are bound to fail because it typically is not possible to prove a monetary damage. ${ }^{55}$

So we probably need a compound administration (Verwaltungsverbund), a network of national authorities working together. This is the well-known concept within the European Union, ${ }^{56}$ not only in data protection. The European Commission is acting as coordinator ("Spinne im Netz"). This model is laid down in Art. 26 Sec. 3, 4 DPD: If a Member State authorizes a transfer of data to a third country which does not ensures an adequate level of protection, the Member State shall inform the Commission and the other Member States. If a Member State or the Commission objects on justified grounds involving the protection of privacy, the Commission shall take appropriate measures agreed upon in a committee-procedure (compare Art. 31 Sec. 2 DPD). Where the Commission decides, assisted by the Committee, that certain standard contractual clauses offer sufficient safeguards, Member States shall take the necessary measures to comply with the Commission's decision. But this network of national administrations ends at the borders of Europe; there is nothing similar on the international level, only some soft law as described in detail by Professor Ko.

Even so, the chances for a better enforcement on the national level should not be underestimated. In Germany, the Data Protection Commissioners (Datenschutzbeauftragte) on Federal and on Länder-level, acting as a sort of ombudsman, can make a lot of publicity. They can combine informal administrative action (negotiations with international companies) with an information policy (press releases about the deficits in data protection - "naming and shaming"). ${ }^{57}$ In a long run, this might even hurt international companies like Facebook or Google, because they are dependent on a good reputation.

\footnotetext{
${ }^{55}$ See Weichert (2001), 1466.

${ }^{56}$ For a short description in English see Ruffert (2011), 2-3; in more detail Siegel (2009), Danwitz (2008), 616-634.

${ }^{57}$ A good example is the strategy of the Data Protection Commissioner of the German State Schleswig-Holstein, Thilo Weichert against Facebook, talking to the press about the difficult negotiations, see press release of 30 September 2011, https://www.date nschutzzentrum.de/presse/20110930-facebook-datenschutz-durchsetzen.html.
} 


\section{E. Conclusion}

Let me finish with quite a paradox observation: The protection of privacy on the internet shows some shortcomings both of law and of economics. But at the same time it is a very good example for the analytical value of law and economics.

On the one hand, most traditional legal instruments render toothless on the international level; neither private nor public law is able to overcome a significant imbalance in power based on information asymmetries between citizens or consumers and international companies. Regulated selfregulation does not work if the state oversight is too weak. On the economic side of the issue, a property rights approach, even if combined with the idea of bounded rationality, is not sufficient for explaining the necessity of data protection on the internet.

On the other hand, a refined economic analysis, combining Sen's capability approach with behavioral law and economics, can at least uncover these shortcomings. It also points to the center of the problems, the lack of transparency and the information asymmetry in data processing on the internet. Informal administrative action on national and European level might help to reduce these difficulties, but will not be able to overcome them.

\section{Bibliography}

Aaken, A. v., "Rational Choice" in der Rechtswissenschaft, 2003.

Acquisti, A., Nudging Privacy: the Behavioral Economics of Personal Information, IEEE Security \& Privacy, Nov-Dez. 2009, pp. 82-85.

Acquisti, A. et al., What is Privacy Worth?, 2009, http://www.heinz.cmu.edu/ acquisti/pa pers/acquisti-privacy-worth.pdf.

Adler, M. D. and Posner, E. A., New Foundations of Cost-Benefit Analysis, 2006.

Albers, M., Informationelle Selbstbestimmung, 2005.

Alkire, S., Why the Capability Approach?, 6 Journal of Human Development (2005) pp. 115-133.

Bäcker, M., Grundrechtlicher Informationsschutz gegen Private, 51 Der Staat (2012), pp. 91-116.

Behnsen, A., Verfassungsrechtliche Fragen einer Reform der Regelungen zu Nährwertinformationen, Zeitschrift für das gesamte Lebensmittelrecht 2009, pp. 1730.

Calo, M. R., Against Notice Skepticism in Privacy (and Elsewhere), 87 Notre Dame Law Review (2012).

Calzolari, G. and Pavan, A., On the optimality of privacy in sequential contracting, 130 Journal of Economic Theory (2006), pp. 168-204.

Camerer, $C$. et al., Regulation for Conservatives: Behavioral Economics and the Case for “Asymmetric Paternalism”, 151 University of Pennsylvania Law Review (2003), pp. $1211-1254$. 
Charlesworth, A., Information Privacy Law in the European Union: E Pluribus Unum or Ex Uno Plures?, 54 Hastings Law Journal 2003, pp. 931-969.

Danwitz, T. v., Europäisches Verwaltungsrecht, 2008.

Debusseré, F., The EU E-Privacy Directive: A Monstrous Attempt to Stave the Cookie Monster?, 13 International Jounal of Law and Information Technology (2005), pp. 70-97.

Ehlers, D., in: Ehlers, D. (ed.), European Fundamental Rights and Freedoms, 2007.

Fehling, M., Ökonomische Analyse im Öffentlichen Recht als Methode zur Reformulierung und Operationalisierung von Gerechtigkeitsfragen, in: Professorinnnen und Professoren der Bucerius Law School (eds.), Begegnungen im Recht, 2011, pp. 39-67.

Härting, N., Starke Behörden, schwaches Recht - der neue EU-Datenschutzentwurf, BetriebsBerater 2012, pp. 459-466.

Hill, K., Is It Time for Privacy Nutrition Labels?, Forbes.Com, 23 March 2010, http://blogs.forbes.com/kashmirhill/2011/03/23/is-it-time-for-privacy-nutrition-labels.

Hoffmann-Riem, $\quad W$., Öffentliches Recht und Privatrecht als wechselseitige Auffangordnungen - Systematisierung und Entwicklungsperspektiven, in: HoffmannRiem, W./Schmidt-Aßmann, E. (eds.), Öffentliches Recht und Privatrecht als wechselseitige Auffangordnungen, 1996, pp. 261-336.

John, L. K., Acquisti, A. and Loewenstein, G., Strangers on a Plane: Context-Dependent Willingness to Divulge Sensitive Information, 37 Journal of Consumer Research (2011), pp. 858-873.

Kaplow, L., Discounting Dollars, Discounting Lives: Intergenerational Distributive Justice and Efficiency, 74 University of Chicago Law Review (2007), pp. 79-118.

Kelley, P.G. et al., Standardizing Privacy Notices: An Online Study of the Nutrition Label Approach, 2010, http://www.cylab.cmu.edu/files/pdfs/tech_reports/CMUCyLab 09014.pdf.

Kommers, $D$., The Constitutional Jurisprudence of the Federal Republic of Germany, $2^{\text {nd }}$ ed. 1997.

Kühling, J./Seidel, C./Sivridis, A., Datenschutzrecht, $2^{\text {nd }}$ ed. 2011.

Kysar, D. A., Regulating from Nowhere, 2010.

Mitglieder des Bundesverfassungsgerichts, Decisions of the Bundesverfassungsgericht, Vol. 2 Part I, Freedom of speech 1958-1995, 1998.

Murphy, R. S., Property rights in personal information: an economic defense of privacy, 84 Georgetown Law Journal (1996), pp. 2381-2417.

Posner, R., The Right of Privacy, 12 Georgia Law Review (1978), pp. 393-422.

Robbeyns, I., The Capability Approach: a theoretical survey, 6 Journal of Human Development (2005), pp. 93-114.

Ruffert, M., European Administrative Law: Annual Report - 2010 - Germany, 2011, http://www.ius-pulicum.com/repository/uploads/09-12-2011-11-44-Ruffert.pdf

Schäfer, H.-B. and Ott, C., Homo Oeconomicus, Behavioral Economics und Paternalismus, Manuscript, 2010 (forthcoming as part of Schäfer, H.-B./Ott, C., Ökonomische Analyse des Zivilrechts, $5^{\text {th }}$ ed. 2012).

Schmidt-Aßmann, E., Regulierte Selbstregulierung als Element verwaltungsrechtlicher Systembildung, in: Die Verwaltung, Beiheft 4, 2001, Regulierte Selbstregulierung als Steuerungskonzept des Gewährleistungsstaats, pp. 253-272.

Schneider, J.-P., Stand und Perspektiven des europäischen Datenverkehrs- und Datenschutzrechts, 41 Die Verwaltung (2011), pp. 499-524.

Schulz, W. and Held, T., Regulated Self-Regulation as a Form of Modern Government: Study commissioned by the German Federal Commissioner for Cultural and Media Affairs; Interim Report (October 2001).

Sen, A., Commodities and Capabilities, 1985. 
Sen, A., Development as Freedom, 1999.

Sen, A., Elements of a Theory of Human Rights, Philosophy and Public Affairs, Fall 2004, 32, 4, pp. 315-356.

Siegel, T., Entscheidungsfindung im europäischen Verwaltungsverbund, 2009.

Simitis, S., Reviewing Privacy in an Information Society, 135 University of Pennsylvania Law Review (1987), pp. 707-746.

Slobogin, C., Die Zukunft des Datenschutzes in den USA, 41 Die Verwaltung (2011), pp. 465-497 (English version: Is the Fourth Amendment Relevant in a Technological Age?, http://www.brookings.edu/ /media/research/files/papers/2010/12/08\%204th\%2 0amendment\%20slobogin/1208_4th_amendment_slobogin.pdf).

Sosnitza, A., Der Kommissionsvorschlāg für eine Lébensmittelinformations-Verordnung, Zeitschrift für das gesamte Lebensmittelrecht 2010, pp. 5-21.

Stigler, G. J., An introduction to privacy in economics and politics, 9 Journal of Legal Studies (1980), pp. 623-644.

Stiglitz, J., Sen, A. and Fitoussi, J.-P., Report by the Commission on the Measurement of Economic and Social Progress, 2009.

Sunstein, C., Laws of Fear, 2005.

Sunstein, C. and Thaler, R.A., Libertarian Paternalism is not an Oxymoron, 70 University of Chicago Law Review (2003), pp. 1159-1202.

Sunstein, C. and Thaler, R.A., Nudge: Improving Decisions about Health, Wealth and Happiness, 2008

Swire, P., The Race to Laxity and the Race to Undesirability: Explaining Failures in Competition Among Jurisdictions in Environmental Law, 14 Yale Law \& Policy Review (1996), pp. 68-103

Tene, O. and Polonetsky, J., To Track or "Do Not Track": Advancing Transparency and Individual Control in Online Behavioral Advertising, 13 Minnesota Journal of Law, Science and Technology (2012), pp. 281-357.

Varian, H., Economic aspects of personal privacy, in: National Telecommunications and Information Administration, Privacy and self-regulation in the information-age, 1996.

Vogel, D., Trading Up: Consumer and Environmental Regulation in a Global Economy, 1995.

Warren, S. and Brandeis, L., The Right to Privacy, 4 Harvard Law Review (1890), pp. 193-220.

Weichert, T., Die Ökonomisierung des Rechts auf informationelle Selbstbestimmung, Neue Juristische Wochenschrift (NJW) 2001, pp. 1463-1469.

Westin, A. F., Privacy and Freedom, 1967.

Whitman, J. Q., The Two Western Cultures of Privacy: Dignity versus Liberty, 113 Yale Law Journal (2004), pp. 1151-1221. 



\title{
Discussion on Haksoo Ko
}

\author{
summarized by
}

\section{José Caiado}

Legal systems will have to deal with two typical privacy issues. One problem relates to standard and complex consumer contracts to which one agrees by simply clicking on the "Agree" button. In reality, however, very few people read the terms that are being agreed to. Another problem is the use of web searches as an advertisement tool. One interesting example is the advertisement of medicine. Google will map certain regions and know in advance where there is an outbreak of the flu, and they will use this to advertise certain products to those people.

The view of the Chicago School is that privacy is a source of inefficiency, generating problems of signaling. This interpretation comes from preinternet times, covering situations such as a job applicant hiding information. Further developments relate to (i) negative externalities (the consumer does not benefit from its data, only the company), (ii) behavior economics, which raised problems of overconfidence and optimism bias, (iii) research about "users' decisions being context dependent", and also (iv) the "paradox of control" in which individuals say they want privacy, but they are not willing to pay for it, so they reveal sensitive information for a very low price. During the discussions, however, it was argued that from a rational choice point of view, one might reach a different conclusion. If one takes into consideration transaction costs, it might be rational for consumers simply to ignore the agreements. Also, behavior studies indicated that consumers might need some protection. This leads us to a "necessary level of protection". It has also been argued that paternalism might be a solution to deal with bounded rationality, especially in its form of "libertarian paternalism". Under this perspective, a legal guideline should require consent in data processing, showing consumers summaries and symbols; there should be a right to revoke consent, and also of a limited period of validity, among others. In German and European law, there are rules on how to limit and define legally valuable consent, how to inform consumers, and there is no limited period of validity of the consent. 
The EU has regulations in place, such as the Data Protection Directive, while the US has no uniform framework, having only some instruments regulated by the FTC that focus on self-regulation. Some proposals for reform include EU proposal for data protection with the "right to be forgotten". In the US there is the implementation of the "do not track" mode.

An interesting way to structure the regulatory responses to these new issues of privacy is to understand the problem in terms of costs and benefits. The main benefit to companies is marketing, which can be very effective. Costs to users can be represented by the unwanted use of information. The real challenge becomes then to determine how the costs and benefits of privacy information disclosure must be balanced. 


\section{Private Military Contractors - Mercenaries Outside the Scope of Law?}

by

\section{Thilo Marauhn ${ }^{*}$}

Politics and academia have now intensely discussed the phenomenon of military contractors for approximately two decades. ${ }^{1}$ In the context of controversial activities of private military contractors in Iraq and Afghanistan ${ }^{2}$, the issue occasionally ranked prominently in a variety of forums, with extensive media coverage. Meanwhile a number of political and legal issues related to private military contractors seem to have been settled. There is also less public debate and contractors, governments, and commentators have moved back to normal. Today's "business as usual" is, however, different from the pre-1990s: First, notwithstanding criticism and scepticism, private military contractors today have consolidated their share in providing national and international security; second, states, reluctant to adopt new binding rules, largely agree on how, in principle, to address these contractors from the perspective of international human rights and humanitarian law; third, contractors, governments, and civil society have jointly developed soft law approaches to improving oversight of the security industry.

Understanding and explaining the factual and legal differences in dealing with private military contractors between the pre-1990s and today is not an easy exercise. Indeed, when the topic had become a prominent issue for politics, law, and the media, some commentators had expected that

* Thilo Marauhn is Professor of Public Law, International and European Law at Justus Liebig University, Giessen, Germany.

${ }^{1}$ There is a huge amount of literature available on private military contractors, with divergent terminology and heterogeneous perspectives. To mention but a few see J.C. Hansen (2012), 698; A. O. Kees (2011), 199; L. A. Dickinson (2010), 355; H. Strydom (2010), 121; J. L. Gómez del Prado and M. Maffai (2009), 1078; M. Sossai (2008), 89; C. Hoppe (2008), 989; and C. Lehnardt (2008), 1015. Among the edited volumes, the following might be of interest: S. Chesterman and C. Lehnhardt (eds.) (2007), F. Francioni and N. Ronzitti (eds.) (2011), and C. Bakker and M. Sossai (eds.) (2012).

${ }^{2}$ For some legal aspects related thereto see B. F. Nichols (2011/12), 459 and D. H. Chen (2009), 101. 
contractors would be a short-lived phenomenon, others had hoped for the acceptance of new, possibly stricter, international legally binding rules, and few had foreseen the development of international soft law standards and institutions. ${ }^{3}$ Perhaps this is due to the fact that the potential of private military contractors and their impact on international security have been overestimated not only at the beginning but also during the two decades-long debates. On the one hand, industry promoters of private military contractors had hoped for higher returns and government sponsors had expected less public expenditure. On the other hand, critiques of private military contractors had hoped for a stronger legislative and regulatory response at the national and international level.

This paper does not aim at providing a comprehensive explanation for the above-mentioned differences. It will present the situation of private military contractors from the perspective of public international law as of today, and it will provide some insights into possible reasons for these developments, contributing thereby to the law and economics debate on private military contractors.

\section{A. Drivers for the Use of Private Military Contractors}

Private military contractors do not deploy themselves. They are called in and employed by other actors. These have, primarily, been governments, but also other actors, including non-governmental parties to non-international conflicts and international organizations. ${ }^{4}$ Even though commentators increasingly question the role of the state not only in international relations generally but in particular in international security, largely referring to the notion of privatisation of international security ${ }^{5}$, states have been and continue to be the primary entities who rely upon private military contractors. Rather than focusing on the sheer number of private military contractors deployed and rather than reconstructing the whole of international relations and international $\mathrm{law}^{6}$, it seems to be more plausible first to look into the reasons for states making use of private military contractors. In this context it is very important to note that private military contractors have replaced parts of the armed forces and of other civil servants; this means that contractors do not normally act on their own initiative but are agents of governments (or other actors). States (or other traditional actors) have remained and continue to be

\footnotetext{
${ }^{3}$ On the debate concerning facts and regulatory prospects see E. Cusumano (2011), 11.

${ }^{4}$ See, among others, C. Spearin (2011), 196.

${ }^{5}$ Among others, D. Avant (2006), 327.

${ }^{6}$ See L. Groth (2012), 29, 33-35.
} 
the principals, making use of private contractors as their agents. ${ }^{7}$ The main question in order to understand the increased use of private military contractors today is why states no longer exclusively rely upon their military and police forces in providing internal and external security but have outsourced parts of the implementation of their security-related foreign policy.

\section{Effectiveness or Efficiency?}

A first aspect to be taken up in trying to answer this question is the relationship between governments and military/police forces on the one hand and between governments and private contractors on the other hand. Military and police forces are state organs. They form part of the executive branch of governments. With the inherent hierarchy in such forms of traditional governance, political decisions can be implemented in a straightforward way, i.e., in the absence of transaction costs it is plausible and likely that such implementation will be effective. However, while command and control structures in foreign and security policy promise a high degree of effectiveness, they entail overall the responsibility of governments: not only are governments in charge of personnel, equipment and budget, the actions of their military and police forces are directly attributable to governments, i.e., governments will be easily held responsible for any misconduct that may occur.

Moving from police and military forces to private contractors may at first sight reduce the potential for effective foreign and security policy action since such private contractors are not subject to direct orders of the government but only to the terms of the contract entered into with the government. Within the framework of such contracts private military companies enjoy a degree of, at least organisational, autonomy. Such organisational autonomy may contribute to increased efficiency; it reduces governmental responsibility for personnel, equipment and budget, and it will also limit state responsibility for misconduct, which may occur. In essence, the move from military and police forces to private military contractors is a move from command and control strategies to more indirect, largely incentive-based approaches in the implementation of foreign and security policy. ${ }^{8}$ The legal rules applicable to civil servants on the one hand and to contractors on the other, nationally and internationally, are different, and a lot of the debate about private military contractors has, from a legal perspective, focused upon questions related to what are the applicable rules.

\footnotetext{
${ }^{7}$ For further ideas on the application of the principal-agent concept to private military contractors see J. Cockayne, (2007), 196.

${ }^{8}$ But see M. Frulli (2010), 435.
} 


\section{An Ideological Turn}

Looking into the motives for governments to move from the use of military and police forces to the use of private military contractors, one of the original and in the early days perhaps dominating factors was the ideological turn linked to the end of the Cold War. ${ }^{9}$ These changes did not come along as a total surprise, since a lot of these tendencies had already developed in the West in the 1980s. Rather than relying exclusively upon the government to provide a number of public services, political decision-makers were increasingly convinced or at least hoped that the marketplace might similarly or better meet public needs. ${ }^{10}$ This move from government action to the marketplace led to the outsourcing of a number of public services and to deregulation, and it contributed to the development of new industries. Governments, on the other hand, got rid of the number of responsibilities, setting off part of the public service workforce and making them available to these new industries. Many governments hoped that this would lead to less public expenditure, to efficiency gains, and to economic growth. This overall political environment, which has often been labelled as neoliberal, also affected the conduct of foreign relations and security policy. With the end of the Cold War, there was a lot of talk about a peace dividend ${ }^{11}$, and governments came under pressure to reduce their military. Indeed, a number of armed forces were dramatically reduced in size, setting off a number of highly qualified staff members.

\section{Flexibility in Addressing a New Security Environment}

With the changes in the global security environment ${ }^{12}$, military involvement of governments outside their own countries changed. New threat perceptions, linked to organised crime, piracy, and terrorism, provided an incentive for governments to increasingly move from open military involvement to covert action, which could not be easily attributed to a particular state or government. Moreover, private contractors seemed to be more flexible for $\mathrm{ad}$ hoc deployment, and perhaps even better trained for a broad variety of military and police activities. ${ }^{13}$ Whether or not the question of lower or less strict standards and escaping direct responsibility was also the matter to employ private military contractors instead of armed forces is debatable but hardly to be proven. Another factor that may play a certain role is the

\footnotetext{
${ }^{9}$ See W. P. Nagan and C. Hammer (2008), 429.

${ }^{10}$ See Groth (Fn. 6), 37-38 and 50-51.

${ }^{11}$ C. W. Kegley and M. G. Hermann (1997), 339.

${ }_{12}$ Cf. C. Kennedy-Pipe (2000a), 1, and C. Kennedy-Pipe (2000b), 9.

${ }^{13}$ See Groth (Fn. 6), 37.
} 
readiness to take certain risks, which may be higher in the case of private contractors than in the case of police and armed forces, in particular in light of the fact that democracies our increasingly faced with problems if they get involved in armed conflicts if this at the same time means that the population has to pay a prize in terms of lives of soldiers. Public perception may be very different if a soldier gets killed compared to a private military contractors getting killed. ${ }^{14}$

\section{Some Figures}

Now coming to numerical data, figures do not necessarily provide explanations for developments, but they can be highly illustrative. In 2008, the size of the private military and security services industry was valued at more than $\$ 200$ billion annually. ${ }^{15}$ In March 2010, there were 150,000 troops - but 200,000 private contractors - involved in the conflicts in Afghanistan and Iraq. ${ }^{16}$ The Chairperson of the Working Group on the Use of Mercenaries as a Means of Violating Human Rights and Impeding the Exercise of the Right of Peoples to Self-Determination, in a presentation at the Human Rights Council in September 2010, pointed out that "Group4Securior", an internationally recognized provider of military and security services, has become the second largest employer world-wide. ${ }^{17}$ Thus, in terms of the personnel involved and compared to traditional armed forces, private military contractors have become sizeable and cannot be ignored. Whether, however, it is appropriate to talk about "an explosive growth in the privatization of international, and domestic, security forces" ${ }^{\prime \prime}$, may be debatable.

\section{B. The Applicable Law - Not in Need for New Standards?}

The law applicable to the activities of private military contractors largely depends on their activities. If employed in situations of armed conflict, including situations of military occupation, the law of armed conflict will apply, among others the Geneva Conventions of $1949^{19}$ (GC) and their

\footnotetext{
${ }^{14}$ Ibid., 30-31.

${ }^{15}$ See S. Perlo-Freeman and E. Skons (2008).

${ }^{16}$ See T. Christian Miller (2010).

${ }^{17}$ For further references see Groth (Fn. 6), 31.

${ }^{18}$ Ibid., 30.

${ }^{19}$ Geneva Convention for the Amelioration of the Condition of the Wounded and Sick in Armed Forces in the Field, UNTS 75, 31; Geneva Convention for the Amelioration of the Condition of Wounded, Sick and Shipwrecked Members of Armed Forces at Sea, UNTS 75, 85; Geneva Convention relative to the Treatment of Prisoners of War, UNTS 75, 135; Geneva Convention relative to the Protection of Civilian Persons in Time of War, UNTS 75, 287.
} 
Additional Protocols $\mathrm{s}^{20}$ (AP) as well as customary international law. ${ }^{21}$ To the extent that international human rights law remains applicable in situations of armed conflict ${ }^{22}$, these rules may also be relevant to the conduct of private military contractors. Outside such situations, general public international law will have to be borne in mind, in particular international human rights law. In so far as private military contractors are not as such addressees of pertinent rules of public international law, the law of state responsibility contributes to establishing a link between these contractors and the states employing them, with the conduct of private military contractors being indirectly affected by human rights and international humanitarian law standards.

\section{Inadequacy of the Mercenary Definition}

While there is no international agreement specifically addressing private military contractors as $\operatorname{such}^{23}$, one might consider whether they qualify as mercenaries. Indeed, in light of the fact that private military contractors are being paid for their involvement in armed conflicts, it has been discussed whether they fall under the international law definition of mercenaries given the profits they receive for their operations. ${ }^{24}$ There are three more or less identical definitions of a mercenary in public international law. They are included in Article 47 AP I, adopted on 8 June $1977^{25}$, in the OAU (Organization of African Unity) Convention for the Elimination of Mercenarism in Africa of 3 July $1977^{26}$, and in the International Convention against the Recruitment, Use, Financing and Training of Mercenaries of 4 December $1989 .{ }^{27}$ Article 47 (1) AP I, by stating that a "mercenary shall not have the right to be a combatant or a prisoner of war" implicitly confirms that

\footnotetext{
${ }^{20}$ Protocol Additional to the Geneva Conventions of 12 August 1949, and Relating to the Protection of Victims of International Armed Conflicts (Protocol I), UNTS 1125, 3; Protocol Additional to the Geneva Conventions of 12 August 1949, and Relating to the Protection of Victims of Non-International Armed Conflicts (Protocol II), UNTS 1125, 609.

${ }^{21}$ The ICRC's customary international law study is the most helpful restatement of customary international law of armed conflict; J.-M. Henckaerts and L. Doswald-Beck (eds.) (2005).

${ }^{22}$ The overlap between international human rights and international humanitarian law is one of the most disputed issues related to the application of both bodies of law; see, among others, C. Tomuschat (2010), 15.

${ }^{23}$ The following discussion is based, among others, on C. Lehnhardt (2011), online edition [www.mpepil.com], visited on 23 January 2013.

${ }^{24}$ See also M. Mancini, F. Z. Ntoubandi and T. Marauhn, (2011), 321.

${ }^{25}$ Cf. Fn. 18.

${ }^{26}$ UNTS $1490,96$.

${ }^{27}$ UNTS 2163,75 .
} 
civilians participating directly in hostilities are not entitled to prisoner of war status $^{28}$.

The three definitions share some basic criteria ${ }^{29}$ : The person qualifying as a mercenary must be "specially recruited ... to fight in an armed conflict" or she "is motivated to take part in the hostilities essentially by the desire for private gain" 31 ; a mercenary "is neither a national of a Party to the conflict nor a resident of territory controlled by a Party to the conflict" ${ }^{32}$; also, a mercenary "is not a member of the armed forces of a Party to the conflict" ${ }^{3}$; and finally, the person qualifying as a mercenary "has not been sent by a State which is not a Party to the conflict on official duty as a member of its armed forces". ${ }^{34}$ Given the fact that these definitional requirements are not only numerous but can be easily circumvented, none of the above legal instruments has had a major impact on international legal practice, nor can these provisions effectively be applied to private military contractors, unless in exceptional cases. ${ }^{35}$

\section{The Status of Contractors in Armed Conflicts}

If taking part in international armed conflicts, as defined by common Article 2 (1) GC and Article 1 (3) AP I or in a situation of occupation, as defined by common Article 2 (2) GC and Article 1 (3) AP I, private military contractors will be subject to the basic distinction between combatants and civilians. ${ }^{36}$ Only if they qualify as combatants, they are entitled to take a direct part in the hostilities without being prosecuted for doing so (unless having committed violations of the laws of war), and they will be granted prisoner of war status

\footnotetext{
${ }^{28}$ In discussing Article 47 (2) (b) AP I, J. de Preux (1987), para. 1806, states: "Only a combatant, and a combatant taking a direct part in hostilities, can be considered as a mercenary in the sense of Article 47".

${ }^{29}$ For a detailed analysis see Mancini, Ntoubandi and Marauhn (Fn. 24), 322-327; on customary law, ibid., 327-329.

${ }^{30}$ Article 47 (2) (a) AP I; Article 1 (1) (a) OAU Convention; Article 1 (1) (a) International Convention.

${ }^{31}$ Article 47 (2) (c) AP I; Article 1 (1) (b) OAU Convention; Article 1 (1) (b) International Convention.

${ }^{32}$ Article 47 (2) (d) AP I; Article 1 (1) (c) OAU Convention; Article 1 (1) (c) International Convention.

${ }^{33}$ Article 47 (2) (e) AP I; Article 1 (1) (d) OAU Convention; Article 1 (1) (d) International Convention.

${ }^{34}$ Article 47 (2) (f) AP I; Article 1 (1) (e) OAU Convention; Article 1 (1) (e) International Convention.

${ }^{35}$ Lehnhardt (Fn. 23), para. 4; see also Mancini, Ntoubandi and Marauhn (note 24), 329333.

${ }^{36}$ On the need to uphold the principle of distinction notwithstanding new challenges see $S$. Oeter (2007), 53.
} 
if captured by enemy forces. ${ }^{37}$ If they do not qualify as combatants, they will be treated as civilians. In other words, they do not have the right to participate directly in the hostilities, and - as long as they do not actually participate they will be protected from attack by enemy forces. Should they, however, participate directly in the hostilities, they may be treated as criminals by the enemy if captured, unless they qualify, among others, as civilians accompanying the armed forces according to Article 4 (A) (4) of GC III, or a similar subcategory of civilian.

Private military contractors, apart from being civilians accompanying the armed forces, may, however, become de facto combatants ${ }^{38}$ according to Article 4 (A) 2 GC III and Article 43 (1) AP I if they are incorporated into the armed forces. Even though this seems to "contradict the very rationale of outsourcing military tasks" ${ }^{\prime 39}$ as private military contractors normally operate separately from the military hierarchy these provisions provide a special status to " $(\mathrm{m})$ embers of other militias and members of other volunteer corps, including those of organized resistance movements, belonging to a Party to the conflict and operating in or outside their own territory" (Article 4 (A) 2 GC III), subject to several conditions ${ }^{40}$ : It requires an organized armed group (a condition, which contractors should easily meet), belonging to a party of the conflict (a condition, which, even though this view is sometimes disputed, can be met by a contract between the state party and the company, as well as by tacit agreement, but not by simply fighting on one side or the other), and the following additional criteria: being subjected to a responsible commander, wearing distinctive signs, carrying arms openly (criteria slightly modified and loosened by Article 44 (3) AP I) ${ }^{41}$, and conducting operations in accordance

\footnotetext{
${ }^{37}$ On the notion of combatant status see, among others, D.P. Ridlon (2008), 199; A. Behnsen (2003), 494.

${ }^{38}$ See Lehnhardt (Fn. 23), paras. 7 and 10.

${ }^{39}$ Ibid., para. 9.

${ }^{40}$ Article 4 (A) (2) GC III reads as follows: "Members of other militias and members of other volunteer corps, including those of organized resistance movements, belonging to a Party to the conflict and operating in or outside their own territory, even if this territory is occupied, provided that such militias or volunteer corps, including such organized resistance movements, fulfil the following conditions: (a) that of being commanded by a person responsible for his subordinates; (b) that of having a fixed distinctive sign recognizable at a distance; (c) that of carrying arms openly; (d) that of conducting their operations in accordance with the laws and customs of war."

${ }^{41}$ Article 44 (3) AP I stipulates: "In order to promote the protection of the civilian population from the effects of hostilities, combatants are obliged to distinguish themselves from the civilian population while they are engaged in an attack or in a military operation preparatory to an attack. Recognizing, however, that there are situations in armed conflicts where, owing to the nature of the hostilities an armed combatant cannot so distinguish himself, he shall retain his status as a combatant, provided that, in such situations, he carries his arms openly: (a) during each military engagement, and (b) during such time as he is visible to the adversary while he is engaged in a military deployment preceding the launching
} 
with the laws and customs of war. The most difficult criterion obviously is the "belonging to a party". As mentioned above, mere fighting will not be sufficient as proof for such a link to one of the parties to the conflict. Rather, the views of the state contracting a private military company must be taken into account. ${ }^{42}$

Indeed, state practice points in this direction: Both the United States and the United Kingdom have frequently contracted private military companies. However, as a matter of routine, contractors were given the status of civilians accompanying the armed force, as provided for in Article 4 (A) (4) Geneva Convention III. ${ }^{43}$ This means that contractors were not authorized to fight, but they obtained a status, which effectively protected them as prisoners of war if captured an enemy party. It can be taken from this practice that authorization to fight may qualify contractors as combatants, but not the mere fact of taking part in hostilities ${ }^{44}$ Even if contracted to fight, it is important to note that contractors must meet the other requirements mentioned above.

In international armed conflicts, there are thus three possibilities to qualify contractors: (1) If contracted to fight (and if meeting the pertinent criteria), they constitute de facto combatants; if not contracted to fight but for other purposes, they will (2) either be civilians accompanying the armed forces (3) or they will be civilians. In none of the two latter cases they have the right to directly participate in hostilities. If, this notwithstanding, they participate directly in hostilities, they will be considered as unprivileged belligerents. ${ }^{45}$

In non-international armed conflicts, there is less clarity since the rules are much less detailed. Common Article $3 \mathrm{GC}$ and AP II do not answer the question of whether a person is a combatant or otherwise entitled to fight. As a consequence, the issue of the combatant status is normally a non-issue in non-international armed conflicts ${ }^{46}$, and private military contractors will thus be subject to the domestic law of the territorial state. Minimum protection for contractors is provided by common Article 3 (1) GC, and, to the extent applicable, Article 4 AP II.

of an attack in which he is to participate. Acts which comply with the requirements of this paragraph shall not be considered as perfidious within the meaning of Article 37, paragraph 1 (c)"'.

${ }^{42}$ Lehnhardt (Fn. 23), para. 11.

${ }^{43}$ For a detailed discussion see G. Bartolini (2011), 218.

${ }^{44}$ On pertinent practice see Mancini, Ntoubandi and Marauhn (Fn. 24), 330-333 and 338-339.

${ }^{45}$ See Lehnhardt (Fn. 23), para. 13.

${ }^{46}$ But see, generally, J. Kleffner (2007), 315. 


\section{Direct Participation of Contractors in Hostilities}

As private military contractors, if involved in situations of an armed conflict as civilians, will lose this status in case of direct participation, it is important to take a closer look at Article 51 (3) AP I ${ }^{47}$ and Article 13 (3) AP II ${ }^{48}$, dealing with direct participation. The most serious consequences of direct participation are the possibility of being directly attacked according to the same rules and principles as combatants and the loss of combatant privilege upon capture (i.e., they will be treated as criminals under the domestic law of the captor) ${ }^{49}$ The question arises, what direct participation means. Neither treaty law nor State practice or international jurisprudence provide a precise definition of what conduct amounts to direct participation in hostilities.

This means that the notion of direct participation in hostilities must be interpreted according to the general rules on treaty interpretation, i.e., in good faith and on the basis of the ordinary meaning to be given to the terms in their context and in the light of the object and purpose of AP I, AP II and other pertinent rules of the law of armed conflict. The rules on treaty interpretation are included in Article 31 (1) of the Vienna Convention on the Law of Treaties and are considered to be customary international law. ${ }^{50}$ The application of these rules to Article 51 (3) AP I and Article 13 (3) AP II was the aim of a clarification process led by the ICRC between 2003 and 2009, the outcome of which, while not being uncontroversial, resulted in a publication, providing "interpretative guidance" on the interpretation of the notion of direct participation in hostilities in contemporary armed conflicts. ${ }^{51}$ This process has been paralleled by similar discussions in legal doctrine and in domestic courts. $^{52}$

There is general agreement that the qualification of civilian conduct as direct participation in hostilities must be judged on a case-by-case basis. The interpretative guidance, however, on the basis of a solid analysis of treaty law, pertinent state practice, jurisprudence, and legal doctrine suggests that the following criteria are cumulative requirements $s^{53}$ :

First, there must be a belligerent nexus, i.e., conduct occurring outside situations of armed conflict (or within such situations but unrelated to the conflict) does not amount to direct participation.

\footnotetext{
${ }^{47}$ Article 51 (3) AP I stipulates: "Civilians shall enjoy the protection afforded by this Section, unless and for such time as they take a direct part in hostilities".

${ }^{48}$ Article 13 (3) AP II reads "Civilians shall enjoy the protection afforded by this Part, unless and for such time as they take a direct part in hostilities".

${ }^{49}$ See M. Sossai (2011), 197, 204-206 and Mancini, Ntoubandi and Marauhn (note 24), 333-336.

${ }^{50}$ See, generally, O. Doerr (2012), 521.

${ }^{51}$ See N. Melzer (2009).

${ }^{52}$ For a contextual review of the ICRC process see N. Melzer (2010b), 151.

${ }^{53}$ See N. Melzer (2010a), paras. 7-16.
} 
Second, there must be harm above a certain threshold resulting from such direct participation, not limited to death and injury of military personnel or damage to military objects, but also including the capture of such personnel or the exercise of control over military objects.

Third, there must be a direct causal link between conduct and harm, however, handled in a flexible manner in order "to include civilian conduct causing harm only in conjunction with other acts". ${ }^{54}$ While typically an agreement can be reached in respect of the qualification of combat operations, disputes continue to occur about preparatory and supportive activities.

Civilians only lose their protection "for such time" that they engage in direct participation in hostilities. This means that they are suspended from protection but they regain such protection as civilians, once direct participation comes to an end. ${ }^{55}$ While this "revolving door"-approach has been subject to some criticism, others have rightly argued that such enhanced (and flexible) protection of civilians helps "to avoid erroneous and arbitrary attacks against peaceful civilians in situations where doubt, suspicion, and uncertainty are endemic" ${ }^{56}$ In the case of private military contractors, direct participation may take the form of organized participation, where contractors assume "a continuous combat function ... in the conduct of hostilities" they will lose their protection on a continuous basis and they "are held to regain protection against direct attack only once they surrender, fall hors de combat or affirmatively disengage from the group in question in a manner recognizable to the adversary" ${ }^{58}$ It is argued, however, that in situations of doubt the "presumption of civilian protection should ... apply". ${ }^{59}$ Not only governments employing private military contractors but even more these contractors themselves must be aware of the intricacies of Article 51 (3) AP I and Article 13 (3) AP II and the notion of direct participation.

\section{Issues of International Human Rights Law}

Should private military contractors be employed outside situations of armed conflict, and thereby perform functions assigned to them by governments, the question arises to what extent these contractors are bound by international human rights law. According to traditional doctrine, private military contractors as such are not addressees of international human rights law. However, home and host states involved in the employment and deployment

\footnotetext{
${ }^{54}$ Ibid., para. 15.

${ }^{55}$ See M.N. Schmitt (2004), 511.

${ }^{56}$ See Melzer (Fn. 53), para. 19.

${ }^{57}$ Ibid., para. 21.

${ }^{58}$ Ibid., para. 21.

${ }^{59}$ Ibid., para. 22.
} 
of private military contractors are subject to numerous human rights obligations. ${ }^{60}$

Addressing the home state of a private military contractor, its responsibility for human rights violations connected to the conduct of such a contractor may be direct or indirect in nature, or - in other words - negative and positive.

First, the home state will bear responsibility for the human rights violations by private military contractors, if the contractor is integrated into the national armed forces. Then the contractor may even be considered to be acting as an organ of the state ${ }^{61}$, in particular, if the government has assigned the exercise of governmental authority to the contractor either operating in or outside its territory. These are all situations of direct responsibility, and they involve the state's negative human rights violations. While the exercise of combat functions may only entail governmental responsibility to the extent that international human rights law is applicable in addition to the law of armed conflict, human rights will be relevant, among others, in post-conflict situations in the case of powers of arrest, interrogation services, and other law enforcement functions as well as in the context of managing detention facilities. ${ }^{62}$

Second, if the home state does not integrate contractors into its governance machinery, but only loosely establishes links with the contractors, then its positive obligations come into play. ${ }^{63}$ Indeed, the home state cannot escape its responsibility for misconduct by outsourcing governmental functions to private contractors. This will even apply if the contractor only acts under indirect control of its home state. ${ }^{64}$

If private contractors are employed by business entities or other nongovernmental actors, responsibility of the home state is even more difficult to establish. ${ }^{65}$ It may then be argued that the home state is under a general obligation to prevent or at least minimize human rights violations by contractors established or licensed under its authority. This will also entail the responsibility to impose criminal sanctions on perpetrators in case of human rights violations and to make available civil remedies to potential victims. ${ }^{66}$

Similar obligations may apply to the host state. Its jurisdiction will normally be established on the basis of the territoriality principle, and may thus exist on parallel tracks to the (extraterritorial) jurisdiction of the home

\footnotetext{
${ }^{60}$ See F. Lenzerini and F. Francioni (2011), 55-60.

${ }^{61}$ See $F$. Francioni (2011), 93, 99-104.

${ }^{62}$ For pertinent universal and regional practice relevant in this context see Lenzerini and Francioni (Fn. 60), 60-78.

${ }^{63}$ See C. Hoppe (2011), 111.

${ }^{64}$ See Francioni (Fn. 62), 102-104.

${ }^{65}$ These issues have been discussed, among others, by F. Francioni (2009).

${ }^{66}$ Ibid.
} 
state of a contractor. ${ }^{67}$ There may be cases of shared responsibility between the two states involved, the home and the host state of a private military contractor. ${ }^{68}$

While it is thus possible to establish international human rights responsibility of host and home state of private military contractors, such responsibility of the home state, compare to its responsibility for a traditional soldier, demonstrates a gap ${ }^{69}$, unless the contractor is fully incorporated. As has rightly been argued, "the state will always face less responsibility for acts of those persons than for acts of soldiers, and its responsibility will be harder to prove". ${ }^{70}$ This gap materializes in a responsibility for off-duty human rights violations as well as in the case of ultra vires or uncontrolled conduct of contractors exercising coercive services. States will typically exploit such options to minimize their international responsibility. ${ }^{71}$ Efforts to narrow down such responsibility gaps must focus on duties to vet, train, instruct, and report, and possibly to prevent known violations.

This analysis already points to the conclusion that rather than focusing on the conduct of private military contractors as such, supervision of these actors seems to be the greater challenge and of utmost importance.

\section{Towards New Treaty Law?}

As early as 1987, at a time when the International Convention against the Recruitment, Use, Financing and Training of Mercenaries had not yet been adopted, the UN Commission on Human Rights decided to appoint a Special Rapporteur on the use of mercenaries as a means of violating human rights and impeding the exercise of the right of peoples to self-determination. ${ }^{72}$ The mandate of the special rapporteur initially focused on mercenaries, and the Commission decided in 2004 that the Special Rapporteur "pay(s) particular attention to the impact of the activities of private companies offering military assistance, consultancy and security services on the international market on the exercise of the right of peoples to self-determination". ${ }^{73}$

In 2005, the Commission decided to end the mandate of the Special Rapporteur and instead established a Working Group, consisting of five

\footnotetext{
${ }^{67}$ For further details see C. Bakker (2011), 130.

${ }^{68}$ On the notion of shared responsibility see, more generally, A. Nollkaemper and D. Jacobs (2011).

${ }^{69}$ See Hoppe (Fn. 1), 992 (as well as all across the contribution).

${ }^{70}$ Ibid., 992.

${ }^{71}$ Ibid., 1012.

${ }^{72}$ See ECOSOC Resolution 1986/43 and UN Commission on Human Rights Resolution 1987/16.

${ }^{73}$ UN Commission on Human Rights Resolution 2004/5, para. 18.
} 
independent experts. ${ }^{74}$ The Working Group is mandated to monitor and research mercenaries and mercenary-related activities in all manifestations, including private military and security companies. ${ }^{75}$ Apart from conducting country visits, receiving individual complaints, publishing reports, studies and articles, the Group has developed guidelines and presented proposals to enhance the protection of human rights in the context of mercenary activities and of the conduct of private military contractors. ${ }^{76}$ Currently, the Group is mandated, among others, "(t)o elaborate and present concrete proposals on possible complementary and new standards aimed at filling existing gaps, as well as general guidelines or basic principles encouraging the further protection of human rights, in particular the right of peoples to selfdetermination, while facing current and emergent threats posed by mercenaries or mercenary-related activities". ${ }^{77}$

In 2010, the Human Rights Council established an open-ended intergovernmental working group ${ }^{78}$ to consider the possibility of elaborating an international regulatory framework on the regulation, monitoring and oversight of the activities of private military and security companies. An optional starting point of their work was and is the "Draft of a possible Convention on Private Military and Security Companies (PMSCs) for consideration and action by the Human Rights Council" ${ }^{\text {"79, }}$, prepared by the Working Group. The main elements of the proposed Convention reaffirm the state monopoly on the legitimate use of force, identify governmental functions that cannot be outsourced to private military contractors; and apply international human rights standards to regulate the use of force and firearms by private contractors.

\section{Supervision of Private Military Contractors: The Potential of Soft Law}

Long before the UN human rights framework, as just discussed, came forward with concrete proposals for the development of treaty-based human rights standards for private military contractors, the Swiss government, the ICRC and the private sector had initiated a number of soft law processes aimed at supervising private military contractors and their conduct. The choice for a soft law approach cannot only be attributed to its non-legally binding character and to the fact that states will more easily reach a politically binding

\footnotetext{
${ }^{74}$ See J. L. Gómez del Prado (2009), $429-430$.

${ }^{75}$ Ibid., 432-434.

${ }^{76}$ Ibid., 434-435 and 439-440.

${ }^{77} \mathrm{UN}$ Doc. A/HRC/RES/7/21.

${ }^{78} \mathrm{UN}$ Doc. A/HRC/RES/15/26

${ }^{79} \mathrm{UN}$ Doc. A/HRC/15/25, Annex.
} 
than a legally binding agreement. Instead, a number of other factors have to be borne in mind. Confirming the existence and applicability of existing rather than the need for new rules is easier to achieve by way of a soft law agreement; furthermore, this process is much faster in producing outcomes since it does not necessitate parliamentary approval or other constitutional requirements. Furthermore, the inclusion of non-state actors, in particular, of business actors, is facilitated by not relying upon formal processes of law. And finally, innovative approaches towards cooperative supervision can much easier be tested based on soft rather than hard law.

\section{The Montreux Document}

In terms of its political and legal relevance, one of the most important soft law documents negotiated and adopted with regard to private military contractors is the so-called Montreux Document. ${ }^{80}$ It constitutes the outcome of a process of intergovernmental consultations initiated by the Swiss Federal Department of Foreign Affairs in late 2005, with the cooperation of the International Committee of the Red Cross. ${ }^{81}$ Based upon extensive consultation with industry and civil society actors, five intergovernmental and four expert meetings were held, leading to the endorsement of the "Montreux Document on Pertinent International Legal Obligations and Good Practices for States related to Operations of Private Military and Security Companies during Armed Conflict" (which is the full title of the Montreux Document) on 17 September 2008.

The first part of the Montreux Document restates international humanitarian law and human rights law as it applies to the activities of private military contractors during armed conflict. ${ }^{82}$ As has been argued, the Document is "a very public reaffirmation by a diverse group of states, including the United States, of the applicability of international humanitarian law (IHL) and human rights to contemporary armed conflict". ${ }^{83}$ By reaffirming existing international law obligations of states to protect human rights and to ensure respect for international humanitarian law, the first part of the Montreux Document can be perceived as a common understanding of all states signatories of their perception of the law as it stands; one might even argue that this amounts to an expression of opinio iuris with regard to states' obligations in respect of private military contractors, since the Document "clearly sets out the specific obligations of individual states under treaty and

\footnotetext{
${ }^{80}$ UN Doc. A/63/467 and S/2008/636, Annex.

${ }^{81}$ For details see $J$. Cockayne (2009), 401, 417-427.

${ }^{82}$ Ibid., 403-411.

${ }^{83}$ Ibid., 403.
} 
customary law". ${ }^{84}$ The first part of the Montreux Document thus does not at all develop new law but restates the capacity of existing law to address the phenomenon of military contractors.

The second part of the Montreux Document goes beyond such restatement. It is less a step towards developing new standards but rather a specification of how to apply the rules spelled out in the first part of the Document. To this end the second part of the Document compiles good practices and aims at assisting states in implementing their international legal obligations. ${ }^{85}$ The sub-sections of the second part of the Document address, among others, the use of force by private military contractors, the issue of direct participation in hostilities, the vetting and training of their personnel, obligations of accountability and, finally, immunities of private contractors from foreign jurisdiction.

The Montreux Document is broad, but it is by no means perfect. It was never intended to be all-inclusive, but it is one step towards international agreement on how to deal with private contractors, and as such it also provides guidance to these contractors. With its best practice approach, it necessarily entails some lacunae; also, it does not fully spell out the implications of states' obligations to apply a due diligence standard towards supervising private military contractors; and finally, remedies for those affected by unlawful conduct will necessitate further clarification as the Document remains fragmented in this regard. ${ }^{86}$ While these deficiencies can and should not be ignored, it has rightly been praised that the Montreux Document "offers a highly credible set of standards, which can ... be adapted and implemented through a wide array of regulatory arrangements. What is called for is a mixture of pragmatism and entrepreneurialism, innovation and risk management, by both public and private actors alike". ${ }^{87}$

\section{The International Code of Conduct for Private Security Service Providers}

Linked to the process leading up to the Montreux Document, the Swiss government encouraged further discussions about soft law standards by the military and security services industry. In parallel to the adoption of the Montreux Document, the Swiss government supported the development of an International Code of Conduct for Private Security Service Providers as a

\footnotetext{
${ }^{84}$ Ibid., 404.

${ }^{85}$ Ibid., 411-417.

${ }^{86}$ Ibid., 427.

${ }^{87}$ Ibid., 428.
} 
multi-stakeholder initiative. ${ }^{88}$ It pursues a two-fold objective: First, it defines principles and standards for the military and the security services industry, based on international human rights and humanitarian law; second, it seeks to improve the industry's accountability, moving towards the establishment of an oversight mechanism. ${ }^{89}$

The articulation of the set of standards is a way to bridge the gap between states as norm addressees of human rights and international humanitarian law, and private military contractors as an important group of actors in situations of conflict, which, even though not directly addressed by rules of public international law, are - one might say on the basis of self-regulation - brought into this normative framework by signing the Code of Conduct. Indeed, the Code, once signed, requires its participating contractors to comply with the standards included therein, irrespective of the national laws and the legal situation in their home and host countries. With negotiations finalized, private contractors began to sign the document in late 2010.90

The Code of Conduct builds upon a mix of certification, auditing, monitoring and reporting. Certification is defined as "a process through which the governance and oversight mechanism will certify that a Company's systems and policies meet the Code's principles and the standards derived from the Code and that a Company is undergoing Monitoring, Auditing, and verification, including in the field, by the governance and oversight mechanism. Certification is one element of a larger effort needed to ensure the credibility of any Implementation and oversight initiative". ${ }^{91}$ According to the Code, signatory contractors accept to be certified on the basis of an independent auditing and verification by the governance and oversight mechanism established under the Code. ${ }^{92}$ Handled by a mix of stakeholders, including signatory companies, governments and civil society, this mechanism is decisive for the functioning of the Code. Auditing will be conducted by independent auditors, accredited by the mechanism ${ }^{93}$, and it includes on-site audits on a periodic basis for the purpose of gathering data. These data will then be reported to the governance and oversight mechanism. It is up to this mechanism to verify whether a signatory is meeting the requirements of the Code. Should this not be the case, the mechanism may decide on what remediation is required.

${ }^{88}$ The Code is available for download at http://www.icoc-psp.org/uploads/INTERN ATIONAL_CODE_OF_CONDUCT_Final_without_Company_Names.pdf, visited on 23 January 2013.

${ }^{89}$ See Section A, para. 5, of the Code (ibid.).

${ }^{90} \mathrm{~A}$ list of signatory companies is available at http://www.icoc-psp.org/uploads/Signa tory_Companies_-_December_2012_-_Composite_List_SHORT_VERSION.pdf, visited on 23 January 2013.

${ }^{91}$ See Section B of the Code (note 88 ).

${ }^{92}$ See Section A, para. 8, of the Code (ibid.).

${ }^{93}$ See Section B of the Code (ibid.). 


\section{Draft Charter for the Oversight Mechanism of the International Code of Conduct for Private Security Service Providers}

In order to enhance the functioning of the above-outlined Code of Conduct, the stakeholders involved in the Code of Conduct began to negotiate a Draft Charter for the Oversight Mechanism of the International Code of Conduct for Private Security Service Providers. ${ }^{94}$ This Charter proposes the overall structure and scope of responsibilities for the mechanism envisaged under the Code of Conduct. The content of the Draft Charter was developed by the multi-stakeholder Temporary Steering Committee established under the Code. It is a consensus-based document among the various representatives participating in the Temporary Steering Committee. ${ }^{95}$ The Draft Charter was first released in early 2012, inviting a process of stakeholder review and comments on the Draft.

The Draft, again, provides an interesting public-private approach to the regulation of private military contractors. Institutionally, it provides for three organs of the mechanism: a plenary, a board, and a secretariat. ${ }^{96}$ The plenary includes representatives from industry, civil society, and governments, as well as private sector clients and other interested parties, but voting is limited to industry. Voting powers cover amendments to the Code of Conduct and to the Oversight Mechanism. The board is deemed to be the primary decisionmaking body of the Mechanism. It is intended to consist of 12 representatives, with industry, civil society and governments being entitled to select four each. The powers of the board will include overseeing the operations of the secretariat, and this will also cover the secretariat's operation of the oversight process. It is interesting to note that the Draft provides that particularly important decisions of the board require a vote of no less than eight members, including at least two members from each of the three stakeholder groups, ensuring that the whole process remains inclusive. Finally, the secretariat will be in charge of administering the Code and it will execute the decisions of the board. Among others, the secretariat will include a full-time executive director.

Stakeholder participation in the oversight mechanism will depend on compliance with a number of criteria to ensure the credibility of all participants.

\footnotetext{
${ }^{94}$ Draft available at http://www.icoc-psp.org/uploads/Draft_Charter.pdf, visited on 23 January 2013.

${ }^{95}$ For further information see http://www.icoc-psp.org/Home_Page.html, visited on 23 January 2013.

${ }^{96}$ Details can be taken from the original text but also from the explanatory note made available on http://www.icoc-psp.org/uploads/Explanatory_Note.pdf, visited on 23 January 2013.
} 
The negotiating process has not yet come to an end. A number of delays have occurred, due also to the complexity of the mechanism, and - which is no surprise - to the innovative composition of its organs.

\section{The Potential of Soft Law Approaches}

This chapter does not address all soft law approaches that have been developed for the regulation of private military contractors. In particular, it does not cover a number of national or fully private self-regulatory approaches, which have gained some prominence ${ }^{97}$, in particular, in some common law countries, first and foremost the United Kingdom. This chapter has focused on those soft law mechanisms that comprise governmental actors.

It is still too early to assess the overall contribution of such soft law approaches to the regulation of private military contractors. It is, however, clear that even beyond the hard law that has been outlined in the second subsection of this chapter, private military contractors are not outside the scope of law.

The very existence and the use of soft law in this particular context should not be understood as an argument eliminating the distinction between law and non-law. This dualism "can be decisive for the implementation of, and the compliance with, the norm". ${ }^{98}$ Neither does soft law as such broaden the concept of international law; it cannot "be added as an additional source to the three traditional sources of international law". ${ }^{99}$ However, it can easily contribute to the purposeful interpretation of existing public international law, indicating more precisely the object and purpose of existing rules with regard to a particular context. The Montreux Document can easily serve as an example whereby states indicate their perception with regard to a number of existing rules of international humanitarian law in respect of the operations of private military contractors.

Another important aspect in soft law approaches to the regulation of private military contractors is the potential of these instruments to contribute to the further development of hard law. ${ }^{100}$ As has been pointed out, soft law can contribute to the development of treaty law, of customary international law, and of municipal law. At the least it can be a source of inspiration for those in charge of law-making stricto sensu. Indeed, "( $t$ )he mere existence of norms in international relations - whether binding or not - allows the world players to refer immediately to these norms, thus avoiding some of the

\footnotetext{
${ }^{97}$ See, among others, the discussion of pertinent initiatives by S. MacLeod (2011), 323 and C. Hoppe and O. Quirico (2011), 362.

${ }^{98}$ See D. Thürer (2009), para. 23.

${ }^{99}$ Ibid., para. 24.

${ }^{100}$ Ibid., para. 32.
} 
lengthy discussions necessitated by every law-making process. Soft law can thus be considered the result of a consultation process preceding legislation proper" ${ }^{101}$ In addition, "soft law has a complementing and strengthening function within the international legal order" ${ }^{102}$

It is exactly this potential of soft law approaches that may be particularly useful for the regulation of private military contractors. Given the fact that there is established (hard) law that can be easily applied to the involvement of private military contractors in various situations, extending from combat to support operations, soft law can be used to fill the gaps and to help in the interpretation of hard law.

\section{Is Established Law Adequate?}

This leads to a number of conclusions on the adequacy of established law addressing private military contractors.

There is an inherent tendency in responses by policymakers, whether private or public, civil society and academia in particular to address new challenges by proposing new laws. If this process is left to uncritically develop itself, this will lead to an ever-growing body of public international law and municipal law, which may not necessarily improve the situation on the ground. The steering effect of legal rules does not only depend on their comprehensiveness but perhaps even more on their clarity.

So far, the law of armed conflict and in particular international humanitarian law has benefited from being much clearer than a lot of other areas of public international law. Such clarity has been decisive because even though addressed to states (and - to a limited extent - to non-state parties to armed conflicts) - individuals, both civilians and members of the armed forces, were able to read, to understand and to apply bees and worms to the individual behaviour. Decision-making on the battlefield can be traced back to governmental entities, but it will always be linked to individuals who bear responsibility based on their function. Taking into account this beneficial clarity of the law of armed conflict and international humanitarian law, there is a need to critically assess to what extent there is a lack of clarity with regards to employing and overseeing the activities of private military contractors in situations of armed conflict. One of the problems outlined above is the notion of direct participation in hostilities. In this regard, indeed, there still is a need for clarification. However, the processes conducted so far in order to achieve such clarification have only been successful to a limited extent, as has been illustrated by reference to the interpretative guidance

\footnotetext{
${ }^{101}$ Ibid., para. 32 .

${ }^{102}$ Ibid., para. 34.
} 
adopted by the ICRC. The Montreux Document as well as the other soft law instruments referred to above may help to contribute a certain (limited) amount of clarity to the conduct of operations by private military contractors in situations of armed conflict, not alone based on the restatement of the law, but primarily on the good practice examples included in the second part of the Document. Thereby soft law can contribute to a purposeful interpretation of pertinent rules of international humanitarian law and of state responsibility.

The situation is much more difficult outside the scope of armed conflicts. The application of international human rights law to and respect for international human rights law by private military contractors is a difficult effort. This is largely due to the fact that international human rights law is less detailed than international humanitarian law and is much more open to interpretation. Moreover, while it is not disputed that international human rights law is directly applicable to government actors; it is much more difficult to bridge the gap between governmental addressees and private contractors. Recently, there have been attempts to develop soft law standards further towards the applicability of human rights law to business activities. ${ }^{103}$ However, these standards have not yet become hard law. In a similar way, the above-mentioned code of conduct and the attached oversight mechanism might contribute to a better and then enhanced application of human rights law to the conduct of private military contractors outside armed conflicts, in particular if involved in police activities or in the management of detention facilities.

Simply aiming at the development of new hard law will not necessarily meet the requirements on the ground. New standards may easily contradict existing standards and thereby weaken rather than strengthen existing rules. The development of soft law standards in this field avoids the trap of weakening existing rules by accepting the prevalence of these rules and simply filling in the gaps with (secondary) rules. This may not necessarily be a complete and coherent answer to the debate about the so-called accountability gap with regard to the conduct of operations by private military contractors. ${ }^{104}$ However, notwithstanding efforts to bridge the accountability gap it is necessary and important to apply existing rules at this moment in time and not postponing the solution of the problem to a near or remote future. Furthermore, all debates about making private entities addressees of human rights entail the risk of weakening rather than strengthening the law. The role of the state in public international at the interface between the

\footnotetext{
${ }^{103}$ Most important in this regard is the adoption of the Resolution on Human rights and transnational corporations and other business enterprises by the Human Rights Council (UN Doc. A/HRC/RES/17/4). For a discussion of the Guiding Principles on Business and Human Rights: Implementing the United Nations "Protect, Respect and Remedy" Framework (UN Doc. A/HRC/17/31, Annex) see, among others, J. M. Kamatali (2011/2012), 437.

${ }^{104}$ See Groth (Fn. 6), 44-62 and A. Mehra (2010), 323.
} 
international and municipal level, at the interface between governmental and private actors, has changed and has become more complex but it has remained as important as it has been in the past.

As has been outlined in the first subsection of this chapter, it is not primarily private contractors who are the driving forces for their own deployment. Rather it is necessary to address the motives and incentives for governments to transfer the fulfilment of certain public tasks to private actors, and the (legal and political) consequences of such outsourcing. Such approaches have to take into account that private military contractors have become important actors in international security matters. Public international law should not focus on the ethics or the morality of individuals working with the inland as part of private military contractors. Public international law should instead be concerned with a practical solution of the problems arising out of a new actor becoming part of the scenery. As this chapter has pointed out, many problems can be solidly addressed on the basis of existing law, and the remaining problems can largely be settled by making use of and further developing the soft law instruments outlined above. Governments, the private security industry and large parts of civil society have opted for a rational approach to settle the problem related to private military contractors, rather than following a grand ethical design with little practical consequences.

\section{Bibliography}

Avant, D. (2006), The Privatization of Security: Lessons from Iraq. Orbis 50 (2), 327-342.

Bartolini, G. (2011), Private Military and Security Contractors as 'Persons who Accompany the Armed Forces'. From Francioni and Ronzitti (eds.), War by Contract: Human Rights, Humanitarian Law, and Private Contractors, Oxford University Press, 218-234.

Bakker, C. (2011), Duties to Prevent, Investigate, and Redress Human Rights Violations by Private Military and Security Companies: The Role of the Host State. From Francioni and Ronzitti (eds.), War by Contract: Human Rights, Humanitarian Law, and Private Contractors, Oxford University Press, 130-148.

Bakker, C. and Sossai, M. (eds.) (2012), Multilevel Regulation of Military and Security Contractors: The Interplay between International, European and Domestic Norms.

Behnsen, A. (2003), The Status of Mercenaries and Other Illegal Combatants Under International Humanitarian Law. German Yearbook of International Law 46, 494-536.

Chen, D. H. (2009), Holding "Hired Guns" Accountable: The Legal Status of Private Security Contractors in Iraq. Boston College International and Comparative Law Review 32, 101.

Chesterman, S. and Lehnhardt, C. (eds.) (2007), From Mercenaries to Market: The Rise and Regulation of Private Military Companies. Oxford University Press.

Cockayne, J. (2007), Make or Buy? Principal-Agent Theory and the Regulation of Private Military Companies. From Chesterman, S. and Lehnhardt, C. (eds.), From Mercenaries to Market: The Rise and Regulation of Private Military Companies. Oxford University Press, 196.

Cockayne, J. (2009), Regulating Private Military and Security Companies: The Content, Negotiation, Weaknesses and Promise of the Montreux Document. Journal of Conflict and Security Law, 13 (3), 401-428. 
Cusumano, E. (2011), Policy Prospects for Regulating Private Military and Security Companies. From Francioni and Ronzitti (eds.), War by Contract: Human Rights, Humanitarian Law, and Private Contractors, Oxford University Press, 11-36.

de Preux, J. (1987), In Discussing Article 47 (2) (b) AP I, from Y. Sandoz (ed.) Commentary on the Additional Protocols of 8 June 1977 to the Geneva Conventions of 12 August 1949, para. 1806.

Dickinson, L. A. (2010), Military Lawyers, Private Contractors, and the Problem of International Law Compliance. New York University Journal of International Law \& Politics 42, 355.

Doerr, O. and Schmalenbach, K. (2012), General rule on interpretation, Vienna Convention on the Law of Treaties, A commentary, Article 31.

Francioni, F. and Ronzitti, N. (eds.) (2011), War by Contract: Human Rights, Humanitarian Law, and Private Contractors, Oxford University Press.

Francioni, F. (2011), The Role of the Home State in Ensuring Compliance with Human Rights by Private Military Contractors. From Francioni and Ronzitti, War by Contract: Human Rights, Humanitarian Law, and Private Contractors, Oxford University Press, 93 110.

Francioni, F. (2009), The Responsibility of the PMSC's Home State for Human Rights Violations Arising from the Export of Private Military and Security Services, EUI Working Paper AEL 2008/18.

Frulli, M. (2010), Exploring the Applicability of Command Responsibility to Private Military Contractors. Journal of Conflict and Security Law 15, 435.

Gómez del Prado, J.L. (2009), Private Military and Security Companies and the UN Working Group on the Use of Mercenaries. Journal of Conflict and Security Law 13, 429-450.

Gómez del Prado, J.L. and Maffai, M. (2009), United Nations Working Group on the Use of Mercenaries as a Means of Violating Human Rights and Impeding the Exercise of the Rights of People to Self Determination \& the Wisconsin International Law Society: Model Law for the Regulation of Private Military and Security Companies. Wisconsin International Law Journal 26, 1078.

Groth, L. (2012), Transforming Accountability: A Proposal for Reconsidering how Human Rights Obligations Are Applied to Private Military Security Firms. Hastings International and Comparative Law Review 35, 29.

Hansen, J. C. (2012), Rethinking the Regulation of Private Military and Security Companies Under International Humanitarian Law. Fordham International Law Journal 35, 698.

Heintschel von Heinegg, $W$. and Epping, $V$. (2007), International Humanitarian Law Facing New Challenges: Symposium in Honor of Knut Ipsen, Springer.

Henckaerts, J.-M. and Doswald-Beck, L. (2005), The ICRC's Customary International Law Study is the Most Helpful Restatement of Customary International Law of Armed Conflict. Customary International Humanitarian Law, Cambridge University Press.

Hoppe, C. (2008), Passing the Buck: State Responsibility for Private Military Companies. European Journal of International Law, 19(5), 989-1014.

Hoppe, C. (2011), Positive Human Rights Obligations of the Hiring State in Connection with the Provision of 'Coercive Services' by a Private Military or Security Company. From Francioni and Ronzitti, War by Contract: Human Rights, Humanitarian Law, and Private Contractors, Oxford University Press, 111-129.

Hoppe, C. and Quirico, O. (2011), Codes of conduct for private military and security companies: the state of self-regulation in the industry. From Francioni and Ronzitti (eds.), War by Contract: Human Rights, Humanitarian Law, and Private Contractors, Oxford University Press, 362-380.

Kamatali, J.-M. (2011/2012), The New Guiding Principles on Business and Human Rights' Contribution in Ending the Divisive Debate Over Human Rights Responsibilities of Companies, Cardozo Journal of International and Comparative Law 20, 437. 
Kees, A. O. (2011), Regulation of Private Military Companies, Göttingen Journal of International Law 3, 199.

Kegley, C. W. and Hermann, M. G. (1997), A Peace Divided? Democracies' Military Interventions and their External Political Consequences. Cooperation and Conflict 32,339 .

Kennedy-Pipe, C. (2000), Security Beyond the Cold War: An Introduction. From Jones, $C$. and Kennedy-Pipe, C. (eds.), International Security in a Global Age, London, 1.

Kennedy-Pipe, C. (2000), From Cold War to New Wars. From Jones, C. and KennedyPipe, C. (eds.), International Security in a Global Age, London, 9.

Kleffner, J. (2007), From 'Belligerents' to 'Fighters' and Civilians Directly Participating in Hostilities. Netherlands International Law Review 54, 315.

Lehnhardt, C. (2011), Private Military Companies. From Wolfrum, R. (ed.), The Max Planck Encyclopedia of Public International Law, online edition available at: www.mpepil.com, visited on 23 January 2013, paras. 4, 7, 9, 10, 11, 13 .

Lehnhardt, C. (2008), Individual Liability of Private Military Personnel Under International Criminal Law. European Journal of International Law 19, 1015.

Lenzerini, F. and Francioni, F. (2011), The Role of Human Rights in the Regulation of Private Military and Security Companies. From Francioni and Ronzitti, War by Contract: Human Rights, Humanitarian Law, and Private Contractors, Oxford University Press, $55-79$

MacLeod, S. (2011), The Role of International Regulatory Initiatives on Business and Human Rights for Holding Private Military and Security Contractors to Account. From Francioni and Ronzitti (eds.), War by Contract: Human Rights, Humanitarian Law, and Private Contractors, Oxford University Press, 343-361.

Mancini, M., Ntoubandi, F. Z., and Marauhn, T. (2011), Old Concepts and New Challenges: Are Private Contractors the Mercenaries of the Twenty-first Century?. From Francioni and Ronzitti (eds.), War by Contract: Human Rights, Humanitarian Law, and Private Contractors, Oxford University Press, 321-342.

Mehra, A. (2010), Bridging Accountability Gaps. Pacific McGeorge Global Business \& Development Law Journal 22, 323.

Melzer, N. (2009), International Committee of the Red Cross: Interpretive Guidance on the Notion of Direct Participation in Hostilities Under International Humanitarian Law.

Melzer, N. (2010a), Civilian Participation in Armed Conflict. From Wolfrum, R. (ed.), The Max Planck Encyclopedia of Public International Law, online edition available at: www.mpepil.com, visited on 23 January 2013, paras. 7-16, 19, 21, 22.

Melzer, N. (2010b), The ICRC's clarification process on the notion of direct participation in hostilities under international humanitarian law, From Tomuschat, C., Lagrange, E., and Oeter, S., The Right to Life, 151.

Miller, T. C. (2010), This Year Contractor Deaths Exceed Military Ones in Iraq and Afghanistan. Pro Publica, available at: http://www.propublica.org/article/this-yearcontractor-deaths-exceed-military-ones-in-iraq-and-afgh-100923.

Nagan, W. P. and Hammer, C. (2008), The Rise of Outsourcing in Modern Warfare. Maine Law Review 60, 429.

Nichols, B. F. (2011/12), Legitimizing a de facto U.S. Foreign Legion in Afghanistan. Michigan State International Law Review 20, 459.

Nollkaemper, A. and Jacobs, D. (2011), Shared Responsibility in International Law: A Concept Paper. ACIL Research Paper No 2011-07 (SHARES Series).

Oeter, S. (2007), Comment: Is the Principle of Distinction Outdated? From: W. Heintschel von Heinegg $(e d$.$) , International Humanitarian Law Facing New Challenges: Symposium$ in Honor of Knut Ipsen, Springer, 53-64.

Perlo-Freeman, S. and Sköns, E. (2008), The Private Military Services Industry. SIPRI Insights on Peace and Security. 
Ridlon, D. P. (2008), Contractors or Illegal Combatants - The Status of Armed Contractors in Iraq. The Air Force Law Review 62, 199.

Schmitt, M. N. (2004), Humanitarian Law and Direct Participation in Hostilities by Private Contractors or Civilian Employees. Chicago Journal of International Law 5, 511.

Sossai, M. (2008), Status of Private Military Companies' Personnel in the Laws of War. The Italian Yearbook of International Law 18, 89.

Sossai, M. (2011), Status of Private Military and Security Company Personnel in the Law of International Armed Conflict. From Francioni and Ronzitti (eds.), War by Contract: Human Rights, Humanitarian Law, and Private Contractors, Oxford University Press, 197-217.

Spearin, C. (2011), UN Peacekeeping and the International Private Military and Security Industry. International Peacekeeping 18, 196.

Strydom, H. (2009/10), An Overview of the UN Draft Convention on Private Military and Security Companies. African Yearbook on International Humanitarian Law, 121.

Thürer, D. (2009), Soft Law. From Wolfrum, R. (ed.), The Max Planck Encyclopedia of Public International Law, online edition available at www.mpepil.com, visited on 23 January 2013, paras. 23-24, 32, 34.

Tomuschat, C. (2010), The Overlap Between International Human Rights and International Humanitarian Law is one of the Most Disputed Issues Related to the Application of Both Bodies of Law, Human Rights and International Humanitarian Law. European Journal of International Law 21, 15. 



\title{
Discussion on Thilo Marauhn
}

\author{
summarized by
}

\section{Jerg Gutmann}

Michael Fehling starts the discussion, asking whether the threshold for initiating military aggression can be expected to be lower as a consequence of the availability of private military contractors. Thilo Marauhn replies that only a low share of private military contractors' activities is directly of military nature. While international organizations require more policing activities, states hesitate to use private military contractors for their classical core military activities. Eyal Benvenisti warns that self-regulation might simply be a means to prevent competition. Thilo Marauhn responds it is evident that even formerly sceptical governments are today in favour of self-regulation. Yet, support for Benvenisti's hypothesis might come from the case of the United Kingdom.

Peter Lewisch asks the author what governance rule should be used to achieve compliance, liability rules or due standards of behaviour. Thilo Marauhn questions the effectiveness of a weak ex-post evaluation and favours, instead, a code of conduct in combination with oversight. Stefan Oeter is sceptical about the role of self-regulation, which can be a way of avoiding even stronger government regulation. Thilo Marauhn describes a slow, gradual move towards government regulation, as self-regulation is increasingly seen sceptical.

Birgit Feldmann tries to distinguish the need for regulation depending on the initiator, which e.g., in case of piracy does not have to be the state. The author agrees that the initiator is decisive for the need for regulation. Dieter Schmidtchen points out the economic perspective that regulation should focus on enhancing the effective cooperation between publicly and privately owned firms. Finally, Florian Jeßberger poses the question whether the making of international law just tries to control excesses. 



\title{
Some Observations on the Economics of Comity
}

\author{
by \\ Christopher R. Drahozal*
}

\begin{abstract}
A. Introduction
Comity is the deference one State shows to the decisions of another State. As explained by the United States Supreme Court in Hilton v. Guyot:

"Comity," in the legal sense, is neither a matter of absolute obligation, on the one hand, nor of mere courtesy and goodwill, upon the other. But it is the recognition which one nation allows within its territory to the legislative, executive, or judicial acts of another nation, having due regard both to international duty and convenience and to the rights of its own citizens or of other persons who are under the protection of its laws. ${ }^{1}$
\end{abstract}

Comity is manifested in an array of judicial doctrines, such as the presumption against the extraterritorial application of statutes and the presumption in favor of recognition of foreign judgments. Comity does not require a State to defer in every case (it is not "a matter of absolute obligation"), but determining when comity requires deference poses difficult doctrinal and theoretical issues.

This paper offers some observations on the economics of comity in an attempt to provide insights into those issues. It first describes the (largely unsatisfactory) attempts to define comity and identifies the various judicial doctrines that are based on comity. Generalizing from the existing literature, which uses game theory (most commonly the prisoners' dilemma game) to analyze legal doctrines based on comity, the paper then sets out a basic and tentative economic analysis of comity. Comity often serves a cooperative function: courts rely on comity as the basis for doctrines that enhance cooperation with other States. In such cases, refusing to grant comity to a decision of

* John M. Rounds Professor of Law and Associate Dean for Research and Faculty Development, University of Kansas School of Law. I appreciated helpful comments from participants at the Annual Meeting of the Midwestern Association of Law and Economics, held at the University of Indiana-Bloomington, and at the Travemünde Symposium on Law \& Economics, in particular my commenter, Dieter Schmidtchen.

${ }^{1} 159$ U.S. 113, 163-64 (1895). 
another State constitutes defection from the cooperative solution. But if the original decision itself constitutes defection - such as a State opportunistically entering a judgment against a foreign citizen - refusing to grant comity would not be defection but would instead be an attempt to sanction the other State's defection. Thus, the central inquiry when a court decides whether to grant comity can be framed as whether the State decision being examined constitutes cooperation or defection. Further, given the uncertainty courts face in making such a determination, comity itself then can be seen as establishing a default presumption that a particular type of State decision constitutes cooperation (or, in cases in which courts refuse to grant comity, as a default presumption of defection).

The paper then argues that any rule a court adopts on the basis of comity should be treated as a default rule rather than a mandatory rule. The argument in favor of default rules over mandatory rules is a familiar one, and seems to apply well here. Thus, as U.S. and U.K. courts have held - but contrary to decisions of the European Court of Justice - comity concerns should not preclude a court specified in an exclusive forum selection clause from entering an anti-suit injunction against foreign court litigation. An arbitration clause, by comparison, provides a much weaker case for finding that the parties contracted around the comity-based default. Finally, the paper suggests possible avenues for future research: in particular, examining the importance of rentseeking and judicial incentives in the economics of comity.

One final note: my focus is principally (although not exclusively) on court cases from the United States because that is the legal system with which I am most familiar. But similar issues arise in other legal systems, and my hope is that the analysis here may help in understanding approaches from those legal systems as well.

\section{B. What is Comity?}

United States courts have repeatedly noted the difficulty of providing a workable definition of comity. In Laker Airways, Ltd. v. Sabena Belgian World Airlines, the D.C. Circuit stated that "[c]omity summarizes in a brief word a complex and elusive concept, the degree of deference that a domestic forum must pay to the act of a foreign government not otherwise binding on the forum." 2 The Second Circuit has described comity in equally general terms: comity is "concerned with maintaining amicable working relationships between nations, a shorthand for good neighborliness, common courtesy and

\footnotetext{
${ }^{2}$ Laker Airways, Ltd. v. Sabena Belgian World Airlines, 731 F.2d 909, 937 (D.C. Cir. 1984).
} 
mutual respect between those who labor in adjoining judicial vineyards." Consistent with these vague definitions, Michael D. Ramsey concludes that "there is no coherent generalized doctrine of 'comity' that informs how and when foreign acts are to be given effect in federal court." "4

Scholarly commentators have attempted to define the concept more precisely, but with only limited success. According to Eleanor Fox, "[c]omity is a horizontal, nation-to-nation concept, seeking - by reciprocal deference - to maximize the joint interests of the affected nations by splitting their differences or otherwise dissipating conflict in view of repeated interactions expected to occur." Joel Paul concludes that comity involves a balancing of "competing public and private interests in a manner that takes into account any conflict between the public policies of domestic and foreign sovereigns." But despite the greater precision of these formulations (at least compared to formulations by the courts), they remain vague in providing guidance as to how the doctrine should be applied.

European commentators have distinguished comity from what appears to be the broader notion of "mutual trust" under EU law. In a series of decisions dealing with application of the Council Regulation No. 44/2001, ${ }^{7}$ the European Court of Justice (ECJ) has held that the courts of one member State cannot enter an anti-suit injunction against an action brought in the courts of another member State, even if the action is brought in bad faith or in violation of a forum selection clause or arbitration agreement. ${ }^{8}$ As the ECJ explained in Erich Gasser GmbH v. MISAT Srl:

[T] he Brussels Convention is necessarily based on the trust which the Contracting States accord to each other's legal systems and judicial institutions. It is that mutual trust which has enabled a compulsory system of jurisdiction to be established, which all the courts within the purview of the Convention are required to respect....

${ }^{3}$ JP Morgan Chase Bank v. Altos Hornos de Mexico, S.A., 412 F.3d 418, 423 (2d Cir. 2005) (internal quotations omitted).

${ }_{5}^{4}$ Ramsey (1998), 895.

${ }^{5}$ Fox (2010), 269.

${ }^{6}$ Paul (1991), 4.

${ }^{7}$ Council Regulation No. 44/2001 of 22 Dec. 2000 on Jurisdiction and the Recognition and Enforcement of Judgments in Civil and Commercial Matters, 2001 O.J. (L 12) 1 (EC).

${ }^{8}$ Case C-185/07, Allianz SpA v. West Tankers Inc., 3 W.L.R. 696 (2009); Case C159/02, Turner v. Grovit, 2004 E.C.R. 1-3565; Case C-116/02, Erich Gasser GmbH v. MISAT Srl, 2003 E.C.R. 1-14693.

${ }^{9}$ Gasser, 2003 E.C.R. at 972 ; see also Turner, 2004 E.C.R. at 928 ("In so far as the conduct for which the defendant is criticised consists in recourse to the jurisdiction of the court of another Member State, the judgment made as to the abusive nature of that conduct implies an assessment of the appropriateness of bringing proceedings before a court of another Member State. Such an assessment runs counter to the principle of mutual trust ...."). 
So formulated, mutual trust goes beyond comity. Comity counsels for deference to a decision by another State, but it permits a court to refuse to defer under appropriate circumstances. Mutual trust, as applied by the ECJ, appears to be a "matter of absolute obligation."10 As stated by Thalia Kruger: "Mutual trust goes further than comity: it is the implication that the Member States of the European Union not only have respect, but also blind trust in each other's courts." ${ }^{11}$ Regardless of the surrounding circumstances, then, "mutual trust" requires a State to defer to the other.

\section{When Do Courts Use Comity?}

Rather than trying to develop a general definition of comity, it may be more helpful to identify the types of cases in which courts in one State show comity to decisions of other States. Table 1 sets out a classification scheme developed by William Dodge that usefully highlights the main uses of comity in U.S. law. ${ }^{12}$

Dodge distinguishes (along the vertical axis) "based on the foreign actor to whom deference is shown." Thus, "prescriptive comity" involves deference to foreign lawmakers, "adjudicatory comity" is deference to foreign tribunals, ${ }^{13}$ and "sovereign party comity" is deference to foreign sovereigns as litigants in a court proceeding. He then (along the horizontal axis) distinguishes between ways in which comity is used:

I distinguish between the operation of comity as a "principle of recognition" - that is, as a means of recognizing foreign law, foreign judgments, and foreign sovereigns as litigants - and the operation of comity as a "principle of restraint" - that is, as a means of restraining the reach of American law, the jurisdiction of American courts, and more specifically the jurisdiction of American courts over foreign sovereign defendants. ${ }^{14}$

Dodge then proceeds to identify a number of U.S. doctrines based in part on comity and to classify them according to his scheme.

This paper focuses on adjudicatory comity, and more specifically on two doctrines that Dodge classifies as involving adjudicatory comity (because the literature is relatively well developed as to those two doctrines). One is the

${ }^{10}$ See Hilton v. Guyot, 159 U.S. 113, 163-64 (1895).

${ }^{11}$ Kruger (2004), 1035; see also Hartley (2005), 823: "Under the Convention, the fact that a judgment was given in breach of a choice-of-court agreement is not a reason for refusing to enforce it. We must trust other courts."

${ }^{12}$ Dodge (2009), 3.

${ }^{13}$ According to Dodge (2009), 23: "To the extent these phrases [like 'judicial comity' or 'the comity of courts,' which others have used instead of 'adjudicatory comity,'] suggest by negative implication that other kinds of comity are not exercised by the courts, they are best avoided."

${ }^{14}$ Dodge (2009), 2. 
recognition of foreign judgments - whether and the extent to which courts from one State will give legal force to court judgments from another State. Dodge classifies the recognition of foreign judgments as involving the principle of recognition because courts are recognizing the judgment of a court in a foreign State. The other is anti-suit injunctions - whether and the extent to which courts from one State will enter an injunction directed at a party to a court action in another State ordering that party not to proceed with its suit. Dodge classifies anti-suit injunctions as involving the principle of restraint because courts that refuse to issue anti-suit injunctions because of comity are restraining the reach of American law.

Table 1: $\quad$ Uses of International Comity in the United States

\begin{tabular}{|c|c|c|}
\hline & $\begin{array}{l}\text { Principle of } \\
\text { Recognition }\end{array}$ & $\begin{array}{l}\text { Principle of } \\
\text { Restraint }\end{array}$ \\
\hline \multirow[t]{2}{*}{$\begin{array}{l}\text { Prescriptive } \\
\text { Comity }\end{array}$} & Conflict of laws & $\begin{array}{l}\text { Presumption against extraterrito- } \\
\text { riality }\end{array}$ \\
\hline & & $\begin{array}{l}\text { Balancing under Restatement } \\
\text { (Third) } \S 403\end{array}$ \\
\hline \multirow{6}{*}{$\begin{array}{l}\text { Adjudicatory } \\
\text { Comity }\end{array}$} & $\begin{array}{l}\text { Recognition of } \\
\text { foreign judgments }\end{array}$ & International comity abstention \\
\hline & & $\begin{array}{l}\text { Enforcement of forum selection } \\
\text { and arbitration clauses }\end{array}$ \\
\hline & & Reasonableness under Asahi \\
\hline & & Forum non conveniens \\
\hline & & Anti-suit injunctions \\
\hline & & $\begin{array}{l}\text { Foreign discovery under Aerospa- } \\
\text { tiale }\end{array}$ \\
\hline $\begin{array}{l}\text { Sovereign Party } \\
\text { Comity }\end{array}$ & $\begin{array}{l}\text { Privilege of } \\
\text { bringing suit }\end{array}$ & Foreign sovereign immunity \\
\hline
\end{tabular}

Not all jurisdictions recognize all of the doctrines identified by Dodge in Table 1. As one example, while courts in common law countries have the power to enter anti-suit injunctions, courts in civil law jurisdictions do not (as a gen- 
eral matter) issue such injunctions. ${ }^{15}$ Moreover, as noted above, the ECJ has ruled that member states within the EU - even common law jurisdictions that otherwise would permit the grant of anti-suit injunctions - may not issue such injunctions against parties litigating in the courts of other member states. ${ }^{16}$

\section{Comity, Cooperation, and Defection}

A common theme in discussions of comity is that comity promotes cooperation among States. Consistent with that theme, a number of scholars have used game theory to analyze rules based on comity principles. ${ }^{17}$ This part describes and expands on those analyses.

In the rest of this part, I follow Andrew Guzman and assume that States are "rational, self-interested, and able to identify and pursue their interests. ${ }^{18}$ Those interests are a function of state preferences, which are assumed to be exogenous and fixed. States do not concern themselves with the welfare of other states but instead seek to maximize their own gains or payoffs." As Guzman notes, these assumptions "are standard assumptions among social scientists and many international law scholars" and "[t]hey imply that states will only cooperate when doing so increases their own payoffs." 19

\section{Granting Comity as Cooperation}

The most common view treats comity-based deference to another State's decision as cooperative behavior. Conversely, when courts refuse to defer (not granting comity), they are defecting from the cooperative solution.

The scholarly literature on the recognition of foreign judgments illustrates this view. The usual starting point is the assumption that mutual recognition of judgments is the optimal solution - that States in the aggregate benefit most if they recognize each other's judgments. But individually, each State prefers that judgments in favor of its nationals be recognized and that judgments against its nationals be denied recognition. Based on these assumptions, for-

\footnotetext{
${ }^{15}$ Lenenbach (1993), 273.

${ }^{16}$ See sub-part B.

${ }^{17}$ Rotem (2010); Whincop (1999); Lee (2006); Stevens (2002); Brand (1995); see also Dodge (2002, 220-26) (using prisoners' dilemma game to analyze prescriptive comity).

${ }^{18}$ Guzman (2008), 17.

${ }^{19}$ The analysis here considers only simple, two-party games - focusing on the behavior of States - as does the existing literature. A more sophisticated analysis would use dynamic games with both businesses and States as actors to examine how businesses respond to different comity-based rules. Such an analysis is beyond the scope of this paper.
} 
eign judgment recognition can be modeled as a prisoners' dilemma game. Table 2 shows the payoffs.

State A prefers to defect regardless of whether State B cooperates or defects. Likewise, State B prefers to defect regardless of whether State A cooperates or defects. Even though collectively they would be better off cooperating - i.e., recognizing the other's judgments on the basis of comity - the equilibrium outcome is that both defect.

Table 2: $\quad$ Prisoner's Dilemma Game

\begin{tabular}{llcc}
\hline & & \multicolumn{2}{c}{ State B } \\
\hline \multirow{3}{*}{ State A } & & Cooperate & Defect \\
& Cooperate & 4,4 & 0,6 \\
& Defect & 6,0 & 2,2 \\
\hline
\end{tabular}

As is well known, this outcome holds only in the case of a one-shot game. In an iterated prisoners' dilemma game, States may be able to reach the optimal solution by cooperating (perhaps using a tit-for-tat strategy and enforcing foreign judgments only on the basis of reciprocity). ${ }^{20}$ The broader point for the economics of comity is that on these assumptions, granting comity by recognizing foreign judgments is the cooperative outcome. Refusing to grant comity (refusing to recognize foreign judgments) is defection.

An alternative view is that cooperation might in fact be individually rational for a State - that is, the game might be an assurance game or "stag hunt" rather than a prisoners' dilemma. ${ }^{21}$ If, for example, the cost savings of not relitigating the dispute resolved in a foreign judgment are sufficiently high, or "[i]f judgment enforcement is appropriately considered an issue of free movement of economic rights" such that the theory of comparative advantage applies, then a State may individually have the incentive to cooperate rather than defect. ${ }^{22}$ The payoffs for such a game are shown in Table 3 .

Table 3: $\quad$ Assurance or "Stag Hunt" Game

\begin{tabular}{llcc}
\hline & & \multicolumn{2}{c}{ State B } \\
\hline \multirow{3}{*}{ State A } & Cooperate & 4,4 & Defect \\
& Defect & 2,0 & 0,2 \\
& & & 3,3 \\
\hline
\end{tabular}

An assurance game differs from a prisoners' dilemma game because it is no longer the case that each State individually has the incentive to defect. Instead, the game has dual equilibria (cooperate/cooperate and defect/defect)

\footnotetext{
${ }^{20}$ Rotem (2010).

${ }^{21}$ Brand (1995); Whincop (1999); Rotem (2010).

${ }^{22}$ Brand (1995), 625.
} 
and the problem becomes one of coordination. In this setting, comity might be "cheap talk" that enables States to coordinate on the optimal solution of cooperation. ${ }^{23}$

This usual analysis implicitly assumes that all foreign judgments are ones that should be enforced. But what if the foreign judgment is not one that normatively should be enforced? What if the entry of judgment in the first place is an opportunistic attempt by a State to benefit its own citizen at the expense of a citizen of a foreign State? If so, then recognizing that judgment would be rewarding defection by the State that entered the judgment. By refusing to recognize the opportunistic foreign judgment, a State is not defecting but rather is sanctioning (or at least not rewarding) defection by the other State. ${ }^{24}$ On this view, the grounds for denying recognition of foreign judgments can be understood as identifying circumstances in which denying recognition would be sanctioning the other State's defection rather than itself being defection.

\section{Refusing Comity as a Sanction for Defection}

Not all cases in which a court declines to grant comity necessarily involve defection by that court. To the contrary, if the foreign State itself is defecting, a refusal to grant comity (refusing to defer to the other State's action) can be a form of sanction imposed on the defecting State..$^{25}$ One example, noted above, is when a court refuses to recognize a foreign judgment on one of the standard grounds. ${ }^{26}$ Another might be when a court enters an anti-suit injunction against litigation in a foreign court. The court of appeals in Laker Airways stated the point well:

When the foreign act is inherently inconsistent with the policies underlying comity, domestic recognition could tend either to legitimize the aberration or to encourage retaliation, undercutting the realization of the goals served by comity. ${ }^{27}$

With this latter example, examining the economics of comity provides insight into when a grant of an anti-suit injunction might be appropriate.

${ }^{23}$ McAdams (2009), 233-35.

${ }^{24}$ Whincop (1999), 426 (" $[\mathrm{I}] \mathrm{t}$ is no surprise that the common law required that the judgment court be jurisdictionally competent in a common law sense. This permits the recognising court to deter cheating by credibly threatening punishment on a tit-for-tat (case-by-case) basis.").

${ }^{25}$ Whincop (1999), 426 ("Courts can perform these disciplinary functions in another way - by grant of an anti-suit injunction restraining a plaintiff from invoking the exorbitant jurisdiction.").

${ }^{26}$ See sub-part D(I).

${ }^{27}$ Laker Airways, Ltd. v. Sabena Belgian World Airlines, 731 F.2d, 909, 937 (D.C. Cir. 1984). 
Commentators have identified three circumstances in which courts are willing to grant anti-suit injunctions:

[C]ourts have directed anti-suit injunctions at proceedings in other jurisdictions in order to achieve one of three broadly stated objectives: the prevention of highly inconvenient or vexatious litigation, the vindication of a prior and independent obligation not to sue, and preservation of the enjoining court's own jurisdiction or other local policy-based need to forestall foreign judicial proceedings. ${ }^{28}$

Taking them in reverse order: the third objective - preserving the enjoining court's own jurisdiction - reasonably could be construed as seeking to identify cases in which the foreign court is acting opportunistically (defecting). The second objective - vindicating a prior and independent obligation not to sue is addressed in sub-part $\mathrm{E}$.

The first objective - preventing inconvenient or vexatious litigation - is the most difficult to evaluate. This objective seems to focus on the behavior of the parties rather than on the behavior of the foreign court. As such, it does not itself provide a reason to believe that the foreign court is acting opportunistically. On the other hand, if the foreign court is facilitating the vexatious litigation, that fact would provide evidence of opportunistic behavior such that comity would not preclude issuing an anti-suit injunction. ${ }^{29}$ But what if the party is merely taking advantage of a structural characteristic of the foreign court system that makes the litigation vexatious (such as lengthy delays in resolving cases, so that even if the foreign court sought to restrain the allegedly vexatious litigation it would take years before it could do so) $?^{30}$ In such a case, my tentative view is that the failure or inability to provide sufficient procedural protections for foreign litigants could be viewed as defection by the foreign State such that comity would not preclude the grant of an anti-suit injunction.

\section{Comity and Uncertainty}

The preceding two sections assume that a court can determine with certainty whether a foreign State is acting opportunistically. But that, of course, is not

\footnotetext{
${ }^{28}$ Bermann (1990), 608.

${ }^{29}$ Although the case ultimately was decided based on the existence of an exclusive forum selection clause, the facts of $E \& J$ Gallo Winery v. Andina Licores S.A., 446 F.3d 984 $\left(9^{\text {th }}\right.$ Cir. 2006) - in which the foreign court appointed a guardian for the American company without giving it notice - provide a possible illustration of opportunistic behavior by the foreign State.

${ }^{30}$ Hartley (2005), 815-21.
} 
the case. Whenever a court decides whether to grant comity to the decision of a foreign State, it is deciding in the absence of complete information. ${ }^{31}$

As such, comity can be seen as reflecting a court's default presumption as to whether foreign States are likely to cooperate or defect. Accordingly, if the court is unable to determine whether to defer using the usual doctrinal means (that is, using proxies to identify cooperation or defection), it then grants comity if its default presumption is that foreign States likely are cooperating or refuses to grant comity if its default presumption is that foreign States likely are defecting.

The competing approaches of the U.S. circuit courts to the issuance of antisuit injunctions illustrate the point. ${ }^{32}$ Courts that follow the so-called "conservative" standard are reluctant to grant anti-suit injunctions, relying heavily on comity concerns as the rationale. Courts following the "liberal" standard are much more willing to grant anti-suit injunctions and place less weight on comity. Other courts follow an intermediate standard that takes a middle ground between the two extremes. By comparison, as noted above, the ECJ has construed Brussels Regulation 44/2001 as based on "mutual trust" such that the courts of one EU member State may never enter an anti-suit injunction against litigation in the courts of another EU member State. ${ }^{33}$

Courts following the conservative standard (those less willing to grant antisuit injunctions) adopt the default presumption that foreign States likely are cooperating, while those following the liberal standard (those more willing to grant anti-suit injunctions) adopt the default presumption that foreign States likely are defecting. The ECJ's "mutual trust" standard, by comparison, is a conclusive presumption that other EU member states are cooperating. This distinction among the various standards then can be evaluated empirically: if foreign lawsuits tend to reflect opportunism by the foreign States in certain circumstances, the liberal standard is more appropriate; if foreign lawsuits tend not to reflect opportunism by foreign States, the conservative standard is more appropriate; and if such suits never reflect opportunism by foreign States (in the case of EU member States), then the ECJ approach is more appropriate. ${ }^{34}$

${ }^{31}$ I appreciate Dieter Schmidtchen for highlighting this issue.

${ }^{32}$ Ali et al. (2008).

${ }^{33}$ See sub-part B.

${ }^{34}$ Another consideration, of course, is administrative costs, which I do not analyze at length here. But if the likelihood of State opportunism (i.e., defection) is sufficiently low, and the costs of identifying such opportunism sufficiently high, a "mutual trust" standard may be appropriate even if there is some non-zero likelihood of opportunism. 


\section{E. Comity and Contract}

Many cases raising issues of comity involve transnational contracts, and many of those contracts include either forum selection clauses or arbitration clauses. ${ }^{35}$ This part considers how those contract provisions affect the economics of comity. It argues that any rule courts adopt on the basis of comity should be treated as a default rule that parties can contract around rather than as a mandatory rule, and then analyzes whether and when forum selection clauses and arbitration clauses contract around those default rules. ${ }^{36}$

\section{Comity and Default Rules}

The argument in favor of contractual default rules is a familiar one.$^{37}$ Default rules avoid locking parties in to inefficient outcomes by permitting them to contract for a different rule that would make the parties jointly better off. Only when contracts give rise to significant externalities (which seems unlikely here) or when one party to a contract needs to be protected from a bad bargain (again unlikely given that parties to international commercial contracts are usually sophisticated parties capable of protecting themselves) is a mandatory rule required. ${ }^{38}$

In this context, comity considerations would at most be relevant for establishing a default rule setting out how the courts of one State will deal with the courts of another State. Whatever that rule is - such as that the court will recognize foreign court judgments or will issue or not issue an anti-suit injunction - it would only be a default rule. If the parties contracted around the default rule, a court that enforced the parties' contract would not be defecting, since its decision was in accord with the parties' bargain. But a State that refused to enforce or abide by the contract would be defecting, such that an antisuit injunction to enforce the contract would be consistent with comity.

Assuming that comity establishes default rules rather than mandatory rules, how do parties contract around those defaults? The next two sections address forum selection clauses (both exclusive and nonexclusive) and arbitration clauses.

${ }^{35}$ Drahozal \& Ware (2010), 433 (finding arbitration clauses in $71 \%$ of sample of international joint venture agreements); Eisenberg \& Miller (2009), 1503-05 (finding forum selection clause in $39 \%$ of sample of corporate transaction and lending contracts).

${ }^{36}$ This approach is analogous to one I have suggested previously for determining when a court should enforce an arbitration award that has been vacated in the arbitral seat. Drahozal (2000). Several commentators have similarly argued for enforcement of choice-of-law agreements as a way of contracting around default rules. O'Hara \&. Ribstein (2000); Whincop \& Keyes (1997).

${ }^{37}$ Ayres \& Gertner (1989); Ayres \& Gertner (1992); Ayres (1998).

${ }^{38}$ Ayres \& Gertner (1989); Ayres (1998). 


\section{Comity and Forum Selection Clauses}

Courts should treat an exclusive forum selection clause as contracting around a comity-based default rule. By agreeing to an exclusive forum selection clause, the parties agree to have a particular court as the proper - and only proper - forum for resolving their dispute. The court chosen by the parties in the forum selection clause should not be constrained by comity principles from resolving the parties' dispute.

The United States Court of Appeals for the Ninth Circuit took an approach consistent with the suggestion here in E\&J Gallo Winery v. Andina Licores S.A. ${ }^{39}$ In Gallo, a California winery entered into a distributorship agreement with an Ecuadorian wine distributor. The agreement included a clause specifying California courts as the exclusive forum for dispute resolution. Despite the forum selection clause, the Ecuadorian distributor filed suit in Ecuador challenging the legality of the distributorship agreement under local law. The California winery sought to enjoin the distributor from pursuing its suit in Ecuador, which the district court denied based on comity considerations.

The Ninth Circuit reversed and held that the injunction should have been granted. When the parties have contracted for an exclusive forum for resolving their dispute, actions by that forum to do so are consistent with comity. As the court of appeals explained:

In a situation like this one, where private parties have previously agreed to litigate their disputes in a certain forum, one party's filing first in a different forum would not implicate comity at all. No public international law issue is raised in this case. There is no indication that the government of Ecuador is involved in the litigation. Andina is a private party in a contractual dispute with Gallo, another private party. The case before us deals with enforcing a contract and giving effect to substantive rights. This is no way breaches norms of comity. ${ }^{40}$

Stated otherwise, whatever rule that comity might have required was only a default rule, which the parties contracted around by agreeing to an exclusive forum selection clause.

British courts likewise have held that they have the authority to enter antisuit injunctions against foreign litigation when the parties have agreed to the U.K. as the exclusive forum for resolving disputes. ${ }^{41}$ By comparison, the ECJ has concluded that Brussels Regulation 44/2001 and its underlying principle of "mutual trust" preclude one EU member State from issuing an anti-suit

${ }^{39} 446$ F.3d 984 ( $9^{\text {th }}$ Cir. 2006).

${ }^{40}$ Ibid. at 994.

${ }^{41}$ Donohue v. Armco Inc., [2002] 1 Lloyd's Rep. 425, 432-33 (H.L.); Continental Bank v. Aeakos Compania Noviera SA, [1994] 1 Lloyd's Rep. 505, 512 (Eng. C.A.). 
injunction against litigation in another EU member State. ${ }^{42}$ The analysis here counsels against such an approach. So applied, mutual trust makes the rule a mandatory rule rather than a default rule; regardless of what the parties' contract provides, injunctive relief is not available. Instead, the parties should be permitted to contract for the availability of an anti-suit injunction.

By comparison, a nonexclusive forum selection clause should not be construed as contracting around comity, in its entirety at least. Unlike an exclusive forum selection clause, a nonexclusive forum selection clause merely identifies a permissible court in which the parties can resolve their dispute. It does not specify the only court in which the parties can resolve their dispute. Accordingly, comity considerations in deciding among permissible courts remain in play.

\section{Comity and Arbitration Clauses}

The analysis is less clear for arbitration clauses. By including an arbitration clause in their contract, the parties agree to have a private judge resolve any dispute that may arise. Litigation in a foreign court over the dispute would be inconsistent with the arbitration clause, as with an exclusive forum selection clause. (Indeed, litigation over the dispute in any court would be inconsistent with the arbitration clause.) But unless the arbitration clause also includes an exclusive forum selection clause - providing that any court proceedings with respect to the arbitration must take place only in a specified court - the arbitration clause itself does not in every case determine the proper forum in which a court action related to the arbitration should be brought. As a result, an arbitration clause contracts around some comity-based default rules but not others.

The State chosen as the arbitral seat - the legal or juridical "home" of the arbitration - plays a central role in connection with the arbitration proceeding. Parties either agree on the seat directly or by agreeing on a provider (which selects the seat). The arbitral seat is the sole jurisdiction ${ }^{43}$ with the authority to vacate an award or to supervise an ongoing arbitration proceeding. ${ }^{44}$ Thus, by agreeing on the seat, the parties are implicitly agreeing on the exclusive court to serve those functions in connection with the arbitration. But the seat is not

${ }^{42}$ Case C-185/07, Allianz SpA v. West Tankers Inc., 3 W.L.R. 696 (2009); Case C159/02, Turner v. Grovit, 2004 E.C.R. 1-3565; Case C-116/02, Erich Gasser GmbH v. MISAT Srl, 2003 E.C.R. 1-14693.

${ }^{43}$ With one exception: when the parties have agreed in their arbitration clause that the arbitration law of another jurisdiction governs. Such contract provisions are exceedingly rare. Karaha Bodas Co. v. Perusahaan Pertambangan Minyak Dan Gas Bumi Negara, 364 F.3d 274, 291 (5th Cir. 2004).

${ }^{44}$ Restatement (Third) of the U.S. Law of International Commercial Arbitration $\S 4-2$ $\&$ reporters' note to Comment b (2012). 
the sole jurisdiction with authority to enforce the arbitration agreement by compelling parties to arbitrate, ${ }^{45}$ nor is it the sole jurisdiction in which an arbitration award can be enforced. ${ }^{46}$ As to those functions, the choice of the seat acts more like a nonexclusive forum selection clause: it identifies a permissible court but not an exclusive court. Accordingly, arbitration clauses contract around comity only in part.

\section{F. Comity, Rent-Seeking, and Judicial Incentives}

Underlying this paper are two additional (and so far implicit) assumptions: first, that the State's preferences for whether to cooperate or defect accurately reflect the preferences of its citizens; and, second, that judges accurately reflect the preferences of the State in their decisions. Both assumptions are subject to question.

First, the State's preferences may be the result of rent-seeking behavior by businesses, lawyers, ${ }^{47}$ and others within the State (such as prospective arbitrators $^{48}$ ). The concentrated economic interests of such parties may result in State preferences for cooperation or defection that are less than optimal for the State as a whole.

Second, the incentives of judges in a State may result in decisions that diverge from the preferences of the State itself. The extent of the divergence depends on the means by which judges are selected and the model of the judicial utility function used. Elected judges (like legislators) may be more subject to rent-seeking behavior than appointed judges. ${ }^{49}$ Appointed judges may make decisions based on their own ideological views, desire for promotion, or preference for leisure. ${ }^{50}$

Future research could usefully examine the effect of rent-seeking and judicial incentives on the economics of comity.

\section{G. Conclusion}

This paper has offered some tentative insights into the economics of comity. First, comity can serve a cooperative function by providing the basis for doc-

${ }^{45}$ Born (2009), 306.

${ }^{46}$ Drahozal (2000), 468-70.

${ }^{47}$ Whincop (1999) 421 ("If lawyers are an effective political interest group in the formulation of a jurisdiction's private international law, they may have incentives to favour non-recognition by their states. A jurisdiction that refuses to enforce foreign judgments arguably increases the incentive of plaintiffs to choose it as a forum.").

${ }^{48}$ Drahozal (2005).

${ }^{49}$ Hansen (1999).

${ }^{50}$ Posner (1993). 
trines that enhance cooperation with other States. On this view, a State that refuses to grant comity is defecting rather than cooperating. But if the original decision itself constitutes defection, refusing to grant comity is not defection but is instead an attempt to sanction the other State's defection. Thus, a court's decision whether to grant comity can be framed as based on whether the State decision being examined constitutes cooperation or defection. Second, given the uncertainty courts face in determining whether a foreign State is cooperating or defecting, comity itself can be seen as establishing a default presumption that a particular type of State decision constitutes cooperation (or, in cases in which courts refuse to grant comity, as a default presumption of defection). Third, rules derived from comity principles should be treated as default rules rather than mandatory rules. Thus, as U.S. and U.K. courts have held - but contrary to decisions of the European Court of Justice - comity concerns should not preclude a court specified in an exclusive forum selection clause from entering an anti-suit injunction against foreign court litigation. Finally, the paper suggests examining the importance of rent-seeking and judicial incentives as possible avenues for future research on the economics of comity.

\section{Bibliography}

Arif, A., Nesbitt, K., and Wessel, J., (2008), Anti-Suit Injunctions in Support of International Arbitration in the United States and the United Kingdom, International Arbitration Law Review, 12-19.

Ayres, I., (1998), Default Rules for Incomplete Contracts, in The New Palgrave Dictionary of Economics and the Law, Peter Newman, Editor, Macmillan Reference, London, Vol. 1, 585-90.

Ayres, I. and Gertner, R., (1989), Filling Gaps in Incomplete Contracts: An Economic Theory of Default Rules, Yale Law Journal, Vol. 99, 87-130.

Ayres, I. and Gertner, R., (1992), Strategic Contractual Inefficiency and the Optimal Choice of Legal Rules, Yale Law Journal, Vol. 101, 729-73.

Bermann, G. B., (1990), The Use of Anti-Suit Injunctions in International Litigation, Columbia Journal of Transnational Law, Vol. 28, 589-631.

Brand, R. A., (1995), Recognition of Foreign Judgments as a Trade Law Issue: The Economics of Private International Law, in Economic Dimensions in International Law, Jagdeep S. Bhandari and Alan O. Sykes, Editors, Cambridge University Press, Cambridge, $592-641$.

Dodge, W. S., (2002), Breaking the Public Law Taboo, Harvard International Law Journal, Vol. 43, 161-235.

Dodge, W. S., (2009), International Comity in American Courts, 1-51, available at http://www.asil.org/files/dodge.pdf.

Drahozal, C. R., (2000), Enforcing Vacated International Arbitration Awards: An Economic Approach, American Review of International Arbitration, Vol. 11, 451-479. 
Drahozal, C. R., (2005), Arbitrator Selection and Regulatory Competition in International Arbitration Law, in Towards a Science of International Arbitration: Collected Empirical Research, Christopher R. Drahozal and Richard W. Naimark, Editors, Kluwer Law International, The Hague, 167-86.

Drahozal, C. R. and Ware, S. J., (2010), Why Do Businesses Use (and not Use) Arbitration Clauses?, Ohio State Journal on Dispute Resolution, Vol. 25, 433-76.

Eisenberg, T. and Miller, G. P., (2009), The Flight to New York: An Empirical Study of Choice of Law and Choice of Forum Clauses in Publicly-Held Companies' Contracts, Cardozo Law Review, Vol. 30, 1475-1512.

Fox, E. M., (2011), Antitrust Without Borders: From Roots to Codes to Networks, in Cooperation, Comity and Competition, Andrew T. Guzman, Editor, Oxford University Press, Oxford, 269-85.

Hanssen, F. A., (1999), The Effect of Judicial Institutions on Uncertainty and the Rate of Litigation: The Election Versus Appointment of State Judges, Journal of Legal Studies, Vol. 28, 205-32.

Hartley, T. C., (2005), The European Union and the Systematic Dismantling of the Common Law of Conflict of Laws, International \& Comparative Law Quarterly, Vol. $54,813-28$.

Kruger, T., (2004), The Anti-Suit Injunction in the European Judicial Space: Turner v. Grovit, International \& Comparative Law Quarterly, Vol. 53, 1030-40.

Lee, S., (2006), Game of Foreign Judgment Recognition, Asia Law Review, Vol. 3, 101-39.

Lenenbach, M., (1998), Antisuit Injunctions in England, Germany and the United States: Their Treatment Under European Civil Procedure and the Hague Convention, Loyola of Los Angeles International \& Comparative Law Journal, Vol. 20, 257-323.

McAdams, R. H., (2009), Beyond the Prisoners' Dilemma: Coordination, Game Theory, and Law, Southern California Law Review, Vol. 82, 209-58.

O'Hara, E. A. and Ribstein, L. E., (2000), From Politics to Efficiency in Choice of Law, University of Chicago Law Review, Vol. 67, 1151-32.

Paul, J. R., (1991), Comity in International Law, Harvard International Law Journal, Vol. 32, pp. 1-79.

Posner, R. A., (1993), What Do Judges and Justices Maximize? (The Same Thing Everybody Else Does), Supreme Court Economic Review, Vol. 3, 1-41.

Ramsey, M. D., (1998), Escaping "International Comity", Iowa Law Review, Vol. 83, 893-952.

Rotem, Y., (2010), The Problem of Selective or Sporadic Recognition: A New Economic Rationale for the Law of Foreign Country Judgments, Chicago Journal of International Law, Vol. 10, 505-37.

Stevens, S., (2002), Commanding International Judicial Respect: Reciprocity and the Recognition and Enforcement of Foreign Judgments, Hastings International \& Comparative Law Review, Vol. 26, 115-58.

Whincop, M., (1999), The Recognition Scene: Game Theoretic Issues in the Recognition of Foreign Judgments, Melbourne University Law Review, Vol. 23, 416-39.

Whincop, M. and Keyes, M., (1997), Putting the "Private" Back into Private International Law: Default Rules and the Proper Law of the Contract, Melbourne University Law Review, Vol. 21, 515-43. 


\title{
Comment on Christopher R. Drahozal
}

\author{
The Economics of Comity
}

by

\author{
Dieter Schmidtchen
}

\begin{abstract}
A. Overview
Comity is one of the important governing principles underlying international law. In very general terms, comity can be defined as a respect shown by one state to foreign lawmakers ("prescriptive comity", Dodge 2009), foreign tribunals ("adjudicatory comity", Dodge 2009) and foreign sovereigns as litigants in a court proceeding. ("sovereign party comity", Dodge 2009). Since comity does not require deference of a State in every case, "determining when comity requires deference poses difficult doctrinal and theoretical issues" (Drahozal 2012: 1). By examining the economics of comity, Drahozal hopes to provide some insight into those issues (Drahozal 2012: 1).

The paper focuses on adjudicatory (judicial) comity. It distinguishes between two ways in which judicial comity is used: On the one hand, it can operate as a principle of recognition and enforcement of foreign judgments, ${ }^{1}$ on the other hand it can operate as a principle of restraining the reach of jurisdiction of home courts, if an issue is already being tried in a court of another jurisdiction. As for the latter principle the paper discusses anti-suit injunctions. One might call - following Lee - the principle of recognition and enforcement "active comity" and the principle of restraint "passive comity" (Lee 2006: 110).
\end{abstract}

\footnotetext{
${ }^{1}$ But note: "States have valid reasons to deny foreign judgments the same force they grant their own judgments since the foreign procedure may be viewed as deficient, or the outcome of the foreign litigation may be viewed as objectionable" (Michaels 2009: 1, para. 1).
} 
Looking at comity as "the basis for doctrines that enhance cooperation with other states" (Drahozal 2012: 1) the central question is whether a "State decision being examined constitutes cooperation or defection" (Drahozal 2012: 1).

Following Guzman (2008) States are assumed to be "rational, selfinterested, and able to identify and pursue their interests. Those interests are a function of state preferences, which are assumed to be exogenous and fixed. States do not concern themselves with the welfare of other states but instead seek to maximize their own gains or payoffs" (Drahozal 2012: 6). There are two other assumptions underlying the paper: "first, that the State's "preferences for whether to cooperate or defect accurately reflect the preferences of its citizens"; and, second, that judges accurately reflect the preferences of the State in their decisions" (Drahozal 2012: 14). As mentioned: "Both assumptions are subject to question" (Drahozal 2012: 14). Rent-seeking behaviour by businesses, lawyers or prospective arbitrators "may result in State preferences for cooperation or defection that are less than optimal for the State as a whole" (Drahozal 2012: 14). The incentives of judges might also be misaligned, causing decisions not in line with the preferences of the State itself: "Elected judges (like legislators) may more subject to rent-seeking behaviour than appointed judges. Appointed judges may make decisions based on their own ideological views, desire for promotion, or preference for leisure" (Drahozal 2012: 14).

Under the heading "comity and cooperation", the paper presents two different games. Following the existing game theoretic literature on the topic, the interaction of States is modelled as a two-player prisoners' dilemma game or, alternatively, as an assurance or "stag hunt" game, with each player having two strategies: cooperate and defect.

Finally, discussing forum selection clauses and arbitration clauses, the paper argues that "comity-based rules should be treated as default rules rather than mandatory rules" (Drahozal 2012: 1).

\section{B. Discussion}

This is an interesting and thought-provoking paper which addresses important aspects of comity. Since the economic analysis of the topic is still in its infancy, the paper is likely to be welcomed.

The arguments in the paper are well presented and it provides new insights into the economics of comity. I largely agree with what is said in the paper. Nevertheless, I would like to make some additional remarks that will mainly be of a complementary character and might be relevant for future research. 
1. The cooperative function of comity is at the heart of Drahozal's paper: "Comity often serves a cooperative function: courts rely on comity as the basis for doctrines that enhance cooperation with other States" (Drahozal 2012: 1). Several questions come to mind:

Positive question: Is comity considered by lawyers and judges in rendering their legal judgment a bright line rule, a vague standard, a policy or a kind of Dworkinean principle ("optimization precept")?²

If comity were considered a rule, in the sense law and economic scholars define the term, "mutual trust" under EU law would - contrary to what is claimed in the paper (Drahozal 2012:3) - not go beyond comity. Mutual trust simply reflects the comity norm which manifests itself in EU law. By the way, comity as a bright line rule is similar to a per-se rule in antitrust; and comity as a standard or Dworkinian principle looks like a rule-ofreason.

Normative question: How should comity be considered? A bright line rule, a standard, a policy or a Dworkinian principle?

Of course, the answer depends on the goals comity should help to realize. A pertinent economic goal would be maximizing the joint wealth of the nations.

Does a concept of comity help identifying cooperative or defective behaviour?

Maybe it does. But as an economist I would hold that we don't need it if we have clearly defined common interests of the community of States.

Do we need comity in order to explain why States behave cooperatively?

As an economist I would say no. Relying on it is pointless. At least if we look at matters from the point of view of an iterated prisoners' dilemma game. If the strategy of cooperation is payoff maximizing than States will cooperate. If not they will defect.

Thus, if we want to understand why States cooperate or defect it suffices to look at the game that States play and derive the equilibria. I suspect

\footnotetext{
${ }^{2}$ Dworkin, in criticizing H.L.A. Hart's position of legal positivism, defines the terms "policy" and "principle" as follows: "I call a 'policy' that kind of standard that sets out a goal to be reached, generally an improvement in some economic, political, or social feature of the community. I call a 'principle' a standard that is to be observed, not because it will advance or secure an economic, political, or social situation deemed desirable, but because it is a requirement of justice or fairness or some other dimension of morality" (Dworkin 1977: 22). Robert Alexy further elaborates on Dworkin's distinction: "By contrast [with the strict nature of rules in the positivistic sense], principles are optimizing commands. As such, they are norms commanding that something be realized to the greatest possible extent relative to the factual and legal possibilities at hand. This means that principles can be realized to varying degrees and that the commanded extent of their realization is dependent on not only factual potential but also legal potential" (Alexy 2002: 70).
} 
that legal scholars need the concept of comity in order to explain matters which economists explain with the help of game theoretical tools.

2. Things look different if we assume that the game States play is an assurance or "stag hunt" game. Reasons are mentioned in the paper (Drahozal 2012: 7). Those games have several equilibria and the question arises how to coordinate on the efficient equilibrium. Here comity might serve as an equilibrium selection device. As mentioned in the paper: "(C)omity might be 'cheap talk' that enables States to coordinate on the optimal solution of cooperation" (Drahozal 2012: 8).

But note: Neither the "stag hunt" game nor the prisoners' dilemma game delivers an answer to the question whether a State's behaviour is actually cooperative or defective.

How to get an answer?

There are two avenues to find an answer: One utilitarian and one contractarian.

The focal point of the utilitarian approach is the maximization of the States' joint payoffs resulting from an optimal international division of labour. A cooperative strategy maximizes the joint payoffs; a defective strategy does not.

The contractarian approach results in so-called standard grounds legitimizing refusal of recognition and enforcement of a foreign judgment. Hence, we have a new game concerned with the problem of determining generally accepted grounds. May be that international conventions - contracts among States (see Michaels 2009) - indicate the solution to these games. ${ }^{3}$

Clearly, both the content and the formation of conventions is an important topic for the economic analysis of comity, although I doubt, whether a recourse to the comity concept itself helps to determine the standard grounds.

3. What is often overlooked in the game-theoretically inspired literature on comity, but explicitly dealt with in the paper, is an implicit assumption: "all foreign judgments are ones that should be enforced" (Drahozal 2012: $8)$.

But what if the judgment is the result of a defection by the State entering the judgment? Of course, as is rightly mentioned in the paper: "By refusing to recognize the opportunistic foreign judgment, a State is not defecting but rather is sanctioning (or at least not rewarding) defection by the other State. On this view, the grounds for denying recognition of foreign judgments can be understood as identifying circumstances in which deny-

\footnotetext{
${ }^{3}$ But note that international conventions are incomplete contracts opening up new avenues for opportunistic behaviour.
} 
ing recognition would be sanctioning the other State's defection rather than itself being defection" (Drahozal 2012: 8).

Obviously, the games presented in the literature on comity do not deal with this important issue. Information is assumed to be symmetric and complete. Neither party can commit errors. But nobody is perfect. For example, a court rendering a judgment might truly believe that it is of a good quality, i.e., in accordance with comity, but actually it is not. Or the recognition court believes that the decision being examined is defective, whereas it is actually cooperative.

What we need are dynamic games of asymmetric and incomplete information, which require for their solution more sophisticated equilibrium concepts than simple Nash. Those games exist in the literature (see, for example, Osborne 2004) but are not applied to the comity area, yet.

4. In the literature, in particular the literature applying the prisoners' dilemma framework, we can find the opinion that becoming a recognition haven, i.e., being reluctant to defer to the decisions of another state, could be a rational strategy of a State.

The reasoning runs as follows: Becoming a recognition haven pays off, since potential defendants will move assets to this state which furthers its economic prosperity. With competition between civil justice systems this incentive sets off a race to the bottom. Wagner (2011: 28-30) shows that this might happen with unilateral competition between civil justice systems. In unilateral competition only plaintiffs represent the demand side in the market for dispute resolution (Wagner 2012: 11). However, with bilateral competition, i.e., competition in which both parties to a dispute represent the demand side, things look different.

Consider, for example contract disputes. Conjectures or assumptions of a race to the bottom neglect the incentives of sophisticated international traders. The ex ante interests of the parties to a contract is to maximize joint benefit from their contract. From this it follows that parties are interested in socially optimal courts, i.e., courts which are considered by both sides as delivering accurate recognition and enforcement (see Wagner 2011: 33-36). Thus, instead of having a race to the bottom, we would have a race to the top.

At the minimum, the potentially disadvantaged party - the judgment creditor - will try to readjust the terms of trade or reject trading at all with a party profiting from the defective behaviour of a State. Another possibility is reference to a forum selection clause as a means expanding the recognition of judgments (Whincop 1999: 15). Still another possibility might be to get an "anti-suit injunction restraining a plaintiff from invoking the exorbitant jurisdiction" (Whincop 1999: 14)

To analyse these issues properly, we would have to set up a 4-player game, with 2 trading parties and at least 2 states. 
Here is a suggestion how to improve insights into the working properties of comity:

Set up a 2-stage game with a contract stage, a litigation stage and an enforcement stage. The parties will look ahead and reason back when concluding a contract and agreeing on the terms of trade (see Schmidtchen et al. 2012).

5. How important is the adjudicatory comity issue for international commerce? Since the amount of international transactions (movement of goods, capital and persons across borders), is growing exponentially, the likelihood of legal disputes might increase; which, in turn, might increase the demand for recognition and enforcement of foreign judgments (Michaels 2009). ${ }^{4}$ It is my feeling that legal scholars are used to overemphasize the relevance of the issue.

I should like to illustrate this by drawing on the New Institutional Economics of International Transaction and empirical evidence. Theory and empirical evidence suggest that rational parties to international transactions will not rely on court ordering alone to overcome contractual hazards in international trade, but will additionally apply means of private ordering.

Private ordering refers to self-help, hostage giving, relational contracts (contracts as governance structures built for long-term relationships), conventions and agreements on rules for settling disputes that could otherwise be brought to court (see Rühl 2010; Schmidt-Trenz and Schmidtchen 1991; Schmidtchen and Schmidt-Trenz 2006). The multinational firm and vertical integration across borders are further examples of private ordering.

The reason why private ordering plays an important role in doing international business is a phenomenon labelled constitutional uncertainty.

Due to the complexities of international procedural law as well as the rules of conflict of laws it is far from clear which court has jurisdiction and which law applies. In addition, the determination of the value at stake might differ as might be the case for the breach remedies (expectation damages, reliance damages or restitution damages - whatever the court awards). Even if the parties to the contract write breach remedies into their contract, courts do not always enforce what players write into their contracts. They often impose transfers on the basis of certain legal principles.

For these reasons, a specific form of uncertainty in the domain of private foreign trade relationships emerges, which is called constitutional uncertainty. This constitutional uncertainty, which can be traced back to problems in rendering and executing judgments, creates contracting problems that are reflected by transactions costs for international economic actors. The question arises whether and how far comity can contribute to a

\footnotetext{
${ }^{4}$ I don't know of any empirical evidence regarding the validity of this presumption.
} 
reduction of those transaction costs. This might also be the question around which the economics of comity can be built.

Although the paper has not explicitly posed this question, it seems to me that it is right to the point.

\section{Bibliography}

Alexy, R. (2002), The Argument from Injustice: A Reply to Legal Positivism (Oxford: Oxford University Press).

Drahozal, C. R. (2012), The Economics of Comity, this volume.

Dworkin, R. (1977), Taking Rights Seriously (Cambridge: Harvard University Press).

Lee, S. (2006), Game of Foreign Judgment Recognition, Asia Law Review, vol. 3, No.2: 101-139.

Michaels, R. (2009), Recognition and Enforcement of Foreign Judgments, Max Planck Encyclopedia of Public International Law www.mpepil.com.

Osborne, M. J. (2004), An Introduction to Game Theory, New York Oxford 2004 [Oxford University Press].

Rühl, G. (2010), The Problem of International Transactions: Conflict of Laws Revisited, Journal of International Private Law, vol. 6 (1), 59-91.

Schmidtchen, D., R. Kirstein and A. Neunzig (2012), Litigation Cost Allocation Rules, Judicial Detection Skill, and the Propensity to International Trade, German Working Papers in Law and Economics vol. 2012 and Social Science Research Network (SSRN) http://ssrn.com/abstract $=2083074$.

Schmidtchen, D. and H.-J. Schmidt-Trenz (2006), Territoriality of Law and the International Trade Game: Towards a New Institutional Economics of International Transactions, 327-348, in: Bindseil, U., Haucap, J., and Wey, Chr. (ed.), Institutions in Perspective. Festschrift in Honor of Rudolf Richter on the Occasion of his $80^{\text {th }}$ Birthday, 327-348, Tübingen: Mohr Siebeck.

Schmidt-Trenz, H.-J. and D. Schmidtchen (1991), Private International Trade in the Shadow of the Territoriality of law: Why does it work?, Southern Economic Journal, 58, 329338.

Wagner, G. (2011), Dispute Resolution as a Product: Competition between civil Justice Systems, Paper presented at the $9^{\text {th }}$ Annual Meeting of the German Law and Economics Association (GLEA), 28/29 October, Bonn.

Whincop, M. (1999), The Recognition Scene: Game Theoretic Issues in the Recognition of Foreign Judgments. Accessed from: http://ssrn.com/abstract=16841. 



\title{
Discussion on Christopher R. Drahozal
}

\author{
summarized by
}

\section{Jan Engelmann}

The papers served as a starting point for an active discussion. There was widespread agreement with the author's approach to build a bridge between the legal concept of comity and game theoretical analysis.

A desire for differentiated empirical evidence for the role that comity plays revealed itself during the discussion. This interest was mentioned in relation to the role played by the general institutional setting of states involved in decisions influenced by comity, in relation to the informal institutions within which those decisions might be taken and in relation to the language used by the judges relying on comity. A thorough empirical analysis was noted to enable a fruitful application of game theory to the phenomenon of comity.

In this instance, a discussant presented examples in relation to the extraterritorial application of decisions taken by different anti-trust agencies. For those agencies, comity seems to function as a broad rule in relation to which informal institutions are developed that guide their behaviour. The importance of the institutional setting was also underlined in relation to the diverging approaches which the US Courts of Appeals for the $2^{\text {nd }}$ and $5^{\text {th }}$ Circuit adopt towards rendering anti-suit injunctions. The different institutional settings of the foreign states rendering the judgments these courts typically deal with seems to influence their individual approaches.

Much discussion focused on the application of game theory and how it can be improved and extended. Since judges are not dealing with questions related to comity on a day-to-day basis, it was questioned whether the time lags between the rounds played in the respective games call for a change of the games used in the analysis. A related remark drew attention to the need for more complex game theoretic modelling taking into account asymmetric and incomplete information. A sound understanding of the role played by the spontaneously developed informal institutions would especially require an application of evolutionary game theory.

Furthermore, it was mentioned that the interests at play where comity is applied should be addressed explicitly in order to clarify the sometimes 
implicit assumptions. This concern was voiced mainly regarding judges but also lawyers and parties. In further comments, discussants brought up the relation between comity and the ordre public's role as one of the standard grounds of refusing enforcement of a foreign judgement. In this regard, the economic discussion should focus on delineating ordre public from comity.

Lastly, the interrelation between comity and reciprocity as a threshold for mutual recognition of judgments was discussed. In a game theoretical setting, reciprocity's role resembles a tit-for-tat strategy in an iterated prisoners' dilemma. The fact that the concept of reciprocity has lost much of its importance in enforcing judgments seems to indicate that reaching cooperative solutions has become possible through other mechanisms. 


\section{Fighting Maritime Piracy - On Possible Actions and Consequences}

by

\section{Birgit Feldtmann}

\section{A. Introduction}

Judge Moore stated in 1927 in the Lotus-case that maritime piracy is an offence against the law of nations and that the pirate

“(...) is denied the protection of the flag which he may carry, and is treated as an outlaw, as the enemy of all mankind - hostis humani generis - whom any nation may in the interest of all capture and punish."

Today the notion of a pirate being an "enemy of mankind" might seem quite extreme, however the main thrust of Judges Moore's considerations are undoubtedly part of international law: Art. 100 of the United Nations Convention on the Laws of the Seas (UNCLOS) emphasises that it is the duty of all nations to cooperate in fighting maritime piracy:

"All states shall cooperate to the fullest possible extent in the repression of piracy (...)"

Furthermore, UNCLOS as well as other international legislation, such as the 1988 Convention for the Suppression of Unlawful Acts against the Safety of Maritime Navigation (SUA Convention), provides the legal basis for various actions against (suspected) pirates, including the capturing and punishing by national forces and courts. ${ }^{2}$

The framework for operations and specific actions against maritime piracy in international law is currently being put to the test in different regions of the world. However, the Horn of Africa/Indian Ocean region is the main focus of international attention and a number of states are cur-

\footnotetext{
${ }^{1}$ The Case of the S.S. Lotus (France vs. Turkey), P.C.I.J. 1927 (Judgment No.9 of $7^{\text {th }}$ September 1927), Dissenting Opinion by Mr. Moore, par. 249.

${ }^{2}$ See under $\mathrm{C}$ and $\mathrm{D}$ below.
} 
rently engaged in different counter-piracy activities and operations in the region.

This article looks at the question of how the international community reacts to the problem of maritime piracy. Firstly, the article takes a brief look at the general problem of maritime piracy; specifically in the Horn of Africa/Indian Ocean region and looks at counter-piracy activities taken by the international community. However, the impact of those activities has been debated and one of the questions that the debate raises is the question of whether or not the legal framework is sufficient. This question forms the background of the article, which in its second part analyses the legal framework for counter-piracy enforcement under international law. The third part of the article examines the question of how this legal framework is implemented in national legislation and guidelines, as well as how it is actually used in different contexts. This is illustrated by two examples, one concerning the question of prosecution (or often rather non-prosecution) of suspected pirates arrested by States engaging in counter-piracy operations, the other concerning the issue of Rules of Engagement (RoE) for the effectiveness of counter-piracy activities. Finally, the article moves to the question of what the consequences of the approaches chosen by the states in question might be.

\section{B. The problem}

Piracy is possibly one of the oldest occupations and has for centuries been a challenge to seafarers. Today, pirate activities are being registered in a number of the world's regions, such as, for example, off the coast of West Africa (Gulf of Guinea) and in East Asian waters (Malacca Straits) ${ }^{3}$. While the situation in West Africa is seen in particular by the shipping industry ${ }^{4}$ as a growing major concern, international focus still rests on the situation in the region of the Horn of Africa and the Indian Ocean. The reasons for focusing on piracy in this area may vary but three main reasons seem to be dominant. The first of these reasons is the modus operandi of the pirates in the region. Piracy in this region does not only mean different forms of violence and robbery against ships and crews but usually includes hijacking the attacked vessel and taking the crew hostage with the aim of securing the payment of a substantial ransom by the ship owner/manager. ${ }^{5}$ The second reason is that Somalia, the costal state where the pirates are based and from where they launch their operations, can be categorised as a "failed

${ }^{3}$ See IMB, Piracy Map 2012: http://www.icc-ccs.org/piracy-reporting-centre/livepiracy-map (last visited 15.7.2012).

${ }^{4}$ See Jyllandsposten, 1.3.2012, 1 and $\S 2,6-7$.

${ }^{5}$ See Struwe (2009), 16 f. and Feldtmann (2010), $107 \mathrm{f}$. 
state", which in the context of the problem of piracy means that Somalia, even if regional differences and certain positive developments on shore are taken into account, is basically unable to guard its coast or to prevent its citizens from committing acts of piracy and is unable to initiate acceptable criminal proceedings against suspected pirates. ${ }^{7}$ The final reason is that Somali pirates operate in a region that has one of the world's most crucial maritime routes ${ }^{8}$ - the passage from Asia to Europe through the Suez Canal, which is used by an average of $1,700-2,000$ vessels a month. ${ }^{9}$

In December 2010, it was reported that since January 2007, 2,600 seafarers have been held hostage by Somali pirates. ${ }^{10}$ The problem of "Somali piracy" seems to have peaked at the beginning of 2011 when the International Maritime Bureau (IMB) registered 32 vessels hijacked by Somali pirates and 746 seafarers held hostage. ${ }^{11}$ More than a year and a half later the numbers are down to 11 vessels and 188 hostages (registered on 30 August 2012). ${ }^{12}$ The decrease in vessels and hostages held by Somali pirates is linked to the fact that the number of (successful) pirate attacks has fallen. The reasons for the fall in the number of attempted hijackings are complex and may vary, the most prominent being named in the international debate are the efforts of the different counter-piracy operations and the factor that the majority of vessels today are following the recommendations and Best Management Practises (BMPs) to prevent hijackings. Furthermore, there has been slow but positive progress in different regions of Somalia and this has also been pointed out as a relevant factor. In addition, there has been a general improvement in security measures on board vessels sailing in the area, including the use of (private) armed guards. It has been claimed that there has not been a successful hijacking of any vessel that had armed guards at its disposal. ${ }^{13}$

The problem of piracy committed by Somali pirates has, as mentioned above, been met by the international community by encouraging and initiating a number of anti-piracy operations in the region with the participa-

\footnotetext{
${ }^{6}$ See Silva (2009), $3 \mathrm{ff}$.

${ }^{7}$ See Pham (2010), $31 \mathrm{ff}$. who also gives an insight in the complex internal structure of Somalia, the role of clan-structure and the diversion between different regions.

${ }^{8}$ Pham (2010), 42.

${ }^{9}$ Struwe (2009), 2 and $9 \mathrm{f}$.

${ }^{10}$ BIMCO, 500 Seafarers held hostage by pirates at Christmas: https://www.bim co.org/Members/News/2010/2010/12/21_500_seafarers.aspx (last visited 15.7.2012).

${ }^{11}$ IMB, Piracy news \& facts (21.01.2011): http://www.icc-ccs.org/home/piracyreporti ng-centre/piracynewsafigures.

${ }^{12}$ IMB, Piracy news \& facts (30.08.2012): http://www.icc-ccs.org/home/piracyreporti ng-centre/piracynewsafigures.

${ }^{13}$ The Economist, Piracy and armed security; Laws and guns; armed guards on ships deter pirates. But who says they are legal: http://www.economist.com/node/21552553 (last visited 30.08.2012).
} 
tion of various nations. ${ }^{14}$ Today three major international military operations are (partly or fully) aimed at counter-piracy: The "alliance of the willing" CTF 151 under the United States led Combined Maritime Forces, NATO's Operation Ocean Shield and EU NAVFOR's Operation Atalanta. ${ }^{15}$ Furthermore, a number of nations, such as China and India, are engaging in their own counter-piracy activities in the region, without formally participating in any international operation.

The background and the specific mandate for each of the different counter-piracy operations varies, which means for example, that certain measures against suspected pirates and their property may be used by one naval force acting under one of the international operations, while the same measures may not be used by another naval force operating under the rules of another operation. ${ }^{16}$ The fact that the efforts of counter-piracy activities are fragmented and are not organised into one collective international operation has led to a number of practical, operational and organisational challenges, for example in connection with the issue of cooperation in connection with specific operations and information sharing. Today many of those problems and challenges have been addressed and practical approaches have been developed, with the result that fragmentation of the counter-piracy operations no longer substantially jeopardises the success of the efforts at sea.

However, the improved cooperation of nations and international operations in counter-piracy is most likely an important factor in the abovementioned decrease in piracy attacks but it has not been able to put an end to the problem of piracy in the region: Somali pirates still account for a considerable amount of registered attacks on vessels ${ }^{17}$ and the radius of the area in which the Somali pirates operate has grown considerably: ${ }^{18}$ in 2007 acts of piracy were mainly reported from the Gulf of Aden and close to Somalia's coast. Today piracy concerns the wider Horn of Africa region, including large parts of the Indian Ocean and up to the Red Sea. To illustrate the scale of the radius of piracy attacks: NATO's Operation Ocean Shield now covers an area of about 6.5 million nautical square miles - an

${ }^{14}$ See Struwe (2009), 10 ff. and Guilfoyle (2010a), 141 ff. (145 ff.).

${ }^{15}$ See Taylor (2012), 337 f. and Geiss/Petrig (2011), $17 \mathrm{ff}$.

${ }^{16}$ See below D.

${ }^{17}$ On 20.11.2012 71 piracy incidents were reported for Somalia in 2012, with $13 \mathrm{hi}$ jackings and 212 hostages: IMB, Piracy news \& facts (20.11.2012): http://www.iccccs.org/piracy-reporting-centre/piracynewsafigures

${ }^{18}$ IMB, Hostage-taking at sea rises to record levels says IMB: http://www.icccs.org/ news/429-hostage-taking-at-sea-rises-to-record-levels-says-imb (last visited 30.8. 2012). 
area that is about half the size of the territory of the United States of America. ${ }^{19}$

While Somali pirates have been widening their area of operation, it has also become obvious that the vast space of the Indian Ocean cannot successfully be fully monitored and secured against pirate attacks. The problem caused by Somali pirates is not a brief episode and will continue to provide challenges to the international community and to maritime traffic. Furthermore, the problem of Somali piracy has also had a substantial economic impact: piracy is a "big business". The average ransom paid for the release of a vessel and its crew was estimated to be about USD 5.4 million in 2010 while the "unofficial record" for the payment of ransom to Somali pirates was reported to be USD 9.5 million $^{20}$ in November 2010. The costs caused by Somali piracy are estimated to have been USD 7 billion in $2011{ }^{21}$ However, the economic aspect is one side of the effects of maritime piracy, another side is the question of human cost and the impact the threat of piracy has on seafarers and their families. ${ }^{22}$

\section{The legal framework for counter-piracy enforcement}

The legal framework setting out counter-piracy enforcement powers can be described as fragmented due to the fact that it consists of different legal acts and it leaves certain unanswered questions. However, it can be argued that UNCLOS is the rather solid "legal backbone" of counter-piracy, setting out the main scope of counter-piracy enforcement powers.

\section{UNCLOS definition of piracy}

As mentioned above, international law considers piracy an unlawful act and expects all states to engage and cooperate in the "repression of piracy

${ }^{19}$ Søværnet; Søværnets Operative Kommando, Fakta om Nato's anti-pirateri operation Operation Ocean Shield: http://forsvaret.dk/SOK/Internationalt/OCEAN/Pages/defau 1t.aspx (last visited 30.8.2012).

${ }^{20}$ BBC, Special report: Pirates hoist ransoms for hijacked ships: http://www.upi.co m/Top_News/Special/2011/01/19/Pirates-hoist-ransoms-for-hijacked-ships/UPI96711295 459904/ (last visited 30.8.2012).

${ }^{21}$ One Earth Future/Oceans Beyond Piracy, The Economic Costs of Somali Piracy: http://oceansbeyondpiracy.org/sites/default/files/economic_cost_of_piracy_2011.pdf (last visited 20.9.2012).

${ }^{22}$ The question of the human cost of Somali piracy is analysed in the following report: International Maritime Bureau/Oceans Beyond Piracy, The Human Cost of Somali Piracy 2011, 2012: http://oceansbeyondpiracy.org/sites/default/files/hcop_2011_vers ion1_4_2.pdf (last visited 20.9.2012). 
on the high seas" (art. 100 UNCLOS). The act of piracy is defined in article 101 UNCLOS:

"Piracy consists of any of the following acts:

(a) any illegal acts of violence or detention, or any act of depredation, committed for private ends by the crew or the passengers of a private ship or a private aircraft, and directed:

(i) on the high seas, against another ship or aircraft, or against persons or property on board such ship or aircraft;

(ii) against a ship, aircraft, persons or property in a place outside the jurisdiction of any State;

(b) any act of voluntary participation in the operation of a ship or of an aircraft with knowledge of facts making it a pirate ship or aircraft;

(c) any act of inciting or of intentionally facilitating an act described in subparagraph (a) or (b)."

In its essence, piracy consists of a number of illegal acts (violence, detention or acts of deprivation) committed against a ship and its crew/passengers. The wording in article 101 in connection with the use of plural (e.g., "illegal acts of violence") and singular (e.g., "any act of depredation") has raised the question of whether one of those acts is sufficient to define an act of piracy or if more than one act has to be committed before an attack against a vessel is understood as piracy. Furthermore the question has been asked which legal system defines whether such an act is illegal. ${ }^{23}$ Those questions seem, however, to be mostly of academic relevance as there is no serious doubt in the legal debate that the attacks committed against vessels in the Horn of Africa region should be categorised as acts of piracy.

Piracy is committed "on the high sea" or "outside the jurisdiction of any state". This leads to the question of whether acts committed in the Exclusive Economic Zone (EEZ) are acts of piracy under UNCLOS. Guilfoyle argues in this context that the UNCLOS provisions on the high sea regime (including the provisions concerning piracy) apply to the EEZ as long as those are not incompatible with the UNCLOS provisions on the EEZ. As this is not the case, due to the fact that the specific EEZ regime is mainly focusing on exploiting, conserving and managing natural resources, the geographical limitation of the UNCLOS definition of piracy should be understood as acts committed anywhere seawards beyond the territorial sea, e.g., including acts committed in the EEZ. ${ }^{24}$

Concerning piracy, the geographical limitation of UNCLOS means that the above-mentioned acts against vessels in territorial waters fall outside the UNCLOS definition of piracy. Such acts may be covered by other in-

\footnotetext{
${ }^{23}$ Guilfoyle (2009), 3 and Geiss/Petrig (2011), 60.

${ }^{24}$ Guilfoyle (2009), 2.
} 
ternational legislation (see below) and are usually referred to as "armed robbery at sea", "armed robbery against ships" ${ }^{25}$ or similar expressions. The use of language concerning acts similar to piracy but committed in territorial waters is not consistent, relevant Security Council resolutions use for example different expressions and the intended, or not-indented, implications of the different terminology remains unclear. ${ }^{26}$ However, in the context of the general legal framework for counter-piracy activities it is sensible to use consistent language by referring to acts covered by UNCLOS article 101 as "piracy" and to similar acts in territorial waters as "armed robbery at sea". ${ }^{27}$

Another element of the UNCLOS definition of piracy is the so-called "two-ship-requirement". Acts of piracy are committed from one (private) vessel to another. Internal attacks, for example conducted by terrorist posing as passengers of a vessel as occurred in the Achille Lauro incident in 1985, are not within the scope of the UNCLOS definition of piracy, but are currently covered by the SUA Convention (see below). ${ }^{28}$

Furthermore, as stated above, the vessel from which the act of piracy is launched has to be a private vessel and UNCLOS requires that the acts are "committed for private ends". The interpretation of this requirement has triggered a substantial legal debate in which it is for example argued that the wording "for private ends" excludes all acts committed for political reasons and therefore acts of terrorism cannot be piracy. ${ }^{29}$ This is currently the position of the International Maritime Organisation (IMO) ${ }^{30}$ Guilfoyle argues, however, that the interpretation of "private ends" should distinguish between acts sanctioned by State authorities (e.g., not for private ends) and non-state sanctioned acts (e.g., for private ends). According to this reasoning, the correct dichotomy in connection with the "for private ends" criteria is "private/public" and not "private/political". ${ }^{31}$

In the context of Somali piracy, the pirates usually launch their attacks from smaller vessels (so-called "skiffs") with the aim of hijacking a vessel and its crew for the purposes of receiving a substantial ransom and today it is widely accepted that the attacks against vessels in the Horn of Africa/ Indian Ocean Region usually fall under the UNCLOS definition of piracy, as long as the attacks are conducted outside territorial waters. ${ }^{32}$

\footnotetext{
${ }^{25}$ See Murphy (2007), 155, 64. and Guilfoyle (2010a), 144.

${ }^{26}$ See Gleiss/Petrig (2010), $72 \mathrm{ff}$.

${ }^{27}$ Gleiss/Petrig (2010), 75.

${ }^{28}$ Geiss/Petrig (2011), 62 and Guilfoyle (2010b), 128.

${ }^{29}$ On this debate see Geiss/ Petrig (2011), 61 with further references.

${ }^{30}$ IMO Doc. LEG 98/8 2011, par. 14.

${ }^{31}$ Guilfoyle (2010a), 143.

${ }^{32}$ Feldtmann (2010), $103 \mathrm{ff}$. and Guilfoyle (2010a), $142 \mathrm{ff}$.
} 


\section{On the scope of counter-piracy enforcement powers granted by UNCLOS}

In cases of (suspicion of) piracy, UNCLOS provides the contracting states with a range of counter-piracy enforcement powers. Article 110 (1) a) UNCLOS grants a right of visit of foreign flagged vessels in order to verify an initial suspicion of piracy, the threshold to this right is "reasonable ground for suspecting" that a ship is engaging in piracy. The right to visit granted in article 110 is an exception to the general regime on the high seas where state vessels (war ships) are not allowed to interfere with vessels flagged in another state. ${ }^{33}$ When a "suspicion remains after the documents have been checked", the investigating state vessel has the right to "proceed to a further examination on board the ship" (article 110 (2) UNCLOS). The wording in article 110 (2) indicates that the powers given by UNCLOS extend proportionally while the initial suspicion is gradually sustained. ${ }^{34}$ If the suspicion is proved to be unfounded no further actions may be taken and compensation for any lost or damage shall be provided (article 110 (3) UNCLOS).

The powers granted by article 110 UNCLOS are aimed at confirming that the vessel in question is a "pirate ship" in accordance with article 103 UNCLOS. A "pirate ship" according to this provision is either a vessel intended to be used for acts of piracy as defined in article 101 or a vessel which has been used for such acts and which is still under the control of the persons who have committed those acts. ${ }^{35}$

If the suspicion that a vessel is either a "pirate ship" or a vessel that has been taken over by piracy and is still under the control of pirates is confirmed, further enforcement powers are granted by article 105. According to this provision any state may seize a pirate ship (or ship under the control of pirates), arrest the suspected pirates and seize the property on board. Consequently, any governmental vessel which meets pirates in international waters has the right to take the necessary action concerning pirate equipment and arrest the (suspected) pirates. Concerning the disposal of pirate equipment (including the sinking of pirate ships), article 105 grants the courts of the seizing state to decide on what to do with pirate equipment and ships. ${ }^{36}$

Article 105 does not elaborate on the question of the use of (lethal) force under counter-piracy operations. The question of the use of force is not directly addressed anywhere in UNCLOS but is it is argued that UN-

\footnotetext{
${ }^{33}$ See Geiss/Petrig (2011), 55 ff. and article 110 (1) UNCLOS.

${ }^{34}$ Geiss/Petrig (2011), 56.

${ }^{35}$ Geiss/Petrig (2011), 59 and Guilfoyle (2009), 5.

${ }^{36}$ Guilfoyle (2012), $775 \mathrm{f}$. On the question whether only the courts of the seizing state or indeed also other courts are granted powers by article 105 see below.
} 
CLOS implicitly permits the use of force as a last resource..$^{37}$ This opinion was confirmed by the International Tribunal for the Law of the Sea in which The M/V "Saiga" (No.2) Case pointed out that the use of force must "be avoided as far as possible" but also accepted that the use of force may in certain circumstances be "unavoidable". If unavoidable force is used the court requires that "it must not go beyond what is reasonable and necessary in the circumstances" and "Considerations of humanity must apply". ${ }^{38}$ Guilfoyle points out that the use of force is also supported by the UN Basic principles on the Use of Force and Firearms by Law Enforcement Officials, which permits the use of firearms in cases of self-defence or in defence of others and to prevent "the perpetration of a particular serious crime involving grave threat to life" ${ }^{39} \mathrm{He}$ argues that in certain circumstances lethal force as a first resource (for example without first firing warning shots) under counter-piracy enforcement may be unavoidable, for example when attempting to free hostages. ${ }^{40}$ Situations where lethal force seems to be the only resource might occur but this should remain an exception. It is therefore important to stress that the use of force in most cases will only be the last resource, after other, less intrusive means have failed, and the principle of proportionality must be obeyed. ${ }^{41}$ The use of lethal force in counter-piracy operations is to be avoided if other, less harmful, means are available in the specific situation.

In addition to the above-mentioned counter-piracy measures, article 105 also clarifies that:

"(...) The courts of the State which carried out the seizure may decide upon the penalties to be imposed (...)."

This means that the State seizing the pirates has the right to exercise criminal jurisdiction in connection with piracy. It is argued that UNCLOS article 101 in conjunction with article 105 enables any State (not only the seizing state) to implement universal jurisdiction for piracy. ${ }^{42}$ This question is rather crucial in the context of Somali piracy because several navies engaging in counter-piracy enforcement have, after the initial seizing of the

\footnotetext{
${ }^{37}$ Geiss/Petrig (2011), $68 \mathrm{f}$.

${ }^{38}$ International Tribunal for the Law of the Sea, The M/V "Saiga" (No.2) Case, Saint Vincent and the Grenadines v. Guinea, Judgement of $1^{\text {st }}$ July 1991, par. 155.

${ }^{39}$ Art. 9 United Nations Basic Principles on the Use of Force and Firearms by Law Enforcement Officials, UN Doc. A/CONF.144/28/Rev.1, 7 September 1990.

${ }^{40}$ Guilfoyle (2012), $773 \mathrm{f}$.

${ }^{41}$ This position is illustrated in the mentioned The M/V "Saiga" (No.2) Case in which the court describes a number of measures which should be used before turning to the use of force: International Tribunal for the Law of the Sea, The M/V "Saiga" (No.2) Case, Saint Vincent and the Grenadines v. Guinea, Judgement of $1^{\text {st }}$ July 1991, par. 156.

${ }^{42}$ Feldtmann/Siig (2009), 71 and Gardner (2012), $803 \mathrm{ff}$.
} 
suspected pirates, been transferring suspected pirates for prosecution to countries in the region, for example Kenya or the Seychelles, without any nexus between the piracy incident or the arrest of the suspected pirates and the receiving/prosecuting state. ${ }^{43}$ If the wording in article 105 would exclude others then the seizing state from initiating criminal proceedings this practice would be in conflict with international law. The legal debate concerning this question raises a number of points and legal arguments: going from the position that article 105 contains a "limited universality principle" (meaning that only the seizing state is competent to exercise universal jurisdiction), to the argument that the provision only provides a "conflictof-law rule" and to the position that the notion in article 105 only reaffirms that prosecution is based on domestic criminal law, to name some major points. ${ }^{44}$ The interpretation that article 105 does not grant the seizing state the exclusive right to prosecute is most convincing, not only because the opposite position is not in accordance with the general intention of the provisions on piracy and the idea of customary international law (and later codification) that all states are granted piracy enforcement powers and universal jurisdiction ${ }^{45}$ over pirates. Furthermore, such a position would be in conflict with other regulations in international law granting to right to exercise domestic jurisdiction due for example to the flag state principle. ${ }^{46}$

Article 105 does not express a general obligation of the seizing (or other states) to prosecute pirates. The wording in article 105 ("may") is too weak to establish any obligation to subject suspected pirates to criminal proceedings. Also article 105 in conjunction with the general obligation to repress piracy as stated in the above mentioned article 100 (which is using the imperative "shall") establishes no explicit (or intended) general obligation to either subject suspected pirates to domestic criminal proceedings or to extradite a suspected pirate to criminal proceedings in the receiving country. ${ }^{47}$

\section{Other relevant international legislation in connection with counter-piracy enforcement}

The relevant provisions of UNCLOS are supplemented by other international legislation such as the above-mentioned SUA Convention and the

\footnotetext{
${ }^{43}$ See Gardner (2012), 801 f., Geiss/Petrig (2011), 197 ff. and below D.

${ }^{44}$ On the debate see for example Gardner (2012), $803 \mathrm{ff}$., Geiss/Petrig (2011), $148 \mathrm{ff}$. and Kontorovich (2012), $4 \mathrm{ff}$.

${ }^{45}$ On the concept of universal jurisdiction over piracy see Kontorovich (2004), $188 \mathrm{ff}$.

${ }^{46}$ See Gardner (2012), 803 ff. and Geiss/Petrig (2011), 148 ff. with further argumenation for this position.

${ }^{47}$ Feldtmann (2011), 184 and Geiss/Petrig (2011), $151 \mathrm{f}$.
} 
Hostage Convention. The Hostage Convention might be relevant due to the mentioned modus operandi of Somali pirates, which includes the hostage taking of the crew. However, in the context of the Somali problem of piracy, the relevance of the Hostage Convention is limited and adds little concerning further enforcement powers, beside other reasons, because the territoriality and active personality principles do not work in the Somali context due to the fact that Somalia is not a party to the Hostage Convention. $^{48}$

The drafting of the SUA Convention was initiated in connection with the above-mentioned "Achille Lauro" incident, which revealed some gaps and limitations in UNCLOS piracy rules. ${ }^{49}$ Furthermore, the SUA Convention was inspired by the United Nations General Assembly's considerations concerning terrorism and terrorist attacks against ships. ${ }^{50}$ This does, however, not mean that the provisions of the SUA Convention are limited to acts of terrorism; terrorism is only mentioned in the preamble and is not an express element of the unlawful acts defined in the SUA Convention's provisions. $^{51}$

As indicated above, the SUA Convention does not focus on the problem of piracy nor does it deal directly with piracy in the UNCLOS sense, but rather it deals generally with unlawful attacks against vessels and maritime navigation. In article 5, the SUA Convention obliges the contracting states to criminalise certain specific acts against ships and their crews and passengers defined in article 3 . Those acts can be acts of piracy as defined in UNCLOS article 101 but also, for example, internal attacks on board a single vessel or acts committed in territorial waters as long as the attacked vessel has been or intended to navigate beyond a single state's territorial waters. ${ }^{52}$ Certain acts of piracy as defined by UNCLOS are outside the scope of the unlawful acts defined in the SUA Convention, for example simple acts of theft from one vessel to another which are not interfering with the safety of navigation. ${ }^{53}$

The signatory states of the SUA Convention have the obligation to ensure the legal basis for prosecuting such acts in their own legal system by establishing domestic criminal jurisdiction if they are committed against a ship sailing under the state's flag, if the acts are committed in the state's territorial waters or if they are committed by a citizen of the state (article 6

${ }^{48}$ See Geiss/Petrig (2011), 162 and Guilfoyle (2009), $27 \mathrm{f}$.

${ }^{49}$ Geiss/Petrig (2011), 42.

${ }^{50}$ See UN General Assembly, A/RES/40/61, para 13, which "Requests the International Maritime Organization to study the problem of terrorism aboard or against ships with a view to making recommendations on appropriate measures": http://www.un.org/d ocuments/ga/res/40/a40r061.htm (last visited 15.10.2012).

${ }^{51}$ Guilfoyle (2009), 12.

${ }^{52}$ Concerning the geographical scope of the SUA Convention see article 4 (1).

${ }^{53}$ See Guilfoyle (2009), 14. 
(1)). Furthermore, the SUA Convention enables - but does not obliges states to have jurisdiction in a number of other situations (article 6(2)), for example when a national of the state was "seized, threatened, injured or killed" under the unlawful attack..$^{54}$

The master of a vessel on which a person suspected of having committed illegal acts as defined in the SUA Conventions article 3 is present "may deliver" him $^{55}$ to a contracting state, for example the nearest port state (article 8 (1)).

The clear intention of the SUA Convention is that attacks against ships and maritime navigation should not only be criminalised on paper, but also that such acts should be prosecuted in domestic courts if a suspected perpetrator is found in a contracting state. This intention is codified as an "extradite or prosecute obligation" in the SUA Convention - however, the implications of this obligation are not quite clear and strongly debated. ${ }^{56}$ One of the main questions in the debate is whether article 10 (in conjunction with article 6 (4)) generally obliges states to prosecute or if the obligation is only triggered in situations when another state is requesting the extradition and the state in which the suspect is present is denying the extradition. ${ }^{57}$ Geiss/Petrig interpret the relevant provisions in the SUA Convention as following the so-called "Hague Model" the obligation to prosecute is not dependent on an extradition request by another state and its denial by the state in which the suspect is present. ${ }^{59}$ They argue further that even if the SUA Convention did not anticipate the situation where a suspect is not present at shore but on board of the state's warships the obligation also in those situations remains. ${ }^{60}$

This understanding of the SUA Conventions provision on the "extradite or prosecute obligation" is challenged and furthermore, state practice in connection with the Somali problem of piracy indicates that many states engaging in counter-piracy do not accept the concept of a general obligation to prosecute. ${ }^{61}$

\footnotetext{
${ }^{54}$ See SUA Conventions article 6 (2) nr. 2 and Feldtmann (2010), $106 \mathrm{f}$.

${ }^{55}$ It seems justifiable limit oneself to use the male form only when referring to pirates as we have not seen female Somali pirates.

${ }^{56}$ See Guilfoyle (2009), 14 ff., Geiss/Petrig (2011), $163 \mathrm{f}$.

${ }^{57}$ See Guilfoyle (2009), $14 \mathrm{ff}$.

${ }^{58}$ See Geiss/Petrig (2011), 163 (footnote 691) with further references.

${ }^{59}$ Geiss/Petrig (2011), 163.

${ }^{60}$ Geiss/Petrig (2011), $163 \mathrm{f}$.

${ }^{61}$ See further below D. See also Guilfoyle (2012), $774 \mathrm{f}$.
} 


\section{The extension of enforcement powers by UN Security Council Resolution}

In the case of the problem of Somali piracy, the general legal framework for counter- piracy enforcement in international law is supplemented by a number of specific UN Security Council resolutions. In the context of this article, two central aspects in particular should be mentioned: Firstly, provisions concerning the extension of the geographical scope of counterpiracy enforcement and secondly, provisions concerning the disposal of pirate equipment and "pirate ships".

A number of UN Security Council authorise counter-piracy enforcement (and enforcement against "armed robbery at sea" ${ }^{62}$ ) within Somalia's territorial sea, airspace and land territory. The precondition for the use of this authority is that the consent of the Transitional Federal Government has been obtained and that the UN Secretary-Genera ${ }^{63}$ has been notified of this consent. The relevant resolutions make reference to the use of "all necessary means" in counter-piracy enforcement. ${ }^{64}$ This wording leads to the question whether this could be interpreted as an extension of powers, for example concerning the question of the use of (military) force beyond the regime of UNCLOS. ${ }^{65}$ Geiss/Petrig assume that the answer to this question depends on the Security Council resolution in question: SC Res. 1846 (2008) (which grants counter-piracy enforcement measures in the territorial sea of Somalia) does not widen the scope of powers due to the fact that the resolution at the same time is clearly emphasising that the powers granted are to be conducted "in a manner consistent with such action permitted on the high seas with respect to piracy under relevant international law" ${ }^{66}$ Concerning SC Res. 1851 (2008) (which permits counter-piracy enforcement "in Somalia", e.g., also on land territory ${ }^{67}$ ) both authors argue that the Security Council is indeed widening the scope of powers beyond UNCLOS' regime, including military force. ${ }^{68}$ However, this does not mean that with this resolution the Security Council has declared international humanitarian law applicable in the context of Somali piracy; counter-

${ }^{62}$ On the concept of "armed robbery at sea" and the distinction to piracy in UNCLOS' sense see above C I.

${ }^{63}$ See SC Res. 1846 (2008) and SC Res. 1851 (2008) as periodically re-enacted, most recently in SC Res. 2020 (2012). See also Geiss/Petrig (2011), $70 \mathrm{ff}$.

${ }_{65}^{64}$ SC Res. 1846 (2008), para 10 b) and SC Res. 1851 (2008), par. 6.

${ }^{65}$ Geiss/Petrig (2011), 76

${ }^{66}$ Geiss/Petrig (2011), $76 \mathrm{f}$.

${ }^{67}$ SC Res. 1851 (2008), par. 6.

${ }^{68}$ Geiss/Petrig (2011), 83. 
piracy enforcement on the high seas and on Somali land and sea territory is based on and limited by human rights law. ${ }^{69}$

As mentioned above, article 105 UNCLOS enables courts to decide on the disposal of "pirate ships" and equipment. In addition a number of Security Council resolutions allow states (without the involvement of courts) the "disposition of boats, vessels, arms and other related equipment used in the commission of piracy and armed robbery at sea". The threshold for this is that there are "reasonable grounds for suspecting" the use of those items for piracy. ${ }^{70}$ States engaging in counter-piracy have under those resolutions the right to summarily dispose of piracy equipment, including the sinking of pirate vessels, beyond the provision of article 105 UNCLOS. ${ }^{71}$

\section{Brief conclusion on the legal framework for counter-piracy enforcement}

In the context of Somalia piracy the legal framework for counter-piracy enforcement granted to states may be fragmented and certain aspects may be disputed, but the general conclusion should be that it is rather robust. Many of the gaps which are present under the UNCLOS regime have been addressed and states are granted a range of powers against suspected pirates and their equipment, including the use of force. The geographical scope for counter-piracy operations is not necessarily limited to the high seas and in the context of the Somali situation, the difference between piracy and "armed robbery at sea" is of less relevance. Counter-piracy enforcement may include the arrest of suspected pirates and the prosecution in domestic courts.

However, the use of the powers granted by international law is not without limitations. It is limited by the framework of human rights. The implications of human rights on counter-piracy enforcement raise a number of questions, for example in connection with the detention of suspected pirates on board warships or in connection with the question of the transfer of suspected pirates to countries willing to initiate criminal proceedings. ${ }^{72}$ In the context of this article, those questions are not in the focus but it is enough to note at this point that the range of enforcement powers must be used in accordance with the human rights regime.

${ }^{69}$ This question was raised because SC Res. 1851 (2008) in para 6 both refers to international humanitarian law and human rights: "that any measures undertaken pursuant to the authority of this paragraph shall be undertaken consistent with applicable international humanitarian and human rights law". See Geiss/Petrig (2011), $131 \mathrm{ff}$.

${ }^{70}$ SC Res. 1851, par. 2., see also SC res. 1846, par. 6.

${ }^{71}$ Guilfoyle (2012), $775 \mathrm{f}$.

${ }^{72}$ See on the question of the role on human rights in counter-piracy enforcement Geiss/Petrig (2011), $101 \mathrm{ff}$. and $207 \mathrm{ff}$. 


\section{On the use of the legal framework for counter-piracy activities}

When following the media coverage on the problem of Somali piracy and the efforts of counter-piracy during the last few years, one might easily be left with the impression that the law is complex and jeopardises the success of the efforts at sea. Just to name one example: In May 2010, the BBC reported the release of a group of suspected pirates arrested during the defence of a Russian oil tanker. The release was according to Russian officials due to "imperfections in international law" and to "an incomplete international legal basis". ${ }^{73}$ The conclusion in this article does not support this impression; as stated above, the legal framework is rather robust and international law grants states the right to subject suspected pirates to domestic criminal proceedings.

This leads to the question why there is this impression that international law is a problem? The assumption of this article is that this impression might be connected to the use of the legal framework by the states engaging in counter-piracy enforcement. To illustrate this assumption, two examples are highlighted in the following text.

\section{The question of prosecution or non-prosecution of suspected pirates}

One of the issues where possible shortcomings of counter-piracy enforcement are discussed is the question of prosecution or non-prosecution of suspected pirates.

When talking about the question of prosecution in connection with piracy, two situations must be distinguished: ${ }^{74}$ The first situation concerns the question of initiating an investigation (and subsequently the prosecution of suspected perpetrators if they can be identified and captured) after a "successful" hijacking and the release of the vessel after the payment of a ransom (for example, "CEC Future case" ${ }^{\text {"75 }}$ ). The second situation concerns the

73 BBC news, Russia frees Somali pirates captured in the Gulf of Aden: http://news.bbc.co.uk/2/hi/8667640.stm (last visited 30.10.2012).

${ }^{74}$ See Feldtmann (2011), $182 \mathrm{f}$.

75 On the "CEC Future case" see Feldtmann (2010), $101 \mathrm{ff}$. The "CEC Future case" has since been developing further, as one of the pirates participating in the hijacking of $M / V C E C$ Future, was captured by the US navy under an attack on the US warship USS Ashland. The pirate was subsequently sentenced in the United States not only for the attack on the American naval vessel, but also in connection with the CEC Future case, even if there was no direct nexus between this case and the United States (beside the fact that the cargo on board of the vessel was belonging to a Texas based company). Furthermore, in April 2011 the pirate's negotiator was in April 2011 arrested in the United 
seizure of suspected pirates by navies during counter-piracy operations (for example the "Absalon situation" ${ }^{76}$ ). The challenge of this situation is often that there is no direct nexus between the capturing state and the acts of piracy: for example when the Danish navy arrests Somali pirates during an attempt to hijack a vessel from the Dutch Antilles (with seafarers on board with different, non-Danish, nationalities) ${ }^{77}$ or when they seize a so-called "mother ship", for example a local "dhow" under the control of pirates with Pakistani and Iranian seafarers held as hostages ${ }^{78}$.

Both situations have their own legal challenges and practical issues. However, in the context of this article, the focus rests on the latter situation because this is the situation that has repeatedly been under the attention of the public eye and it has been criticised that states are practicing too often a "catch and release" (also called "deter and disrupt") strategy in this situation. $^{79}$

The question of strategies concerning the prosecution of suspected pirates encountered by navies has been particular debated after UN Special advisor Jack Lang submitted his Report of the Special Advisor to the Secretary-General on Legal Issues Related to Piracy off the Coast of Somalia (in short: the Lang Report) in January 2011 in which the "seriousness of the situation" is emphasised and it is claimed that "more than 90 per cent of the pirates apprehended by States patrolling the seas will be released without being prosecuted" ${ }^{80}$

The notion that 9 out of 10 suspected pirates encountered by the navies are released without any legal consequences has since been challenged; partly on the basis of the Lang Report itself, which at the same time claims that since December 2008 over 2,000 pirates have been apprehended and

States and is currently under prosecution. See U.S. Department of Justice, Press release (7.4.2011): http://www.clipper-group.com/About-Us/News/Piracy/2011/ /media/Files/Pi racy/pressreleaseusdeptjust07042011.ashx and U.S. Department of Justice, Press release (21.4.2011): http://www.clipper-group.com/AboutUs/News/Piracy/2011/ /media/Files/Pi racy/alimohamedali042111.ashx (both last visited 30.10.2012)

${ }^{76}$ On the "Absalon situation" see Feldtmann (2011), $182 \mathrm{ff}$.

77 On this situation, the "Cygnus case", see Gardener (2012), 799.

${ }^{78}$ On this situation see Søværnet; Søværnets Operative Kommando, Nyt og presse, Absalon har standset endnu piratmoderskib: http://forsvaret.dk/SOK/Nyt $\% 20$ og\%20Pres se/pirateri/Pages/2012-04-12-moderskib.aspx (last visited 30.10.2012).

${ }^{79}$ See House of Commons; Foreign Affairs Committee - Tenth report; Piracy off the coast of Somalia, 20.12.2011, par. 58: http://www.publications.parliament.uk/pa/cm2 01012/cmselect/cmfaff/1318/131802.htm (last visited 20.9.2012). See also the "Lang Report", UN Doc S/2011/30 par. 14.

${ }^{80} \mathrm{UN}$ Doc S/2011/30 par. 11 and par. 14. 
that at time of the report's publication, 738 pirates had been submitted to criminal proceedings in 13 countries. ${ }^{81}$

From the Danish perspective, the question of the prosecution rate has been a debated issue as well. In summer 2012, it was reported that since the autumn of 2008 when the Danish navy had started its engagement in counter-piracy operations, a total of 286 suspected pirates had been detained in connection with counter-piracy enforcement. Of those, 41 were transferred for prosecution to countries like the Netherlands, The Seychelles, and Kenya. ${ }^{82}$ This meant that 245 suspected pirates were subsequently released without any further consequences.

When considering the question of those releases, it is important to realise that the reasons for such conduct might differ and that some of those releases were based on what can be called "legitimate rule-of-law considerations". ${ }^{83}$ To put this argument to the point: Somali seafarers are innocent until proven guilty, i.e., the burden of proof must also be lifted in cases of suspicion of piracy. This can be challenging in situations where the suspected pirates are not apprehended in the act of attacking a specific vessel but for example, are found carrying arms in a suspicious vessel. It might seem like common sense to conclude that persons found in this setting in a piracy high risk area are indeed pirates, but it must also be considered that in this part of the world some people not engaged in piracy (for example, fishermen) carry weapons to protect themselves. ${ }^{84}$ Another legal challenge is the question of criminalisation: If the suspected pirates were not engaged in a specific attack, there is the question of whether the domestic legal system in question has criminalised the act of "cruising with piracy equipment with the intention to attack vessels" as a punishable crime. ${ }^{85}$

However, even if the above-mentioned obstacles can be met (e.g., it can be proven that the suspected pirates have committed an act criminalised in domestic criminal law), state practice indicates that this does not ensure that suspected pirates are submitted to criminal proceedings; when naval forces encounter suspected pirates, four options are open: $:{ }^{86} 1$ ) The national legal system of the seizing state prosecutes the suspected pirates, 2) The suspected pirates are transferred to a domestic legal system with a direct nexus to the piracy incident (for example, the flag state of the attacked

${ }^{81}$ UN Doc S/2011/30 par. 42 and par. 43. See also Guilfoyle (2012), 770 (footnote 11).

${ }^{82}$ Søfartens Leder 3/2012, The Elephant in the Room, 24.

${ }^{83}$ See Feldtmann (2011), 186.

${ }^{84}$ On the question of sufficient evidence see Guilfoyle (2012), 770 and House of Commons; Foreign Affairs Committee - Tenth report; Piracy off the coast of Somalia, 20.12.2011, par. 78 ff.: http://www.publications.parliament.uk/pa/cm201012/cmsel ect/cmfaff/1318/131802.htm (last visited 20.9.2012).

${ }^{85}$ Feldtmann (2011), 186.

${ }^{86}$ See Feldtmann (2011), 185 ff. 
vessel), 3) The suspected pirates are transferred to the domestic legal system of a state in the region with no direct nexus to the incident (for example, to Kenya on the basis of transfer-agreements ${ }^{87}$ ) or 4) The suspected pirates are released as no national legal system is able and willing to prosecute.

Many seizing states seem to avoid the first option: the fact that international law does not include a clear general obligation to codify and exercise universal jurisdiction in cases of piracy means that there are several approaches concerning the question of jurisdiction for piracy in national systems of criminal justice. Some legal systems have chosen universal jurisdiction for piracy (for example, the Netherlands) in their domestic criminal law. Others have chosen only to have criminal jurisdiction regarding cases of piracy with a direct connection to the state (e.g., its ships or citizens) and for situations where international law clearly obligates the state to have jurisdiction - this is the approach Denmark has chosen. ${ }^{88}$ This means that when the Danish navy encounters suspected pirates and there is no connection to Danish interests, the domestic rules on criminal jurisdiction do not allow for proceeding with the case in Denmark. ${ }^{89}$ But even countries that have codified universal jurisdiction in cases of piracy in their domestic criminal law seem to be unwilling to use those provisions when capturing suspected pirates, at least when there is no nexus to own interests. ${ }^{90}$

Also concerning the second option, state practice indicates that there is a difference between what is legally possible and the willingness to initiate criminal proceedings. Under the regime of the SUA Convention, as mentioned above, the flag state is obliged to criminalise certain attacks against ships. However, some flag states seem to show very little interest in receiving suspected pirates from other nation's navies. ${ }^{91}$

The scenario preferred by many seizing states seems to be the third option: the transfer of the suspected pirates to a country that is willing and able to prosecute either under a transfer agreement $t^{92}$ or on the basis of an

${ }^{87}$ On transfer agreements, see Geiss/Petrig (2011), $198 \mathrm{ff}$.

${ }^{88}$ Feldtmann (2010), $106 \mathrm{f}$.

${ }^{89}$ Feldtmann/Siig (2009), $73 \mathrm{ff}$.

${ }^{90}$ See Guilfoyle (2012), 777.

${ }^{91}$ In the "Cygnus case", see Gardener (2012), 799 ff., it took over a month (from 2.1.2009 to 12.2.2009) for the Netherlands to accept the transfer of the pirates captured by the Danish navy after an attack of a vessel under the flag of the Dutch Antilles, see Søværnet; Søværnets Operative Kommando, Nyt og presse, De fem pirater er nu overdraget til Holland (The five pirates are now transferred to the Netherlands): http://fo rsvaret.dk/SOK/Nyt\%20og\%20Presse/internationalt/Pages/Defempiraterernuoverdragettil Holland.aspx (last visited 20.9.2012).

${ }^{92}$ See Geiss/Petrig (2011), 198 ff. 
ad hoc agreement. ${ }^{93}$ Denmark, for example, stresses in its "Strategy concerning the Danish efforts in counter-piracy 2011-2014" from May 2011, its intention to establish transfer agreements with "willing states" in the region. ${ }^{94}$ The scenario of pre-trial transfer is, however, only partly a solution to the problem at hand, as the problem is not necessarily to find a country willing to prosecute, but to find a country which is willing to execute the sentence given by the court. ${ }^{95}$ However, the Danish example shows that this option of transfer to a "willing" country in the region is not always accessible. ${ }^{96}$ Furthermore, the scenario of transferring suspected pirates to a "willing" country in the region raises a number of questions, such as those regarding legal and physical capacity to deal with piracy cases and often human rights issues, to mention only two. ${ }^{97}$

When the first three options are not possible or not chosen for other reasons, the fourth option, the release of the suspected pirates, remains and as mentioned above, this option has been used in a considerable number of cases.

This "catch and release" practice is, as shown above, in some situations unavoidable, for example when the burden of proof cannot be lifted. However, in other situations non-prosecution is the result of an unwillingness to fully use the legal framework, for example because of domestic considerations. A recent debate in Denmark shows that there is no political desire to bring suspected Somali pirates to Denmark for prosecution, also in situations where a direct nexus between the piracy incident and Danish interest exists. The basis for this lack of political desire includes the fear that convicted Somali pirates will not be able to be transferred back to the unstable situation in Somalia after they have served their sentences in Denmark. ${ }^{98}$

93 This practice has for example been used by the Danish authorities, see http://forsvaret.dk/SOK/Nyt $\% 200$ g\%20Presse/pirateri/Pages/12 formodedepiraterersatilan d.aspx (both last visited 30.10.2012).

94 Ministry of Foreign Affairs of Denmark (and others), Strategi for den danske indsats mod pirateri 2011-2014, 24. (Strategy for the Danish efforts against piracy)

95 See Guilfoyle (2012), 777.

96 The Danish navy has in several cases announced that they had to release suspected pirates because no country was willing and able to take them, see for example Søværnet; Søvænets Operative Kommando, Nyt og presse, Krigsskibet ABSALON forbliver midlertidigt i operationsområdet: http://forsvaret.dk/SOK/Nyt $\% 200$ \% $\% 20$ Presse/pirateri/Pages/2012-04-16 ABSALON. aspx and Søværnet; Søværnets Operative Kommando, Nyt og presse, 12 formodede pirater er sat i land: http://forsvaret.dk/SOK/Nyt $\% 200 g \% 20$ Presse/pirateri/Pages/12formodedepiraterersatiland.aspx (last visited 30.10.2012).

97 Some of the challenges connected with prosecution the region are shown by Kenya's example by Petrig (2009).

${ }^{98}$ The recent debate was trigged by a statement by a Danish politician who in the light of yet another case of releases of suspected pirates suggested that in the future the Danish navy will refrain from trying to arrest pirates. As a result of this statement the Danish union for shipmasters and other maritime officers, "Søfartens Ledere", conducted a sur- 


\section{The question of limitation of counter-piracy measures by Rules of Engagement (RoE)}

Another point of criticism in connection with counter-piracy efforts is that the action taken by the some of the countries participating in the different naval operations is not "robust" enough compared to other nations that have taken a tougher approach. According to a British House of Commons Foreign Affairs Committee report, some nations, for example Russia, India and China, "have taken a particularly uncompromising line against pirate vessels". This "uncompromising line" is seen in contrast with other nations" approach, which is categorised as "a more cautious line". 99

The question of different approaches named in the report of the Foreign Affairs Committee is linked to the question of the specific Rules of Engagement (RoE) that are utilised by different naval operations. RoE govern the limits of naval action; they are drawn up on the basis of international and domestic law and on the basis of the specific mandate for the operation as well as on limitations laid down by national mandate. The RoE of different counter-piracy operations are not published and are not commented on in detail by officials. ${ }^{100}$ However, some (limited) information about RoE connected with counter-piracy is in the public domain. One example in this connection concerns EU's counter-piracy operation, EU NAVFOR's Operation Atalanta. In March 2012, the European Union announced that it would prolong Operation Atalanta for two more years (until December 2014) and that the range of the operation would be extended "to include Somali coastal territory". ${ }^{101}$

As mentioned above, since 2008, SC Res. 1851 has permitted counterpiracy enforcement "in Somalia", e.g., also on land territory, under certain conditions. However, this option was not granted by Atalanta's RoE before

vey on the issue attitudes towards the question of prosecution of Somali pirates with representatives from all political parties present in the Danish parliament. The results of this survey show that there is little willingness to use existing means to prosecute Somali pirates in Danish courts, even if there is a direct link to Denmark (e.g. the suspected pirate for example attacked a Danish vessel). The results of the survey were published in Søfartens Ledere 3/2012, The elephant in the room, $24 \mathrm{ff}$.

${ }^{99}$ House of Commons; Foreign Affairs Committee - Tenth report; Piracy off the coast of Somalia, 20.12.2011, par. 59 f.: http://www.publications.parliament.uk/pa/cm201 012/cmselect/cmfaff/1318/131802.htm (last visited 20.9.2012)

${ }^{100}$ See House of Commons; Foreign Affairs Committee - Tenth report; Piracy off the coast of Somalia, 20.12.2011, par. $60 \mathrm{ff}$.: http://www.publications.parliament.uk/pa/cm2 01012/cmselect/cmfaff/1318/131802.htm (last visited 20.9.2012).

101 Reuters, EU extends Somalia counter-piracy operation by two year (23.3.2012): http://www.reuters.com/article/2012/03/23/eu-somalia-piracy-idUSL6E8EN65720120323 (last visited 30.8.2012). 
March 2012. The question of engaging in counter-piracy enforcement not only at sea but also on land is of course connected to a number of very legitimate considerations and reservations, ${ }^{102}$ but the result of the approach prior to March 2012 also had some interesting implications, which can be illustrated by the following example ${ }^{103}$ :

One of the approaches used by naval forces is to destroy piracy equipment from the air, for example by shooting holes in small pirate vessels ("skiffs") "parked" at the Somali coastline with the objective of making those vessels unusable:

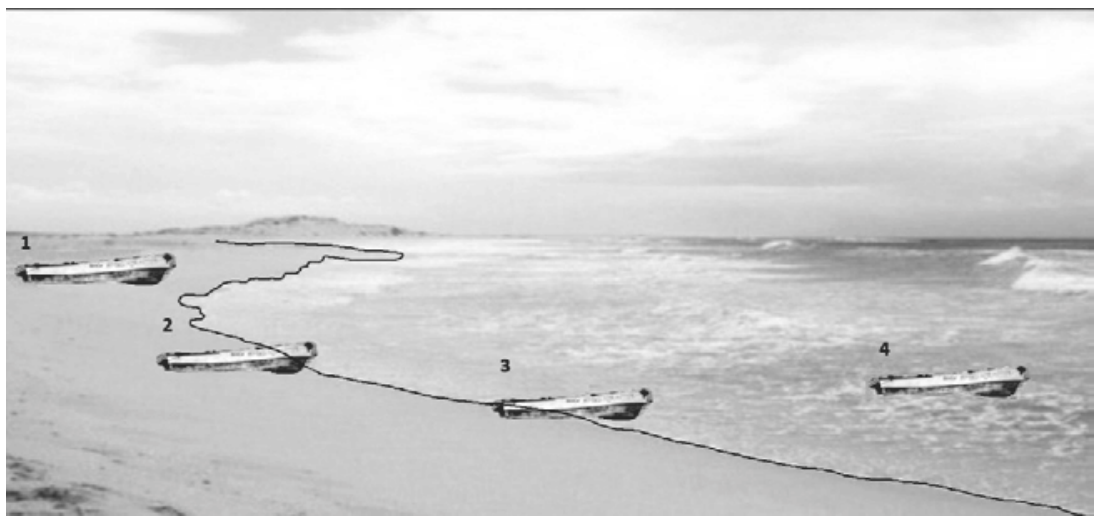

The former RoE for Operation Atalanta only granted operations in Somalia's territorial and internal waters, but not at shore. ${ }^{104}$ This means that vessel 1 on the illustration above ${ }^{105}$ clearly was beyond Operation Atalanta's reach. The question concerning vessel 2 and 3 was more challenging and hotly debated, as parts of those vessels are situated on shore, i.e., on Somali soil. Only vessel 4 in the above illustration is unquestionably a legitimate target under the former RoE of Operation Atalanta.

The example shows that the limitations laid down by a RoE can lead to situations which may give the impression of a "half hearted" approach. Under the new RoE, all four vessels in the illustration would be legitimate targets for Operation Atalanta forces. This has been indirectly confirmed

${ }^{102}$ See Ehrhart/Petretto (2012).

${ }^{103}$ The example used here was discussed under the "Maritime Legal Dimensions Seminar" (5.-8.3.2012) at the German Naval Operations School, Navy Tactics Center, in Bremerhaven.

104 See Reuters, EU extends Somalia counter-piracy operation by two years (23.3.2012): http://www.reuters.com/article/2012/03/23/eu-somalia-piracy-idUSL6E8EN 65720120323 (last visited 30.8.2012).

${ }^{105}$ This illustration was made by my research assistant Mr. Awale I. Mohamed, whom I would like to thank for his contribution. 
by an EU official, who according to the news agency Reuters, explained that "the force would still only operate at sea and in the air, though could now target pirates' weaponry and other equipment on land". ${ }^{106}$

\section{Some concluding remarks on the two examples}

The two examples briefly touched on here raise a number of questions and considerations, though there is not enough space in this article to cover all of them. In connection with the question of prosecution, it is for example asked what an increase in the prosecution rate really would achieve and more specifically whether more prosecutions would have a deterrent effect. ${ }^{107}$ It is widely accepted that the long-term solution to Somali piracy depends on sustainable improvements on shore and not individual punishment. Another aspect in this context is whether it really would be a sensible solution to prosecute suspected pirates far away from their country of origin and in a legal system they most likely will have no understanding of. ${ }^{108}$

In addition, the decision to use RoE that do not to grant all of the measures permitted by international law may be based on legitimate considerations and the states engaging in counter-piracy have to navigate through a complex environment of national and international law, human rights, "rule of law" considerations and potential limitations laid down by the specific nation state's domestic democratic process.

The argument put forward in this article is therefore not that every nation should use the legal framework in the most extensive way possible, nor is its intention to advocate a "particularly uncompromising line", which some countries actively pursue. Concerning the Russian approach, it has for example been reported that a Russian naval vessel seized a group of pirates after they had tried to attack a Russian flagged vessel. The pirates were subsequently "released" in a small boat without means of navigation and far away from shore. After the incident, Russian officials declared that they expected the pirates had been lost at sea. ${ }^{109}$ Such an approach is, not only from a legal point of view, unacceptable in the $21^{\text {st }}$ century.

The argument in this article is that the more restrictive approaches chosen by some countries might be based on legitimate considerations, but at

106 See Reuters, EU extends Somalia counter-piracy operation by two years (23.3.2012): http://www.reuters.com/article/2012/03/23/eu-somalia-piracy-idUSL6E8EN 65720120323 (last visited 30.8.2012).

${ }^{107}$ See Guilfoyle (2012), $768 \mathrm{ff}$.

${ }^{108}$ See Feldtmann (2011), 187.

${ }^{109}$ See Feldtmann (2011), 188 with further references. 
the same time could they lead to certain outcomes that were not necessarily intended or desirable.

\section{E. Reflections and some concluding remarks}

As mentioned above, the public debate concerning counter-piracy enforcement reveals a perception that it is not robust enough. This perception seemed to be shared by relevant stakeholders, such as the shipping industry. To name an example: Mr. Per Gullestrup, CEO of Clipper Group, which in 2008-2009 had to deal with the hijacking of their vessel M/V CEC Future by Somali pirates, ${ }^{110}$ argued in November 2011 in the Danish Maritime Magazine that the "international community has fully shown it incompetence by being unable to solve this problem". In his opinion the shipping companies had borne the burden of their responsibility and were spending "fortunes on protection" while at the same time the current efforts by the international community were only treating the symptoms. ${ }^{111}$

Another example of the stakeholder's perception is the perspective of seafarers, who are the potential and in over 2,600 cases $^{112}$ real victims of Somali pirates. The "catch and release" approach has left the impression that crimes against seafarers are not taken seriously enough by the countries who are engaged in counter-piracy and that piracy is a crime without consequences for the perpetrator. ${ }^{113}$

The notion of an ineffective counter-piracy effort is questionable, taking the above mentioned significant fall in piracy attacks into account, but it should also be remembered that the fall in piracy attacks is due to a number of factors. ${ }^{114}$ However when the Lang Report was presented in the beginning of 2011, over 700 seafarers were in the hands of Somali pirates and the perception of the situation was rather pessimistic.

The perception of the stakeholders at that time is relevant because it can be expected that this influenced the decisions taken at the time. The assumption of this article is that at the beginning of 2011, stakeholders had the impression that counter-piracy operations were somewhat ineffective and that to some extent they were left alone with the problem. ${ }^{115}$ This as-

\footnotetext{
${ }^{110}$ On this case see Feldtmann (2010), $101 \mathrm{ff}$.

${ }^{111}$ Danish Maritime Magazine 5/2011, 14-15.

112 BIMCO, 500 Seafarers held hostage by pirates at Christmas: https://www.bim co.org/Members/News/2010/2010/12/21_500_seafarers.aspx. (last visited 20.8.2012).

${ }^{113}$ See for example the website "Save our seafarers", which focuses on the question of prosecution of suspected pirates: http://www.saveourseafarers.com/our-campaign.html. On the perspective of the seafarers, see also Feldtmann (2012), $30 \mathrm{f}$.

${ }^{114}$ See above B.

115 This is also the impression Per Gullestrup gives in Danish Maritime Magazine $5 / 2011,14-15$.
} 
sumption can be based on statements like the above mentioned by representatives of the shipping industry and can further can be illustrated by a Danish example: In 2009, the Danish Shipowner Association (Danmarks Rederiforening) clearly ruled out the use of private armed guards (or Privately Contracted Armed Security Personnel (PCASP) as they are formally termed) on Danish vessels. The reasons for this included the consideration that ships are workplaces and there was a risk of escalating the situation. Furthermore, the argument was put forward that the protection of vessels ought to be a state responsibility. ${ }^{116}$

In 2011, the situation had changed completely and the same organisation advocated for a change in the Danish regulation of weapons with the aim of giving smooth access to PCASP. This development was supported by representatives for seafarers and in the summer of 2012, the Danish legislation on weapons (våbenloven) was drastically changed; giving ship owners relatively easy access to put weapons (and PCASP) on board their vessels. ${ }^{117}$

This move towards a privatisation of maritime security has not only been taken place in Denmark, but also in other countries affected by the problem of piracy. ${ }^{118}$ The wish to protect vessels is understandable, but the movement towards the extended use of PCASP is not without challenges. One of these challenges is the question of the legal framework for PCASP and their actions under domestic and international law, but also in coastal or port states which are visited by vessels that have PCASP. Another challenge is the question of quality of private providers of maritime security and the question of control. Finally the question of the framework for the use of (lethal) force by private actors in self-defence (or defence of others) is rather crucial.

The question is no longer whether there is a move towards extended private security as (one) answer towards the problem of maritime piracy, but rather how this development can be conducted and controlled in a sensible way, governed by the principles of the "rule of law". Recent incidents including the shooting of Indian fishermen (in the particular case by Italian naval personnel put on a merchant vessel $)^{119}$ and the release of a video

${ }^{116}$ See for example TV2 nyhederne, Skibe får ingen soldater mod pirater (ships don't get soldiers against pirates): http://nyhederne.tv2.dk/article.php/id-37010912\%3Askibef\%C3\%A5r-ingen-soldater-mod-pirater.html?rss (last visited 30.10.2012). See also Feldtmann/Siig (2011).

${ }_{117}$ On the new Danish regulation see Møberg/Gulisano (2012).

${ }^{118}$ Concerning the situation in the United Kingdom see: House of Commons; Foreign Affairs Committee - Tenth report; Piracy off the coast of Somalia, 20.12.2011, par. 31 ff.: http://www.publications.parliament.uk/pa/cm201012/cmselect/cmfaff/1318/131802.ht $\mathrm{m}$ (last visited 20.9.2012). Concerning the situation in Germany see: Salomon (2011).

${ }_{119} \mathrm{BBC}$ news India, India protests to Italy over shooting of fishermen: http://ww w.bbc.co.uk/news/world-asia-india-17058693 (last visited 30.10.2012). 
showing a rather unrestricted use of lethal force by PCASPs ${ }^{120}$ indicate that the development towards armed protection of ships has to be monitored closely. It is crucial that the high seas do not turn into a kind of "wild west"-area, governed by the law of the gun.

\section{Bibliography}

Ehrhart, H. G. and Petretto, K.: Ist die Mandatserweiterung von Atalanta sinnvoll? (23.4.2012): http://soldatenglueck.de/2012/04/24/70494/ifsh-studie-zu-eu-navfor-som alia-ist-die-mandatserweiterung-von-atalanta-sinnvoll/

Feldtmann, B.: Hvem går planken ud?; Om pirateri som en straffri beskæftigelse; kronik, Søfartens Ledere 3/2012., 30-31.

Feldtmann, B.: Should we rule out criminal law as a means of fighting maritime piracy? - An essay on the challenges and possibilities of prosecuting Somali pirates, in Anderson, Ulrika/Wong, Christoffer/Hansen, Helen Örenmark (ed.), Festskrift till Per Ole Träskman, 2011, 179-188.

Feldtmann, B.: Er strafferet et effektivt middel i kampen mod sørøveri? - Et dansk indblik i strafferetlige udfordringer på baggrund af kapringen af CEC Future, in Elholm, Thomas and others (ed.), Liber amicarum et amicorum Karin Cornils, 2010, 101-120.

Feldtmann, B. and Siig, K. M.: Hvem går planken ud? - Om manglen på strafforfølgelse af pirater, Nota Bene (May 2011): http://link.sdu.dk/nyhedsbreve/jura/notabene05 11.html.

Feldtmann, B. and Siig, K. M.: Dine, mine og vore pirater - Et indblik i juridiske (og andre) problemstillinger $\mathrm{i}$ forbindelse med bekæmpelse af pirateri i internationale farvande, in Pedersen, Hans Viggo Godsk (ed.), Juridiske Emner ved Syddansk Universitet 2009, 2009, 68-82.

Gardener, M.: Piracy Prosecutions in National Courts, Journal of International Criminal Justice (JICJ) 10/2012, 797-821.

Geiss, R. and Petrig, A.: Piracy and Armed Robbery at Sea; The Legal Framework for Counter-Piracy Operations In Somalia and the Gulf of Aden, 2011.

Guilfoyle, D.: Prosecuting Somali Pirates; A Critical Evaluation of the Options, Journal of International Criminal Justice (JiCJ) 10/2012, 767-796.

Guilfoyle, D.: Counter-piracy Law Enforcement and Human Rights, ICLQ vol. 59, 2010, 141-169.

Guilfoyle, Douglas: The Legal Challenges in Fighting Piracy, in van Ginkel, Bibi/van der Putten, Frans-Paul, The International Response to Somali Piracy; Challenges and opportunities, 2010, 127-152.

Guilfoyle, D.: Treaty Jurisdiction over Pirates: A Compilation of Legal Texts with Introductory Notes; Report prepared for CGPCS's WG 2 3rd meeting, August 2009.

Kontorovich, E.: The Penalties for Piracy; A Discussion Paper, 2012 (available at: http://oceansbeyondpiracy.org/sites/default/files/obp_penalties_for_piracy_final.pdf.

${ }^{120}$ The mentioned video was put in "youtube" and triggered for example a debate in Denmark on the question of quality and control of PCASP's. See DR nyheder, Vagter på Mærsk-skibe kaldes 'skydegale cowboys' (guards used by Mærsk are called "shooting happy cowboys": http://www.dr.dk/Nyheder/Udland/2012/05/21/185942.htm (last visited 30.10.2012). 
Kontorovich, E.: The Piracy Analogy: Modern Universal Jurisdictions Hollow Foundation, Harvard International Law Journal, Vol. 45/2004, 183-236.

Murphy, M.: Piracy and UNCLOS: Does International Law Help Regional States Combat Piracy?, in Lehr, Peter (ed.), Violence at Sea; Piracy in the age of global terrorism, 2007, 155-182.

Møberg, I. B. and Gulisano, C. A.: Civile, bevæbnede vagter på danske skibe, Juristen 2012, 206ff.

Petrig, A.: Ungelöste Probleme der Pirateriebekämpfung vor Somalia, Neue Züricher Zeitung, 22.12.2009: http://www.nzz.ch/nachrichten/politik/international/ungeloeste probleme_der_piraterie_bekaempfung_vor_somalia_1.4306460.html.

Pham, J. P.: The Failed State and Regional Dimensions of Somali Piracy, in van Ginkel, Bibi/van der Putten, Frans-Paul, The International Response to Somali Piracy; Challenges and opportunities, 2010, 31-64.

Salomon, T. R.: Sicherheitsdienste gegen somalische Piraten; Wettrüsten als fragwürdige Strategie, Legal Tribune Online (22.8.2011): http://www.lto.de/recht/hintergruende/h/ sicherheitsdienste-gegen-somalische-piraten-wettruesten-alsfragwuerdige-strategie/.

Silva, M.: Somalia Sate Failure, Piracy and the Challenge to International Law, 2009 (http://works.bepress.com/mario_silva/1).

Struwe, L. B.: Piratpatrulje ved Afrikas Horn; Rapport ved Dansk Institut for Militære Studier, 2009.

Taylor, A. D.: Piracy today - an update, in Comité Maritime International (CMI), Yearbook 2011-2012; Beijing I Documents for the Conference, 2012, 334-344. 


\section{Comment on Birgit Feldtmann}

\section{Fighting Maritime Piracy - On Possible Actions and Consequences}

by

\section{Max Gössler}

\section{A. Introduction}

Piracy has become a focus of the public since attacks of Somali pirates have drastically increased in 2008. The international community seemed to be incapable of dealing with the problem, as the attacks continued to rise although a number of operations had been sanctioned. To this day more than 3.000 seafarers have been held hostage by Somali pirates, while, in addition to the human suffering, losses caused by piracy have also hit maritime actors. The rises in ransom payments, insurance and wage premiums but also costs of re-routing and increased speed harm ship-owners severely. In addition, ship-owners face high costs during long-lasting negotiations with pirates until their vessels are set free. Secure maritime routes at the Horn of Africa are not only essential for crews and shipowners but also for maritime transport. A blockade of the Suez Canal would implicitly increase the shipping distance for many bilateral trade relations. Unquestionably, longer trade distances will have a negative effect on the volume of trade. ${ }^{1}$ According to Feyrer (2009) roughly 20 percent of the bilateral trade patterns depend on the Suez Canal. In 2011 17.799 ships with a dead weight tonnage of 929 billion tons have passed the channel which accounts to 11 percent of total seaborne trade in the same year. ${ }^{2}$

The persistence of political instability and poor living conditions in Somalia have made people increasingly willing to resort to forms of violence;

\footnotetext{
${ }^{1}$ Disdier and Head (2008).

${ }^{2}$ Suez Canal Authority (2012).
} 
thus creating a breeding ground for piracy. Another result of the state failure is that Somalia is not able to enforce, prosecute or guard its coast on its own. The various anti-piracy operations of the international community can at best be described as fragmented and were not able to prevent merchant ships from getting hijacked. ${ }^{3}$ The most effective protection seems to be employing armed security guards onboard because down to the present day not a single ship with armed security onboard has been reported hijacked.

In her article, Birgit Feldtmann discusses how the international community reacts to the problem of maritime piracy. She first gives a brief overview of the general problem of maritime piracy and analyses the counterpiracy activities around the Horn of Africa/Indian Ocean region taken by the international community. There have been concerns whether the legal framework is sufficient to fight piracy, as the success of these actions was only limited. The most relevant international legislation in connection with counter-piracy enforcement is the United Nations Convention on the Law of the Sea (UNCLOS) and the Convention for the Suppression of Unlawful Acts Against the Safety of Maritime Navigation (SUA Convention). In the present case, the latter is of less relevance because Somalia is not part of it. However, as she points out, the legal framework is rather robust and counter-piracy enforcement may include the use of force (based on and limited by human rights), the arrest of suspected pirates and the prosecution in domestic courts. Against this background, it is still unclear whether it is allowed to transfer suspected pirates to other countries and to take suspects into custody on warships without a trial. The article further analyses the legal framework for counter-piracy enforcement under international law and how it is implemented in national legislation and how it is interpreted in different contexts. She addresses these issues with two examples, the Rules of Engagement (RoE), which is the extent to which force is used to fight piracy, and the question of prosecution or non-prosecution. She concludes with the analysis of the consequences connected to the different actions chosen by the states affected by the problem.

It is not the goal of this paper to deepen the legal analysis, but to rather view some of Birgit Feldtmann's arguments in the context of simple microeconomic considerations of representative ship-owners and pirates. The effectiveness of the legal framework may be limited if the agents' decisions are not affected by the legal system. To evaluate possible actions and opportunities by the international community from an economic point of view, one can be making use of the assumptions of a representative agent in a simple rent-seeking model. Using the model, changes in ransom demand, penalties and sovereign protection can be analyzed. From a microe-

\footnotetext{
${ }^{3}$ Leeson (2009).
} 
conomic perspective, actions only alter decisions made by the agents, if these actions are credible and affect expected payoffs. This is only the case if pirates believe they will be prosecuted and sentenced. As Birgit Feldtmann points out, the legal framework is rather robust and states are granted rights to use force to fight piracy and to prosecute suspects. Still, the use of the legal framework is far away from universal jurisdiction. She further states that most states follow a catch and release approach, where pirates are only prosecuted if there is a connection to the seizing state or where international law clearly obligates a prosecution. Therefore, as long as the states do not exhaust the legal framework and avoid prosecution of suspected pirates, the deterring effect from prosecution is diminished. The threat of law enforcement loses credibility, too. As a result, the level of penalty becomes irrelevant. However, in the context of the model it becomes clear that prosecution and law enforcement are not the most efficient variables to eliminate piracy from an economic point of view. They are effective in the short term, but only if the level of penalty outweighs prospective returns from piracy. If this is not the case, it is shown that ship-owners may even be worse off. The most efficient implication is to raise opportunity costs of the pirate. Higher domestic income levels make piracy less attractive and reduce rent-seeking costs.

It is the aim of this paper to point out the economic interaction between pirates and ship-owners in a rent-seeking context and to show how these microeconomic motives may lead to an escalation of violence. In order to motivate the model, relevant background information is presented in the next section. In Section $C$ the model is explained, changes in exogenous variables are analyzed, and policy implications are derived. Finally, the results are summarized and are set in comparison to the results derived by Birgit Feldtmann.

\section{B. Background}

The piracy problem at the Horn of Africa can be distinguished from earlier forms of piracy by its modus operandi, in particular by the kidnap \& ransom model. Between 2006 and 2010, worldwide acts of maritime piracy significantly increased from 239 attacks to 445 attacks in 2010. Almost the entire increase is attributed to the increasing activity of Somali pirates. The share of worldwide attacks involving firearms was 22 percent $(53$ incidents) in 2006 and increased to more than 50 percent (243 incidents) in $2010 .{ }^{4}$ Only looking at African pirates, the use of guns has increased from around 30 percent in 2002 to more than 90 percent in 2010 (Bowden,

\footnotetext{
${ }^{4}$ IMB Annual Piracy Report 2012.
} 
2011). Obviously a significant armament has taken place during these years. According to the International Maritime Bureau (IMB), Somali pirates fire automatic weapons and Rocket Propelled Grenades (RPG) in order to board and hijack vessels. The fact that pirates have more often attacked steaming ships and that they have increased their scope of action as far as 1000 nautical miles away from the coast is evidence for an increasing degree of professionalism, which requires certain investments like mother-ships, speedboats, larger teams, etc. There is no reliable data on ransom payments; however, total ransom payments are estimated to be US\$ 159.62 million in 2011 with an average ransom of around US\$ 5 million. ${ }^{5}$ It is not quite clear how these ransoms are split up in the value chain between actual pirates and financiers, sponsors, government officials and other interest groups. Based on rough estimates, it is assumed that pirates are only able to keep about 30 percent of the revenue from piracy, whereas up to 70 percent is distributed among the people involved ashore and therefore is disposable for further piracy operations. ${ }^{6}$ Independently of the value chain split, the ransom payments should be sufficient to finance piracy investments. In contrast, such amounts of money are obviously a great threat to the shipping industry. Apart from ransom payments, ship-owners need to account for higher insurance premiums, higher labor costs, the cost of re-routing, the cost of increased speed and all costs related to security and defense measures.

Besides these economic factors the human factor should not be forgotten, as the lives of many seafarers are at stake. Sovereign protection for merchant ships around the Horn of Africa is provided through the EU NAVFOR Somalia - Operation Atalanta and the Combined Maritime Forces. These counter-piracy operations are coordinated through the monthly Shared Awareness and Deconfliction (SHADE) meetings in Bahrain, with representatives from more than 25 countries. $^{7}$ Although the naval operations were not completely ineffective, piracy was not reduced. ${ }^{8}$ To this day ships are still getting attacked and kidnapped by pirates in the whole Indian Ocean even though the growth rate of pirate attacks has decreased in 2011 and 2012. ${ }^{9}$ Because of the size of the Indian Ocean, it is more or less impossible to patrol the Indian Ocean with sovereign forces. It is therefore inevitably up to the ship-owners to protect their ships independently. Considering that the shipping industry has focused on nonlethal defense measures during the first years of the piracy problem at the Horn of Africa, the activity level of pirates and their increasing tendency to

\footnotetext{
${ }^{5}$ Bowden (2011).

${ }^{6}$ Geopolicity (2011).

${ }^{7}$ Combined Maritime Forces (2011).

${ }^{8}$ Shortland \& Vothknecht (2011).

${ }^{9}$ IMB (2013).
} 
violence is now combated with a noticeable shift towards more robust defense measures. Shipping industry organizations responded to this threat by developing guidelines called Best Management Practices (BMP) in order to support ships to deter and defend pirate attacks in close co-operation with interested international shipping and trading organizations including the EU, NATO and the International Maritime Bureau. The $4^{\text {th }}$ edition has been released in 2011 and among other things it is now recommended to have armed security guards onboard when travelling through high risk areas. ${ }^{10}$ As Birgit Feldtmann has mentioned as well, politics have reacted on the current demand for more intense defense measures. The prime minister of the U.K., David Cameron, announced on October 30th 2011 that private armed guards will be allowed to operate on U.K.-flagged ships so as to defend pirate attacks. ${ }^{11}$ Similar developments have taken place in other countries, too. The next section sheds some light on these developments from a microeconomic perspective.

\section{A Rent-Seeking Model of Piracy}

The model is set up in the framework of a simple coordination game in order to illustrate the danger of an escalation of violence between shipowners and pirates: Following both Becker (1968) and Brown and Reynolds (1973), an average utility maximizing pirate and an average utility maximizing ship-owner, have the opportunity to either avoid a confrontation or to risk a clash. Although the modeling of a single representative pirate does not reflect the multi-stage hierarchy of the Somali piracy business, ${ }^{12}$ it is still useful to analyze the strategic interaction and the armament on both sides. Due to a number of reasons the shipping industry is in praxis not able to avoid the Suez Chanel. Still, there exists a theoretical threshold where the shipping industry cannot bear the risk of piracy any longer and is forced to re-route or even establish new maritime trade patterns.

The pirate is willing to give up piracy if the autonomous legal income $X^{N P}$ makes him better off compared to the uncertain potential income $X^{P}$ from piracy. He does not know whether he will be successful with the attack and will get a ransom or whether he will fail and face a penalty. On the other side there is an average ship-owner who owns only one ship. Revenue is assumed to be constant and exogenous. Freight rates, good prices and output of shipping services are ignored as well as variable costs which depend on the amount of freight transported. Security can be regarded as a public good and should therefore be provided by the state. In

\footnotetext{
${ }^{10}$ BMP4 (2011).

${ }^{11}$ House of Commons - Foreign Affairs Committee (2011).

${ }^{12}$ Leeson (2007).
} 
the case of piracy, it is difficult to define a single state which is responsible for the provision of security in international waters, as Birgit Feldtmann pointed out. However, in the case of an economic theoretical model it is legitimate to simplify and think of the international union as the sovereign agent. The sovereign does not have any other (economic or political) motivations affecting its actions, e.g., tax-income or tariffs on international trade are ignored and its actions are not modeled endogenously. In order to combat piracy, the sovereign agent has can affect the outcome of the model in different ways: It can increase the penalties a perpetrator has to implicitly pay when getting convicted or it can choose to increase sovereign protection by financing security measures which aim to reduce piracy, for example by increasing the number of marine ships, marine patrol aircrafts or by sending sovereign security forces on board of merchant ships. ${ }^{13}$

\section{Route Choice}

Let $\pi^{D R}$ be the ship-owner's profit from choosing the direct route. If the ship-owner avoids the piracy area his profits decrease due to higher costs and foregone profits from trade with adjacent states. These profits of the alternative route are labeled $\pi^{A R}$. When both players enter piracy, it is assumed that the pirate will always find a ship to attack. ${ }^{14}$ The outcome, however, is uncertain for both agents, as neither of the players knows, whether he will prevail.

Figure 1: $\quad$ Normal Form Representation

\begin{tabular}{|c|c|c|}
\hline Ship-Owner & Direct Route (DR) & Alternative Route (AR) \\
\hline Piracy (P) & $E\left[U\left(X^{P}\right)\right] ; E\left(\pi^{D R}\right)$ & $0 ; \pi^{A R}$ \\
\hline Legal Alternative (LA) & $U\left(X^{N P}\right) ; \pi^{D R}$ & $U\left(X^{N P}\right) ; \pi^{A R}$ \\
\hline
\end{tabular}

The optimal strategy of the pirate then depends on whether his expected utility out of piracy is larger than his utility out of legal income. As long as

$$
E\left[U\left(X^{P}\right)\right]>U\left(X^{N P}\right)
$$

holds, the pirate is worse off choosing legal alternative income opportunities. Similarly, the optimal strategy of the ship-owner depends on his ex-

${ }^{13}$ In the framework of the model, there are also other possible policy instruments to think of, however at this point, it makes sense to simplify.

${ }^{14}$ This assumption is plausible, due to the amount of ships travelling through the Gulf of Aden. 
pected profits from choosing the direct route and on his secure profits when avoiding piracy. If and only if

$$
E\left(\pi_{P}\right)>\pi_{N P}
$$

holds, the ship-owner chooses the direct route. Independently of the pirate's strategy there is no Nash equilibrium where condition (2) is violated. The pirate will not be able to generate any income, if the ship-owner avoids the piracy region. Suppose the pirate is active in the legal sector. In this case, the ship-owner does not have to worry about piracy and is better of choosing the direct route with higher profits. Therefore this game has two possible Nash equilibria in pure strategies. ${ }^{15}$ If condition (1) and (2) hold neither of the players has any incentive to deviate. The ship-owner will choose the direct route and the pirate will attack the ship. If condition (1) is violated but condition (2) holds, working in the legal sector and choosing the direct route is a Nash equilibrium. Whether conditions (1) and (2) hold depends on the probability, the profit and the utility. However, by investing into crime or defense, respectively, each agent can influence the probability to his advantage. For example, buying weapons, attacking with larger teams or more ships increase the pirate's chances to prevail. As the investment decisions affect the probability and hence expected profits and expected utility and thus the Nash equilibrium in the game, the utility or profit maximization under uncertainty needs to be analyzed in greater detail.

\section{Probability function}

The probability $p$ describes the likelihood of a pirate attack resulting in failure. Consequently $1-p$ reflects the probability of the pirate being successful with the attack. According to Tullock (1980) the probability is endogenous to the agents' investment decision. The higher the ratio of the ship-owner's investment relative to total investment (investment of the ship-owner and the pirate), the higher is the probability for the ship-owner to successfully defend a pirate attack. Let $D$ be the investment of the shipowner and $I$ the investment of the pirate. Following Tullock (1980) the probability is modeled as follows: $:^{16}$

${ }^{15}$ For reasons of simplicity we restrict the analysis to Nash equilibria in pure strategies only, although it would make sense to allow for mixed-strategy Nash equilibria. Allowing the pirate to randomize over his strategies could very well represent the fact that not every ship travelling through the Gulf of Aden gets attacked by pirates.

${ }^{16}$ As Hirshleifer (1989) points out two-sided peace can never occur in a Nash equilibrium if the ratio form is used. Especially in a context with imperfect information, the defeated side may have incentives to surrender. When the defeated side does not lose 


$$
P(p=1)=\frac{D}{I+D}
$$

If $D=I>0$, the probability will always be equal to 0.5 . From equation (3) it follows that the effect of a marginal change in $D$ on the probability $p$ is positive, but decreasing with the total amount invested by the pirate and the ship-owner. In turn, a marginal change in $I$ affects the probability $p$ negatively but the effect also decreases with the total amount invested. This means, the more is invested by both agents, the smaller is the effect of a one unit change in either of the investments on $p$. In Figure 2 two probability functions for different levels of total investment are displayed with respect to the difference in investment levels. The dashed line represents the probability function for a smaller total investment in comparison to the solid line. The lower total investment, the steeper the slope of the inflectional tangent of the probability function at $D=I$ and the faster the convergence of the probability function to its limit values.

Figure 2: $\quad$ Probability distribution

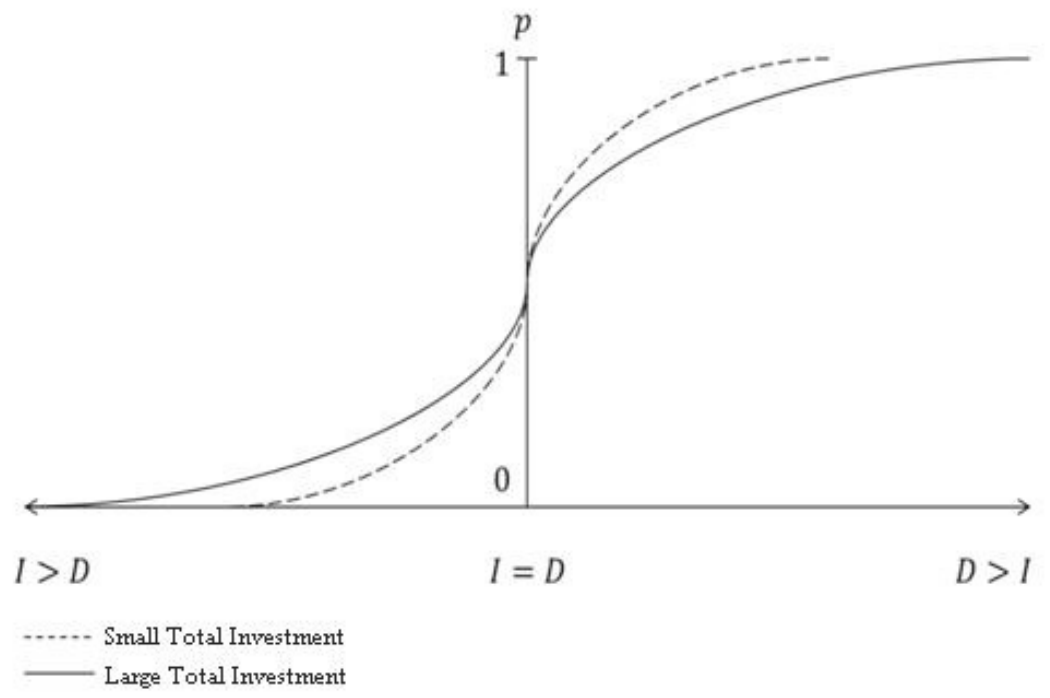

everything, although it did not invest at all, the probability may be better described as a logistic function of the difference between the agents' investments. However, in comparison to a war between nations the booty cannot be split. In addition, it is rather easy for the pirate to assess the value of the booty. Therefore the ratio form seems more applicable in this context. 


\section{Utility and Profit Maximization}

The pirate and the ship-owner maximize utility and profits, respectively, by choosing an optimal level of investment. The decision has to be taken ex-ante and therefore reduces income in the case of success and in the case of failure. The pirate's utility is modeled as a positive function of income:

$$
\frac{\partial U}{\partial X}>0
$$

If the attack is successful the pirate gets the ransom $R$ which is reduced by his investment $I$, so that his utility $U\left(X_{1}^{P}\right)=R-I$. If the pirate fails with the attack his utility is reduced by his investment and by the penalty $f$, which is the monetary equivalent to the disutility of being imprisoned, paying a penalty or even death. His utility becomes $U\left(X_{2}^{P}\right)=-f-I$. Clearly the pirate is worse off in the case of failure, as $X_{2}^{P}$ is greater than $X_{1}^{P}$ and hence $U\left(X_{2}^{P}\right)$ is greater than $U\left(X_{1}^{P}\right)$. From the pirate's perspective an increase in $I$ increases the chance of getting $X_{2}^{P}$. However, this investment also reduces income in both outcomes to the same extent. In order to maximize his expected utility, he needs to choose $I$ with respect to its effect on the probability $p$. Due to the uncertainty of the success of the attack, the pirate maximizes his expected utility subject to $p$, as shown in the following expression:

$$
\max . E\left[U\left(X^{P}\right)\right]=(1-p(I, D)) U[R-I]+p(I, D) U[-f-I]
$$

There are two possible outcomes for the ship-owner, when choosing the direct route. In either case he gets the yield $Y_{P}$ which is reduced by his investment into security measures. If the pirates are successful the shipowner has to pay a ransom $\varphi R$ for his ship and the crew. The factor $\varphi$ determines the ship-owner's actual cost resulting from a successful pirate attack. When a vessel is hijacked ship-owners usually face costs which are many times greater than the initial ransom payment, for example due to long lasting negotiations with pirates etc. An increase in these costs is implicitly reflected through an increase in $\varphi$. However, ship-owners may also reduce potential losses from piracy by buying insurances against piracy. ${ }^{17}$ The cost of the premium is implicitly included in $\varphi$. The total cost of piracy is therefore reflected in terms of $R$.

\footnotetext{
${ }^{17}$ In praxis certain areas with high piracy risk are declared as war risk zones and are excluded from standard hull and cargo insurance protection. For trips in areas like the Gulf of Aden, additional war risk premiums have to be bought per trip and are calculated in the short term individually (Engerer \& Goessler, 2011). Changes in the risk of piracy are therefore reflected in changes in the war risk premium, in this model through changes in $\varphi$.
} 
The ship-owner maximizes expected profits subject to $p$ :

$$
\max . E(\pi)=(1-p)\left[Y_{P}-\varphi R-D(I, S)\right]+p\left[Y_{P}-D(I, S)\right] .
$$

The pirate maximizes equation (4) which yields the following first order condition:

$$
\frac{\partial E[U(X)]}{\partial I}=\frac{D}{(I+D)^{2}}(R+f)-1=0 .
$$

Analogous to the pirate maximization of the ship-owner's profit function leads to:

$$
\frac{\partial E(\pi)}{\partial D}=\frac{I}{(I+D)^{2}} \varphi R-1=0 .
$$

By solving equations (7) and (8) for the respective investment variables, a quadratic expression of the following form is obtained for the pirate

$$
0=I^{2}+2 D I+D^{2}-D(R+f)
$$

and the ship-owner

$$
0=I^{2}+2 D I+D^{2}-I \varphi R .
$$

Due to the quadratic form of equation (9) and (10) there are two solutions for the optimal amount invested. The pirate's reaction function depends on the amount invested by the ship-owner and is positively related to the ransom $R$ and the penalty $f$. The ship-owner's response depends on the amount invested by the pirate and is positively connected to the ransom payment and the factor $\varphi$. As the investment is restricted to positive values only, the respective reaction functions can be written as follows:

$$
\begin{gathered}
I^{*}(D, R, f)=-D+\sqrt{D(R+f)} \\
D^{*}(I, \varphi, R)=-I+\sqrt{I \varphi R}
\end{gathered}
$$

\section{Cournot Equilibrium and Comparative Statics}

The reaction curves $I^{*}(D, R, f)$ and $D^{*}(I, \varphi, R)$ are illustrated in Figure 3. Let us assume that conditions (1) and (2) hold. The Cournot Nash equilibrium is then determined through the intersection of the two reaction curves in point A. It is algebraically expressed as follows: 


$$
D^{N E}=\frac{(R+f)(\varphi R)^{2}}{(R+f+\varphi R)^{2}} \quad I^{N E}=\frac{\varphi R(R+f)^{2}}{(R+f+\varphi R)^{2}}
$$

The reaction curves of both agents are positively related to their respective determinants. As long as $\varphi<1$ holds, $I^{*}$ is greater than $D^{*}$ in the Nash equilibrium.

Figure 3a and 3b: Reaction Functions and Shifts Associated to Changes in Ransom Payments and Level of Penalty
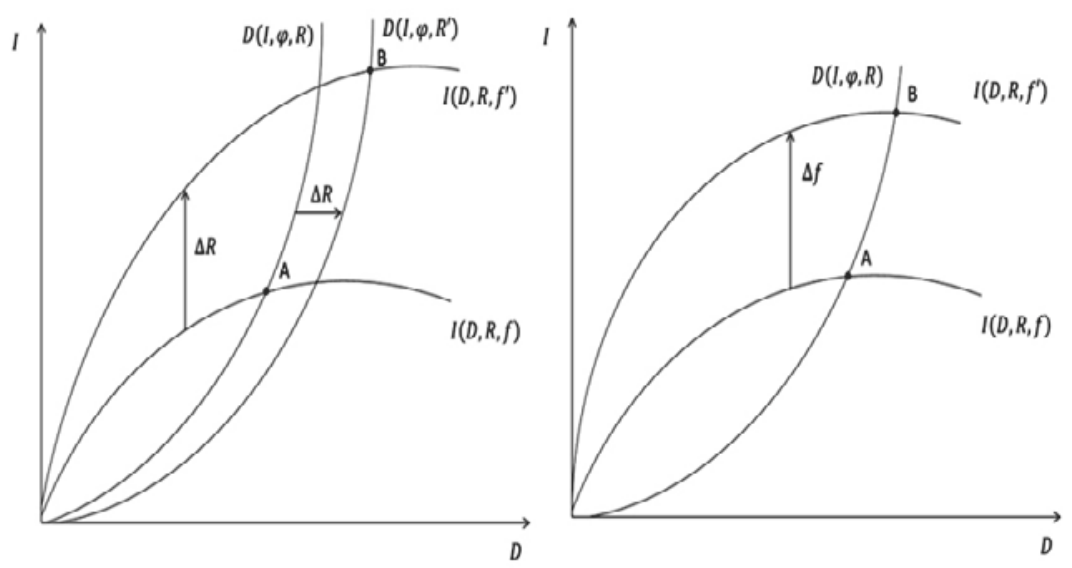

$D(I, \varphi, R)$ : Reaction Function of the Ship-owner

$I(D, R, f)$ : Reaction Function of the Pirate

By substituting $D^{N E}$ and $I^{N E}$ into (1) the probability $p$ in the Nash equilibrium is determined in terms of $R, f$ and $\varphi$ :

$$
p^{N E}=\frac{\varphi R}{\varphi R+R+f}
$$

As one can see, the reaction functions, the Nash equilibrium and thus the probability of successfully defending an attack only depend on the values of $R, f$, and $\varphi$. It is the objective to analyze changes in these exogenous variables to see how the outcome of the model is affected. However, we restrict our analysis to variables affecting the pirate's behavior, as we are particularly interested in his response to policy interventions. A rise in $R$ increases the investment of each agent for any given investment of the opponent. Figure $3 \mathrm{a}$ shows that higher ransom demands shift the reaction curve of the pirate upwards and shift the reaction curve of the ship-owner to the right. The Nash equilibrium is characterized by greater investments into security and attacking measures and thus potential greater violence. A 
positive change in $f$ only affects the reaction curve of the pirate and shift it upwards as can be seen in Figure 3b. The ship-owner's profits are not affected by $f$. His reaction function does not shift. Still, according to his reaction function his optimal investment level responds to the change in the pirate's investment. ${ }^{18}$ Increases in the size of the penalty $f$ decrease $p$ due to the fact, that the change in the pirate's investment is greater than the response in the ship-owners investment. The pirate is worse off when getting caught and increases his investment in order to maximize his utility and to avoid the greater penalty. The ship-owner's reaction function is not affected. Therefore, measures of the international union to combat maritime piracy by increasing the penalty for acts of maritime piracy reduce the probability of defending a pirate attack in the equilibrium. ${ }^{19}$ Although the increase in $f$ increases the pirate's optimal investment $I^{*}$ and hence his chances to be successful with piracy, his expected utility is still reduced, because the decrease in income outweighs the effect of the decrease in $p .^{20}$ In order to reduce piracy, $f$ needs to be set such that expected utility is reduced enough to make income from legal alternatives more attractive. Otherwise piracy is not reduced and the equilibrium is characterized with a higher total investment into crime and defense. The ship-owner is worse off in the Nash equilibrium as his expected profits are reduced due to the change in $p$.

\section{Budget Constraints}

Suppose the ship-owner faces budget constraints and cannot afford investing more than in point $\mathrm{A}$ in Figure 4. Let point B reflect the Nash equilibrium in the absence of binding budget constraints. It is never optimal for the pirate to invest as much as to force the ship-owner to choose an alternative route because the pirate would deprive himself of his own booty. Therefore, from the pirate's perspective, the point A is always optimal, as long as his expected income is greater than his legal income opportunities. Suppose now that only the pirate is constraint in his budget and that he is not able to afford his optimal investment level in response to the ship-owner's investment. The ship-owner now has an incentive to supplant the pirate. Under the assumption that the pirate's capacities limit his investment to point $\mathrm{C}$, the optimal response of the ship-owner according to his reaction function lies in point $\mathrm{C}$, too. As long as equation

\footnotetext{
${ }^{18}$ Similarly, $\varphi$ is only a determinant of the ship-owner's reaction function.

${ }^{19}$ First partial derivatives of the probability function in the Nash equilibrium: $\frac{\partial p^{N E}}{\partial R}>0 ; \frac{\partial p^{N E}}{\partial \varphi}>0 ; \frac{\partial p^{N E}}{\partial f}<0$.

${ }^{20}$ Independently of the pirate's investment level, $\frac{\partial E[U(X)]}{\partial f}<0$ always holds.
} 
(1) holds in point C, piracy is more attractive than the alternative. Let D reflect the threshold where a marginal increase in the ship-owner's security measures results in a situation where the pirate is better off earning his income through legal activities. The ship-owner's best response would be to invest just as much as to oust the pirate. In this case the Nash equilibrium is reflected through the strategies (LA, DR). However this equilibrium only holds, if the threat of the shipowner to invest slightly more than D is credible. This is true if condition 1 holds. Suppose point D reflects the threshold of the pirate and suppose E reflects the threshold of the ship-owner such that he is better off choosing the direct route. In this case, the ship-owner's threat of investing more than $\mathrm{E}$ is not credible and the pirate will not prefer to choose alternative income opportunities. Thus, in equilibrium point $\mathrm{E}$ reflects the associated investment of both players and in the Nash equilibrium piracy occurs. ${ }^{21}$

Figure 4: Reaction Functions in the Presence of Budget Constraints

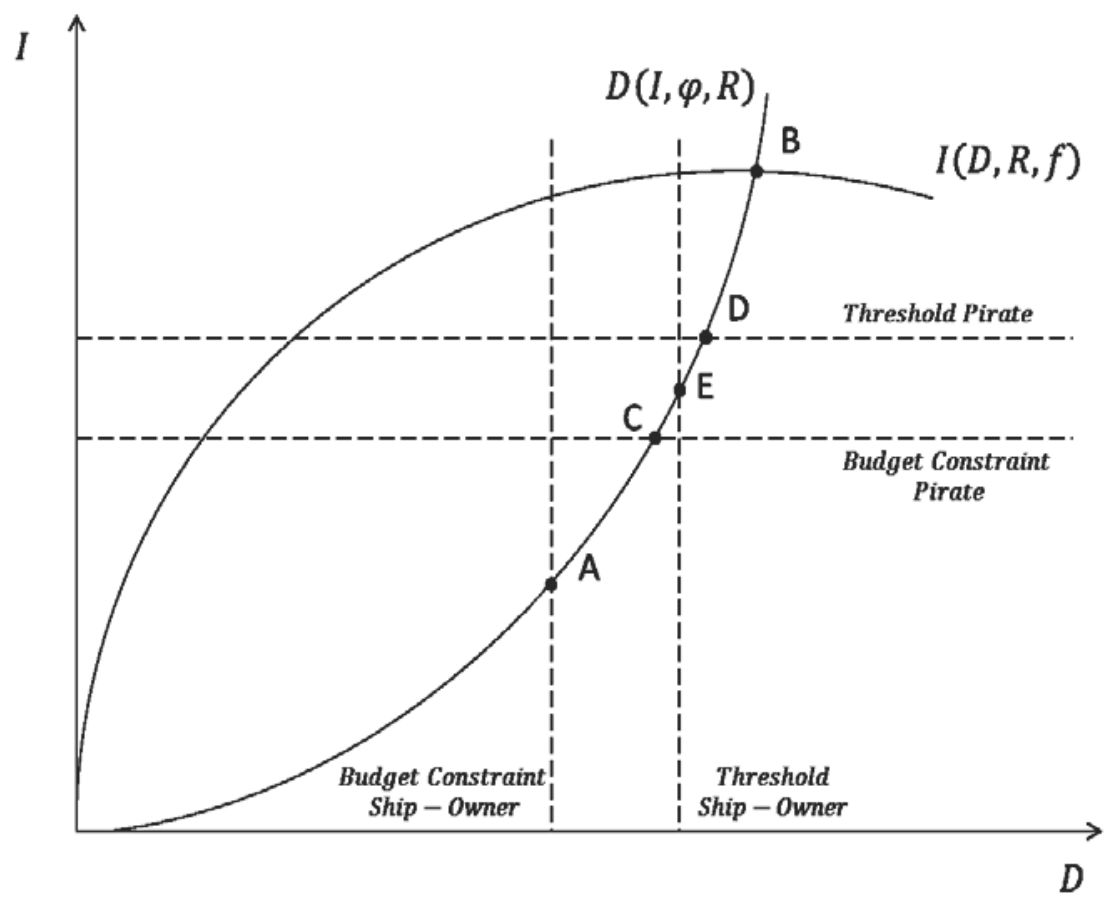

$D(I, \varphi, R)$ : Reaction Function of the Ship-owner

$I(D, R, f)$ : Reaction Function of the Pirate

\footnotetext{
${ }^{21}$ Note that the pirate does not have any incentive to oust the ship-owner.
} 


\section{Implications}

In the framework of the model presented above there are four ways for policy makers to combat piracy. First of all, the level of penalty can be increased. This will reduce expected utility of the pirate, who will respond with higher investments into attacking measures, if affordable. As long as his expected utility from piracy is greater than his utility from alternative income, the probability of success of an attack changes in his favor and to the disadvantage of the ship-owner. Penalties need to be set such that expected returns from piracy are less attractive than alternative income. Practically this is hard to implement and does not make much sense, as low per capita income and high ransom payments have made pirates already willing to risk their lives. What kind of penalty could be more deterring than death? Secondly, the international community could increase the level of sovereign protection, either by increasing the size of safety corridors, or by providing sovereign security guards onboard of merchant ships. In the framework of the model both alternatives could be regarded as a subsidy for the ship-owner, because the sovereign protection increases the probability of successfully defending an attack. Taking this into account the ship-owner decreases his investment for a given level of the pirate's investment. However, resources are still wasted and the danger of an escalation is not eliminated. The pirate will respond to total security investments, thus also to increases in sovereign protection. Thirdly, by regulation the state could force the ship-owner to invest more than the optimal level. This is very costly for ship-owners and would not deescalate the situation. All three points discussed so far have in common, that resources are wasted for protecting or robbing existing wealth. Even if the ship-owner's investment forces the pirate to work in the legal sector, the ship-owner needs to maintain his credibility by keeping up his level of protection. Although these three policy implications bear the risk of an escalation of violence, there are not any better solutions to protect ships and crews in the short run. The fourth policy implies zero rent-seeking costs, but its impact only becomes noticeable in the long run. If alternative legal income opportunities are increased such that these are more attractive relative to the expected return of piracy, then social welfare is optimized because neither the ship-owner nor the pirate have an incentive to waste resources on rent-seeking. Or put differently, raising the pirate's opportunity costs is the most peaceful, sustainable and optimal way to fight piracy, at least from a long-term perspective. 


\section{Summary and Conclusion}

A rent-seeking model was used to analyze the interaction of pirates and ship-owners in a Cournot fashion. The model points out different possibilities to lower the incentives of piracy, such that the decision process of potential pirates based on their economic motives leads to a reduction in piracy. The model is further able to explain the recent decline in attacks as well as the escalation of violence in previous years. As long as the domestic income in Somalia is low, as ransoms are high and as long as the respective capacities for investing into attacking or defense measures are sufficient on both sides, the danger of an increasing willingness to resort to violence exists. In that case law enforcement has no deterring effect. However, if one of the agents is constrained in his budget such that he is not able to optimally react on additional investments by his opponent, his expected income is reduced and opportunity costs rise as alternative income opportunities become more attractive. The recent developments in Somalia seem to be in line with this argumentation. It is unlikely that the deterring effect of penalties or better legal income opportunities were the reason for the recent decline in attacks. Although it is not proven, the increasing security measures of the ship-owners in combination with measures of the international union seem to be rather causal for the decline. Against this background the ship-owners' call for armed security on board of merchant ships is understandable. However, from an economic perspective this situation is not welfare optimal, because resources are used to secure already existing wealth. Furthermore, as Birgit Feldtmann concludes as well, the use of private force needs to be monitored closely, in order to prevent the disproportionate use of violence. It is to conclude from the microeconomic analysis that the most efficient solution to the problem is to raise opportunity costs of the pirates, namely income out of legal activities, in order to make piracy less favorable, e.g., by increasing development aid. This is however only true in the long term and is rather difficult in the context of a failed state like Somalia. As Leeson (2009) demands, the international community must therefore work within an international framework that includes military, civilian, academic, private sector, and NGO sources, as no single entity or state is able to meet the complex requirements to solve the problem by itself. 


\section{Bibliography}

Becker, G. S. (1968). Crime and Punishment: An Economic Approach. Journal of Political Economy 76, 169-217.

BMP4. (2011). Best Management Practices for Protection Against Somalia Based Piracy. Edinburgh: Witherby Publishing Group Ltd.

Bowden, A. (2011). The Economic Cost of Somali Piracy. One Earth Future Foundation Working Paper.

Brown, W. W., and Reynolds, M. O. (1973). Crime and 'Punishment': Risk Implications. Journal of Economic Theory 6, 508-514.

Combined Maritime Forces. (17. 05 2011). Accessed 14.02.2011 from Combined Maritime Forces: http://combinedmaritimeforces.com/2011/05/17/19th-shade-meets-to-dis cuss-counter-piracy/.

Disdier, A.-C., and Head, K. (2008). The Puzzling Persistence of the Distance Effect on Bilateral Trade. The Review of Economics and Statistics, 37-48.

Eide, E. (1999). Economics of Criminal Behaviour. In B. Bouckaert, \& G. De Geest, Encyclopedia of Law and Economics, Vol. V (345-389). Cheltenham, Edward Elgar.

Engerer, H., and Goessler, M. (2011). Maritimer Terrorismus und Piraterie aus Sicht der deutschen Versicherungswirtschaft - Ergebnisse einer Befragung deutscher Transportversicherer. PiraT-Arbeitspapiere zur Maritimen Sicherheit Nr. 12.

Feyrer, J. (2009). Distance, Trade, and Income - the 1967 to 1975 Closing of the Suez Canal as a Natural Experiment. NBER Working Paper.

Geopolicity. (2011). The Economics of Piracy: Pirate Ransoms \& Livelihoods off the Coast of Somalia.

Hallwood, P., and Miceli, T. J. (2011). 'Keystone Cops' Meet 'Pirates of the Somali Coast': The Failure of International Efforts to Control Maritime Piracy. University of Connecticut Department of Economics Working Paper Series.

Hirshleifer, J. (1989). Conflict and Rent-Seeking Success Functions: Ratio vs. Difference Models of Relative Success. Public Choice 63, 101-112.

International Maritime Bureau. (2013). Piracy and Armed Robbery against Ships. Annual Report 2012. Barking, Essex: ICC International Maritime Bureau.

Leeson, P. T. (2007). An-arrgh-chy: the law and economics of pirate organization. Journal of Political Economy, 115(6), 1049-1094.

Leeson, P. T. (2009). Piracy, Economics, and the Law. The Clip Report, 7-19.

Shortland, A., and Vothknecht, M. (2011). Combating "Maritime Terrorism" of the Coast of Somalia. CEDI Discussion Paper Series.

Stringer, D. (2011). Accessed 14.03.2013 from Navy Times: http://www.bloomberg.com/ news/2011-10-30/u-k-ships-to-carry-armed-guards-against-pirates-cameron-says.html

Suez Canal Authority (2012). Traffic Statistics. Accessed 27.03.2013 from http://www.su ezcanal.gov.eg/TRstat.aspx? reportId=3.

United Nations. UNdata. Accessed 15.03.2013 from http://data.un.org/Coun tryProfile.aspx ?crName=Somalia. 


\title{
Discussion on Birgit Feldtmann
}

\author{
summarized by
}

\section{Viola Prifti}

A vivid discussion of the paper focused on the prosecution of pirates as a means of fighting piracy acts. The debate was initially divided between an economic and legal perspective. From a legal standpoint, it was argued that applying criminal law sanctions to piracy offences is justified by the acts of violence on innocent seafarers. It was specifically underlined that penal sanctions aim at avoiding a 'wild west-style justice' scenario at sea. On the other hand, these measures were not considered to be very effective from an economic perspective. The reason behind the economic argumentation lied in the public good nature of punishment and the high costs of its provision. Since these elements are a main cause of free-riding problems among states, underprovision of punishment was reckoned as the expected outcome. Increasing the cost of investments in piracy by destroying its infrastructure was instead suggested as a more viable option.

In this respect, it was emphasized that counter-piracy activities should regard piracy as an organized crime. At this point, there was general agreement to attack the organization of the structure rather than focusing on individual piracy actions. A related comment called the attention to single pirates who act as agents on behalf of the principals' instructions. Therefore, destroying the whole organization was proffered as the most effective solution. In addition, it was suggested that counter-piracy actions should consider hiring pirates as security guards. This option was mentioned to be under discussion for Somali pirates. A toolbox comprising all of the above solutions was, consequently, proffered as a comprehensive means to fight piracy.

Lastly, a conclusive remark drew attention to the effectiveness of the above recommendations in terms of time horizons. In this regard, it was argued that increasing the opportunity costs of piracy will have a short term impact. Military intervention, enforcement of the rule of law, and economic development was - on the contrary - deemed to be a long term solution. 



\title{
A Success? \\ Reflections on the First Ten Years of the International Criminal Court
}

\author{
by \\ Florian Jeßberger / Julia Geneuss
}

On 1 July 2002, the Statute of the International Criminal Court (ICC) entered into force. The tenth anniversary of the establishment of the first permanent international criminal court seems to be a good occasion to look back and reflect on achievements and shortcomings. In this paper, this stocktaking exercise is supplemented by the attempt to apply some elements of a law \& economics approach to issues of international criminal justice in general and the ICC in particular. The latter is done, first and foremost, in order to identify topics and themes for a future research agen$\mathrm{da}-$ and it is warranted precisely because, as will be shown, there still is a significant lack of in-depth research concerning basic issues underlying and shaping the emerging system of international criminal justice.

This paper is organized in three parts. The first chapter briefly summarizes the key characteristics of the ICC, its roots and competences, and outlines its practice (A.). The second chapter inquires into the roles and functions which may be ascribed to the ICC (B.). The third chapter endeavours to identify a few, rather arbitrarily chosen issues which may deserve further scrutiny from the perspective of law \& economics (C.).

\section{A. The ICC in a Nutshell}

The internationalization of criminal justice through the establishment of international enforcement mechanisms is a recent phenomenon. Three milestones have marked the path of the emergence of the system of international criminal justice as we know it today: After World War II, the formation of the International Military Tribunal (IMT) at Nuremberg - and its 'little sister', the International Military Tribunal for the Far East (IMTFE) at Tokyo - set the precedent. For the first time, individuals were actually held criminally responsible directly under international law for the atroci- 
ties they committed during the war, a revolutionary undertaking at the time. Quickly, the so-called Nuremberg Principles were confirmed in resolutions of the UN General Assembly, and refined in drafts and reports by the International Law Commission. In addition, numerous international treaties, the most important being the Geneva Conventions and the Genocide Convention, tied in with the Nuremberg experience. However, it soon turned out that, with powerful states engaged in a cold war, enforcement of international criminal law, either through international or national courts, would rarely take place.

This changed in the mid-1990s with the establishment of the ad hoc Tribunals for the former Yugoslavia and Rwanda, the second milestone in the development of international criminal law. Both Tribunals were created as subsidiary organs by the UN Security Council under Chapter VII of the UN Charter, i.e., as instruments to restore international peace and security. The jurisdiction of the Tribunals is strictly limited in temporal and geographical terms and only applies to the atrocities committed in the two conflicts, the Yugoslavian wars and the Rwandan genocide respectively. After nearly 20 years of what has, according to many, to be regarded as quite successful operation, the ad hoc Tribunals are about to complete their tasks.

The final and most lasting milestone for international criminal law has been the establishment of the permanent International Criminal Court at The Hague. In summer 1998, the UN convened a conference in Rome with a participation of 160 states, 33 Intergovernmental Organizations and a Coalition of more than 200 NGOs. On 17 July 1998, after one month of intense discussions, the Statute of the ICC was adopted: 120 states voted in favor, 21 abstained, and 7 voted against the Statute - the US, Iraq, Israel, China, Yemen, Libya, and Qatar. Just four years later, on 1 July 2002 after the 60th ratification, the Rome-Statute - the first comprehensive codification of international criminal law - entered into force. As of today, the number of states parties stands at 121 . Still, powerful and populous states, such as the US, China, Russia and India, have not yet ratified (or even signed) the Statute. This is one reason why it would be a mistake to regard the ICC as a truly universal 'world criminal court'.

\section{Institution-Building}

The ICC is established not as an organ of the UN but as an independent organization with an independent budget. Thus, in this regard it could only marginally draw on the experience of the ad hoc Tribunals. A large part of the ICC's first years were devoted to institution-building from scratch and, 
despite all of the criticism, it is no surprise that it took some time for the Court to become fully functional.

After the Statute entered into force on 1 July 2002, the Assembly of States Parties - the ICC's 'management oversight and legislative body' adopted the budget of the Court, drafted and adopted the 'Rules of Procedure and Evidence' and the 'Elements of Crimes', and elected the judges, the Prosecutor and his two Deputies. In mid-March 2003 the first 18 judges of the ICC were sworn in. The first prosecutor of the Court, the Argentinean Luis Moreno-Ocampo, was inaugurated in June 2003. This summer he has been succeeded by Fatou Bensouda from Gambia. The judges elected the Presidency of the Court, which in turn assigned the judges to the three different judicial divisions, and recruited and hired legal staff. The judges - all from different legal backgrounds, some criminal lawyers, some diplomats - drafted and adopted the 'Regulations of the Court', established the Office of Public Counsel for the Defence, the Office of Public Counsel for the Victims, and the Victims Participation and Reparations Section. Today approximately 750 staff members are working in The Hague, plus numerous interns and academic researchers. In addition, the Court operates four field offices in Africa.

Over the years, the budget of the Court has constantly increased; from 30 million Euros for the first financial period to approximately 90 million in 2008, to 103 million in 2011. The expenses of the Court are provided by its member states - with Germany and Japan being the major contributors. In addition, at least in theory, according to Article 115(b) of the ICCStatute, the UN shall also provide funds 'in particular in relation to the expenses incurred due to referrals by the Security Council'. However, as will be explained in more detail below, the UN so far has not contributed to any of the Court's expenses.

\section{Jurisdiction, Triggers, Admissibility}

The Court's jurisdiction is limited in several ways. Its subject matter jurisdiction (ratione materiae) encompasses the international core crimes only: genocide, crimes against humanity, war crimes and the crime of aggression. Its temporal jurisdiction (ratione temporis) is restricted to international crimes that were committed after the entry-into-force of the ICCStatute on 1 July 2002. Most importantly, the Court's geographical and personal jurisdiction (ratione loci et personae) is limited according to the territorial and nationality principles, i.e., the crimes must have been committed within the territory or by a national of either a state party or a state which has accepted the Court's jurisdiction in a particular case. This is another reason why the ICC can hardly be regarded as a universally ac- 
cepted and universally operating institution. There is, however, one notable exception to this last mentioned jurisdictional limitation. If the UN Security Council refers a situation to the ICC, the Court's jurisdiction is universal indeed and does encompass crimes that were committed on the territory of non-member states and by non-member state nationals. In this case, the Court's authority flows not from its member states but from the Security Council which may take authoritative action with regard to any UN member state in order to maintain world peace and international security.

Once the Court can claim jurisdiction, this jurisdiction needs to be activated before the Prosecutor can start investigating a specific conflictsituation. This activation can take place through three different modalities, the so-called trigger mechanisms: First, the ICC's Prosecutor can initiate investigations on its own initiative (proprio motu). At the conference in Rome this prosecutorial power was one of the most controversial issues, since several states feared political abuse. Therefore, as safeguard mechanism according to the Statute the Prosecutor needs the Pre-Trial Chamber's approval to initiate investigations. Second, a situation can be referred to the Court by a state party, irrespective of whether the state has a connection to the conflict situation. And finally, as we have already seen, the Court's jurisdiction can be activated by the UN Security Council with the referral of a situation according to a Chapter VII resolution. Thus, the Security Council can use the ICC as a 'permanent ad hoc court' in order to maintain or restore international peace and security. As the flip side of the coin, the Security Council, again acting under Chapter VII, according to Article 16 ICC-Statute can also deactivate the Court's jurisdiction by requesting a (indefinitely renewable) deferral of investigations or prosecution for a period of 12 months.

Once the ICC's jurisdiction has been activated or as a first step as regards her proprio motu powers, the Prosecutor decides to initiate a formal investigation of the situation. A situation generally relates to a specific conflict and is limited in temporal and geographical, sometimes even personal boundaries, e.g., the 'Situation Uganda' or the 'Situation Libya'. During the formal investigations of the entire conflict situation the Prosecutor identifies specific incidents and alleged perpetrators and decides to commence the prosecution of a particular individual, i.e., requests the PreTrial Chamber to issue an arrest warrant or a summons to appear. As regards the decision to investigate or prosecute, the issue of admissibility of the situation or case before the Court becomes relevant, particularly with regard to the much-discussed, core structural principle of complementarity. Generally speaking, the principle of complementarity is a conflict rule, which regulates the relationship between the ICC and national jurisdictions and which distributes the competence to investigate, prosecute and adjudicate. According to this principle, national jurisdictions have (formal) pri- 
macy to investigate, prosecute and punish international crimes. Only when they are unable or unwilling to do so in a genuine and effective manner, the ICC can step in and take over. It should be noted, however, that it is up to the ICC to determine whether any such domestic efforts are sufficient with regard to the criteria set out in the Statute. So far, the ICC interpreted this admissibility threshold rather strict.

\section{Practice}

Currently, the prosecutor of the ICC is investigating seven situations. Of these seven situations, three were referred to the ICC by the state parties on whose territory the crimes took place - arguably after the Prosecutor solicited them to do so (DR Congo, Uganda, Central African Republic). This comparably large number of so-called self-referrals is remarkable and the popularity of this instrument was obviously not anticipated by the drafters of the Statute. Similarly, in one situation a non-member state accepted the Courts jurisdiction and the Prosecutor decided to open investigations (Côte d'Ivoire). Two of the seven situations were referred to the Court by the UN Security Council (Sudan, Libya). So far, only in one situation the Prosecutor opened investigations propio motu (Kenya). In addition to those situations, further eight situations are subject to a preliminary examination by the Prosecutor, including Afghanistan, Colombia, Georgia and Nigeria.

With a look at how the different situations came before the Court, the widespread criticism of Afro-centricity and neo-imperialism becomes less convincing. While all seven situations the Court is currently investigating are situated in Africa, three of them were self-referred by the territorial state and in one case the non-member territorial state accepted the Court's jurisdiction according to Article 12(3) ICC-Statute. In addition, two other conflict situations situated on the African continent were referred to the ICC by the Security Council - with the African members of the Council voting in favour of the Resolutions. Only in one case - the 'Situation Kenya' - did the Prosecutor initiate investigations on his own initiative.

However, it is also important to mention at least one situation, the one concerning Iraq, in which after having received numerous communications from NGOs and individuals as regards the alleged commission of crimes by UK soldiers, i.e., nationals of a state party (mistreatment of detainees and willful killing of civilians), the Prosecutor decided not to initiate a formal investigation. The Prosecutor argued that the crimes committed in this situation were not grave enough compared to the atrocities committed in African countries - a decision that led to broad criticism in public and academia. Another delicate issue concerned a statement lodged in January 
2009 by the Palestinian National Authority under Article 12(3) ICC-Statute which allows states not party to the Statute to accept the Court's jurisdiction. In April 2012, the Office of the Prosecutor finally announced that the determination whether Palestine is a 'state' in terms of the Statute and therefore eligible to make such a declaration goes beyond its mandate and should be left to the relevant bodies of the United Nations.

The Court received its first referral in January 2004 from Uganda, six months after the Prosecutor was inaugurated. In April of the same year the second self-referral came from the Democratic Republic of the Congo (DRC). The first warrants of arrests against a particular defendant were issued in the Ugandan situation in July 2005. The first person who was actually surrendered to the Court was the Congolese Thomas Lubanga Dyilo in January 2006. The trial against Lubanga started in January 2009, six and a half years after the establishment of the Court. After several difficulties (relating, in particular, to issues such as victim participation and disclosure of evidence), the Court rendered the long-awaited trial judgement on 14 March 2012. Trial Chamber I found Lubanga guilty of the war crime of conscripting and enlisting children and using them to participate actively in hostilities. On 10 July 2012 Lubanga was sentenced to 14 years of imprisonment.

Besides the Lubanga-trial, there are currently two other ongoing trials against three accused. Seven individuals are in custody of the Court awaiting trial or confirmation of charges. 18 arrest warrants have been issued (including two against then sitting heads of state) and nine summonses to appear. In three cases (against four defendants) confirmation of charges have been declined by the Pre-Trial Chamber. Up to now, the trials alone have resulted in a total of 4.200 documents filed by the parties and participants, with over 2.200 judicial decisions rendered or orders issued, and approximately 1.800 victims participating in the proceedings through counsel (Ušacka, 2011).

\section{Much Ado About Nothing?}

There can be no doubt that, during the first decade of its existence, the ICC - judges, prosecutors and administration alike - managed to accomplish a huge task, which included not only building an international institution from scratch but also applying and partly consolidating new and un-tested law. Still, many key issues remain either to be determined or highly controversial, such as fundamental questions regarding selection (of situations to investigate and cases to prosecute), and interaction (with other international tribunals, with the UN, with state parties, with domestic justice systems). It is striking that the ICC, so far, concentrated on less controversial 
cases and defendants, in particular cases in which those defendants are not supported by their home states and, additionally, there is (more or less) broad agreement (or indifference) within the international community about the Court's intervention (Langer 2011).

It is also true, that in terms of numbers of suspects under investigation, not to speak about numbers of convictions, the ICC so far has a rather poor output - certainly, if compared to an average criminal court in any domestic system, but also if compared to, say, the ICTY. To many of its supporters this observation is sobering, or even disappointing. However, given the specific circumstances under which the ICC operates and which differ significantly not only from the domestic level but also from the UN backed ad hoc Tribunals, this comparison is neither fair nor appropriate.

So, what makes us think that the ICC so far has been 'a success'? Or, alternatively, what makes us believe, apart from rather simplistic numbers counting, that the ICC has not been successful so far? Of course, there are different ways to answer these questions. Certainly, any answer has to determine a benchmark for measuring 'success' in the first place. In order to identify an appropriate benchmark one has to go one step back and try to define what exactly is the purpose and function - 'the job' - of the ICC.

\section{B. The ICC Still in a Crisis of Identity: Three Courts in One}

According to the Preamble of the ICC-Statute, the Court was established first, to put an end to impunity for perpetrators of 'unimaginable atrocities that deeply shock the conscience of humanity', and second, to contribute to the prevention of such crimes. However, it is quite surprising to note that even after one decade of existence the ways and means how best to achieve these goals, the ICC's specific role and function within the international system, its 'identity', are still not fully determined. Traditionally, the ICC is regarded as a criminal court proper. By now, however, a growing number of scholars seem to agree that the Court has a 'janiform nature' as an ordinary criminal court on the one hand and as a security court on the other (Fletcher \& Ohlin 2005; Ohlin 2010). But closer scrutiny reveals that the ICC's function may better be described by reference to Chimera, the threeheaded creature of Greek mythology rather than by reference to the Roman god Janus. We would submit that it is possible, and necessary, to distinguish three functions rather than two, the third being the one of a "watchdog court'.

Each of those three, separate functions addresses a different level within the multi-levelled system of criminal justice: the individual (perpetrator) 
level, the international (state) level, and the supranational (international community) level.

\section{Determination of Individual Responsibility: The ICC as a Criminal Court}

At first glance, the ICC is an ordinary criminal court operating very similar to criminal courts existing in any domestic legal system. Its task is to prosecute and, where appropriate, convict individuals for specific crimes under its jurisdiction. As a criminal court, the ICC is borne by and derives its authority from its member states. Those states, i.e., the 121 states which ratified the Statute, delegated part of their criminal jurisdiction to the Court which led to a pooling of criminal legal authority.

It would be even more precise to regard the ICC as a complete criminal justice system of its own: comprising not only of a court, but also of a prosecutor, a defense unit, and a, rather incomplete though, police unit (by proxy of the (member) states' law enforcement authorities).

In its function as a criminal court, the ICC is a 'repressive project' that adjudicates individual guilt and innocence only after the crimes have been committed. From a retributive perspective the punishment of the perpetrators of international crimes by the ICC is a good in itself that contributes to diminish impunity. Of course, due to resource constraints it is to be feared that the Court's contribution to put an end to impunity will be rather marginal. The consequentialist approach, on the other hand, where punishment of perpetrators is done in order to prevent future criminal acts focusing either on the same individual (specific deterrence) or on the society at large (general deterrence) is debatable. Many scholars doubt that potential perpetrators involved in mass atrocities - in particular leaders of a state or an organization - will act rationally, weigh the consequences of their actions, and take into account a possible indictment by the ICC (Tallgren 2002).

\section{The Duty to Prosecute and the Principle of Complementarity: The ICC as a 'Watchdog Court'}

Thus, even when acting as a pure criminal court the ICC's main addressees do not seem to be the individuals as potential defendants. Instead, it may be argued that its main purpose is to push states to comply with their international obligations to investigate, prosecute and punish perpetrators of international crimes and, thus, rather indirectly contributes to the overall goals of putting an end to impunity and prevent future atrocities. This obli- 
gation, which is directed first and foremost at the territorial state, has its basis in various international treaties as well as in customary international law. Through the principle of complementarity the ICC is designed as a 'watchdog court' that monitors the territorial state's prosecutorial activity. Only when the state is unable or unwilling to genuinely prosecute and punish the perpetrators of international crimes the ICC is competent to do so itself. Thus, the ICC's possible intervention looming over the affected states' reputation serves as a tool to trigger domestic prosecution and is a 'catalyst for compliance' (Stahn 2011). Otherwise put: the ICC increases, on the part of the states, the costs of default (Megret 2005).

But the principle of complementarity is not only used as a 'stick' to threaten states to comply with their duty to investigate, prosecute and punish international crimes. In its variant as 'positive complementarity' it is used by the Prosecutor as 'carrot' to proactively engage with, assist and encourage states to carry out their primary responsibility of investigating and prosecuting crimes and come to terms with their violent past. It is before this background that the statement of Prosecutor Moreno-Ocampo must be understood who said that the ICC can be regarded as a 'major success' when it had no cases to prosecute.

When making this statement a couple of years ago the Prosecutor, however, seems to have underestimated the popularity of the so-called selfreferrals, a practice which, ultimately, turns the very idea of complementarity inside out. In these cases, states 'waive' their primacy in favor of prosecution by the Court. It is still up for debate whether self-referrals are to be regarded as blessing or curse for the ICC. On the one hand, since the ICC has no enforcement tools of its own this consensual activity of the Court enhances the prospects of the referring state's cooperation and therewith of 'success' (in the sense of successful accomplishment of investigations, prosecutions and possibly trial). On the other hand, those self-referring states outsource their international obligations - and the financial (and political!) burden that comes with it - to investigate, prosecute and punish international crimes. With their self-referrals territorial states 'hijack' the Court and tie up personal and financial resources that could otherwise have been used for investigations propio motu. The ICC must be careful not to become a 'lever', which can be switched on and turned off at the command of states (Stahn 2011).

\section{The Court and the Council: The ICC as a 'World Security Court'}

Reducing the ICC to an ordinary criminal court or to an international institution stimulating and monitoring domestic justice systems would still not 
fully capture its role within the international system. When a situation is referred to the ICC by the Security Council under Chapter VII of the UNCharter the Council employs the Court as an institution to help restore international peace and security with regard to an ongoing conflict between different groups (not necessarily states). In this case, the Court's authority flows not from its states parties, but from the Security Council. In this role the Court transcends the classic goals of criminal law to adjudicate individual guilt (Fletcher \& Ohlin 2004; Ohlin 2010). Instead the Court becomes a player with primarily preventive functions on the international level.

Before this background it has been argued that the international community of states might use the ICC as an 'excuse' and replace military intervention in ongoing conflicts by a less-costly legal intervention. There is, in our view no proof for this assumption (cf. Neumayer 2009). Quite to the contrary, in particular after the Libya-referral there seems to be a strong tendency to regard the notion of 'responsibility to protect' and the legal intervention by the ICC as two separate, but closely connected concepts of a broader peacebuilding strategy (Stahn 2011).

This said, it is still questionable whether the intervention of the ICC can actually contribute to constrain violence in an ongoing conflict and help restore peace between the warring parties. Often the Court is criticized for doing more harm than good to peace negotiations when legally intervening in ongoing conflicts. There is also, of course, a problem with regard to the politicization of the Court when its mandate becomes more 'diplomatic'. And while it might be true that the issuance of an arrest warrant by the ICC attaches a stigma to dictators like the Sudanese President Al Bashir or the late Libyan Colonel Gaddafi and leads to some sort of international delegitimization - due to problems of cooperation Al Bashir still travels to ICC member states without being arrested.

As regards the Darfur and the Libya referrals, there are two additional problems that complicate the relationship between the Court and the Council: First, at the initiative of the US according to both Security Council resolutions which referred a situation to the ICC and despite Article 115 ICC-Statute, the UN shall not provide any funds for the expenses incurred in relation to the situations referred to the Court. Thus, the Security Council 'free-rides' the Court shifting the expenses from UN member states to the ICC's states parties. For example, in the budget for 2012 the expenses for the investigation of the situation in Libya are estimated to amount to 7.2 million Euros. As regards these unfunded mandates there has been some expression of dissatisfaction by the President of the Assembly of States Parties ('We cannot have situations in which States (including nonparty States) send things to the Court and then don't pay'). Nonetheless both referrals - in particular the Libyan referral which was adopted unani- 
mously by the Council enjoying the support of the non-states parties US, Russia, China and India - are generally regarded as highly significant for the Court as a permanent fixture within the international system and were accepted by the Court without further ado.

A second problem relates to the exemption of nationals from nonmember states from the jurisdiction of the Court. Again at the initiative of the US which feared that members of its military could come under the jurisdiction of the Court, according to both Security Council referrals nationals of non-member states do not fall under the Court's jurisdiction for any acts arising out of or related to military operations established or authorized by the Security Council or the African Union. Thus, the Council reserves the right to specify in detail the ICC's jurisdiction ratione personae. Concerning the principle of equality this approach seems questionable. In a similar way, again on the initiative of the US in the very first year of the Court's existence the Security Council exercised its powers under Article 16 ICC-Statute and exempted non-member state nationals active in a (military) operation established or authorized by the UN. This specially tailored de-activation of the Court's jurisdiction was renewed one time for another 12 months before the remaining members of the Security Council signaled that they would not vote for a second renewal (Werle 2007).

\section{Benchmarking Success}

It has been shown, that the ICC can be regarded as 'three courts in one': In its basic function the ICC is a criminal court supported and financed by the Assembly of States Parties. At the same time it acts as a 'watchdog', perhaps coming most closely to a truly 'supranational tribunal', and serves the purpose of making sure that states fulfill their obligations to investigate, prosecute and punish international crimes. In addition, the ICC can be regarded as a 'security court'. In this function the Court is more of an organ of the UN and - in theory - funded by the UN with the purpose of maintaining or restoring international peace and security.

With respect to all these different functions, it is very difficult to empirically measure success and effectiveness of the Court. This is true in particular as regards its function as a criminal court since this issue relates to fundamental and highly disputed questions of the fundamental goals of punishment in general and international punishment in particular. As already mentioned it is doubtful whether the Statute and the ICC can have a deterrent effect, not only because of the general insecurities attached to this purpose of punishment, but additionally because of the Court's - geographic, temporal, cultural, linguistic, etc. - distance from the crimes. 
Likewise, it is very difficult to assess whether the ICC in its function as a 'security court' did actually contribute to restore peace or at least deescalate an ongoing conflict. However, after its first decade of existence it can be observed that the Court by now plays an important role on the international level, which is even acknowledged by states who cannot be considered as belonging to the ICC's closest circle of friends. Whether this politization of the Court is desirable or problematic in the sense that it dismisses the Court to a mere 'bargaining chip' in the hands of the Security Council member states is a different - and difficult - question.

Thus, maybe the most successful - and maybe empirically best measurable - function of the ICC is its role as a 'watchdog court'. Already in the first years of the ICC's existence, although the Statute does not establish any obligations to do so, several states have taken the opportunity and implemented international crimes into their domestic legal order. In view of the principle of complementarity, those states are in a better position to prosecute their own nationals for international crimes and prevent an intervention by the Court. Thus, the Court by its mere existence changed the landscape of international criminal justice not only at the international, but also, and perhaps primarily so, at the national level.

\section{Some (Very) Preliminary Thoughts on the Economic Analysis of International Criminal Justice}

For sure, the major problem in assessing the ICC's success is the lack of research as regards the effects produced by the Court in its first decade. This is unsatisfactory, not the least because the claim of rationality and efficiency is core to every criminal law system - be it international or domestic. Because of this, an economic approach to the analysis of international criminal law may be useful. This holds true notwithstanding that such an approach should be aware of both the general limitations of the economic analysis of international law (cf. Paulus 2009) and the general limitations of a purely utilitarian approach to criminal law (which at least to a certain extent is hostile to traditional European thinking about crime and punishment).

Criminal law is a well-established subject of law and economics, generally focusing on the individual's behavior. The economic analysis of international law, on the other hand, focusing on states as the most important actors within the international legal system is less frequent. International criminal law, a hybrid creature at the intersection of criminal and international law itself a rather young discipline, so far has rarely been subjected to a law and economics perspective. 
While international criminal law is made by states, in contrast to traditional international law its norms do not regulate the relationship between states, but directly impose obligations on the individual. Individuals are the addressees of international criminal law. Thus, an analysis of international criminal law can either focus on the individual, i.e., whether international criminal law has an effect on the individuals' behavior, or on the actions of states. Reflecting this structure of international criminal law - at the intersection of individual responsibility and international/inter-state regulation - there are two natural starting points of a cost/benefit analysis which is crucial to a law \& economics approach.

First, it is possible to think about international criminal law in terms of crime and punishment; such a micro-analysis would take on a perspective which is well known in Law \& Economics (see 1.). Second, an economic analysis of international criminal law in general and the ICC in particular could start from the perspective of states as major actors in the international arena. In such a macro-analysis, the 'sovereignty costs' connected to the surrender of states to the ICC system could be taken into consideration as well as possible benefits (see 2.)

Perhaps a third, separate starting point for an economic analysis of international criminal law (which we will not address further) could inquire into the costs and benefits of establishing mechanisms for the determination and enforcement of individual responsibility on the international level as compared to applying (traditionally existing) inter-state mechanisms of state responsibility. To a certain (although probably small) extent this analysis could benefit from the discussion 'tort law vs. criminal law' on the domestic level (e.g., Posner 1985).

\section{Raising Costs by Increasing Probabilities of Enforcement: A 'Micro-Perspective'}

Traditionally, international criminal law is framed as a response to the widespread impunity of crimes of concern to the international community as a whole. Its very basic idea is to hold accountable those individuals who attack peace, international security and, as the ICC Statute calls it, the well-being of the world.

Of course, general economic theories explaining crime and punishment are, in principle and subject to specific modifications, applicable also to crimes under international law, such as genocide, crimes against humanity and war crimes. Notwithstanding structural specificities of these crimes, i.e., the so-called international element which provides that those crimes have an international dimension, they are ordinary crimes giving rise to individual responsibility. 
Starting from Becker's seminal works on (the economic analysis of) crime and punishment we know that individuals are more likely to commit crimes when the costs of crime are lower and when the probability of apprehension is lower. Now, it may be argued that the establishment of the ICC as well as the emergence of an international system of criminal justice increases the costs of crime. Those costs comprise of not only incarceration, but various elements that would also include, for instance and perhaps relevant for a court which commands only very limited enforcement mechanisms, the social stigma attached to incarceration. Still, the probability of apprehension, even ignoring punishment, is significantly low if it comes to state-sponsored crimes such as international core crimes. Therefore, the argument that - because disproportionate selectivity is a structural feature of the prosecution of international, state-sponsored crimes - the chances of conviction and punishment are (still!) so low that the expected costs of punishment are unlikely to surpass the possible benefits of perpetrating crimes under international law (Langer 2011) has its merit. This would, however, miss out that a significant portion of the 'costs' produced by the ICC does not materialize in prosecutions in The Hague but rather on the domestic level.

\section{Why Some States Join the ICC and Why Some Don't: A 'Macro-Perspective'}

Joining the ICC means not only direct financial costs in form of the member states' contributions to the Court's budget. Additional and perhaps more sensible costs relate to sovereignty. When states join the ICC, they transfer parts of their criminal jurisdiction to the Court and give up some of their decision making autonomy (Simmons \& Danner 2010). In addition, states take the risk that one of their nationals may face a charge before the ICC - a fact which would, arguably (but perhaps with some notable exceptions, see infra), not be in the interest of any state.

These costs are unprecedented. Although the IMT and the IMTFE were established by states, they were only endowed with jurisdiction over crimes committed by the defeated enemies. And both ad hoc Tribunals were not established by states but by the UN Security Council with jurisdiction limited to specific conflict-situations only and excluding, as a matter of fact, nationals of the members of the Security Council.

The question arises why despite those sovereignty costs states actually decided to establish and join the ICC - and why they did not, for instance, opt to subject the ICC's jurisdiction to the recognition of the ICC's jurisdiction by the state concerned in a specific case or even restrict themselves to refine existing and, perhaps, create new international treaty regimes in 
order to enhance interstate cooperation. Why do 121 states obviously believe that the costs of joining the ICC-Statute are outweighed by potential gains; why do other states believe that the costs are too high?

It is obvious that motives vary from state to state (cf. Simmons \& Danner 2010). To approach an answer to these questions, it may therefore be helpful to distinguish different groups of states. There is a variety of possible criteria for such a distinction, including the political 'strength' and geopolitical standing of the respective state, the possible exposure of nationals of the respective state to prosecution and punishment, the quality of the internal order of the respective state (democracy, rule of law, human rights), the stability of the respective state, and the historical record of international crimes committed either by or against the respective state.

For example, strong states without a history of recent conflicts on their territory - for example most of European states - might see no disadvantages (no 'risk') in joining the Court. They assume that, safeguarded by the principle of complementarity, the ICC will never adjudicate crimes that were committed either on their territory or by their nationals, either because they believe that they will not be involved in such conflict-situations or, if exceptionally, their citizens that are somehow involved in an international conflict do commit such crimes they believe that they will be willing and able to investigate and prosecute themselves. Thus, they assume their actual sovereignty costs will be rather low - while earning at least a lot of reputational benefit. All in all it seems like these states while providing the main part of the ICC's budget, regard the Court as an institution established not for themselves, but for others.

In addition, at least some of these states, those which have implemented the principle of universal jurisdiction, might even see an extra benefit in joining the ICC. Those states are now able to argue that a specific case should rather be adjudicated by the ICC (given that the ICC has jurisdiction) than by its own domestic courts under the principle of universal jurisdiction. Thus, the ICC takes the pressure off those states when it comes to investigation or prosecuting politically sensitive cases. It's also usually those states, like Germany and Spain, that argue that the principle of complementarity must be construed in a way that gives the ICC's jurisdiction precedence over the jurisdiction of third states. Being able to point at the ICC when it comes to politically sensitive cases that fall under a state's universal jurisdiction means less pressure and less political (internal) and diplomatic (external) costs.

With regards to weaker, internal conflict-prone states - particularly African states - it is less clear why they decided to join the ICC. Since there is a higher risk of ICC scrutiny their sovereignty costs seem to be much higher. Several factors are mentioned to explain why those states join the ICC, generally external factors like peer pressure, expectations of devel- 
opment aid, or simply to appease the Court. Another, specific benefit to those states may be that they - through the mechanism of self-referrals can now use the Court as a tool to comply with their obligation to punish perpetrators of international crimes. This way, the activity of the Court can be regarded as a matter of choice, as an expression rather than a limitation of their own sovereignty - a benefit and not a cost. Others developed what they call a 'credible commitment theory' and argue that joining the Court is a self-binding commitment by the respective government addressed at the state's own population (Simmons \& Danner 2010).

\section{Concluding Remarks}

Ten years after it has been established, and despite many flaws, the ICC is a functioning criminal court indeed. The times when the ICC was applauded for the very fact that it exists are, however, over. Now, what matters is that the Court gains momentum.

Whether the first ten years can be regarded as a success very much depends on the perspective. Possible benchmarks for assessing the Court's performance relate to what function is ascribed to the Court. We would submit that at least regarding stimulation of domestic activity against international crimes, most notably the implementation of the Statute, the Court may be regarded as a success. Whether the same holds true with regard to the Court's direct contribution to the 'fight against impunity' and the prevention of future international crimes and, even more doubtful, with regard to the Court's capacity to contribute to the maintenance of international peace and security is not as clear.

Anyway, it's about time to address a number of crucial issues related in more depth. There are good reasons to think that an economic analysis could help to understand and explain the ICC as a major player in international criminal justice - and, ultimately, to improve it.

\section{Bibliography}

Arsanjani, M. H. and Reisman, W. M., The Law-in-Action of the International Criminal Court, American Journal of International Law 99 (2005), 385.

Becker, G. S., Crime and Punishment: An Economic Approach, Journal of Political Economy 76 (1968), 169.

Dunoff, J. L. and Trachtman, J. P., The Law and Economics of Humanitarian Law Violations in Internal Conflict, American Journal of International Law 93 (1999), 394.

Ehrlich, I., Criminal Justice, in Newman, P. (ed.), The New Palgrave Dictionary of Economics and the Law (1998).

Fletcher, G. and Ohlin, J., The ICC - Two Courts in One?, Journal of International Criminal Justice 4 (2006), 428. 
Goldsmith, J., The Self-Defeating International Criminal Court, University of Chicago Law Review 70 (2003), 89.

Langer, M., The Diplomacy of Universal Jurisdiction, American Journal of International Law 105 (2011), 1.

Megret, F., Why Would States Want to Join the ICC? A Theoretical Exploration Based on the Legal Nature of Complementarity, in Kleffner, J. (ed.), Complementary Views on Complementarity (2005).

Nerlich, V., The International Criminal Court 2002-2010 - A View from the Inside, Criminal Law Forum 22 (2011), 199.

Neumayer, E., A New Moral Hazard? Military Intervention, Peacekeeping and Ratification of the International Criminal Court, Journal of Peace Research 46 (2009), 659.

Ohlin, J., Peace, Security, and Prosecutorial Discretion, in Stahn, C. and Sluiter, G., The Emerging Practice of the International Criminal Court (2009), 185.

Paulus, A., Potential and Limits of the Economic Analysis of International Law: A View from Public International Law, Journal of Institutional and Theoretical Economics 165 (2009), 170.

Posner, R., An Economic Theory of the Criminal Law, Columbia Law Review 85 (1985), 1193.

Posner, R. and Sykes, A. O., The Economics of State and Individual Responsibility Under International Law, American Law and Economics Review 9 (2007), 72.

Schabas, W., The International Criminal Court at Ten, Criminal Law Forum 22 (2011), 493.

Simmons, B. A. and Danner, A., Credible Commitments and the International Criminal Court, International Organizations 64 (2010), 225.

Stahn, C., How is the Water? Light and Shadow in the First Years of the ICC, Criminal Law Forum 22 (2011), 175.

Tallgren, I., The Sensibility and Sense of International Criminal Law, European Journal of International Law 13 (2002), 561.

Ušacka, A., Promises Fulfilled? Some Reflections on the International Criminal Court in Its First Decade, Criminal Law Forum 22 (2011), 473.

Werle, G., Principles of International Criminal Law, $2^{\text {nd }}$ ed. (2007). 



\title{
Comment on Florian Jeßberger / Julia Geneuss
}

\author{
A Success? \\ Reflections on the First Ten Years \\ of the International Criminal Court
}

by

\author{
Eyal Benvenisti
}

\section{A. Introduction}

In their review of the practice of the International Criminal Court (ICC) in its first decade, Florian Jeßberger and Julia Geneuss (Jeßberger and Geneuss) provide a comprehensive account for assessing the achievements of the court and of the challenges it faces. They identify the court's three roles (a criminal court, a "watchdog" court, and a "world security" court) and point out that it is very difficult to empirically measure its success and effectiveness on each of these three functions. Nevertheless, they suggest that its effectiveness can be proven merely by the very fact of its existence, as "the establishment of the ICC as well as the emergence of an international system of criminal justice increases the costs of crime." They also elaborate on the question why states join the ICC. This is an illuminating account to which I subscribe. In the following comments I would like to offer three points for further reflection on the role of the ICC from the perspective of law and economics: the role of the ICC as lawmaker, the motivations state actors have for setting it up, and the extent to which this court is independent. 


\section{B. A Fourth Role?}

As Jeßberger and Geneuss mention, the rise of international criminal adjudication is a post-Cold War phenomenon. The special tribunals which were set up starting with the ICTY and the ICTR not only adjudicated perpetrators (the first role, according to Jeßberger and Geneuss), and not only contributed, albeit indirectly, to the third role of constraining violence in other ongoing conflicts. The emerging jurisprudence of these courts has also had a tremendous impact on developing the law on the conduct of hostilities: questions thus far discussed under international humanitarian law (IHL) have found judicial answers - often quite innovative ones - in the judgment of ad-hoc criminal tribunals. ${ }^{1}$ Specifically, these courts revolutionized the law pertaining to non-international armed conflicts (civil wars), imposing on governments fighting "rebels" strict rules accompanied by effective enforcement measures. Until the ICTY ruled on this matter, the law on "internal armed conflict" was quite meager - due to the resistance of many non-western governments - and the ICTY purposefully transformed that law by creative analysis of "state practice" that allowed it to invoke "customary international law" as the basis of its judgments. ${ }^{2}$

Undoubtedly, those states which were behind the creation of the ad hoc tribunals were aware of the law-making potential of these ad-hoc criminal courts. They realized that through judge-made law that creatively invoked customary international law they could impose on recalcitrant governments, mainly in the developing world, constrains they would hesitate to commit to in treaties. In fact, some of those states expressed their apprehension that the newly established tribunals would make new law and

\footnotetext{
${ }^{1}$ On the lawmaking by international criminal tribunals, see Kuhli et al. (2011); Swart (2010); Danner (2006).

${ }^{2}$ This is vividly recalled by the late Antonio Cassese, who served as President of the ICTY, in an interview with Professor Weiler conducted in 2003 (http://www.ejiltalk.org/ nino-in-his-own-words/). According to Cassese, the court faced the following challenge: "because this [wa]s an internal armed conflict, we [couldn't] apply rules which only apply to international armed conflict." The question was therefore "shall we move forward and be creative? [...] should we stick to the traditional concept that war crimes can only be committed in international armed conflict?" Cassese abhorred such an outcome: "This to me [wa]s crazy! A rape is a rape; a murder is a murder, whether it is committed within the framework of an international armed conflict, a war proper, or a civil war. The doctrine that had been upheld by everybody, including the International Committee of the Red Cross, was that if you kill civilians, you rape women, you murder wounded POWs in an internal armed conflict - this is not a war crime. [...] So I said 'why don't we jettison this stupid distinction?' My colleagues said 'yes we agree with what you are saying, it's very nice, but how can you create this criminal offence?' [...] So I took six months, and set up a team. [we went] through state practice and we came up with a lot of evidence... well some evidence.[laughter]".
} 
sought to limit that possibility, ${ }^{3}$ but of course, to no avail. The same states may have different preferences with respect to the ICC, which is a general, "ex ante," court whose jurisprudence could affect their own behavior. The extent to which the ICC's jurisprudence would ultimately reflect these preferences and be more timid in expanding state obligations than the adhoc courts remains to be seen.

Indeed, the story of lawmaking by international criminal tribunals offers a good example for an economic analysis of international lawmaking: by empowering international courts which can "find" new norms by interpreting existing texts and practices, those states that set up such courts can overcome the need to obtain other states' consent for new legal obligations. $^{5}$

\section{Whose Motivations?}

Jeßberger and Geneuss discuss the motivations of states to set up or join the ICC. They distinguish between groups of states. There are those states which do not anticipate that their military and civilian leadership would find themselves subject to the ICC's jurisdiction either because these states are not expected to engage in armed conflicts or because their internal judicial system is sufficiently robust to offer reliable prosecution that would eliminate the need for ICC prosecution under the complementarity criterion. Moreover, the ICC relieves states from the costly obligation - indeed, the global collective action problem - of trying foreign defendants.

Jeßberger and Geneuss find less clear the motivation of "weaker, internal conflict-prone states" to join the ICC. And indeed, scholars have come up with several explanations which Jeßberger and Geneuss mention, and these explanations may well be accurate. These writers approach the question of motivations from the perspective of states as unitary actors. But economic analysis of state practice and of international law must not remain at the level of states. Instead such analysis must look beyond the "veil of sovereignty" and in the best tradition of political economy it must examine the motivations of different actors within the state that pushed for joining the ICC or those who opposed the court. Indeed, it has been acknowledged that international law is often used by domestic actors to stabilize their internal relationships. A treaty can lock in political victory

\footnotetext{
${ }^{3}$ Cogan (2008) cites on p. 438 statements by the representatives of Argentine and Venezuela during the Security Council debates on the establishment of the ICTY and the ICTR to the effect that these international tribunals would not have powers to modify international law.

${ }^{4}$ Arsanjani/Reisman (2005).

${ }^{5}$ Benvenisti/Downs (2011); Bogdandy/Venzke (2011).
} 
better than a constitutional provision. ${ }^{6}$ Setting up international organizations can insulate the regulation of issues such as trade or human rights protection from domestic contestation. Examples include the adoption of regional human rights regimes, such as the European Convention on $\mathrm{Hu}-$ man Rights, ${ }^{7}$ and the international regulation of trade. ${ }^{8}$

There is no reason to think that the same doesn't hold true in the context of the regulation of warfare and the prevention of crimes by soldiers and commanders. Indeed, in a forthcoming article, Amichai Cohen and I argue that the evolution of IHL and many of its doctrines can be explained as designed to resolve acute problems of governance that take place during fighting, as soldiers and even their commanders, might have different goals than the goals of the government that sent them to battle. From a principal agent perspective, IHL as well as international criminal law should be viewed as tools for the principals (the government vis-à-vis the army, or army commanders vis-à-vis their subordinates) to control their military agents. ${ }^{9}$ A relative weak government that has limited information about what transpires in the battlefield and few tools to induce compliance by is military, could use the credible threat of external enforcement through, inter alia, foreign or international criminal courts. Accordingly, relatively weak governments whose armies may be involved in armed conflicts and who are concerned about the negative results of insubordination might opt for an external court who would serve as a credible threat to the troops. As the surprising examples of "self-referrals" suggest, weak governments can also benefit from an international court to resolve the politically sensitive trial of army heroes. ${ }^{10}$

\section{Is The Court Independent?}

Economic analysis of courts operating within states explores the factors that ensure their independence and thereby their ability to promote outcomes of their choice through creative interpretation and application of the law. This scholarship suggests that judicial independence depends on the degree of political competition among the major political actors and the extent there are policy differences among them. In general, the greater the competition and policy differences, the more "political space" is available for courts to operate within, and the broader their independence and discretion is in setting and implementing policies. The absence of these

\footnotetext{
${ }^{6}$ Benvenisti (2008).

${ }^{7}$ Moravcsik (2000).

${ }^{8}$ Down/Rocke (1995).

${ }^{9}$ Benvenisti/Cohen (2014).

${ }^{10}$ Arsanjani/Reisman (2005).
} 
conditions renders dependent courts which follow the dictates of the political branch that controls them. ${ }^{11}$ The same analysis is applicable to international courts: to the extent that the court is controlled by a handful of states it is likely to show partiality to their demands. ${ }^{12}$

This analysis can be used to study the extent to which the ICC is independent of the state parties that are parties to the ICC Statute, or perhaps to another group of states. One of the more sensitive questions in the design of the ICC processes was the how to ensure the independence and as a result - the impartiality of the Prosecutor. Jeßberger and Geneuss do not address this question directly. They assume that the ICC is independent because it is "established not as an organ of the UN but as an independent organization with an independent budget." Independence is conditioned by a host of factors which include nominations, promotions, respect to judgments, the ability to shape public opinion, and finally the control of the court's budget. ${ }^{13}$

Among the factors that promote independence of the ICC judges and Prosecutor is the fact that they are elected for non-renewable term. States cannot "punish" them the way they can punish, say, the UN Secretary General, or judges of the Appellate Body of the WTO, by not reelecting him (or her) for another term. Other factors that are more problematic are the Prosecutor's dependence on powerful states in a number of areas. The Prosecutor would need assistance by powerful states that control conflict zones in the gathering of evidence and in arresting and extraditing suspects. Powerful states can effectively put pressure on other countries to cooperate with the court. Finally, and perhaps most delicately, is the dependence on states contributions to the ICC's budget. As Jeßberger and Geneuss point out, the court's budget is quite limited, and is shouldered primarily by a handful of states, led by Germany and Japan. Together Japan and the European Union provide more than three quarters of the ICC's budget. ${ }^{14}$ Approved annually, the negotiation over the budget has proved a taxing experience for a Prosecutor eager to expand the court's scope of activities and facing donors eager to cut expenses. Informally, the ritual of budget approval has become an opportunity for the donor countries to canvass the Prosecutor's plan of action for the forthcoming year. Beyond the Prosecutor's independence, state contributions may informally be connected with the composition of judges. One report criticized Japan because

11 Stephenson (2003); McNollgast (2006); McNollgast (1995); Ginsburg (2003), 21-33; Ramseyer (1994); Landes/Posner (1975).

${ }_{13}^{12}$ Benvenisti/Downs (2011).

${ }^{13}$ On the requirements for independence and impartiality of international criminal tribunals see Meron (2005), 360-61.

${ }^{14}$ See the annual reports of the Committee on Budget and Finance, available on the ICC website. 
they "successfully nominated two judges who were not qualified lawyers." 15 The EU and Japan are also well represented among the court's judges. Small wonder that some observers have linked the court's budgetary constraints to the question of its independence. ${ }^{16}$

\section{Bibliography}

Arsanjani, M. H. and Reisman, W. M. (2005), "The Law-in-Action of the International Criminal Court" in: The American Journal of International Law 99, 385-403.

Benvenisti, E. (2008), "Reclaiming Democracy: The Strategic Uses of Foreign and International Law by National Courts" in: The American Journal of International Law 102, 241-274.

Benvenisti, E. and Downs, G. W. (2011), "Prospects for the Increased Independence of International Tribunals" in: German Law Journal 12, 1057-1082.

Benvenisti and Cohen, War is Governance: Explaining the Logic of the Laws of War from a Principal-Agent Perspective in: Michigan Law Review 112 (forthcoming 2014).

Bibas, S. and Burke-White, W. W. (2010), "International Idealism Meets DomesticCriminal-Procedure Realism" in: Duke Law Journal, Vol. 59, 637-704.

Binham, C. (14 Sep. 2011), "The Hague Struggles to Find Judges" in: Financial Times, available at: http://www.ft.com/intl/cms/s/0/ecbbe978-dede-11e0-9130-00144feabdc0 .html\#axzz22qkZb5Zo (5. Aug. 2012).

Bogdandy, A. Von and Venzke, I. (2011), "Beyond Dispute: International Judicial Institutions as Lawmakers" in: German Law Journal 12, 979-1004, also available at: http://www.germanlawjournal.com/pdfs/FullIssues/PDF_Vol_12_No_05_Beyond\%20 Dispute\%20Special_Complete\%20Issue.pdf (5. Aug. 2012).

Cassese, A. (2003), "Nino in His Own Words", available at: http://www.ejiltalk.org/ninoin-his-own-words/ (5. Aug. 2012).

Cogan, J. K. (2008), "Competition and Control in International Adjudication" in: Virginia Journal of International Law 48, 412-449.

Danner, A. M. (2006), "When Courts Make Law: How the International Criminal Tribunals Recast the Laws of War" in: Vanderbilt Law Review 59, available at: http://papers.ssrn.com/sol3/papers.cfm?abstract_id=822809 (5. Aug. 2012).

\footnotetext{
${ }^{15}$ Binham (2011).

${ }^{16}$ Bibas/Burke-White (2010), 677: "Second, financial dependence can compromise independence and impartiality. Funding often turns on the support of rich, powerful states. When the ICTY Prosecutor decided not to investigate crimes by NATO forces in Kosovo and Serbia, she might have feared that such an investigation would jeopardize the U.S.'s and U.K.'s financial support. The ICC Prosecutor's decision not to investigate crimes by British forces in Iraq raised the same question of independence"; O'Donohue (2005), 603: "[...]having failed to invest in appropriate mechanisms to consult with the Prosecutor on strategy issues which fully respect his independence, states have actively used the budgetary process as a forum for strategic discussions and have made decisions that impact on the strategy of the Prosecutor." In general see Reydams/ Wouters (2011) (p. 3: "As he depends on external support and cooperation for the accomplishment of his mission, an international prosecutor can ill afford to ignore the positions of the various stakeholders and the distribution of power among them.")
} 
Downs, G. W. and Rocke, D. M. (1995), Optimal Imperfection? Domestic Uncertainty and Institutions in International Relations.

Ginsburg, T. (2003), Judicial Review in New Democracies: Constitutional Courts in Asian Cases.

Kuhli, M. and Günther, K. (2011), "Judicial Lawmaking, Discourse Theory, and the ICTY on Belligerent Reprisals" in: German Law Journal 12, 12611278, available at: htt p://www.germanlawjournal.com/index.php?pageID=11\&artID=1360 (5. Aug. 2012).

Landes, W. M. and Posner, R. A. (1975), "The Independent Judiciary in an InterestGroup Perspective" in: Journal of Law and Economics 18, 875-901.

McNollgast (1995), "Politics and the Courts: A Positive Theory of Judicial Doctrine and the Rule of Law" in: Southern California Law Review 68, 1631-1683.

McNollgast (April 2006), "Conditions for Judicial Independence", Research Paper No. 07-43, available at: http://ssrn.com/abstract=895723 (5. Aug. 2012).

Meron, T. (2005) "Judicial Independence and Impartiality in International Criminal Tribunals" in: The American Journal of International Law 99, 359-369.

Moravcsik, A. (2000), "The Origin of Human Rights Regimes: Democratic Delegation in Post War Europe" in: International Organization 54, 217-252.

O'Donohue, J. (2005), "The 2005 Budget of the International Criminal Court: Contingency, Insufficient Funding in Key Areas and the Recurring Question of the Independence of the Prosecutor" in: Leiden Journal of International Law 18, 591-603.

Ramseyer, J. M. (1994), "The Puzzling (In)dependence of Courts: A Comparative Approach" in: Journal of Legal Studies 23, 721-747.

Reydams, L. and Wouters, J. (2011), The Politics of Establishing International Criminal Tribunals, available at: http://ssrn.com/abstract=2020329 (5. Aug. 2012).

Stephenson, M. C. (2003) “"When the Devil Turns...': The Political Foundations of Independent Judicial Review" in: Journal of Legal Studies 32, 59-89.

Swart, M. (2010), "Judicial Lawmaking at the ad hoc Tribunals: The Creative Use of the Sources of International Law and 'Adventurous Interpretation"” in: Zeitschrift für ausländisches öffentliches Recht und Völkerrecht 70, 459.

The annual reports of the Committee on Budget and Finance, available on the ICC website. 



\title{
Discussion on Florian Jeßberger / Julia Geneuss
}

\author{
summarized by
}

Joseb Gudiashvili

Opening the discussion, Professor Fehling emphasizes the importance of using the methodological tools of economics in order to analyze the international criminal law and court. In addition, he proposes following two questions or controversies, which could be implemented into economic model of Prof. Jeßberger:

In Fehling's view, it is relatively unclear the strategic goal of the ICC. Is it to enhance ideal of justice across the globe? Or it is to promote the idea of European neo-colonialism? It is only for very weak countries? He supposes that some countries are immune towards the ICC influence, whereas others and mainly among less developed countries in Africa are less immune. On the other hand side, according Mr. Fehling, the International Criminal Court establishes basic ideas of criminal procedure, so called minimal standards in international criminal justice.

Stefan Voigt shortly depicts an economics model of Sutter, regarding the ICC and emphasizes a time inconsistency problem. Using a backward induction method in evaluating the ICC success, Voigt remarks that International Criminal Court can be seen as a deterrent factor for potential perpetrators of international crimes. But, if rulers already commit crimes against humanity, ICC could play very negative rule in enhancing their willingness to hold in power.

Taking his word, Prof. Kirchner questions following approach to see states as rational utility maximizers and proposes to stick to the methodology of individual actors. According his view, main actors are citizens, which demand from their states to "buy" international security and global rule of law as a global public good. Therefore, one can observe certain collective action problems in international criminal justice within the ICC system.

In addition, Mr. Kirchner observes the ICC as a principal instrument to expose crime-prone situations around the globe.

In response to above remarks, Prof. Jeßberger admits the selectivity issue, put forward by Prof. Benvenisti and observes it as a rather general problem for criminal law, even for domestic criminal law. Furthermore, Mr. Jeßberger 
does not agree with labelling of the court as neo-colonial institution or sole court for one continent and suggests to analyze the referrals. From all ongoing judicial cases within the International Criminal Court, the prosecutor initiated only one case and all remaining cases were either referred by African states or by the United Nations Security Council. Regarding the substantive part of the Rome Statute, Mr. Jeßberger sees it as a model code for substantive procedure and points out its influence, as well as convergence factor for domestic legislations.

Reopening the discussion, Mr. Benvenisti suggests measuring the effectiveness of the International Criminal Court via comparing the indictments before and after establishment of the court. According to his opinion, comparison of indictments could define the role of the ICC in increasing or diminishing of rule of law worldwide.

The next comment comes from Mrs. Feldtmann and she asks the presenter and fellow professors, whether pure indictment numbers can be seen as success. Furthermore, he suggests examining more closely the function of the court, its stakeholders and future role. Getting back to the argument of Mr. Voigt, Prof. Marauhn remarks the importance of time inconsistency and payoffs of relevant parties. Additionally, he recommends to analyze incentives of governments to sign the Rome Statute and observe it in accordance to commitment theories. Furthermore, Mr. Marauhn emphasized the role of specific interest groups within European liberal democracies, which may demand from their governments more human right protection and rule of law worldwide.

Taking his word, Prof. Schmidtchen agrees with Mr. Kirchner and sees international criminal justice as global public good, where no country is willing to bear individual costs for more human rights protection and lesser crimes worldwide. Moreover, he sees certain possibility of ICC abuse in order to gain competitive advantage over rivals in a domestic political power games. Florian Jeßberger partially agrees with this argument and brings an example of Libya, where ICC became active and started prosecution only with regard to crimes committed by Gaddafi and his close allies and not with regard to crimes committed by rebels.

In summary, Eyal Benvenisti observes the International Criminal Court as a more or less cost-efficient and effective instrument to prevent massacres and crimes against humanity in less developed and more violent-prone countries. In order to prevent massive humanitarian crises, he observes two main strategies:

1. Military Intervention

2. Using international law in general and International Criminal Court in particular, as a legal strategy for global security

Adding on that remark, Prof. Oeter brings an example of United States of America and its refusal to ratify the Rome Statute of International Criminal 
Court because of anticipated military interventions and strategy of preemptive strikes.

Closing the discussion, Laarni Escresa turns to the transaction cost analysis and depicts minimization of transaction costs between ad hoc international tribunals and permanent court as possible success factor of ICC. Furthermore, she supposes that specialized mixed courts can be more effective in delivering justice. 



\title{
The European Constitutional Impossibility Theorem
}

\author{
by \\ Christian Kirchner ${ }^{*}$

\section{A. Introduction}

\section{The problem}

The history of European integration since 1951 may be seen as a road to an 'ever closer union'. The signatories of the Treaty of Rome expressed their determination "to lay the foundations of an ever closer union among the peoples of Europe." The preamble of the Maastricht Treaty added the principle of subsidiarity. ${ }^{1}$ The preamble of the Lisbon Treaty returned to the text of the preamble of the Treaty of Rome without reference to the principle of subsidiarity.

The move towards 'an ever closer union', i.e., deeper integration, means that more and more powers have to be conferred on the European level. This can be undertaken by Treaty revisions, ${ }^{2}$ by court decisions of the European courts or by a new interpretation of the Treaties establishing the European Union $^{3}$ by the European Commission, the Council, and the European Parliament.

\footnotetext{
* Prof. Dr. iur. Dr. rer. pol. Dr. h.c. Christian Kirchner, LL.M. (Harvard), Humboldt University, School of Law / School of Business and Economics, Member of the managing board of Wittenberg Center for Global Ethics e.V.

${ }^{1}$ The signatories of the Maastricht Treaty wanted "to continue the process of creating an ever closer union among the peoples of Europe, in which decisions are taken as closely as possible to the citizen in accordance with the principle of subsidiarity."

${ }^{2}$ The terms 'Treaty revision' and 'Treaty amendment' are both being used for substantial changes of a Treaty; but 'Treaty amendment' has a more positive connotation. 'Treaty revision' is a neutral term.

3 Treaty establishing the European Coal and Steel Community; available at: http://www.lexnet.dk/law/download/treaties/Est-1951.pdf (last access: 13 Sept. 2012); Treaty establishing the European Economic Community (EEC); available at: http://ww w.lexnet.dk/law/download/treaties/Ect-1957.pdf; (last access: 13 Sept. 2012); Treaty establishing the European Atomic Energy Community (Euratom); available at: http://www.lexnet.dk/law/download/treaties/Eat-1957.pdf (last access: 13 Sept. 2012); Single European Act (SEA); available at: http://www.lexnet.dk/law/download/treaties/Sea-1986.pdf
} 
The goal of an 'ever closer union' has been criticised because of its centralisation effect. ${ }^{4}$ Centralisation leads to higher externalities in the light of divergent preferences of citizens of different Member States. Agency costs will rise because of enhanced difficulties of citizens to make political decision makers follow citizens' preferences (democracy deficit). Decentralisation means a lower degree of integration. This may be accomplished by repatriating powers to Member States. The same procedures to be applied for the transfer of powers to the European level could be employed for repatriating powers. Treaty revisions are the most important instrument here as well.

If Treaty revisions play a prominent role in power transfers into both directions, procedural rules for Treaty revisions are of utmost importance for either centralisation or decentralisation. In order to find out whether moves towards more (or less) integration can be undertaken within the present legal structure of the European Union, it is necessary to analyse the existing Treaty revision provisions (positive analysis) and possible circumventions. This type of analysis is different from the studies which have been interested in the effects of different degrees of centralisation. ${ }^{5}$ Some of these studies have dealt with the constitutional problems in Europe. ${ }^{6}$ It was the European Constitutional Group ${ }^{7}$ which brought into play the issue of a Treaty revision clause. ${ }^{8}$ The prominent goal of that clause was to prevent further centralisation. As a consequence the clause adopted a strict unanimity rule. But the introduction of that clause into the proposals of the European Constitutional Group was not based on an analysis of existing Treaty revision provisions. It was a working group at the European University Institute which presented an analysis of Treaty revision clauses. $^{9}$ But this was not a positive but a normative analysis without a clear methodological fundament, stressing the need for more 'flexibility' in order to be able to attain the goal of deeper integration. The EUI-proposal which cul-

(last access: 13 Sept. 2012); Treaty on European Union (TEU) (Maastricht Treaty); available at: http://www.lexnet.dk/law/download/treaties/Ect-1992.pdf (last access: 13 Sept. 2012); Treaty on European Union (TEU) (Amsterdam Treaty); available at: http://www.lexn et.dk/law/download/treaties/Eut-1997.pdf (last access: 13 Sept. 2012); Treaty on European Union (TEU) (Nice Treaty); available at: http://www.lexnet.dk/law/download/treaties/Eut2001.pdf (last access: 13 Sept. 2012); Treaty on European Union (TEU) (Lisbon Treaty); available at: available at: http://www.lexnet.dk/law/download/treaties/Eut-2001.pdf (last access: 13 Sept. 2012).

${ }^{4}$ European Constitutional Group (1993), (2006); Kirchner (1997); Vaubel (1997).

${ }^{5}$ Blankart (2007); Feld/Zimmermann/Doering (2007); Salmon (1987).

${ }^{6}$ Blankart (2007); Bernholz/Schneider/Vaubel/Vibert (2004); Breuss/Eller (2004); European Constitutional Group (1993), (2004); Kirchner (1997).

${ }^{7}$ Information concerning the European Constitutional Group under: http://www.freiheit.or g/webcom/show_article.php/_c-603/_nr-7445/i.html (last access: 12 Sept 2012).

${ }^{8}$ European Constitutional Group (1993), (2003), (2006), bringing into play a revision clause.

${ }^{9}$ EUI (2000). 
minated in the call for an abolition of the unanimity rules for Treaty revisions,${ }^{10}$ did not find sufficient political support. The revision of the revision clause of the old Treaty on European Union (Nice Treaty) in the new Treaty on European Union (Lisbon Treaty) did not give up the unanimity rule as such. But it mitigated the effect of that rule, by providing three different types of Treaty revisions, two of them with reduced Member State participation.

In December 2011, the Member States of the European Union failed to attain a unanimous vote on a 'fiscal compact', which demonstrated the problems of the - revised - Treaty revision provisions of the Lisbon Treaty. In the light of these problems the author undertook a short economic analysis of the unanimity rule for Treaty revisions. ${ }^{11}$ It is the purpose of this paper to develop a more refined analysis of the Treaty revision provisions of the Lisbon Treaty on the fundament of that earlier paper. The following considerations are not confined to an economic analysis of Art. 48 TEU. They are looking into the underlying legal issues as well and deal with alternative modes of Treaty revisions. ${ }^{12}$

\section{The thesis of the paper}

The thesis of this paper is that due to present legal provisions for Treaty revisions in the Lisbon Treaty major moves into the direction of either deeper or less integration are impossible (European Constitutional impossibility theo$\mathrm{rem}^{13}$ ). This is the case for a revision of existing revision provisions as well. Thus, the present balance of competences between Member States and the European level is being petrified. Only slight shifts of power can be achieved within the present legal structure of the European Union.

\section{Structure of the paper}

For analysing the 'European Constitutional impossibility theorem' the methodological fundament of the analysis is of utmost importance. The assumptions of constitutional economics (as a sub-discipline of New Institutional Economics) have to be introduced. On that methodological fundament the historical and the political context of European Treaty revisions have to be brought into play. Legal issues of European Treaty revisions cannot be left

${ }^{10}$ EUI (2000), 19-26.

${ }^{11}$ Kirchner (2012).

${ }^{12}$ It has been Thomas Eger who has drawn my attention to Art. 20 TEU (enhanced cooperation) in his comment. This gives me an opportunity to comment on his comment.

${ }^{13}$ The term has been introduced by the author in his presentation at the Fifth Annual Conference of the Transatlantic Law Forum at Bucerius Law School "Constitutionalism in Crisis?", Hamburg, Oct. 28 - 29, 2011. 
aside, because the economic analysis to be undertaken here is not interested in Treaty revisions under model assumptions but in Treaty revisions of the present European constitution in the given legal context. But the constitutioneconomics analysis is going beyond the existing legal discussion. It is based on a clear methodological fundament and separating clearly between a positive and a normative approach.

\section{B. Methodological issues}

\section{Constitutional Economics: assumptions}

Constitutional economics ${ }^{14}$ - as a sub-discipline of New Institutional Economics $^{15}$ - is dealing with specific legal rules; constitutional ones. It may be understood as economics of constitutions under the assumptions of scarce resources, self-interested rational behaviour of all actors (citizen, political actors, and others), incomplete information and the existence of transaction costs. ${ }^{16}$ Constitutions are being understood as a set of fundamental meta-rules which govern law-making and decisions on lower levels. Some, but not all scholars of Constitutional Economics share the assumption of bounded rationality with New Institutional Economics. ${ }^{17}$

Constitutional economics is interested - like New Institutional Economics - in the rules of the game, and how such rules affect the game. But it is confined to constitutional rules. If actors have to decide which constitutional rules to opt for, they are acting under a veil of uncertainty,$^{18}$ which is reducing decision costs. But the degree of uncertainty may change over time. It is different for initial constitutional decisions and for later constitutional revisions. ${ }^{19}$

Decisions to be taken under the veil of uncertainty may be fully rational. But the rationality assumption in the field of constitutional economics is neither very realistic nor useful in terms of its heuristic value. The complexity of the analysis is being raised if the assumption of bounded rationality ${ }^{20}$ is being

${ }^{14}$ Brennan/Buchanan (1985/1993); Buchanan (1974), (1986), (1990); Buchanan/Tullock (1962); McKenzie (ed.) (1984); Mueller (2008); Pies (1993), 121-155; Vanberg/Buchanan (1989); Van den Hauwe (1999); Voigt (1999).

${ }^{15}$ Coase (1984); Erlei/Leschke/Sauerland (2007); Furubotn/Richter (2005); North (1990); Richter/Furubotn (2010); Voigt (2009).

${ }^{16}$ Richter/Furubotn (2010), 2-14; Voigt (2009), 19-33.

${ }^{17}$ Richter/Furubotn (2010), 2-14, 519-550.

${ }^{18}$ Literature in Fn. 42.

${ }^{19}$ Kirchner (2012).

${ }^{20}$ Kahnemann (1994), (2011); Kahnemann/Tversky (1979); Kirchner (1994); Selten (1990); Simon (1982). 
introduced. Today that assumption is based on empirical research of existing rationality deficits. ${ }^{21}$

In constitutional-economics analysis the assumption of systematically incomplete information and of information asymmetries between different groups of actors are playing a prominent role. ${ }^{22}$ Treaty revisions within the structure of European Union law take place in a context of representative democracy with only minor elements of direct democracy. Thus information asymmetries between citizens of Member States and national and European political decision makers are a decisive factor in Treaty revisions. Such asymmetries are more pronounced in relations between Member States citizens and European political decision makers compared to those between citizens and their national political decision makers.

\section{The context}

\section{Historical context}

In order to understand the problem of constitutional petrification due to application of the unanimity rule it is helpful to have a look into the origins of the unanimity concept. This concept has to be seen as a necessary complement to the concept of national sovereignty. The concept of sovereignty of nation states - i.e., external sovereignty - has been developed in the 17th century, but can be traced back to medieval times. ${ }^{23}$ It is being attributed to the writings of Hugo Grotius, ${ }^{24}$ but may be traced back to a Spanish scholar named Francisco de Vitoria. ${ }^{25}$

It makes sense to distinguish the internal and the external concept of national sovereignty. The concept of internal sovereignty refers to the authority over a given territory and its inhabitants. ${ }^{26}$ The concept of external sovereignty relates to the relationship of nation states to one another and means that there is no final authority above and beyond the sovereign state. ${ }^{27}$ The principle of

${ }^{21}$ Conslik (1996); Jolls/Sunstein (eds.) (2000); Kahnemann (1994); Korobkin/Ulen (1999).

${ }^{22}$ This is due to the fact, that the principal-agent relationship between citizens as principals and political decision-makers as agents is one of the main corner stones of constitutional economics.

\footnotetext{
${ }^{23}$ Kantorowiz (1957); Philpott (2001), (2010).

${ }^{24}$ Grotius (1625).

${ }^{25}$ Scott (2000).

${ }^{26}$ Held (2003).

${ }^{27}$ Philpott (2010).
} 
national sovereignty was protecting nation states by the guarantee that no foreign nation would interfere into internal affairs. ${ }^{28}$

The concept of (external) sovereignty had been the necessary precondition for negotiating and concluding a Peace Treaty between the German emperor, the German princes and those European nation states which were involved in the Thirty Years' War in $1648 .{ }^{29}$ The old concept of supremacy of the German emperor over the princes of the various German states had to be abandoned in order to allow a peace between equals. National sovereignty of the parties concluding the Peace Treaties of 1648 had the consequence, that the unanimity principle had to be applied. Any diversion from that principle would have violated the (external) sovereignty of a state which did not approve the Treaty. Thus the unanimity rule in public international law may be described as an offspring of the principle of national sovereignty. Whereas the principle of national sovereignty has been criticized and modified, when it comes to the doctrine of non-intervention into internal affairs, ${ }^{30}$ it has not been challenged in the concept of concluding Treaties under public international law and has found its way into the Vienna Convention on the Law of Treaties. ${ }^{31}$

In order to solve the problem of unanimity within the World Trade Organization, a distinction is being made between multilateral and plurilateral agreements. ${ }^{32}$ Whereas multilateral agreements apply to all members of WTO, plurilateral agreements are applied only to those countries, which are the signatories of such Treaties. ${ }^{33}$ Thus agreements, for which unanimity cannot be achieved, may be concluded as plurilateral agreements. The unanimity problem is being solved by confining the parties of the agreement to parties which are consenting.

\section{Legal context}

The legal context for Treaty revisions of Treaties establishing the European Union comprises: (1) public international law with its focus on the principle of unanimity (see Section C.I) and (2) European Union law.

\footnotetext{
${ }^{28}$ Straumann (2008).

${ }^{29}$ Peace Treaty between the Holy Roman Emperor and the King of France and their respective Allies, available at: http://avalon.law.yale.edu/17th_century/westphal.asp (last access: 7 Sept. 2012).

${ }^{30}$ Held (2003); Osiander (2001); Philpott (2001) and (2010).

${ }^{31}$ Vienna Convention on the Law of Treaties, done at Vienna on 23 May 1969, entered into force on 27 January 1980; available at: http://untreaty.un.org/ilc/texts/instru ments/english/conventions/1_1_1969.pdf (last access: 7 Sept. 2012).

${ }^{32}$ Bhagirath, L. D. (1998), 3 ; an example for a plurilateral agreement is 'The plurilateral Agreement on Government Procurement (GPA)'; available at: http://www.wto.org/eng lish/tratop_e/gproc_e/gp_gpa_e.htm (last access: 9 Sept. 2012).

${ }^{33}$ Bhagirath, L. D. (1998), 3.
} 
After the failure of the European Constitutional project the Nice Treaty was revised by the Lisbon Treaty, which fell back behind the deeper integrationgoals of the 'Constitution for Europe', but nevertheless advanced into that direction. ${ }^{34}$ Art. 48 TEU $^{35}$ was revised in order to introduce a simplified revision procedure (Art. 48 par. 6$)^{36}$ and a general bridging provision (passerelle) (Art. 48 par. 7). ${ }^{37}$ The different procedure will be discussed in more detail in Section F.I. But it is important to understand that the unanimity rule as such has not been abandoned.

The Treaty on European Union (Lisbon Treaty) allows a sub-group of Member States to enter into so-called enhanced cooperation (Art. 20 TEU). This might serve as an instrument to evade the unanimity rule. Thus, this instrument will be discussed in more detail in Section F.II.

\section{Economics of the unanimity rule in constitution-building}

\section{Unanimity Rule in the 'Calculus of Consent'}

Economic analysis of the unanimity rule has been one of the major topics in the Calculus of Consent by James Buchanan and Gordon Tullock. ${ }^{38}$ This rule is a corner stone of an individualistic approach to constitutional economics. It minimizes externalities and protects individual freedom. But this positive appraisal of the unanimity rule may be revisited in the light of decision costproblems. $^{39}$

\section{Economics of constitution-building, the veil of uncertainty and decision making costs}

In constitution-building the drafters are acting under a 'veil of uncertainty'. ${ }^{40}$ This veil of uncertainty, used in constitutional economics, is in some way similar to the veil of ignorance. ${ }^{41}$ The latter one may be traced back to Harsanyi. ${ }^{42}$ It is one of the methodological cornerstones in Rawls' 'Theory of Jus-

\footnotetext{
${ }^{34}$ Kurpas (2007); Streinz (2008).

${ }^{35}$ From now on 'Art. 48 TEU' is referring to the Lisbon Treaty.

${ }^{36}$ Literature on the simplified revision procedure: Benz (2008); Ó Broin (2010).

${ }^{37}$ Ó Broin (2010), 2; Crowe (2008), 204.

${ }^{38}$ Buchanan/Tullock (1962), chapter 7.

${ }^{39}$ Kirchner (2012); the following line of discussion is based on that article.

${ }^{40}$ Vanberg/Buchanan (1989), 52-56; Van den Hauwe (1999).

${ }^{41}$ On the distinction between veil of ignorance and veil of uncertainty: Van den Hauwe (1999), 619-621); Leschke (1995).

${ }^{42}$ Harsanyi (1953).
} 
tice'. ${ }^{43}$ In Rawls' approach the 'original position' corresponds to the state of nature in the traditional theory of social contract, but not to an actual historical state of affairs. The 'original position' is being understood as a purely hypothetical situation. ${ }^{44}$ According to this methodological instrument actors do not know their place in society, their class position or social status, their fortune in the distribution of natural assets and abilities, their intelligence, strength and their like. ${ }^{45}$ This methodological instrument may be helpful in discussing standards of fairness and justice. But if the constitution-building process has to be analysed and normative propositions have to be developed, it makes sense not to refer to such a hypothetical situation. Thus, in constitutional economics a less impermeable veil has been developed: the veil of uncertainty. ${ }^{46}$ Here it is sufficient that actors, who want to build a constitution, are not certain about the effects of rules in separate individual positions, so that particular interests cannot be related to particular rules. ${ }^{47}$ The veil of uncertainty in constitutional economics may be understood as a specific case of the assumption of systematically incomplete information in New Institutional Economics. Translated back into the terminology of constitutional economics this means, that the veil of uncertainty is less impermeable compared to the veil of ignorance.

The veil of uncertainty may be understood as a device to reduce decision making costs. If in the constitution-building process the participating actors do not know how they will be affected by the rules chosen, they will come to a collective decision at lower costs compared to a situation, where they are better informed. As a consequence decision making costs will rise if the veil of uncertainty becomes more permeable.

\section{Constitution-building and the combination of the unanimity rule and the veil of uncertainty}

If the unanimity rule serves as the meta-rule in constitution-building no participant has to accept externalities from rules he did not consent. Thus, the unanimity rule is protecting the preferences of all participating actors. The result of constitution-building is conformity with normative individualism. If decision making costs are zero the unanimity rule is the optimal solution. But decision making costs are existent. In order to come close to the optimal result, it is essential to reduce decision making costs. If decisions are being taken under a thick veil of uncertainty decision making costs are supposedly mini-

\footnotetext{
${ }^{43}$ Rawls (1971); Rawls (1979).

${ }^{44}$ Rawls (1979), 10.

${ }^{45}$ Rawls (1979), 10.

${ }^{46}$ Leschke (1995), 78.

${ }^{47}$ Van den Hauwe (1999), 620.
} 
mal. The combination of the unanimity rule and the veil of uncertainty are promising a result close to optimum.

\section{Constitution-building in a principal-agent-context}

If the constitution-building actors do not draft and enact the constitution on their own, but if they delegate constitution-building to experts, e.g., members of a constitutional convention, this will affect the veil of uncertainty as well as decision making costs. Now information asymmetries are coming into play. In constitutional economics this means that the veil of uncertainty is different for principals and agents. In constitutional economics citizens are the principals, whereas political decision makers, to whom constitution-building powers have been delegated, are their agents. The agents are supposedly better informed about the expected effects of the rules they are drafting than the principals. The rationale behind the delegation of powers is to reduce decision making costs. But decisions taken by the agents may diverge from citizens' preferences, thus adding preference costs. In order to prevent or minimize such preference costs citizens may try to control agents, producing agency costs. They are confronted with a trade-off between preference costs and agency costs.

It has been argued that the veil of uncertainty is different for principals and agents. In a principal agent relation the agent supposedly is better informed than the principal. But when it comes to constitution-building principals do have a strong incentive to protect them and prevent high preference costs in the future. Thus, the common assumption of information asymmetry between principal and agent might have to be qualified in constitutional economics. But there are good reasons to stick to the information asymmetry assumption in constitutional economics. The means and ends-paradigm and the critique of that paradigm have to be brought into play. ${ }^{48}$

\section{Constitution-building, the means and ends-paradigm and its critique}

To better understand the information asymmetry between principals and agents it is necessary to have a closer look into the process of constitutionbuilding. The envisaged constitution may be regarded as a tool to serve certain ends. Then the constitution is an instrument to attain certain goals. Thus, the drafters of a constitution are confronted with the means and endsparadigm and its critique.

${ }^{48}$ Hayek (1937); Homann (1980), 286-300; Kirchner (2010), 140-141; Luhmann (1973); Pies (1993), 24-37; Streit (2005), 270. 
The means-and-ends paradigm has its origin in the problem of solving or mitigating scarcity of resources. In order to do so, resources have to be used where they are producing the optimal output. Given the ends the input (means) has to be minimised. Or put into the other version: Given the means output has to be maximised. This simple relationship between input and output has been criticized because unintended side effects are not being taken into account. ${ }^{49}$ Thus, the goal to be attained is no longer given, but is depending on the input. This insight is important for any endeavour in the field of law-making and/or constitution-building. In case of constitution-building the drafters have to find out what could be the unintended side effects. The intended positive effects of the envisaged constitution are clearly visible, whereas prediction of the potential side effects is difficult. The information asymmetry between agents and principals is being reinforced by the fact that agents have better access to information concerning possible side effects of constitutional rules.

If the agent - engaged in constitution-building - finds out such side effects he will have no incentive to inform the principals about side effects which will have negative consequences for the principals. As a rational actor the agent will not endanger his re-election. In case the agent is expecting that the side effects will only become public after the expiration of his political mandate he is not interested in informing principals during the period of his mandate.

The means-and-ends paradigm is essential for constitutional economics. It can explain a tendency of exploiting the given information asymmetries by political decision makers in order to draft constitutional rules, which are being favoured by their constituency not being aware of potential unintended consequences.

\section{Constitution-building in case of a hybrid constitution}

The conventional model of constitution-building is referring to a situation where citizens of a well-defined nation state agree on a set of meta-rules which define the basic legal structure of the state and in most cases fundamental rights of citizens. There are principal agent relations between citizens, members of a constitutional convention or of the legislature. In case of a constitution of an international organization additional actor will enter the scene. Members of governments of nation-states - acting as agents of their citizens agree on the meta-rules for the given international organization in a Treaty under public international law. This constitution then has to be ratified in the envisaged Member States either by the legislature or by referendum. Principals are no longer being represented by members of a constitutional conven-

\footnotetext{
${ }^{49}$ Hayek (1969).
} 
tion or of the legislature but by members of government. Agency costs are rising because of the longer agency chain. Citizens elect the members legislature which then elects and controls the government. In the ratification process citizens have the choice between accepting and refusing the Treaty negotiated and signed by their government. But they cannot rewrite the text of the Treaty. Thus, in case of constitution-building for an international organization the position of principals are much weaker compared to the case of national constitution-building. From the perspective of citizens their veto power is decisive. This is especially true in case of ratification by referendum. Whereas the Treaty is one of international law, ratification rules are governed by national law. The position of citizens is being better protected by national law. They may be interested in strict ratification rules which are strengthening their position. But in the end citizens' position in constitution-building for an international organisation is much weaker compared to their position in national constitution-building.

This complicated process of constitution-building in case of international organizations may explain, why the meta-rules for the General Agreement on Tariffs and Trade (GATT) allow for multilateral and plurilateral Treaties. Plurilateral Treaties are only binding the participating GATT Members. The unanimity rule is applied, but the group of participating countries if flexible (see Section C.I.)

Whereas legal rules for constitution-building for the nation state and for international organizations are well defined, the picture is much more complex and rules for constitution-building have been changing over time in case of hybrid constitutions. A hybrid constitution is defining the meta-rules for a supranational entity (from now on called 'supranational union') which has been endowed with law-making power to enact supranational law. The first supranational constitution has been the Treaty Establishing the European Coal and Steel Community in $1951 .{ }^{50}$ In 1957 the Member States of that Community enacted the Treaty Establishing the European Economic Community (Rome-Treaty) and the Treaty establishing the European Atomic Energy Community. ${ }^{51}$ In all three cases the Member States concluded a Treaty governed by public international law. At first glance the three communities look like common international organizations. But these supranational organizations are insofar different from international organizations as they have their own legislature and judiciary. Whereas the legislature is confined to enact supranational law within the limits of the Treaties (so-called secondary law),

50 Treaty establishing the European Coal and Steel Community; available at: http://www.lexnet.dk/law/download/treaties/Est-1951.pdf (last access: 13 Sept. 2012).

51 Treaty establishing the European Economic Community; available at: http://www.lexnet.dk/law/download/treaties/Ect-1957.pdf (last access: 13 Sept. 2012); Treaty establishing the European Atomic Energy Community; available at: http://www.lexn et.dk/law/download/treaties/Eat-1957.pdf (last access: 13 Sept. 2012). 
the law courts are interpreting the Treaties (so-called primary law). They are engaged in judicial law making as well on the level of primary and of secondary law. ${ }^{52}$

This specific type of hybrid constitution - combining international and supranational law - is combining elements of international and supranational law for a supranational union of nation states which itself is a hybrid between a confederation and a federal state. ${ }^{53}$ International Treaties form the legal fundament of the supranational union, emphasizing its confederate nature. Supremacy of supranational law of the supranational union vis-à-vis national law of Member States in a system of vertical allocation of powers on the European and on the national level is emphasizing the federal character of the supranational union. It has been the German Federal Constitutional Court which has underlined the confederate nature of the supranational union with the argument that sovereignty of Member States must not be eroded under the German constitution. ${ }^{54}$ National sovereignty of Member States is the legal fundament for constitution-building on the supranational level. According to this position the various Treaties establishing the European Community and then the European Union are Treaties under public international law. This means the unanimity rule cannot be given up.

If constitution-building for a supranational union, e.g., the European Union, takes place on the level of international law, it is closer to the creation of international organizations than to national constitution-building. The position of citizens of the Member States is extremely weak. The legal instruments to protect the principals are - national - ratification rules.

\section{E. The economics of constitutional revisions}

\section{The dynamics of the veil of uncertainty and the petrification effect}

The economics analysis of a revision of an existing constitution is differing from that of constitution-building in one important aspect. The veil of uncertainty has been changed between the time of the original constitution-building and the time of the revision. The actors who are engaged in revision of a giv-

${ }^{52}$ Ginsburg (2005); Komarek (2011).

${ }^{53}$ Kirchner (1997).

${ }^{54}$ BVerfG, 2 BvE 2/08 vom 30.6.2009, Absatz-Nr. (1 - 421), available at: http://www. bundesverfassungsgericht.de/entscheidungen/es20090630_2bve000208en.html (last access: 13 Sept. 2012), and http://www.bundesverfassungsgericht.de/entscheidungen/es2009 0630_2bve000208en.html (last access: 13 Aug. 2012); press release: Federal Constitutional Court - Press office -, Press release no. 72/2009 of 30 June 2009; available at: http://www. bundesverfassungsgericht.de/pressemitteilungen/bvg09-072en.html (last access: 13 Sept. 2012). 
en constitution are well informed about the effects of constitutional rules of the present constitution. They know much about the non-intended consequences of that constitution. Thus, in drafting revisions they are better equipped in understanding, of how the new rules are working in practice. The veil of uncertainty has become less impermeable. This means higher decision making costs. The simple message is self-evident: Decision making costs for revisions of existing constitutions are higher compared to that of initial constitution-building (petrification effect). ${ }^{55}$

The petrification effect is reinforcing path dependency. Even if the present constitution turns out to be suboptimal in the light of principals' preferences it is very costly to revise that constitution. This effect should be known ex ante so that constitution drafters have the chance of solving or mitigating the problem by drafting a revision clause that provides for a certain degree of flexibility. In practice most revision clauses contain various super majority provisions but in most cases not the unanimity rule. As a consequence preference costs are higher. Protection of minorities is being weakened.

If the drafters of the constitution did not tackle the problem of petrification and path dependence ex ante and have written a strict revision clause it is extremely difficult to amend this revision clause which does not allow flexibility. The reason is simple: In order to amend the revision clause it is necessary to revise the - old - constitution. The old revision clause is being applied. Minorities which are protected by the strict revision clause may not be interested to lose their status and block a revision of the revision clause. The petrification of the revision clause is reinforcing the petrification of the constitution as such.

\section{Escaping the petrification trap by circumventing the unanimity rule}

If a strict revision clause of a constitution is preventing major changes of that constitution, citizens might watch for other solutions than revising the existing constitution. They may abandon the old constitution and draft a new one. They may interpret the old constitution in a manner which is giving space for the desired changes. They may disregard the old constitution or parts of it and allow unconstitutional activities. Legal scholars would identify the third option as unlawful and focus their attention on measures to prevent such unconstitutional activities. Economists are more realistic. They would be interested in the incentives to engage in unconstitutional activities and their probability.

\footnotetext{
55 This constitutional-economics definition of 'petrification' is different from the definition in Austrian constitutional law, where the petrification doctrine ("Versteinerungstheorie") is indicating a specific mode of interpreting the constitution; Gamper (2009), 160.
} 
They would be interested in measures to prevent such activities as well but would put the question, how effective such measures would be.

The implications of these three unconventional problem solutions are different. A new constitution-building endeavour is very costly, but it minimizes preference costs. A new interpretation of the old constitution is a matter of judicial law-making, which can only be done by a law court. The agency relation between citizens as principals and judges is an indirect one. Even if the judges are being appointed by political decision makers who act as agents of citizens, the power of principals is decisively weakened. Agency costs are rising. Thus preference costs in case of judicial revision of a constitution are very high. This is the price for the - necessary - independence of the judiciary. The third problem solution - allowing unconstitutional - activities has its price as well: The actors are deciding on their own which unconstitutional activity they prefer. For principals it becomes extremely difficult to control them. Agency costs and preference costs are rising tremendously.

\section{Revision of a hybrid constitution}

In case of a revision of a hybrid constitution public international law comes into play and thus the unanimity rule (see Section C). Even if all governments of the international Treaty would agree on the revision, ratification might cause difficulties. In case of ratification via a vote of the legislature members of the legislature come into play as new actors. Principal-agent relations between citizens and members of the legislature are different from that between citizens and members of government. Citizens are in a better position to control members of the legislature than to control members of government, if members of the legislature have to expect not be re-elected if they do not take into account citizens' preferences. A revision of a hybrid constitution becomes more difficult, if a referendum is necessary to ratify the Treaty in question.$^{56}$ Citizens are directly involved and can better protect their preferences.

Ratification rules are part of national law. The member states of a supranational union with a hybrid constitution may adopt easy or strict revision rules. Members of the government might prefer easy ratification rules, in order to facilitate national ratification. If they have negotiated the terms of revising an international Treaty they are supposed to be interested in an easy ratification. Thus they would prefer ratification by the legislature. Citizens are supposed to prefer strict ratification rules, thus strengthening their position vis-à-vis members of the government. According to this hypothesis the problem is being understood as a conflict between national principals and national agents. But this view does not take into account the international dimension of the problem.

\footnotetext{
${ }^{56}$ Hug/Schulz (2007).
} 
The unanimity rule applicable for revisions of international Treaties is relevant for the bargaining positions of participants of that Treaty. Under the unanimity rule it makes sense to play a veto game. The actor who has held back his consent until all other actors have given their consent is in a strong bargaining position. This is a rent-seeking game. In this game two different veto positions have to be distinguished: (1) the veto on the level of negotiating the Treaty, and (2) the veto on the ratification level. Whereas the veto on the negotiation level has been studied in detail, ${ }^{57}$ the veto on the ratification level did not find much attention. ${ }^{58}$ For the citizens and members of government of a potential veto player it might make sense to adopt strict ratification rules in order to strengthen the veto position in the negotiation process. Even if the government has given its consent it might have a chance to renegotiate the terms of the revision of that Treaty if national ratification cannot be achieved without certain changes.

Whereas the original hypothesis has stressed the interest of national governments in easy ratification rules in order to evade effective control exercise by their citizens, the second hypothesis is contradicting the first one: it could make sense for all national actors to adopt strict ratification rules in order to strengthen the international bargaining position of that country.

If a country belonging to a supranational union with a hybrid constitution has been able to strengthen its bargaining position via strict ratification rules other Member States might copy the strict ratification rules. This may lead to a race to the top (in terms of better protecting citizens' preferences). Thus, the revision of a hybrid constitution becomes extremely costly in terms of decision making costs. In the end the petrification of the hybrid constitution is complete.

The picture of a hybrid constitution developed here is incomplete insofar as there is not only the choice between ratification via the legislature or via referendum. In case of ratification via the legislature citizens might try to stop ratification via the judiciary. Now, another actor comes into play, in most cases the constitutional court of the country. The court might stop ratification or might introduce certain reservations and formulate conditions which have to be fulfilled in order to allow ratification. If the other Members of the supranational union have ratified the Treaties the judgement of the constitutional court of the veto player may lead to renegotiation of the Treaty. In case of stopping the ratification as such the Treaty has to be renegotiated. In case of a reservation of the veto player renegotiation on the introduction of such reservations might be necessary. If the Treaty is being concluded under the Vienna Convention on the Law of Treaties ${ }^{59}$, articles 19-23 of that convention are covering the process of how to introduce unilateral reservations into an exist-

\footnotetext{
${ }^{57}$ Koenig/Finke (2007).

${ }^{58}$ But Hug/Simon (2007) and Kirchner (2012).

${ }^{59}$ See Fn. 31.
} 
ing international Treaty. If not all Member States of the supranational union have signed (and ratified) the Vienna Convention, renegotiation on the acceptance of the reservation by the other Member States are necessary. In order to make such acceptance binding under international law, it is necessary to revise the original Treaty. It is doubtful whether or not such Treaty revision has to be ratified in the Member States accepting the reservation.

If the non-veto players realize that their relative bargaining position has been weakened by the veto player, who has forced the other Member States to accept its unilateral reservation, they might be interested in the future to bring into play their national constitutional court in the next round of a Treaty revision. A new race to the top is starting. ${ }^{60}$

\section{Escaping the petrification gap by circumventing the ordinary revision procedure}

The arguments developed in E.II are valid for dealing with problems of circumventing the specific revision procedures for a hybrid constitution as well. But some qualifications are necessary.

If a veto player tries to block the revision of a hybrid constitution the remaining Member States might escape the unanimity rule by circumventing a revision of the hybrid constitution and conclude a new international Treaty in which they define binding rules for the parties of that Treaty but not for the veto player ${ }^{61}$ But it is questionable, whether this new Treaty is compatible with the existing hybrid constitution. In effect the new international Treaty is derogating provisions of the existing hybrid constitution. The parties signing the new Treaty are creating a dilemma. They are being bound by provisions of the existing hybrid constitution and at the same time by provisions of the new Treaty. If provisions of the existing hybrid constitution and those of the new Treaty are not compatible, it is legally doubtful, which provisions are applicable and binding.

If the new international Treaty is outside the existing hybrid constitution the courts of the supranational union have no jurisdiction over the provisions of the new Treaty. But these courts have to enforce the provisions of the existing hybrid constitution. They are not supposed to care about conflicts with international law outside the hybrid constitution. In the end the Member States which have signed the new international Treaty are now servants to two masters. Under the assumption of self-interested rational behaviour members of governments of the countries which have signed the new Treaty one may expect them to act opportunistically and stick to such provisions which are more favourable at the time that decision has to be taken. The rationale at the

\footnotetext{
${ }^{60}$ This idea has been introduced by Sven Hoeppner in a discussion on 12 September.

${ }^{61}$ Kirchner (2012), Section D.
} 
time of signing the new Treaty may be different from the rationale at the time, when the decision has to be taken, which provisions to apply. If the new provisions are stricter in terms of creating obligations under international law and thus limiting national sovereignty one may predict that the new obligations will not be fulfilled. It makes sense to stress supremacy of the hybrid constitution vis-à-vis the new Treaty provisions. In such a situation courts of the supranational union, which have an interest in the supremacy paradigm, will protect the Member States against the application of the provisions of the new Treaty.

The problem situation is different, if the hybrid constitution as such contains opt-out or opt-in provisions which allow for agreements between a group of Member States of less than total membership. Whether or not this is a way out of the petrification gap depends on how the opt-out or opt-in provisions are being formulated. In case of an opt-out provision Member States not willing to agree to a revision of the hybrid constitution may opt for not being bound by the revised Treaty provisions. In case of an opt-in provisions only such Member States are being bound, which enter into the agreement.

As well opt-out as opt-in provisions may be understood as instruments to allow for different speeds of integration within a supranational union. ${ }^{62}$ They replace unanimous revision of the existing hybrid constitution by establishing different rules for sub-groups of Member States of the old constitution. In economic terms this means more complexity and thus higher variable costs for the supranational union on one side but lower adaptation costs on the other side. Such adaptation costs are supposedly lower than the cost for revising the old constitution. With higher heterogeneity within the group of Member States of a supranational union entity revision costs are rising tremendously, whereas variable costs are expected to rise only modestly due to the fact that there are high fixed costs for establishing a supranational union together with its legal and organisational structure.

\section{F. Petrification of the constitution of the European Union}

\section{Problems of Treaty revisions under Art. 48 TEU}

Today the Treaty on European Union (Lisbon Treaty - TEU) and the Treaty on the Functioning of the European Union (TFEU) are containing the metarules for the European Union. From a constitutional economics point of view they are forming the EU-constitution.

The Treaty revision rules are to be found in Art. 48 TEU (see Section C.II). As it has been mentioned above Art. 48 TEU provides for different modes of

${ }^{62}$ Holzinger/Schimmelpfennig (2012); Kirchner (2007); Weidenfeld (2008). 
Treaty revisions, the ordinary revision procedure (Art. 48 par. 2-5), a simplified revision procedure (Art. 48 par. 6) and a general bridging clause (passerelle) in par. 7, which may be understood as another simplified revision procedure.

In the ordinary revision procedure Treaty revisions (Art. 48 par. 2-5) have to be agreed upon by a conference of representatives of the governments of the Member States unanimously. That conference's decision may be based on the results of a Convention composed of representatives of the national Parliaments, of the Heads of State or Government of the Member States, of the European Parliament and of the Commission. The revisions shall enter into force after being ratified by all the Member States in accordance with their respective national constitutional requirements.

Treaty revisions under the simplified revision procedure of Art. 48 par. 6 TEU require a unanimous decision by the European Council. The revision enters into force after being "approved by the Member States in accordance with their respective constitutional requirements". The scope of application of the simplified revision procedure of Art. 48 par. 6 TEU is restricted to revisions of Part Three of the Treaty on the Functioning of the European Union. The revisions may not increase the competences conferred on the Union in the treaties (Article 48 par. 6, third sentence TEU).

Treaty revisions under the general bridging procedure according to Art. 48 par. 7 TEU are being based on a unanimous decision of the European Council after obtaining the consent of the European Parliament. But the revision is blocked if at least one national Parliament of a Member State makes known its opposition to the proposal within six months (Art. 48 par. 7, third sentence TEU). The general bridging procedure is only applicable for selective revisions, which refer to voting in the Council or to the legislative procedure.

These three options for revision of the Treaty have different economic implications. Whereas all three options provide for the application of the unanimity rule, the scope of application, the national ratification process and the involvement of national Parliaments of Member States are different.

The ordinary revision procedure comes close to the revision of a hybrid constitution as being discussed in Section E.III. The petrification effect is tremendous. Member States have an incentive to participate in the race to the top. But members of government may be more interested in minimising citizens' control and strengthening their position as agents.

The simplified revision procedure of Art. 48 par. 6 TEU is limited in its scope of application (Part Three of the Treaty on the Functioning of the European Union). The fact that revisions under this procedure may not increase the competences conferred on the Union in the treaties is reflecting the anxiety of Member States which agreed to this simplified revision procedure that their national sovereignty may be eroded by Treaty revisions under the simplified procedure. The necessary approval by the Member States "in accordance with 
their respective constitutional requirements" allows for strict national ratification requirements despite the fact, that Art. 48 par. 6 TEU does not refer to 'ratification'. Thus Art. 48 par. 6 TEU does not block the race to the top as being discussed above. In economic terms decision making costs of the ordinary procedure are much more time consuming and costly compared to the revision procedure of Art. 48 par. 7 TEU. Thus this type of simplified revision procedure is reducing revision costs and thus is facilitating Treaty revisions. But on the other hand it does not give up the unanimity rule and the option of national ratification.

It is interesting to note, that the general bridging procedure of Art. 48 par. 7 TEU does not give up the unanimity rule. The decision of the European Council must be taken unanimously. Under this procedure national parliaments of Member States may play a decisive role. This is important because citizens may control members of parliament more easily than members of government. But national parliaments have to notify their opposition within six months after the decision of the European Council. This may be understood as weakening potential veto players. Let us assume, that the government is agreeing to a certain Treaty revision and a majority of members of the national Parliament are opposed. The latter ones are not being protected by a ratification procedure, in which they have to express their agreement with the Treaty revision. If they do not act at all they lose their veto position. But the general bridging procedure of Art. 48 par. 7 TEU does not exclude national rules under which the national parliament has to 'ratify' a Treaty revision under the general bridging procedure (quasi-ratification procedure). This is no ratification in the sense of public international law. But the parliament may bind itself to either approve the Treaty revision or to notify its opposition. Such a procedure under national law comes close to a ratification process. In the end Member States by means of national rules may modify the general bridging procedure in a manner in which they are strengthening their position vis-à-vis other Member States. If one Member State is introducing such national rules of quasi-ratification a race to the top as being discussed above may start.

All three modes of Treaty revision procedures under Art. 48 TEU do not prevent veto players to block a Treaty revision. All three procedure allow Member States to introduce national ratification rules or quasi ratification rules which strengthen their position vis-à-vis other Member States, thus opening a race to the top.

Under all three procedures national constitutional courts can be involved. This has become manifest with the last (preliminary) decision of the German Federal constitutional Court of 13 September 2012. ${ }^{63}$ The Court has made the

63 Bundesverfassungsgericht, Decision of 12 Sept. 2012; available at: http://www.bundesverfassungsgericht.de/entscheidungen/rs20120912_2bvr139012.html (last access: 12 Sept 2012): excerpts in English; available at: http://www.bverfg.de/en/deci 
ratification possible under a condition concerning the interpretation of the ESM Treaty. Thus, the German government had to make a reservation when notifying the ratification. The provisions on reservations of the Vienna Convention cannot be applied because France is not a member of that convention. Thus the other Member States had to accept the unilateral German reservation. It is doubtful whether the decision to accept the German reservation is constituting another Treaty revision which has to be ratified according to the national procedures of ratification in the other Member States. If the assumption of opportunistic behaviour of political actors is being introduced (see Section B), one may expect that in case of an extension of the agreed upon limits of liability in the ESM Treaty by a new interpretation of that Treaty a national government of a Member State which is in favour of that extension will argue that the acceptance of the German reservation is legally not binding. In such a case the expected response of the German Federal Constitutional Court in a similar situation in the future would be to ask the government not to notify the ratification unless the reservation has been accepted by the other Member States and the agreement on the acceptance has been ratified according to national ratification rules.

To sum up the analysis of existing Treaty revision procedure in the Treaty on European Union (Lisbon Treaty): It has been demonstrated that the unanimity rule together with national ratification procedures and quasiratification procedures, national rules on how to deal with Treaty revisions under the general bridging procedure and national rules governing the involvement of a national constitutional court in ratification procedures or quasi-ratification procedure is petrifying the status quo of the Treaty on European Union (Lisbon Treaty). According to the analysis only minor modifications of the EU-constitution are possible. The European constitutional impossibility theorem has been approved for Treaty revisions under Art. 48 TEU.

\section{Circumventing Art. 48 TEU}

The problems discussed in Section E.III under the heading of opt-out and optin provisions have been demonstrated in the European Union by a number of opt-out cases ${ }^{64}$ and opt-in-cases. The most prominent opt-in case has been the Schengen Treaty. ${ }^{65}$ But this Treaty has later been integrated into the frame-

sions/rs20120912_2bvr139012en.html (last access: 12 Sept. 2012); Press release of the German Federal Constitutional Court of 12 Sept. 2012; Federal Constitutional Court, Press release no. 67/2012 of 12 September 2012; available at: http://www.bundesverfassungs gericht.de/pressemitteilungen/bvg12-067en.html (last access: 12 Sept. 2012).

${ }^{64}$ Adler-Nissen (2011); Holzinger/Schimmelpfennig (2012).

${ }^{65}$ General secretariat of the Council (2001); The Schengen Agreement of 14 June 1985, as being incorporated into the EU framework by a protocol of the Treaty of Amsterdam: Official 
work of European Union law. All these cases have demonstrated that different degrees of integration are possible and can be handled.

In order to have a general opt-in framework, Art. 20 TEU (Lisbon Treaty) has modified the so-called 'enhanced cooperation', which had originally been introduced by the Amsterdam Treaty. A group of at least eight Member States thus may agree on deeper integration in a special field of activities. Art. 20 par. 2 TEU states that "enhanced cooperation shall aim to further the objectives of the Union, protect its interests and reinforce its integration process." As far as the procedural provisions to start enhanced cooperation Art. 20 TEU is referring to articles 326-334 TFEU. Whereas the wording of Art. 20 par. 2 TEU opens space for broad interpretation and thus is creating legal uncertainty, the articles on the procedural rules are confining the space of application of enhanced cooperation considerably. Thus it becomes extremely costly to start enhanced cooperation under Art. 20 TEU. Thus the instrument of enhanced cooperation is no way out of the petrification trap when it comes to a quasirevision of existing Treaty provisions.

If enhanced cooperation is no relevant substitute for Treaty revision provisions Member States which are confronted with the strategy of a veto-player may find another escape from the application of such provisions and circumvent Art. 48 TEU. They may agree on a Treaty under international law outside the framework of European Union law. This case has been discussed in Section E.II. It has been demonstrated that this is not a real escape in the light of potentially opportunistic behaviour of one or more players. Nevertheless a sub-group of Member States on 9 December 2011 agreed on the socalled Fiscal Pact. ${ }^{66}$ In criticising this Treaty I have argued that countries which have signed the Fiscal Pact nevertheless might invoke their rights under Art. 126 TFEU under the expectation that the European Court of Justice will let them do so because of the doctrine of supremacy of European Union law. ${ }^{67}$ In the end circumvention the Treaty revision procedures of Art. 48 TEU by entering into an international Treaty outside the framework of European Union law, is a very risky endeavour. It is no way out of the petrification trap.

\section{G. Outlook}

The analysis of treaty revisions of hybrid constitutions in general and of the Treaty revision procedures of Art. 48 TEU together with potential circumven-

Journal L 239, 22/09/2000 P. 0019 - 0062; available at: http://eur-lex.europa.eu/LexUriS erv/LexUriServ.do?uri=CELEX:42000A0922\%2801\%29:EN:HTML (last access: 12 Sept. 2012).

${ }^{66}$ Kirchner (2012), Section D.

${ }^{67}$ Kirchner (2012), Section D; Kirchner (2011). 
tions of these provisions has made clear that only minor revisions of the existing European constitution are possible. The European Constitutional Impossibility Theorem has not been proved in a strict test. But it has been demonstrated that revisions of the European constitution are extremely costly. This fact is preventing any substantial Treaty revision in the future. The incentive for Member States to participate in a race for stricter ratification or quasiratification rules may lead to a situation, where impediments for Treaty revisions become insurmountable. If Member States or the European Commission should not just try to circumvent the Treaty revision provisions but ignore them and take recourse to unconstitutional activities and engage in de-facto revisions of the Treaty the price of legal uncertainty and weakening the rule of law would be tremendous endangering the European integration process as such.

\section{Bibliography}

Adler-Nissen, $R$. (2011), "Opting out of an ever closer Union: the integration doxa and the management of sovereignty", in: Western European Politics, 34, 1092-1113; available at: http://curis.ku.dk/ws/files/34283859/WEU.pdf (last access: 15 Sept. 2012).

Benz, A., Treaty amendment after Lisbon - from intergovernementalism to supranational constitutionalism? (2008), Paper presented at the 7th Biennial Conference of the European Community Studies Association (ECSA) - Canada: "The Maturing European Union", 25-27 September 2008, Edmonton, Alberta, Available at: http://web.uvic.ca/ecsac/bienni al2008/Conference\%20Program_files/Benz.pdf (last access: 4 Sept. 2012).

Bernholz, P., Schneider, F., Vaubel, R., and Vibert, F. (2004), An Alternative Constitutional Treaty for the European Union. In: Public Choice 118, 451-468.

Bhagirat, L.D. (1998), The WTO Agreements. Deficiencies, Imbalances and Required Change, Penang, Malaysia.

Blankart, Ch. B. (2004), The European Constitution - Neither Fish nor Fowl. English translation of "Die EU-Verfassung - weder Fisch noch Vogel" In: Neue Zürcher Zeitung Nr. 158, July 10/11, 2004, 19.

Blankart, Ch. B. (2007), Föderalismus in Deutschland und Europa, Baden-Baden.

Brennan, G. and Buchanan, J.M. (1985/1993), The reasons of rules. Constitutional political economy, Cambridge, England (German translation: Die Begründung von Regeln. Konstitutionelle Politische Ökonomie, Tübingen 1993).

Breuss, F. and Eller, M. (2004), The Optimal Decentralisation of Government Activity: Normative Recommendations for the European Constitution, in: Constitutional Political Economy 15, 27-76.

Buchanan, J. M. (1974), The Limits of Liberty: Between Anarchy and Leviathan, Chicago.

Buchanan, J. M. (1986), The Constitution of Economic Policy, Nobel Prize lecture, reprinted in American Economic Review, 77 (3), 243-250, electronic copy available at: http://www.nobelprize.org/nobel_prizes/economics/laureates/1986/buchanan-lecture.htm (last access: 7 Sept. 2012).

Buchanan, J. M. (1990), The Domain of Constitutional Economics, Constitutional Political Economy 1, 1-18. 
Buchanan, J. M. and Tullock, G. (1962), The calculus of consent: Logical foundations of constitutional democracy. Ann Arbor; Reprint in: The Collected Works of James M. Buchanan, Vol. 3., with a Foreword by Robert D. Tollison, Indianapolis; available at: http://files.libertyfund.org/files/1063/0102.03_Bk.pdf (last access: 17 Feb. 2012).

Coase, $R$. (1984), The New Institutional Economics, in: Journal for Institutional and Theoretical Economics 140, 229-231.

Conslik, J. (1996), Why bounded rationality? In: Journal of Economic Literature 34, 669-700.

Crowe, R. (2008), The Treaty of Lisbon: A Revised Legal Framework for the Organisation and Functioning of the European Union, published online, available at: http://www.springerlink.com/content/0p7830150w668026/fulltext.pdf (last access: 3 Sept. 2012).

Erlei, D., Leschke, M., and Sauerland, D. (2007), Neue Institutionenökonomik, 2nd ed., Stuttgart.

European Constitutional Group (1993), A Proposal for a European Constitution. A Report by the European Constitutional Group, London; available at: http://ww w.progressfoundation.ch/PDF/medien/156_Right\%20of\%20Secession,Roland\%20Vaubel, European\%20Constitutional\%20Group,A\%20Proposal\%20for\%20the-\%20E.pdf (6 Sept. 2012); and: http://www.freiheit.org/files/600/legal_text.pdf (6 Sept. 2012); for other publications of The European Constitutional Group: http://www.freiheit.org/120 3/601c/index.html (last access: 6 Sept. 2012).

European Constitutional Group (2004), The Constitutional Proposal of the European Convention: An Appraisal and Explanation, in: Economic Affairs, 24, 22-27.

European Constitutional Group (2006), A Proposal for a Revised Constitutional Treaty; available at: http://www.vwl.uni-mannheim.de/vaubel/pdf-Dateien/Proposal.pdf (last access: 7 Sept. 2012).

European University Institute (EUI) (2000), Reforming the Treaties' Amendment Procedures, Second report on the reorganisation of the European Union Treaties submitted to the European Commission on 31 July 2000, Florence; available at: http://www.eui.eu/RSC AS/Research/Institutions/2ndrapport_UK.pdf (last access: 9 Sept. 2012).

Feld, L.P., Zimmermann, H., and Doering, T. (2007), Fiscal Federalism, Decentralization and Economic Growth, in: Baake, P. and Borck, R. (eds.), Public Economics and Public Choice, Contributions in Honor of Charles B. Blankart, Berlin, 104-114.

Furubotn, E. and Richter, R. (2005), Institutions and Economic Theory. The Contribution of the New Institutional Economics, 2nd ed. Ann Arbor.

Gamper, A. (2009), On the Justiciability and Persuasiveness of Constitutional Comparison in Constitutional Adjudication, in: icl-journal.com, 3, $150-169$; available at: http://www.internationalconstitutionallaw.net/download/11c5af833cb73305dc7f2d11f00d 77a4/A._Gamper.pdf (last access: 13 Sept. 2012).

General secreatriat of the Council (2001), The Schengen Acquis integrated into the European Union, Luxembourg; available at: http://consilium.europa.eu/uedocs/cmsUpload/SCH.A CQUIS-EN.pdf (last access: 12 Sept. 2012).

Ginsburg, T. (2005), International Judicial Lawmaking, University of Illinois College of Law, Law and Economics Working Papers, Paper 26; available at: http://law.bepress.com/uiuc lwps/art26 (last access: 20 Sept. 2012).

Grotius, H. (1625). De jure belli ac pacis libri tres. In quibus ius naturae \& gentium: item iuris publici praecipua explicantur. Paris, engl. translation: The Rights of War and Peace (2005), Indianapolis.

Guttmann, J.M. (1998), Unanimity and majority rule: the calculus of consent reconsidered, in: European Journal of Political Economy 14, 189-207. 
Harsanyi, J.C. (1953), Cardinal Utility in Welfare Economics and in the Theory of Risktaking, in: The Journal of Political Economy 61, 453-435; available at: http://econ.ucd enver.edu/beckman/Econ\%206053/Harsanyi-risk.pdf (last access: 13 Sept. 2012)

Hayek, F. A. von (1937), Economics of Knowledge, in: Economica 4, 33-54.

Hayek, F. A. von (1969), Die Ergebnisse menschlichen Handelns aber nicht menschlichen Entwurfs, in: Hayek, F. A. von, Freiburger Studien, Tübingen, 97-107.

Held, David (2002), Law of States, Law of Peoples (Three Models of Sovereignty), in: Legal Theory 8, 1-44.

Held, D. (2003), The Changing Structure of International Law: Sovereignty Transformed?, available at: http://www.polity.co.uk/global/pdf/GTReader2eHeld.pdf (last access: 7 Sept. 2012).

Holzinger, K. and Schimmelfennig, F. (2012), Differentiated Integration in the European Union: Many Concepts, Sparse Theory, Few Data, in: Journal of European Public Policy $19,292-305$.

Homann, K. (1980), Die Interdependenz von Zielen und Mitteln, Tübingen.

Hug, S. and Schulz, T. (2007), Referendums in the EU's constitution building process, in: Rev.Int.Org 2, 177-218, available at: http://www.springerlink.com/content/k015842 731348564/fulltext.pdf (last access: 8 Sept. 2012).

Jolls, Ch., Sunstein, C. R., and Thaler, R. H. (2000), A Behavioral Approach to Law and Economics, in: Sunstein, C. R. (ed.), Behavioral Law \& Economics, Cambridge, England, $13-58$.

Kahnemann, D. (1994), New Challenges to the Rationality Assumption, in: Journal of Institutional and Theoretical Economics 150, 18-36.

Kahnemann, D. (2011), Thinking, fast and slow, New York.

Kahnemann, D. and Tversky, A. (1979), Prospect Theory: An Analysis of Decision under Risk, in: Econometrica, XVLII, 263-291.

Kantorowicz, E. (1957), The King's Two Bodies: A Study in Medieval Political Theology, Princeton, NJ.

Kirchner, Ch. (1994), New Challenges to the Rationality Assumption, Comment on Kahnemann, in: Journal of Institutional and Theoretical Economics 150, 37-41.

Kirchner, Ch. (1997), Competence Catalogues and the Principle of Subsidiarity in a European Constitution, in: Constitutional Political Economy 8, 71-87; available at: $\mathrm{http} / /$ www.springerlink.com/content/kx70u7m052722w32/fulltext.pdf (last acccess: 8 Sept. 2012).

Kirchner, Ch. (2007), Europäischer Verfassungsvertrag, EU-'Reformvertrag' und multioptionaler Verfassungsvertrag, in: Wirtschaftsdienst, 87, 508-511; available at: https://www.econstor.eu/dspace/bitstream/10419/42740/1/540191760.pdf (last access: 6 Sept. 2012).

Kirchner, Ch. (2010); Die ökonomische Theorie, in: Riesenhuber, K. (ed.), Europäische Methodenlehre, $2^{\text {nd }}$ ed., Berlin, New York.

Kirchner, Ch. (2011), Nettonutzen des Eurozonen-Fiskalpaktes geringer als von der Politik suggeriert. In Börsen-Zeitung, No. 242, 15 Dec. 2011, 7.

Kirchner, Ch. (2012), The unanimity rule revisited: the case of revisions of hybrid constitutions, in: Public Choice 152, 445-449; available at: http://link.springer.com/artic le/10.1007/s11127-012-9997-x\#page-1 (last access: 12 Sept 2012).

Koenig, T. and Finke, D. (2007), Reforming the equilibrium? Veto players and policy change in the European constitution-building process, in: Rev. Int. Org. 2, 153-176; available at: http://www.sowi.uni-mannheim.de/lspol2/Publikationen/2007_Koenig_Finke_Reform ing.pdf (last access: 8 Sept. 2012). 
Korobkin, B.R. and Ulen, T. S. (1999), Law and Behavioral Science: Removing the Rationality Assumption from Law and Economics, Discussion Paper, Max Planck Institute for the Research into Economic Systems, Jena, available at: http://teaching.ust.hk/ econ325/read ings05/0007Khorobkin-Ulen.pdf (last access: 7 Sept. 2012).

Komárek, J. (2011), Judicial Lawmaking and Precedent in Supreme Courts, LSE Law, Society and Economy Working Papers 4/2011; available at: http://www.lse.ac.uk/col lections/law/wps/WPS2011-04_Komarek.pdf (last access: 18 Sept. 2012).

Kurpas, S. (2007), The Treaty of Lisbon - How much 'Constitution' is left? An Overview of the Main Changes, CEPS, Policy Brief No 147, Dec.; available at: http://ssrn.com/abstr act $=1334072$ (last access: Sept. 7 2012).

Leschke, M. (1995), Die Beiträge von John Rawls und James M. Buchanan zur liberalen Gestaltung der demokratischen Grundordnung, in: Pies, I./Leschke, M. John Rawls politischer Liberalismus, Tübingen, 63-91.

Luhmann, N. (1973), Zweckbegriff und Systemrationalität, Über die Funktion von Zwecken in sozialen Systemen, Frankfurt/Main.

McKenzie, R. (ed.) 1984, Constitutional Economics, Lexington, Mass.

Mueller, D. C. (2008), Constitutions, economic approach to, in: The New Palgrave Dictionary of Economics, 2nd Edition, Houndmills Basingstoke, UK.

North, D. (1990), Institutions, Institutional Change and Economic Performance, Cambridge, Mass. 1990.

Ó Broin, P. (2010). How to Change the EU Treaties. An Overview of Revision Procedures under the Treaty of Lisbon, CEPS Policy Brief, No. 215, electronic copy available under: www.ceps.eu/ceps/download/385 (last access: 17 Aug. 2012).

Osiander, A. (2001), Sovereignty, International Relations, and the Westphalian Myth, in: International Organization 55, 251-287; available at: http://www.labmundo.org/discip linas/OSIENDER_sovereignty_international_relations_and_the_westphalian_myth.pdf (last access: 7 Sept 2012).

Philpott, D. (2001), Revolutions in Sovereignty: How Ideas Shaped Modern International Relations, Princeton, NJ.

Philpott, D. (2010), Sovereignty, Stanford Encyclopedia of Philosophy, available at: http://plato.stanford.edu/entries/sovereignty/ (last access: 13 Sept. 2012).

Pies, I. (1993), Normative Institutionenökonomik, Tübingen.

Rawls, J. (1971), A Theory of Justice, Cambridge, Mass.

Rawls, J. (1999), A Theory of Justice, rev. edition, Cambridge, Mass; available at: http://espectroalejandria.files.wordpress.com/2012/04/82985311-a-theory-of-justice.pdf (last access: 8 Sept. 2012).

Richter, R. and Furubotn (2010), E. Neue Institutionenökonomik, $4^{\text {th }}$ ed., Tübingen.

Salmon, P. (1987), Decentralization as an Incentive Scheme, in: Oxford Review of Economic Policy 3, 24-43.

Scott, J. B. (2000), The Spanish Origin of International Law: Francisco de Vitoria and His Law of Nations, Union, New Jersey.

Selten, $R$. (1990), Bounded Rationality, in: Journal of Institutional and Theoretical Economics 146, 649-658.

Simon, H.A. (1982), Models of bounded rationality, Cambridge, Mass.

Straumann, B. (2008), The Peace of Westphalia as a Secular Constitution. Constellations 15 (2), 173-188; available at: http://www.iilj.org/aboutus/documents/Straumann.Westph alia.pdf (last access: 17 Feb. 2012).

Streinz, $R$. The European Constitution after the Failure of the Constitutional Treaty (2008), in: ZÖR 63 (2008), 159-187; available at: http://www.springerlink.com/content/ehrj55r526 11q275/fulltext.pdf (last access: 14 Aug. 2012).

Streit, Manfred E. (2005), Theorie der Wirtschaftspolitik, $6^{\text {th }}$ ed., Stuttgart. 
Vanberg, V. and Buchanan, J.M. (1989), Interests and Theories in Constitutional Economics, in: Journal of Theoretical Politics 1, 49-62.

Van den Hauwe, L. (1999), Public Choice, Constitutional Political Economy and Law and Economics, in: Backhaus, J. (ed.), The Elgar Companion to Law and Economics, $2^{\text {nd }}$ ed., Cheltenham, UK, pp. 603-659; available at: http://encyclo.findlaw.com/0610book.pdf (last access: 6 Sept. 2012).

Vaubel, R. (1997), The constitutional reform of the European Union, European Economic Review 41, 443-450; available at: http://www.sciencedirect.com/science/article/pii/S00 14292197000135 (last access: 6 Sept. 2012).

Voigt, S. (1999), Constitutional Law, in: Backhaus, J. (ed.), The Elgar Companion to Law and Economics, $2^{\text {nd }}$ ed., Cheltenham, UK, pp. 529-542, available at: http://encyclo.findla w.com/0610book.pdf (last access: 6 Sept. 2012).

Voigt, S. (2009), Institutionenökonomik, $2^{\text {nd }}$ ed., Paderborn, 2009.

Weidenfeld, $W$. (2008), Making the Case for a Multi-Speed Europe, CAP-News of 30 July 2008; available at: http://www.cap-lmu.de/aktuell/pressespiegel/2008/multi-speedintegration.php (last access: 7 Sept. 2012). 


\title{
Comment on Christian Kirchner
}

\section{The European Constitutional Impossibility Theorem}

\author{
by \\ Thomas Eger*
}

\begin{abstract}
A.
Christian Kirchner deals in his interesting contribution basically with two important questions:

1. To what extent do constitutions in general and hybrid constitutions, such as the Lisbon Treaty, in particular reflect the preferences of the citizens?

2. How difficult is it to efficiently adapt existing (hybrid) constitutions to changing circumstances?

With respect to the first question, Kirchner refers to the economics of constitution-building and points out that the participants of the constitution-building process act under a veil of uncertainty, which leads ex ante to some convergence of interests and thus lowers decision making costs. With an impermeable veil of uncertainty decision making costs become very low and the unanimity rule will be (close to) the optimal one in the constituent assembly. Since the citizens delegate the drafting and enactment of the constitution to experts, principal-agent problems between citizens and experts have to be taken into account. It is assumed that the intended positive effects of the envisaged constitution are also visible to the principals, whereas the agents are better informed about potential negative side effects. In case the agent expects the side effects to become public only after the expiration of his political mandate, there is no incentive for the political decision makers to reveal them to the citizens. Due to these principalagent problems the constitutional rules typically will not reflect citizens' preferences in an undistorted way. Even though I share Kirchner's basic
\end{abstract}

\footnotetext{
${ }^{*}$ I wish to thank Dagmar Ahlgrimm and Agnes Strauß for valuable comments.
} 
argument, an explicit formulation of the agent's objective function is missing. In this respect, the final version differs from the first version of the paper, where Kirchner argued that drafters' interest to earn reputation as the 'fathers and mothers of the constitution' explains their incentive not to fully inform the citizens about all potential risks.

In case of a hybrid constitution, which defines the meta-rules for a supranational entity, the agency chain becomes longer and agency costs are rising: The principals, i.e., the citizens, are now represented by members of national government, who agree on a Treaty under public international law. The government is elected and controlled by the legislature, which is elected by the citizens; the ratification (by the legislature or by referendum) is governed by national law. Kirchner comes to the conclusion that due to the longer agency chain - citizens' position in hybrid constitutionbuilding is much weaker than in national constitution-building.

\section{B.}

The focus of Christian Kirchner's paper is on the second question, the revision of (hybrid) constitutions, with special focus on the European Union. From an economic point of view, the most important difference between constitution-building and constitutional revisions is the following: Due to their experience with the existing constitution, the parties concerned are much better informed about the actual costs and benefits of the constitution at the revision stage as compared to the stage of constitution-building. The veil of uncertainty has become transparent, which leads to higher decision making costs. For this reason, even those constitutions, that turn out not to reflect citizens' preferences in a proper way, are difficult to revise under unanimity ('petrification effect'). This explains why revision clauses typically replace the unanimity requirement by qualified majorities, which lowers decision making costs, but weakens the protection of minorities.

The situation is different with the revisions of hybrid constitutions, which are governed by international public law. Without explicit exceptions, Treaty revisions do not only require the application of the unanimity rule, but also have to be ratified according to national rules by the legislature or by referendum. This implies, that apart from the national governments, who are engaged in the negotiations, additional players, such as citizens, national legislature and national (constitutional) courts come into play. Christian Kirchner correctly points out that strict ratification rules make, on the one hand, governments' lives less comfortable, whereas they strengthen, on the other hand, the international bargaining position of a country. This might lead to a race for ever stricter ratification rules and to 
an extreme increase in the decision making costs of revising a hybrid constitution.

The Treaty on European Union provides in Art. 48 TEU for three different revision procedures of the "constitution" of the European Union, the ordinary revision procedure, the simplified revision procedure and a general bridging clause. However, as Kirchner has convincingly shown, all these procedures do not prevent veto players to block a Treaty revision. The consequence is the "petrification" of the existing Treaty, which is further strengthened by the involvement of a national constitutional court in ratification procedures.

\section{C.}

How can we escape this "petrification trap"? Kirchner identifies two strategies to circumvent the ordinary revision procedure. (1) Ex post, Member States, that are going to revise a hybrid constitution, but are blocked by a veto player, may conclude a new international Treaty, which is only binding for the parties of the new Treaty, but not for the veto player. However, as Kirchner stresses, problems will arise if the new Treaty is not compatible with the existing hybrid constitution. The parties may be bound by two contradicting sets of rules. (2) Ex ante, the parties to the original Treaty may agree on opt-out or opt-in provisions, which allow for agreements among a subset of all Member States. Examples are Denmark's and the UK's opt-outs from the third phase of the European Monetary Union, the UK's and Ireland's opt-out from the Schengen legislation after its inclusion into European Union law with the Treaty of Amsterdam (1998), and the UK's and Ireland's opt-in regarding Justice and Home Affairs (Sion 2004; Jensen/Slapin 2012). According to Kirchner, these provisions increase the complexity and the variable costs for the supranational union, but lower adaptation costs (compared to a revision of the existing - hybrid - constitution).

The Amsterdam Treaty introduced the possibility of "enhanced cooperation' by a group of Member States, which was modified by the Lisbon Treaty (Art. 20 TEU and Arts. 326 - 334 TFEU) and transformed into some kind of "general opt-in framework". Enhanced co-operation has been established as an ultima ratio, to allow a subgroup of at least nine Member States to intensify integration when there is no consensus among all member States to achieve this level of integration. The procedure to trigger enhanced co-operation is tough: The Member States concerned have to address a request to the Commission, the Commission 'may' submit a proposal to the Council, the Council and the European Parliament have to agree on the proposal. Excluded from enhanced co-operation are fields 
with exclusive competence of the Union, special provisions apply for the Common Foreign and Security Policy.

Christian Kirchner is not convinced that the instrument of enhanced cooperation provides a way out of the petrification trap. Let us discuss some experiences with and the implications of this instrument, to see whether his skeptical view is justified. The first time the mechanism of enhanced cooperation was used refers to the area of divorce of international couples. Since Member States differed a lot on which country's law should be applied in case of divorce the European Commission intended to harmonize Private International Law accordingly. However, a unanimous agreement between all 27 Member States was not feasible, due to the opposition of the more liberal Nordic countries. For this reason, Council Regulation (EU) No. 1259/2010 of December 20, 2010, authorized 14 Member States to proceed with enhanced co-operation in the field of divorce law. ${ }^{1}$ This Regulation applies for divorce petitions brought after June 21, 2012.

The second example of enhanced co-operation refers to a unitary patent protection in the European Union. The European Commission has been trying for many years to reduce the enormous translation costs, which make patent protection in Europe much more expensive than in the USA or Japan: To validate a patent in several Member States it has to be translated into the official national languages of all corresponding countries. ${ }^{2}$ The idea, to submit patent applications in one of the three official languages of the European Patent Office (English, French or German) and to translate the patent claims into all three official languages, was opposed by Spain and Italy. To overcome this stalemate the Commission presented a proposal on enhanced co-operation in the field of unitary patent protection among all Member States, except Spain and Italy. Both excluded countries challenged the validity of the application of the enhanced co-operation procedure in this field before the Court of Justice of the EU. In November 2012, the final decision on enhanced co-operation is still pending.

The third example is a very recent one, which has not come into force yet. Since there was no unanimous agreement on the European Commission's proposal for a Directive on a financial transaction tax, ten Member States $^{3}$ requested to proceed with this tax through enhanced co-operation. On October 23, 2012, the Commission adopted a corresponding proposal for a Council decision.

The crucial question is to what extent enhanced co-operation could be a suitable instrument to solve the petrification problem. It has been shown

\footnotetext{
${ }^{1}$ Austria, Belgium, Bulgaria, France, Germany, Hungary, Italy, Latvia, Luxembourg, Malta, Portugal, Romania, Slovenia and Spain.

${ }^{2}$ For more details see Guellec/van Pottelsberghe (2007, 191-196).

${ }^{3}$ Austria, Belgium, France, Germany, Greece, Italy, Portugal, Slovakia, Slovenia and Spain.
} 
that the threat of enhanced co-operation can undermine the veto power of each single Member State by deterring inefficient blocking of reforms and blackmail of the majority by veto players, if two conditions hold (Berglöf et al. 2009):

1. The formation of a "club in the club" (i.e., enhanced co-operation within a subgroup) has to be exempted from unanimous approval.

2. The "inner club" must impose some negative externalities on the rest of the club, or membership of the "inner club" is per se valuable. If this condition holds, the members of the "outer club" face an incentive to give up their veto against closer co-operation.

Thus, the option of multispeed integration does not necessarily lead to a lack of coherency and the danger of disintegration, but may avoid petrification (at least to some extent) in a similar way as a switch from unanimity to qualified majority does. ${ }^{4}$

The request for enhanced co-operation by a subgroup of Member States has typically induced other Member States to participate in the enhanced co-operation. ${ }^{5}$ Member States might be more reluctant to block decisions on enhanced co-operation than to block other decisions that directly affect all Member States. More research is needed to better understand the economics of negotiations on enhanced co-operation.

\section{D.}

Even though the hybrid constitution of the European Union allows for some flexibility, Christian Kirchner is right in his statement that this „,constitution", i.e., primary EU law, is very difficult to change. But does this necessarily lead to "petrification"? We have to take into account that high costs to change the law (the "constitution") increase the judicial discretion (Voigt 2012). Thus, it is no wonder that the European Court of Justice was able to interpret the Treaty in a way far beyond what was expected by the Member States as "the masters of the Treaty", when signing and ratifying the Treaty. This judicial discretion helped to remove non-tariff barriers between the Member States and even non-discriminatory obstacles to the four basic freedoms in a way, which would not have been possible by unanimous explicit agreement between all Member States. ${ }^{6}$ Consequently,

\footnotetext{
${ }^{4}$ Of course, the instrument of enhanced co-operation is only applicable in one direction, towards more integration. It is not applicable, if a subgroup of Member States intends to reduce the achieved level of integration.

${ }^{5}$ In the case of divorce law, originally 10 countries applied for enhanced co-operation, but finally 14 countries have been included. In the case of unitary patent protection, the original request by 12 Member States has led to a final proposal for enhanced co-operation by 25 Member States.

${ }^{6}$ See, for example, Eger/Schäfer 2012, in particular the introduction and chapters 6 and 7.
} 
the high decision costs of changing the hybrid constitution, due to the unanimity requirement, strengthened another kind of flexibility, i.e., flexibility via judicial discretion. It has to be discussed whether this model is characterised by a lack of democracy, i.e., a lack of a presentation of citizens' preferences, compared to the inclusion of national governments and parliaments in the decision making process. However, this discussion would go beyond what is needed for a comment on the paper presented by Christian Kirchner.

\section{Bibliography}

Berglöf, E., Burkar, M., Friebel, G., and Paltseva, E., Club-in-the-Club: Reform under Unanimity, Economic Policy Research Unit (EPRU), University of Copenhagen, Working Paper Series 2009-07.

Eger, Th. and Schäfer, H.-B. (eds.), Research Handbook on the Economics of European Union Law, Cheltenham 2012.

Guellec, D. and van Pottelsberghe de la Potterie, B., The Economics of the European Patent System, IP Policy for Innovation and Competition, Oxford 2007.

Jensen, C. B. and Slapin J. B., Institutional Hokey-Pokey: The Politics of Multispeed Integration in the European Union, in: Journal of European Public Policy 19(2012), 779-795.

Sion, M., The Politics of Opt-Out in the European Union: Voluntary or Involuntary Defection?, in: A. Cashin and J. Jirsa (eds.): Thinking Together, IWM Junior Visiting Conferences 16 (2004), Vienna.

Voigt, S., Spielräume des EuGH - eine ökonomische Analyse. Kommentar zu Christian Hillgruber und Carl Otto Lenz, in: Behrens. P., Th. Eger and H.-B. Schäfer (Hg.), Ökonomische Analyse des Europarechts, Tübingen 2012, 37-43. 


\section{Discussion of Christian Kirchner}

\section{The European Constitutional Impossibility Theorem}

by

\section{Elif Erdemoglu}

Prof. Oeter stated that he was not convinced that enhanced cooperation circumventing the existing framework of rules is an alternative to the impossibility theorem. "Treaty making beyond the constitution" suffers from the same incentive problems as operating inside the constitutional framework does. The primary law of the European Union is perceived as an obstacle for the achieving results. Some provisions of the primary law that make the sanctions of some violations non-automatic, like the fiscal law that tries to create some automaticity. Problem of opportunity of the States exists since they aim to squeeze out benefits from veto conventions. The question is whether this is valuable for the long run or whether another constitution is needed.

Prof. Häberli said that in GATT, consensus is needed every time. Everything else goes under single-undertaking and it was a condition to join the WTO. After 10 years of negotiation, 150 pages of agreements on NAMA, industrial tariffs, under the fiction of single undertaking everybody has a private application, tailored for everyone, by maintaining a consensus basis decision taking for specific decisions. Big countries have a natural preference for unanimity. There are two possibilities: Either to have a new body, G-20 that directs new situations or to have informal clubs like in WTO, called the Green Room, which is not the big members. i.e., African countries are represented because they have special sensitivity to industrial tariffs. In Switzerland, referendums are seen as a solution to many problems. A parliamentary decision that has less than 80 percent support has no chance to survive. Pragmatic spirit of GATT can be a solution for many things. 
Prof. Fehling announced his four observations; First, he asked which constitutional amendments are talked about stating that there are several sorts of amendments, charter of fundamental rights, as an example for a large amendment, but it was difficult to achieve and there are amendments that are easier than the others. Like reversion of the big constitutional setting, but even there if you go step by step there might be a chance not to revise the system, but to go step by step in the end it can be a right amount to complete change for example the changes regarding the European Parliament. You have to distinguish between different sorts of constitutional amendments. The most difficult thing is to revise the economic model, because class interest and other issues play a large role. Secondly he criticized the principle agent model by being not complex enough. Citizens, institutions and the European Union, in reality there is also the effects of many interest groups, political parties, representing different interests. The paper argues secondary law can be affected by political interests on the national level. Not only between the member states and the European Union, it is also between different political interests and this should be in the model. Thirdly, there might be more dynamics in time, when looking at the history of the European Union, the window of opportunities; they can change the constitution like when there is a big crisis, a pressure from the outside. New problems are the ones that lead to the conclusion that at a certain amount of time, that new possibilities, constitutional changes, financial markets, budget crisis etc. several things would not be possible. Lastly, Prof. Fehling asked about the changes about the jurisprudence of the court of justice and whether there is a chance to readjust the constitutional framework by a new interpretation of the constitutional provisions. It is not impossible that in different times, under different conditions, different interpretations of constitutional provisions would be possible.

Prof. Benvenisti pointed out that the generalization of points to public international law. He suggested that the concept of exit should be introduced into the equation. If the exit option is less costly, then unanimity can be overcome by threatening with exit. He declared that he is not sure whether exit can be introduced into the European Union.

Prof. Engert said that if it mitigates the veil of uncertainty, if European Union evolves and people know what to expect from the EU, it would not mitigate the Principle-Agent Problem. The Principle-Agent Problem helps to mitigate distributional struggles related to constitutional changes. Because the citizens who would lose, are more distant and less informed about the consequences for them. The EU is as "political elites" in the agency framework, the agents of citizens will be more in favor of the treaties. The agents want it more than the citizens themselves. As concluding remarks he stated that to enter into a new agreement if ratification problem has the chance of bringing the EU down. If that does not happen, signing 
parallel treaties are not a way out, because any new treaty would be negotiated in the shadow of the old treaty. States are locked in to the preexisting EU constitutional provisions.

Prof. Voigt referred to the book by Elkins, Ginsburg \& Melton about the factors that determine the endurance of nation-state constitutions. Prof. Voigt pointed out that the difficulty of changing nation-state constitutions can be seen as a conscious choice by the drafters, since they want to enhance constitutional longevity. He also contributed to the discussion about the "veil of uncertainty" by referring to Buchanan \& Tullock's work. Those authors do not necessarily rely on incomplete information to make their point about the "veil of uncertainty". Individuals are fully informed about their current position in society but assume for a moment that they cannot tell what position they will have in the future. Furthermore, Buchanan \& Tullock's formulation of the veil of uncertainty does not include agency problems. Instead these authors assume direct democracy, which means that citizens decide directly what type of constitution will be chosen, without making reference to an intermediate agent. To include information asymmetry between citizens and governments in the choice to modify constitutions would go beyond Buchan \& Tullock's approach. Prof. Voigt also questions if the agent (the government) is necessarily more informed about his future position in society than the principal (the citizens). For example, politicians generally experience high career uncertainty because reelection is always insecure, while the average citizen can probably assess future professional prospects more accurately. In his next remark Prof. Voigt says that whether a state has a parliamentary or a presidential form of government can make a difference for the strategy of a state towards constitutional change at the EU level. Prof. Voigt's final comment is that direct democracy not only has benefits at the domestic level, but should also improve a country's bargaining position at the EU level. The question arises why direct democracy is not more widely adopted by European states.

Prof. Eger said that he is not convinced by the ex-post opportunism cannot be mitigated by the enhanced cooperation. There is article 128 on the fiscal discipline, with some criteria and relatively weak monitoring. Secondary law, and constitutional articles on enhance cooperation, if nine or more parties decide they want to get rid of bad monitoring and transfer the enforcement power to the EU commission, then it is an enhanced cooperation and the constitution lets this. Prof. Oeter declared that this would not be possible without making a change in article 128 because the primary law has supremacy.

Prof. Marauhn expressed opinion on two issues. Firstly he referred to the role of European Court of Justice. He cited that the paper argues the following, while ECJ would be more an element of slowing down the pro- 
cess of change, since it would try to keep up the constitution as doctrinal. He questioned the role of the ECJ that has never been as doctrinal as the Federal Constitution Court on the ground that its objective has never been the law, or the doctrine but the integration process. The ECJ would not accept the illegal treatment of the constitution, in light of the overall objective of the integration process because this may risk a breakdown of the integration process and only leaving the alternative to draft a new constitution. Since ECJ is kind of a political actor on the scene, as the federal constitutional court is, this element should be considered as inserting a little bit of dynamics into this analysis to leave some doors open rather than making it impossible. He also pointed out the role of national parliament's stating that they are not the same actor as the nation governments they have different positions. He asked how to distinguish their roles. His final remark was that the possibility of drafting a new constitution, many problems in the integration process, still difficult, who is going to reduce the number of participants, with a national constitution the area is clear who is participating it is clear now, is it equally clear who would draft it, would that be the same costs and benefits, if the size is equal, maybe it enhances the cooperation if we reduce the number of participants, but is it feasible.

Prof. Voigt closed the session by quoting a game theorist, stating that no external enforcement for constitutions is possible, they have to be selfenforcing. 


\title{
Foreign Direct Investment in Agriculture: Land Grab or Food Security Improvement?
}

by

\author{
Christian Häberli ${ }^{*}$
}

\section{A. Introduction}

"Large-scale acquisition of land by foreign investors" is the correct term for a process where the verdict of guilt is often quicker than the examination. But is there something really new about land grab except in its extent? In comparison with colonial and post-colonial plantation operations, should foreign investors today behave differently? We generally accept coffee and banana exports as pro-growth and pro-development, just as for cars, beef and insurance. What then is wrong with an investment contract allowing the holder to buy a farm and to export wheat to Saudi Arabia, or soybeans and maize as cattle feed to Korea, or to plant and process sugar cane and palm oil into ethanol for Europe and China? Assuming their land acquisition was legal, should foreigners respect more than investment contracts and national legislation? And why would they not take advantage of the legal protection offered by international investment law and treaties, not to speak of concessional finance, infrastructure and technical cooperation by a development bank, or the tax holidays offered by the host state? Remember Milton Friedman's often-quoted quip: "The business of business is business!" And why would the governments signing those contracts not know whether and which foreign investment projects are best for their country, and how to attract them?

Besides, foreign investors are not the only land grabbers. There are many similar practices by absentee landowners in South America or South Asia, or by Israeli settlers in occupied Palestinian territories.

* Christian Häberli is a Senior Research Fellow at the World Trade Institute (University of Bern, Switzerland). Research for this chapter was funded by the Swiss National Science Foundation under a grant to the National Centre of Competence in Research on Trade Regulation, based at the University of Bern's World Trade Institute in Bern, Switzerland.

1 The New York Times Magazine, 13 September 1970. 
This chapter tries to show that land grab, where it occurs, is not only yet another symptom of regulatory failures at the national level and a lack of corporate social responsibility by certain private actors. National governance is clearly the most important factor. Nonetheless, I submit that there is an international dimension involving investor home states in various capacities. The implication is that land grab is not solely a question whether a particular investment contract is legal or not.

Since about 2008, advocacy groups have drawn attention to numerous cases of what they consider as land acquisitions with a doubtful legal basis, especially in so-called weak states. Economic studies as far back as 1989 have shown the advantages and the intrinsic distortions of agricultural FDI in a food security perspective (Drèze and Sen 1989) and taking into account variables such as tenancy, dualistic land ownership distributions, social divisions, and anti-small farmer biased land reforms in poor countries (Binswanger, Deininger and Feder 1993). Since then, numerous impact modelling and assessment studies have been conducted, often with the World Bank economic research programme, and in a land governance framework (Deininger, Selod and Burns 2011). A recent modelling study concludes that local populations can be better off with agricultural FDI if their government has the necessary negotiating capacity and willingness, and if alternative sources of income are available at a sufficient level of remuneration (Dessy et al. 2011, p. 28).

Legal scholars and policy makers lag far behind. The numerous new proposals for codes of conduct, voluntary guidelines and principles for responsible agricultural investment are typically less than three years old, and they tend to focus on the national dimension of land grab. This chapter deals with legal issues which seem to have largely escaped the attention of both human rights lawyers and, especially, of investment lawyers. It addresses this fragmentation between different legal disciplines, rules, and policies, by asking two basic questions: (i) Do governments and parliaments in investor home countries have any responsibility in respect of the behaviour of their investors abroad? (ii) What should they and international regulators do, if anything?

\section{B. What is the food security issue here?}

I am addressing these questions from a food security vantage point. Food security as a scientific and a policy subject has been defined in several different ways over the last few decades. The present, generally accepted definition for policy purposes was laid down in 2001 in the "State of Food Insecurity" Report (FAO 2002): 
Food security [is] a situation that exists when all people, at all times, have physical, social and economic access to sufficient, safe and nutritious food that meets their dietary needs and food preferences for an active and healthy life.

The emphasis here is on consumption and on access to food for all people, as already outlined by Amartya Sen in his path-breaking book on poverty and famines (Sen 1981). However, this definition omits the two other components of food security, besides production, i.e., trade and investment. $^{2}$

For the two questions examined here it is important to point out that food security has totally different connotations at the household, national and global levels. Agricultural FDI can increase global food security. A recent econometric study confirms OECD and FAO models showing that, while not a panacea to reduce high cereal prices, FDI will bring about substantially lower food prices when expanding agricultural land area, and thus increase national food security in host countries (Kappel et al. 2012 p. 19). At the same time agricultural FDI can also impair food availability at the local level. Similarly, protection of small farmers may improve their own food security but also mean higher food prices for poor urban households. As shown in a national court case of (refused) tariff protection for the Ghanaian poultry industry, this dilemma extends to the processing stage (Gathii 2012 p. 103s). The lack of multilateral disciplines on agricultural subsidies is certainly not helping small farmers in poor countries to compete. This explains why trade liberalisation (and food aid) is seen as acting to the detriment of West African rice farmers, because it "has not only undermined the capacity of developing-country farmers to expand, but has made the future of small-holder farmers worse, as it serves to intensify pre-existing problems of poverty, trade inequity and inequality" (Aniekwe 2010 p. 4.6.1).

The approach chosen for the legal analysis of agricultural FDI is not a search for a higher "moral ground" than profit-maximising return-oninvestment considerations. I am not even arguing that food security is what economists call a public good which can only be produced with government intervention. Nonetheless, agricultural FDI does relate to food security as per the above definition, and land grab is a concern which came to the forefront in the context of the international food crisis in the years 200708. As a matter of fact, every government in the world recognises food security as a priority policy objective, often based on a constitutional mandate, albeit with very different and sometimes beggar-thy-neighbour im-

${ }^{2}$ An interesting proposal has recently been made for an Index of National Food Security that may be readily measured and related to agricultural trade policies and the WTO, informing policy makers and the public debate alike. Cf. Daniel A. Sumner and Frank H. Buck, Agricultural trade policy and food security, University of California (paper on file with author). 
plementation measures. While this is not the topic of this chapter, it is certainly noteworthy that the recent food crisis triggered a flurry of intergovernmental activities at all levels, albeit without any rules changes, and perhaps tellingly at the same time as the Doha Round negotiations collapsed (Häberli 2012a, p. 77).

This was not the first food crisis in history, nor was it the biggest global hunger crisis. But the unique combination of structural and cyclical factors which caused a dramatic world market price increase for many basic food items also triggered what many economists now consider as a reversal of the decade-old downward trend of agricultural commodity prices. In 2011, the Organisation for Economic Co-operation and Development (OECD) and Food and Agriculture Organization (FAO) reiterated their earlier assessment that "agricultural commodity prices in real terms are likely to remain on a higher plateau during the next decade compared to the previous decade"; somewhat surprisingly they also warned that "[p]rolonged periods of high prices could make the achievement of global food security goals more difficult, putting poor consumers at a higher risk of malnutrition" (OECD/FAO 2011, p. 14). Indeed, looking at these and other often self-contradictory political statements, including by the World Bank and by NGOs, Swinnen and Squicciarini have called for a "more nuanced debate on how prices and policies affect food security; neither high nor low prices are panaceas" $(2012$, p. 405).

As a matter of fact, higher prices were good news for efficient farmers in Australia and Argentina who immediately responded with production increases. However, the first victims were poor consumers in Cairo who for decades had been accustomed to relying on dumped wheat imports, at prices which Egyptian farmers could never compete with.

Unfortunately, and this is not new, but relevant for my research question, poor farmers in many countries were unable to benefit because the price increases did not reach them, or because they lacked what is called supply response capacity. In these countries this led first to a further increase in the food bill. Secondly, land owned by poor and subsistence farmers unable even to feed themselves became even more attractive for land grabbers endowed with capital, technologies, and access to new markets. As pointed out above, land grab is not a phenomenon limited to foreign investors, because some nationals (in extreme cases, generals) participate in this race for profitable land deals; nor does it always imply a formal land purchase, because land often is only leased for a period of 10, 20 or 99 years; contract farming is yet another form with different food security implications. These facts have to be kept in mind even though this chapter only refers to foreign and direct investment (FDI) in agriculture.

The growing productivity and profitability gap between subsistence farmers and cash croppers is probably the main cause for the accelerating 
land ownership changes. An improving FDI climate and increasing risktaking by investors scouring the world for farmland are additional factors. This makes for even more difficult answers on how to save local farmers without at the same time increasing the food bill, especially when put in a dynamic perspective of rapid demographic changes and growing urbanisation, not to speak of climate change. For instance, it is no longer clear that cooperatives of various types are the best means to overcome the organisational handicaps of remote areas and small producers. Some governments have started to realise the impediment which traditional and communal structures represent for innovation and modernisation. For instance, the time-honoured ejidos, a type of communal land ownership in Mexico, have recently been described as a reason for low yields and for insufficient investment and capital, basically for lack of securitised collateral. ${ }^{3}$ A fact which seems obvious but which is often neglected in discussions on how small farmers should organise is that a lack of reward for efficiency will not increase food security.

The only fact which is clear in this complex debate is that, in terms of its impact on food security, FDI in agriculture means different things to different people. Moreover, governments, international organisations, scientists, and private operators use very different premises and criteria when they look at FDI from a food security perspective.

Governments at all times have sought to attract FDI as such. Many consider agricultural FDI as a component of their food security equation. Traditional investment issues such as protection, promotion, expropriation and compensation may look different in this perspective. What matters here is which regulatory framework relating to FDI will best support national food security defined in a large sense. Agricultural investment projects can (but will not automatically) contribute to national food security even if they are export-oriented or if they produce biofuels, feed crops, natural rubber or cotton.

Many intergovernmental organisations as well as the G8 and the G20 have adopted numerous resolutions and decisions aiming at increasing food security through more research and investment, local empowerment, and sustainable agriculture. ${ }^{4}$ They recognise that all the world's farmers can only feed this world if production, trade, research and investment

\footnotetext{
${ }^{3}$ Opinion expressed by the Mexican Minister for Agriculture, Francisco Mayorga, in Neue Zürcher Zeitung, 3 February 2012, p. 7.

${ }^{4} \mathrm{See}$, for instance, the interagency report by a dozen international organisations submitted on 12 June 2012 to the Mexican Presidency of the G20 "Sustainable Agricultural Productivity Growth and Bridging the Gap for Small-Family Farms". It addresses 10 recommendations to the $\mathrm{G} 20$, in particular with regards to productivity improvements for small farms, including throiugh FDI. The report can be found at http://www.fao.org/economic/g20/en/ (accessed 13 June 2012).
} 
(whether domestic or foreign) increase substantially. It has also been recognised that trade becomes even more important in a climate change perspective. WTO Director-General Pascal Lamy argues that despite the "carbon footprint" of international transportation, trade in food "becomes an environmental obligation" because food should be produced where there is sufficient water. ${ }^{5}$

Agronomists and other natural scientists tell us that the earth can feed nine and more billion people. They agree that the challenge is enormous, especially in a dynamic context of climate change, increasing soil erosion and water scarcity. Most scientists and international organisations including the FAO also consider that substantial productivity, yield and postharvest improvements are necessary, and that production, processing and consumption patterns and technologies throughout the food chain have to change. The potential of biotechnology and of organic agriculture is hotly debated, albeit often by bystanders in food secure countries, and opinions diverge on the production potential of small farmers. ${ }^{6}$ Even food giant Brazil has regions exposed to chronic hunger, and millions of people living in abject urban poverty. Nonetheless, there seems to be general agreement that this world can feed itself even as two billion "vegetarians by default" in China and India become richer and start to eat meat regularly - a particularly dramatic development for global food security these new consumer habits require a 5 to 9 -fold increase of cereals and oilseed production, not to mention the also increasing water requirements and greenhouse gas production.

Social scientists look at broader issues as well. Recent history confirms that hunger is what Nobel Prize winner Amartya Sen and Jean Drèze were already calling a "multi-headed monster" back in 1989 (Drèze and Sen, 1989, p. 15). More recently, economists have learned that they also have to look at governance issues, way beyond traditional offer and demand equations (Cotula 2012, p. 674). They also look at related trade issues such as price volatility, risk management and export restrictions (Anderson and Nelgen 2011, p. 37; Karapinar 2012, p. 11). Most scientists also agree that the additional production cannot take place where it is most needed, and that most countries cannot be self-sufficient. This is where appropriate trade rules are needed to ensure that food can flow to where it is most needed.

Legal analysts face the problem that investment, trade, and human rights lawyers speak different languages, that they are often unaware of the

\footnotetext{
${ }^{5}$ Speech at The Economist Conference "Feeding the World" on 8 February 2012 in Geneva, available at http://www.wto.org/english/news_e/sppl_e/sppl216_e.htm accessed on 14 February 2012.

${ }^{6}$ Cf. Georg Keckl in Neue Zürcher Zeitung, 31 January 2012, arguing that agricultural land was never as fertile, and that yields have never been higher than today.
} 
treaty obligations and the various facets of national legislation of investor home states, and that the policy instruments in this area are even more fragmented than elsewhere. Land grabbing occurs especially in weak states. Much of it is a result of regulatory failures and corruption at the national level and many legal scholars describe these basic governance problems. Land tenure seems to be the biggest single problem. In Gabon, Benin and many other countries only $1 \%$ of agricultural land is registered with titles for individual landowners and ancestral communities. Land and ownership mapping prior to registration of land titles acquires a new sense of urgency in the face of land grabbing. Communal land tenure is especially vulnerable, even where it is in principle recognised in national constitutions. Nepal, Cambodia, and the Philippines regulate by various means both the granting of permanent titles to local indigenous communities, and delegated management where public land and natural resources are entrusted to local communities for a period of time (Andersen 2011 p. 26). In both cases access to such land by non-indigenous people raises particular issues. An example with a negative impact even on local food security is the well-studied "inalienability concept" in war-torn Sierra Leone where vast areas of land are possessed by customary landholders but unrented, unsold and uncultivated, partly because both non-lineage descendants and foreigners are prohibited from growing even trees for profit, with a clearly negative impact on national food security (Unruh 2008, p. 103). At the same time, Sierra Leone is also a country with an ambitious but also controversial biofuels project, presented at the Annual World Bank Conference on Land and Poverty, on 25 April 2012, by the Geneva-based company Addax \& Oryx. ${ }^{7}$ Regardless of these complexities, whereas agricultural land in all countries is never ownerless, it seems clear that much is underutilised, and even China has fallow land. Africa is the continent with the largest unused farm land surface. Violations of non-registered or communal land rights, the legal protection of women farmers, or "water grabbing", are clearly issues which must be solved at the national level. As is the case, for instance, for child labour, implementation of legislation and its administrative and judicial enforcement are often even bigger problems. With very few exceptions, notably Cotula, Spieldoch and Murphy, and Unruh, none of the legal studies published on agricultural FDI deal with the international dimensions of the problem which are the subject of this chapter.

Naturally, private operators look first at the economic and technical feasibility of an agricultural investment project. To varying degrees they also take other factors into account, such as national legislation, govern-

\footnotetext{
${ }^{7}$ See http://www.landandpoverty.com/agenda/thematic-sessions-day3.html accessed 1 June 2012.
} 
ance, fiscal incentives, and reputation. Their exports may increase economic growth, GDP and government revenues. They may also create new jobs, including for the former landowners, bring new technologies for production and processing, and increase yields and productivity in the whole sector. Nonetheless, their contribution to national food security is, at best, incidental. Because they mostly produce for exports their investment may be positive for global food security, but small or nil for host country food security except where they provide the foreign exchange necessary to buy cheaper food abroad. On the negative side, there are cases of hit-and-run operations with short-term land leases and which are likely to cease after the expiry of fiscal incentives. Degraded soils, erosion, deforestation, and depletion of groundwater are more likely to result from such investments than jobs and government revenues. In fact, only investors intending to stay may want to ensure that their investment responds to sustainable agriculture principles. Under these circumstances, land sales and long leases with sustainability provisions lead to more national food security than tax holidays and short-term operations with little if any vertical integration.

The question then would seem to be whether national food security in its multifaceted context would be better or worse off without FDI. The counterfactual, put simply, would be a comprehensive ex ante/ex post impact assessment of an investment project, taking all relevant factors into account, including available alternatives and public interest. As pointed out by Laarni Escresa in this book, this involves numerous issues such as price bubbles and productivity increases through FDI, as well as the existence or absence of land titles which in turn impacts on situation rents and raises the "fair price" question.

The following sections return to the international dimensions of land grab: Section $\mathrm{C}$ analyses regulatory deficiencies in investor home states. Section $\mathrm{D}$ describes the relevant international treaty provisions. Section E concludes with suggestions for further research and for initial policy changes.

\section{Regulatory deficiencies in investor home states and international investment and trade law}

The legal situation was simpler in colonial times, albeit nowhere uniform. Just about everywhere, land ownership was regulated and enforced by the colonial powers. After independence, however, new foreign investments in most countries went into manufacturing. With some notable exceptions of large holdings in foreign hands, farm ownership was with nationals and naturalised colonials, even though foreign traders and powers continued to exercise considerable influence on the local markets and on production 
patterns (Cotula 2012, p. 661). Even today, globally operating international food companies typically abstain from actually buying farm land in the countries where they invest in factories, but many have increased vertical integration by procuring inputs from contract farmers and by extending technical assistance to them in order to raise production standards.

The sudden increase of FDI in recent years came as a surprise to many. As recently as 2008 the World Bank was still complaining about a lack of investment in agriculture over the preceding decades and even the relative decline of official development assistance for agricultural projects; it ruefully acknowledged its own, decade-long lack of engagement (IBRD 2008 p. 16). Only two years later, on the basis of case studies of 19 projects in the field, it noted a rapid increase of local and foreign investment, but often at the cost of environmental and social concerns. This detailed report concluded by calling for an "Evidence-Based Multistakeholder Approach" (IBRD 2010 p. 141).

At the non-governmental level, a number of initiatives were undertaken as a response to land grab. For instance, in 2010 experts from a number of specialised non-governmental organisations (NGOs) called for human rights impact assessments (HRIA) ${ }^{8}$ for trade and investment agreements (Berne Declaration et al. 2010). ${ }^{9}$ A similar expert meeting in 2011 worked on transparency and accountability tools in agricultural FDI (Global Witness 2011). Also in 2011, the Tirana Declaration adopted by the International Land Coalition (ILC) denounced "all forms of land grabbing, whether international or national" and called for

"models of investment in agriculture and other rural land-based activities that are socially, economically and environmentally sustainable and that reduce poverty and hunger" (ILC 2011a).

The actual extent of this new phenomenon remained unclear for some time. As recently as 2009 the best available data on the extent of land grab were mere estimates based on media reports and accompanied by big caveats:

\footnotetext{
${ }^{8}$ HRIAs are used, inter alia, by the Scottish Human Rights Commission and the Canadian "Rights \& Democracy" (International Centre for Human Rights and Democratic Development) for investments. The latter has issued a "step by step guide to assess the impact of foreign investments on human rights" (found at http://www.ddrd.org/site/_PDF/publications/Getting-it-right_HRIA.pdf accessed 1 June 2012). According to Rights \& Democracy, it is a tool by which "local civil society organisations can assess the specific human rights impacts of foreign investment projects on local communities and seek appropriate remedies. It is primarily an ex post assessment tool."

9 The background paper for this expert group meeting was presented by James Harrison from the University of Warwick School of Law where a human rights impact assessment tool was developed for a variety of fields (cf. Harrison, James (2011). Human rights measurement: reflections on the current practice and future potential of human rights impact assessment, 3(2) Journal of Human Rights Practice, 162-187 (1757-9619)).
} 
"Well-documented examples are scarce, details on the deals are often murky, and some reports are contradictory" (IFPRI 2009). Today there is more reliable information. A recent ILC report finds that between 2000 and 2011, large-scale land acquisitions increased by 203 million hectares globally - a huge figure by all accounts (Anseeuw et al. 2012a). ${ }^{10}$ Also, a land matrix established by ILC estimates that $22 \%$ of this newly acquired land, mainly in Africa and Asia, is used for mining, tourism, industry and forestry, $58 \%$ for biofuels production, and only $20 \%$ for food production (Anseeuw et al. 2012b). Lorenzo Cotula (2012) provides a good political economy analysis of the international drivers and implications of the "global land rush". A few sample farming contracts are available on a FAO-operated website. ${ }^{11}$

Many cases attract the attention of advocacy groups, and considerable media coverage. Allegations of corruption and illegal land acquisition with the active connivance of national and local authorities abound, more often than not with a credible background. Dispossessions of holders of nonregistered or communal land rights make for headlines and opposition by concerned NGOs on behalf of the rural poor. ${ }^{12}$ The Daewoo vs. Madagascar story is only one of the better-known early cases which according to some NGO sources has led to the toppling of the government and to increased civil strife in that country. ${ }^{13}$ The Oakland Institute has published a series of country reports called Understanding Investment Deals in Afri$c a{ }^{14}$ Other studies quantify and describe the issue in a national, regional and global governance perspective (ILC 2011b).

Although a fairly accurate picture of the increasing number of investment projects, and a number of plausible cases of actual, illegal land grab have now been made public, there still is no overview of all investments actually carried out, let alone of their impact. One difficulty in analysing land grab and for carrying out independent impact assessments is the fact that most investment contracts are not in the public domain. ${ }^{15}$ Therefore the

${ }^{10}$ By way of comparison, Germany has $17 \mathrm{~m}$ hectares of farmland, corresponding to $47 \%$ of its territory (Source: Wikipedia accessed on 29 May $2012 \mathrm{http} / / /$ de.wikiped ia.org/w/index.php?title=Landwirtschaft\&stable $=1$ ).

${ }^{11}$ Contract Farming Resource Centre, Toolkit available at http://www.fao.org/ag/ ags/contract-farming/toolkit/en/. For a 2009 contract farming investment by the Indian company Varun in Madagascar see http://farmlandgrab.org/2849 both accessed on 11 June 2012.

${ }^{12}$ Financial Times, 8 September 2010.

${ }^{13}$ Tom Burgis and Javier Blas. Madagascar Scraps Daewoo Farm Deal, in Financial Times, 18 March 2009. This case is also described by Meinzen-Dick and Markelova (2009, p. 76).

${ }^{14}$ See, for instance, Oakland Institute 2011.

${ }^{15}$ The situation is somewhat more transparent for mining contracts. For agricultural investments, according to Cotula (2011) all contracts in the Democratic Republic of Congo were also available online, but at the time of writing this was no longer the case. 
extent of forced displacements of local farmers and expropriation compensation offered (or refused) remains totally unclear, and the same is true for the social and environmental damage which may have been caused by large agricultural projects. Hence an exact measurement of the actual extent of land grab - whatever its definition - is simply not possible. Besides, quite a few cases concern domestic investment projects. Others involve investors from neighbouring countries conducting large projects with allegedly illegal means. Moreover, many such projects are implemented by way of land leases, or contract farming, rather than land acquisitions. The size of some operations can be large but they may also be relatively small, with perhaps only 400 hectares involved. In other words, while the rapidly increasing acquisition of farmland is evident, the extent of (illegal) land grab remains unclear, except that it seems not to be limited to "large" and "foreign" investors as narrowly defined.

The fuzzy borders of the land grab phenomenon and the uncertainties and imprecision regarding its extent are but one difficulty for a scientific analysis of its international implications. The human rights and development aspects are being scrutinised by a number of researchers and in different fora. However, a reliable analysis from a food security perspective of the relevant international and national legal investment framework is so far largely absent.

What can then be said about investment treaties and national legislation applying to agriculture?

It appears that even modern versions of regional and bilateral investment treaties (BITs) do not contain specific provisions on agricultural land purchases. The rights and obligations applying, respectively, to investors and states have evolved, especially in non-European BITs, but it has been pointed out that most of this "rebalancing" has been "limited to reformulating core obligations, like national treatment and prohibitions on expropriation without compensation, and adding exceptions to preserve host state policy-making flexibility in specific areas" (VanDuzer 2010, p. 2).

A notable "European" innovation addressing the development impact of FDI is Article 72 of the EC-CARIFORUM Economic Partnership Agreement which obliges the parties to ensure, among others that investors

"establish and maintain, where appropriate, local community liaison processes, especially in projects involving extensive natural resource-based activities, in so far that they do not nullify or impair the benefits accruing to the other Party under the terms of a specific commitment."

Such provisions laying down concrete obligations relating to the development impact of foreign investment are still new, and practical experience is therefore still lacking. Moreover, most of the large projects reported as land grab cases take place in countries without BITs. 
In addition, in most cases there is an investment contract which presumably (without being published) is completely legal i.e., does not violate any national laws. It has been agreed between a private company or a public entity (perhaps a sovereign wealth fund) and a competent national authority, often times with accompanying contractual commitments, for example, for infrastructure, health and education facilities, and training components. Such comprehensive investment agreements are decidedly difficult to assess - the more so since in reality they do not always seem to fully materialise. Needless to say, many governments and local authorities are wary of foreigners telling them how to pursue their food security objectives and farm policies, or how to manage their natural resources.

This situation both attracts international criticism and makes it difficult. Lack of evidence and of transparency are one problem. Investors point out the competitive situation they find themselves in and that their projects comprise roads, schools, hospitals, technology transfer and technical assistance. How can such package deals, which may or may not be fully implemented, be analysed, especially in the absence of an agreed standard for comprehensive impact assessments? Does this mean that international rules and treaties neither should nor could offer any remedy?

An additional difficulty lies in the so-called stabilisation provisions contained in a number of investment contracts, by which governments commit not to increase for instance social or environmental standards during a project's lifetime (Cotula 2011, p. 40; Mann 2011, p. 7). While such provisions can improve the investment climate, they are also seen as a case of regulatory chill possibly even condoning land grab.

The main question examined here is the role played by home governments in land grab cases. Can home states fight corruption abroad, and yet close their eyes if their companies violate human rights or lastingly damage the environment in their operations abroad? How could they act unilaterally, and as treaty-makers? Can they, for instance, ask for a comprehensive impact assessment of a large investment project, or for a copy of an investment contract? If they could, should they then be satisfied with a positive feasibility study result showing an overall positive national welfare increase? In such cases the "only" question would be whether landowners are adequately compensated, rather like they would be for a railway or another infrastructure project anywhere in the world, and whether access to courts is possible and effective. But is that a matter for involvement of foreign governments? As already pointed out, international investment rules do not foresee such situations, and investor home states can thus argue that they have neither an obligation nor the necessary legal instruments to intervene where land grab is claimed or suspected. Do home states hence bear no responsibility for the behaviour of private companies abroad? In 2006, Anne van Aaken submitted that "investment law must 
evolve and be interpreted consistently with international law, including human rights law, multilateral environmental treaties and WTO law." She also pointed out that "both investment hawks as well as critics of 'neoliberal' investment law, make a strong argument for applying special areas of international law also to investment law; though both sides focus on different law: one side on WTO law, the other side on multilateral environmental treaties, human rights, etc." (van Aaken 2006, pp. 92 and 94). I have argued elsewhere that the international legal framework applying, respectively, to food security, trade, and investment, appears like a particularly flagrant case of rules fragmentation (Häberli 2012a and 2012b).

Inasmuch as foreign investors often enjoy better treatment than national ones, what we have here is a case of overprotection and under-regulation. Seen from this angle, land grab prevention through inaction is more than a problem of governance and government ethics - even where an investor operates totally independently and without any support from its home state. Hence the argument has been made that home states have responsibilities that go beyond anti-corruption regulations in a global food security perspective (Richardson 2011, p. 44).

There is more. A closer look at today's realities shows that, in one way or another, governments and international lending agencies are increasingly and directly involved. They may be providing technical assistance, vocational training, technology transfer and infrastructure through their development agencies or concessional finance through a development bank, in addition to offering the classical panoply of investment protection and promotion to their nationals. Arguably, a sovereign wealth fund investing in land would also be liable for the compatibility of its operations with the international obligations of its state owner. Under such circumstances the international land grab responsibility acquires a new dimension.

A comparable example could be the export risk guarantee schemes operated by most developed and by some developing countries. In most of these schemes the competent authorities are increasingly obliged by their constituents to look carefully at the social and environmental implications of, say, a large dam project before they can approve a guarantee for the political risks involved.

It is submitted here that FDI promotion and protection by home states raise questions which so far have escaped both national regulators and investment treaty makers. As will be shown below, each country has international obligations in the field of food security. This means that investment promotion and protection, regardless of their impact on food security, indicate a lack of government coherence, to say the least, if not a violation of relevant international law provisions. As mentioned above, traditional international investment treaties are still almost exclusively aimed at investor protection, promotion, and compensation in cases of discrimination and 
expropriation. The more than 3,000 BITs and investment chapters contained in regional trade agreements make no mention of specific situations relating to agricultural FDI. So far there seem to be no investment dispute settlement cases directly involving land grab.

Besides, potential problems in this context also lie in the applicable multilateral trade rules subscribed to by the same home and host states. For instance, WTO rules prevent the application of different import tariffs for more or less sustainable production, or for the processing of biofuels; at the same time, production subsidies for biofuels largely escape trade disciplines even though they distort investment and competition with nonsubsidised supplies from other countries (Cotula 2012 p. 668; Häberli 2012 b p. 212). Moreover, import licensing conditions differentiating between biofuels production methods imposed by developed countries and by the European Union may conflict with the "like product" rules laid down under the national treatment provision in Article III of the GATT 1994.

Another example where trade and investment rules may collide with the right to food are export restrictions on food crops in order to ensure adequate food supplies to a state's own population. While it is generally agreed that such export restrictions are in most cases self-defeating, there might be situations where export restrictions are the only available tool against trade measures taken by another country. Where such policies are adopted by a host country despite the investment agreement signed with a foreign investor and a BIT, this might require a more differentiated legal base under GATT Article XI, able to trump, with an appropriate compensation mechanism, those contractual commitments.

\section{International legal provisions relevant to land grab}

As indicated in the introduction, the 2007-08 food crisis led to a flurry of intergovernmental initiatives and new standards for food security improvements. Responsible Agricultural Investment Principles have been adopted by the competent intergovernmental organisations (FAO et al 2010). The OECD guidelines for multinational investors were amended on 25 May 2011 by the Declaration on International Investment and Multinational Enterprises. The International Finance Corporation further developed its 2006 performance standard in respect of Land Acquisition and Involuntary Resettlement (IFC 2006; IFC 2012). Very recently, the FAO adopted Voluntary Guidelines on the Responsible Governance of Tenure of Land, Fisheries and Forests in the Context of National Food Security (FAO 2012). The United Nations Conference on Trade and Development adopted an Investment Facilitation Compact for sound investment rules and principles, stating that "the sensitive issue of access to land requires 
careful balancing of the rights and obligation of agricultural investors" (UNCTAD 2012, p. 21). Earlier on, the United Nations Global Compact was launched in July 2000; today it is the world's largest corporate responsibility initiative, with ten universally accepted principles in the areas of human rights, labour, environment and anti-corruption. ${ }^{16}$

The normative value of these instruments varies and quite a few are yet to become operational. I have described them in another publication, also showing how they relate to the fundamental texts of all three "book" religions Judaism, Christianity and Islam (Häberli 2012c). Put into a historical context, they find their origins in the Universal Declaration of Human Rights (1948) which also gave rise to a number of UN treaties.

The conceptual basis for all these instruments is the International Covenant on Economic, Social and Cultural Rights (ICESCR 1966). It has been ratified by 160 governments. In respect of what today is called the right to food (R2F), Art.11/2 specifies that:

'The States Parties to the present Covenant, recognizing the fundamental right of everyone to be free from hunger, shall take, individually and through international co-operation, the measures, including specific programmes, which are needed:

(a) To improve methods of production, conservation and distribution of food by making full use of technical and scientific knowledge, by disseminating knowledge of the principles of nutrition and by developing or reforming agrarian systems in such a way as to achieve the most efficient development and utilization of natural resources; (b) Taking into account the problems of both food-importing and food-exporting countries, to ensure an equitable distribution of world food supplies in relation to need. ${ }^{17}$

This provision constitutes a legal obligation for all states to take R2Frelated action. It is clearly not limited to the territory of a signatory state. Unfortunately it still fails to inform investment policies and treaties relevant for food security.

FDI can be seen as a means to "achieve the most efficient development and utilization of natural resources" for the R2F, as expressed in the ICESCR. This is where the obligation of home states to take "positive action" kicks in. In other words, a fresh look at the BITs signed by home states is warranted, including investment chapters contained in regional trade agreements. The main thrust of these provisions is to make FDI more

${ }^{16}$ According to the Global Compact's website, 127 companies and 84 non-business stakeholders joined the Global Compact in April 2012, while 115 companies were delisted for failing to communicate on progress. The total figures as of 30 April 2012 were as follows: (1) Business participants: 6,946 (2) Non-business participants: 3,269 (3) Communications on Progress (COPs) submitted: 15,060 (4) Delisted business participants: 3,402. See http://www.unglobalcompact.org/NewsAndEvents/UNGC_bu lletin/2012_05_01.html accessed 1 June 2012.

${ }^{17}$ Adopted by UN General Assembly Resolution 2200A (XXI) of 16 December 1966; entry into force 3 January 1976 (emphasis added). 
attractive by ensuring investor rights - especially in countries with weak legal systems. However, it is precisely in such countries that the recent wave of agricultural investment has shown the shortcomings criticised even by the World Bank, and which these BITs clearly fail to remedy. To take one example, if a foreign investor is being sued, or expropriated, by a successor government claiming invalidity of an earlier investment contract because of corruption, that investor might obtain protection under a BIT or under the Convention on the Settlement of Investment Disputes between States and Nationals of Other States which entered into force on October 14, 1966 (ICSID 1966). The chances are that such an investor would obtain a compensation award even where an investment project had actually evicted small farmers against their rights and wills.

The first step for home governments accepting their international human rights obligations would thus be to engage in a cross-examination among the different agencies with a regulatory impact on FDI and food security. This is not only a case for human rights and development agencies, and delegations to a dozen different intergovernmental institutions involved in food security issues. Still other agencies represent their countries on the governing boards of development banks where concessional financing for investment projects is available, in investor-state dispute settlement. There are investment insurance mechanisms with state involvement. Last but not least many food security aspects have so far escaped WTO Member representatives and negotiators (de Schoutter 2011, p. 2).

It seems clear that for large-scale agricultural land acquisitions investor host states alone cannot fulfil their R2F obligations without the cooperation and support of home states. What is necessary in that perspective is a food security impact assessment of all agricultural FDI projects. Such an assessment can only take place with the active concurrence of the home state, regardless of the actual role played in a concrete case.

\section{E. Conclusions}

Large-scale land acquisitions are a recent phenomenon which has already been quite well documented and described by economists and other scholars, and not least by advocacy groups. However, legal studies especially of the international issues of agricultural FDI are still virtually non-existent. This makes allegations of the illegality of these acquisitions (land grab) so much easier. Much more scientific analytical and empirical research on the questions and issues outlined in this paper is thus necessary, and urgent.

Meanwhile, it seems clear that investor home states and international organisations cannot remain aloof. I consider two lines of action to be necessary. 
First, governments must respect the general public international law principle, going back to Hippocrates, to (at least) "do no harm" (primum non nocere). This obligation is already quite well established in international environmental case law. ${ }^{18}$ The "responsibility to protect" would be especially big where governments guarantee or otherwise promote such investments through national or international investment credits, development projects for infrastructure or training, and insurance guarantees. National legislation and commitments to fight corruption abroad are not sufficient. As a minimum, home states must look into allegations that their investors may have misused a "weak state" situation and taken possession of agricultural land without full compensation of previous owners, or that they might conduct unsustainable operations with resultant land degradation, soil erosion and encroachment on neighbouring lands and water rights.

Secondly, the obligation to act exists independently of a direct or indirect home state involvement in a particular investment project. It is based on international human, social and economic rights and the corresponding treaty obligations which these same states have ratified. Hence, international investment treaties and trade rules must be re-examined for their public interest relevance in general and, in particular, for their impact on food security. An appropriate legal basis would be the introduction in investment treaties of a public interest clause. Such a clause would need to be clearly related to investor behaviour and go beyond the general international law principles of good faith and fair and equitable treatment, or the escape clauses found in some BITs of the United States of America. For agricultural investments, such a clause should for instance allow an investment dispute arbitrator to deny BIT protection for an investment contract obtained through massive and evidenced corruption, or for a project involving serious human rights violations.

These are by no means easy tasks. Especially investment promotion agencies and financial organisations may argue that it is not for them to examine the human rights and food security implications of investment projects, and that government intervention of this type may also scare away the geese that lay the golden eggs. The same agencies will also point out that the governments with which they have signed a BIT are unlikely to accept a revision of those treaties where they only see interference in their internal policy space.

Interestingly, new challenges in the context of labour, environmental and public health considerations are beginning to change the political landscape at least for new treaties, and this is happening outside Europe. While

${ }^{18}$ For cases of international environmental law, notably the Trail Smelter case (1938 and 1941) cf. Nadakavukaren and Cottier (2012). 
the EU and its Member States maintain their basic objective of maximising investor protection, other regions seem to take a more differentiated approach. For instance, the investor-state arbitration provisions in the ongoing Trans-Pacific Partnership Agreement (TPPA) negotiations are being reviewed as a result of several legal challenges to Australia's rigorous antismoking policies by a BIT-protected tobacco company (Nottage 2011, p. 21); Australia is now seeking to exclude itself from such provisions. On the other hand, NGO activism in the context of the North American Free Trade Agreement (NAFTA) is increasingly frowned upon by the same governments which had opened an access to court possibility for their NGOs. Recent studies show that there is precious little evidence of a positive impact of investment treaties in attracting FDI; they also point to recent examples of BIT provisions with a "better balance between investor protection and the regulatory freedom of host states" (VanDuzer 2011, p. 4). Others even argue that BITs are no longer necessary because private insurance instruments are now available by which investors can cover both the commercial and the sovereign risk which their investments involve.

The second thoughts of governments in respect of investment protection and promotion may yet extend to investments in agriculture. For instance, governments may come to review their support, in whichever form, to a large irrigation project involving the displacement of people without full compensation. Even more importantly, they may review their own food security and agricultural trade policies in the light of their international human rights obligations, and take positive action in order to ensure the R2F everywhere.

Investment law, and investment treaties, have so far not been seriously scrutinised in this context. Their principal objective being investment promotion and protection, most of them still fail to take on board other considerations and interests such as human rights and food security. It is argued here that policy and rules fragmentation cannot serve as an excuse for not considering the possible negative outcome of over-protection and under-regulation in host states, regardless of whether they are parties to investment agreements.

The food security impact of agricultural FDI especially in weak states is far from clear, and an overall impact assessment would hardly be feasible. But there are enough allegations and some serious evidence of land grab to warrant a re-examination of the relevant regulatory framework by home states and in the competent intergovernmental organisations. Many policy analyses and international guidelines and recommendations already exist and show the way for implementation in both host and home states. Because the road to improvements is a long one, the groundwork should start immediately. 


\section{Bibliography}

Andersen, K. E. (2011). Communal Tenure and the Governance of Common Property Resources in Asia: Lessons of Experiences in Selected Countries. FAO Land Tenure Working Paper 20. Rome.

Anderson, K. and Nelgen, S. (2012). Trade Barrier Volatility and Agricultural Price Stabilization. 40(1) World Development 36-48.

Aniekwe, C. C. (2010). Agricultural trade liberalization and small-holder development: West African rice farmers in perspective. Proceedings of the Second Africa Rice Congress, Bamako, Mali, 22-26 March 2010: Innovation and Partnerships to Realize Africa's Rice Potential.

Anseeuw, W., Wily, L. A., Cotula, L., and Taylor, M. (Anseeuw et al. 2012a). Land Rights and the Rush for Land: Findings of the Global Commercial Pressures on Land Research Project. International Land Coalition. Rome, 2012.

Anseeuw, W., Boche, M., Breu, T., Giger, M., Lay, J., Messerli, P. and Nolte, K. (Anseeuw et al. 2012b). Transnational Land Deals for Agriculture in the Global South. Analytical Report based on the Land Matrix Database. CDE/CIRAD/GIGA, Bern/Montpellier/Hamburg, 2012.

Berne Declaration, Canadian Council for International Co-operation \& Misereor (Berne Declaration et al. 2010): Human Rights Impact Assessment for Trade and Investment Agreements. Report of the Expert Seminar, June 23-24, 2010. Geneva, Switzerland.

Binswanger, H., Deininger, K. and Feder, G. (1993). Agricultural Land Relations in the Developing World. 75 (5) American Journal of Agricultural Economics 1242-1248.

Convention on the Settlement of Investment Disputes between States and Nationals of Other States (ICSID 1966). United Nations Treaty Series vol.575, registration number I-8359.

Cotula, L. (2012). The International Political Economy of the Global Land Rush: A Critical Appraisal of Trends, Scale, Geography and Drivers. 39 (3-4) The Journal of Peasant Studies 649-680.

Cotula, L. (2011). Land Deals in Africa: What is in the Contracts? International Institute for Environment and Development (IIED), London.

Deininger, K., Selod, H. and Burns, A. (2011). The Land Governance Assessment Framework: Identifying and Monitoring Good Practice in the Land Sector. World Bank Publications, 2011.

De Schutter, O. (2011). The World Trade Organization and the Post-Global Food Crisis Agenda: Putting Food Security First in the International Trade System. Briefing Note 04, November 2011.

De Schutter, O. (2009). Large-scale land acquisitions and leases: A set of minimum principles and measures to address the human rights challenge. Report of the Special Rapporteur on the right to food. UNHCR Document A/HRC/13/33/Add.2, 28 December 2009.

Dessy, S., Gohou, G., and Vencatachellum, D. (2011). Foreign Direct Investments in Africa's Farmlands: Threat or Opportunity for Local Populations? Centre Interuniversitaire sur le Risque, les Politiques économiques et l'Emploi (CIRPÉE). Cahier de recherche/Working Paper 12-03, January 2011.

Drèze, J. and Sen, A. K. (1989). Hunger and Public Action (reprinted in 2002, OUP, Oxford).

FAO (2012). Voluntary Guidelines on the Responsible Governance of Tenure of Land, Fisheries and Forests in the Context of National Food Security. 11 May 2012, Rome.

FAO (2002). The State of Food Insecurity in the World 2001. Rome. 
FAO, IFAD, UNCTAD and the World Bank Group (FAO et al. 2010). Principles for Responsible Agricultural Investment that Respects Rights, Livelihoods and Resources. Extended version, Rome, January 25, 2010.

Gathii, J. (2012). Food Sovereignty For Poor Countries in the Global Trading System. 57(XX) Loyola Law Review 100-131.

Global Witness (2011). Promoting transparency and accountability in land related investments (research and dialogue project as a result of a meeting hosted by CDE at the University of Bern in April 2011, with Oakland Institute and ILC, 18 July 2011).

Häberli, C. (2012a). Do WTO Rules Improve or Impair the Right to Food? in Melaku Desta and Joe McMahon (Eds), Research Handbook on International Agricultural Trade (Edward Elgar, Cheltenham/UK and Northampton/US, 2012) pp. 50-72.

Häberli, C. (2012b). What's wrong with WTO rules applying to food security? in Rosemary Rayfuse and Nicole Weisfelt (eds), The Challenge of Food Security, forthcoming in October 2012 at Edward Elgar, pp. 191-216.

Häberli, C. (2012c). God, the WTO - and Hunger. in Krista Nadakavukaren Scheffer (Ed), Poverty and the International Economic Law System: Duties to the Poor, forthcoming in 2012 at Cambridge University Press.

International Bank for Reconstruction and Development (IBRD 2008). The World Bank Annual Report 2008, Year in Review. Washington, DC.

International Bank for Reconstruction and Development (IBRD 2010). Rising Global Interest in Farmland: Can it Yield Sustainable and Equitable Benefits? Washington, DC, released September 7, 2010, final version printed in 2011.

International Finance Corporation (IFC 2006). Performance Standard 5: Land Acquisition and Involuntary Resettlement. 30 April 2006, Washington.

International Finance Corporation (IFC 2012). Guidance Note 5: Land Acquisition and Involuntary Resettlement. 1 January 2012, Washington.

International Fund for Agricultural Development (IFAD 2010): Rural Poverty Report 2011 - New realities, new challenges: new opportunities for tomorrow's generation. November 2010, Rome.

International Covenant on Economic, Social and Cultural Rights (ICESCR 1966). New York, 16 December 1966. Entry into force on 3 January 1976. United Nations Treaty Series vol. 993 , p. 3.

International Land Coalition (ILC 2011a). Securing land access for the poor in times of intensified natural resources competition. Tirana Declaration adopted at the ILC Global Assembly on 26 May 2011.

International Land Coalition (ILC 2011b). International instruments influencing the rights of people facing investments in agricultural land. Prepared by Simone Heri, World Trade Institute, Albert ten Kate and Sanne van der Wal, SOMO, Elisabeth Bürgi Bonanomi, World Trade Institute, and Katja Gehne, World Trade Institute. January 2011.

Kappel, R., Pavletic, I. and Schüpbach, J. (Kappel et al. 2012). Can Foreign Direct Investment in Agriculture Save Us from High Food Prices? Second Draft of a paper in ETH/NADEL. Zürich, April 2012.

Karapinar, B. (2012). Defining the legal boundaries of export restrictions: A case law analysis. 15(2) Journal of International Economic Law 1-37.

Mann, H. (2011). Stabilization in investment contracts: Rethinking the context, reformulating the result. 1(2) Investment Treaty News Quarterly 6-8. The International Institute for Sustainable Development, Geneva.

Meinzen-Dick, R. and Markelova, H. (2009). Necessary Nuance: Toward a Code of Conduct in Foreign Land Deals (in Land Grab? The Race for the World's Farmland. Michael Kugelman and Susan L. Levenstein (Eds). Woodrow Wilson International Center for Scholars, Washington, DC pp. 69-81. 
Montilla L., and Schwarze, J. Large-Scale Agricultural Investments in Light of John Rawls's Theory of Justice. Journal of Agricultural and Enviromental Ethics. Special issue on Ethical Aspects of Large-Scale Land Acquisition in Developing Countries (forthcoming September 2012).

Nadakavukaren Schefer, K. and Cottier, T. (2012). Responsibility to Protect (R2P) and the Emerging Principle of Common Concern. Text on file with author.

Nottage, L. (2011). The Rise and Possible Fall of Investor-State Arbitration in Asia: A Skeptic's View of Australia's "Gillard Government Trade Policy Statement". Sydney Law School Legal Studies Research Paper No. 11/32, June 2011.

Oakland Institute (2011). Understanding Land Investment Deals in Africa: Country Report: Ethiopia.

Organisation for Economic Co-operation and Development (OECD 2008). OECD Guidelines for Multinational Enterprises. Paris.

OECD-FAO Agricultural Outlook 2011-2020 (OECD/FAO 2011). OECD Publishing and FAO, Paris and Rome.

Richardson, J. (2011). Agricultural Development and Land Rights: Who Wins and Who Dies? JMR Portfolio Intelligence, December 17, 2011.

Sen, A. (1981). Poverty and Famines. Oxford University Press.

Spieldoch, A. and Murphy, S. (2009). Agricultural Land Acquisitions: Implications for Food Security and Poverty Alleviation. in Michael Kugelman and Susan L. Levenstein (Eds) Land Grab? The Race for the World's Farm Land. Woodrow Wilson International Center for Scholars, Washington, DC. pp. 39-63.

Swinnen, J. and Squicciarini, P. (2012). Mixed Messages on Prices and Food Security. 335(6067) Science 405-406 (27 January 2012).

UNCTAD (2012). Investment Policy Framework for Sustainable Development. Geneva.

Unruh, J. (2008). Land Policy Reform, Customary Rule of Law and the Peace Process in Sierra Leone. 2 African Journal of Legal Studies 94-117.

Van Aaken, A. (2006). Fragmentation of International Law: The Case of International Investment Law. 17 Finnish Yearbook of International Law 91-130.

VanDuzer, A. J. (2010). A Commonwealth Guide on International Investment Agreement Provisions Promoting Sustainable Development. Issue Paper 72 published by the Economic Affairs Division of the Commonwealth Secretariat.

Von Braun, J. and Meinzen-Dick, R. "Land Grabbing" by Foreign Investors in Developing Countries (IFPRI 2009): Risks and Opportunities (IFPRI Policy Brief 13, April 2009). 



\section{Comment on Christian Häberli}

\section{Foreign Direct Investment in Agriculture: Land Grab or Food Security Improvement?}

\section{Laarni Escresa}

\section{A. Introduction}

Owing to the sheer size of the area involved, the rise in large scale foreign investment in agriculture in developing countries has raised a number of concerns ranging from the impact on the host country's food security to the human rights issues of displaced individuals and, in some cases, stirred political instability. Christian Häberli's paper aims to contribute towards its resolution by posing a normative question regarding the possible role of international law in addressing food security issues. He finds justification in some of its tenets, particularly the need to avoid the fragmentation of international law. This implies that international trade and investment law should not conflict and should be reconciled with international human rights law and other conventions or agreements that are committed to assuring food security.

His paper first lays down the relationship between large scale foreign direct investment and food security. It cites studies showing that evidence on the impact of FDI on host countries is mixed. In cases where large scale FDI negatively impacts on the food security, the host country is usually plagued with weak institutions. In such a situation, Häberli asks whether there is a responsibility and role for governments of the investor home countries to regulate the behavior of firms when doing business in another country. He also posed the problem to the international community and enumerated existing international legal measures that may be relevant to the issue and discussed their respective weaknesses.

In order to help answer the normative question, my comment to the paper aims to provide a positive economic analysis of land grab, the term 
commonly used to refer to this trend and to distinguish it from previous agricultural FDI. This can serve as a complement to the normative analysis provided by Häberli. By providing greater clarity, I hope to shed light on the interlocking issues raised in the previous article with the aim of aiding in the identification of the appropriate role for international law and the international community, if there should be any. My approach is heavily rooted in the analysis of prices, factor inputs, the mobility of factors of production, and the role of law and legal institutions. Any positive analysis would be incomplete without considering the politico-economic behavior of all the actors and stakeholders involved. However, due to time considerations it is beyond the scope of our comments.

\section{B. Background: Landgrab, food security and factor movements}

\section{Price shocks and food security}

The distinguishing feature of land grab from past investment in agriculture is primarily the size of the land area involved ${ }^{1}$. According to the Deininger, et al (2011), the average size of investment in farmlands during the period covered ranges from 700 hectares in Ethiopia to 59,374 in Liberia. What triggered the trend is the spike in world food prices in 2006-2008 and in 2010 that made investment in agriculture more profitable ${ }^{2}$.

Prior to the early $2000 \mathrm{~s}$, the price of agricultural commodities had been on the decline and concern over the consequences of the deteriorating terms of trade for agricultural producers had been raised. The price increase therefore should have been a welcome development. However, not all countries have the capacity to expand production in the short or in the medium term, especially if the country faces existing resource constraints such as the lack of arable land, capital, or technology. It may also be the case that the country has the resource endowment but poor institutions serve as obstacles in mobilizing resources that will lead to higher productivity.

On the other hand, higher agricultural prices also raised the price of food necessary for consumption. Since food is income inelastic, it is the

\footnotetext{
${ }^{1}$ For a review of large scale FDI in agriculture, see Cotula, et al (2009) and Görgen, et al (2009).

${ }^{2}$ See Headey and Fan (2008) for an analysis of the causes of rising food prices. There are many reasons for the spike in world prices: the weather shocks, expansion of biofuels, increase in demand as well as macroeconomic factors such as the depreciation of the dollar, trade and public policies.
} 
poor who suffered more from the price increase. The net effect of higher agricultural price on individuals then depends on the income and the consumption effect (See Ivanic and Martin, 2008; and Dorward, 2012). If the increase in income is higher than the corresponding increase in consumption expenditure, then the individual is better off. In such a situation, food security is also met to the extent that it is defined as access to food ${ }^{3}$. There are two things that should be noted here. The goal of food security should be distinguished from self-sufficiency. The former can be achieved with international trade while the latter means that the domestic demand for food should be met by the domestic economy. Second, its attainment varies according to social groups even within a country. Thus, a country may be a net food exporter but there can also be poor individuals or groups who are also net buyers of food.

One way by which the attainment of food security can be measured is by looking at the extent of undernourishment in the population. A study by the FAO (2011) shows that the effect of higher world food prices on the level of undernourishment is different for two sets of countries. The percentage of undernourished individuals went down for countries who are net sellers. Some of these countries such as Brazil, China and India also used a combination of trade restriction and other safety nets which kept prices relatively low. For net importing countries like Uganda, Senegal, Mozambique, Ethiopia, Kenya, Zambia, undernourishment went up.

\section{Price shock and global factor movements}

Following the world food spike, firms from capital rich countries, facing relative land constraint at home expanded investment in agriculture in poor and relatively capital-starved, land abundant countries. Some governments have also encouraged the move after having realized their dependence on imported food or fuel, two important and politically sensitive commodities, and decided to shelter their domestic market from price fluctuations by engaging in agricultural FDI. Most of the present and future output is intended for export back to the investor's home country.

According to Deininger, et al (2011), the reported large scale agricultural investment covered 45 million hectares of land in 2009 alone. This implies an average expansion rate of 4 million hectares. Foreign investors

\footnotetext{
${ }^{3}$ The FAO (2003) defines food security to "exist(s) when all people, at all times, have physical, social and economic access to sufficient, safe and nutritious food which meets their dietary needs and food preferences for an active and healthy life. Household food security is the application of this concept to the family level, with individuals within households as the focus of concern." http://www.fao.org/docrep/005/y4671e/y46 71e06.htm.
} 
have expressed interest in around 56 million hectares of land, two-thirds of which is located in sub-Saharan Africa.

The same study also showed that the large scale investment tends to flock to countries with poor governance structure and weak institutions ${ }^{4}$. Stories that appeared in the media also claimed that the land deals have poor contract terms for the host country. Some contracts take the form of long-term land lease contracts that promise employment and infrastructure projects with low rental fees of land (Cotula, 2011). Due to the weak institutions and the lack of good governance, concerns have been raised on whether the rate of return of land as stipulated in the contract price may be unfair.

Contracts involving the land deals are private and most are not available to the public. This makes reliable data hard to find and makes evaluation difficult. Table 1 (see pp. $318 \&$ 319) shows the largest FDI investment by land size, the host countries and their respective Property Rights Index. From this set alone, it appears that there is a correlation between large scale investment in agriculture and the host country's quality of institutions.

While the Deininger, et al (2011) highlighted the benefits the host country receives from these investments, it has also raised concern regarding the interests of some sectors of society whose rights may have been sidestepped or ignored. It has also warned that in an effort to attract capital inflow, there might be a possible danger of a "race to the bottom". On the other hand, others are sceptical about the welfare gains from such investment and whether they serve the goals of sustainable development.

Perhaps one of the questions that needs to be asked is to what extent is the contract price, specifically the rental rate of land as specified in the contract reflect the marginal productivity of the land? What is the shadow price of land in the host countries and what explains the divergence from the actual contract price?

Another set of questions that needs to be asked is why is the agricultural sector in some of the African countries continues to lag behind? As agricultural producers, what prevents them from a positive supply response from higher world food prices and thus achieving the twin goals of meeting food security at home and global food price stability? Is large scale foreign direct investment the most effective and efficient way to raise agricultural productivity in these countries? Are there economies of scale that can be taken advantage of?

Our objective is not so much to answer all of these questions but rather to raise them pointedly in order to obtain greater clarity. In the next section, we will continue to identify some of the factors that may explain land

\footnotetext{
${ }^{4}$ See also Cotula, et al (2009) and Cotula (2011).
} 
grab and explore its relationship. In the process, we raised more questions than answers.

\section{Theoretical and empirical issues of the land grab problem}

\section{Price increase, volatility in food and agriculture and the global factor markets}

Economic theory predicts that under an open economy with perfect markets, an increase in the price of a particular commodity will lead to an increase in the rate of return of the factor that is most intensively used in its production. Thus the world food spike provides incentives for a reallocation of input factors among different sectors and across borders that eventually leads towards higher agricultural production as well as equalization of factor prices 5 .

A peculiarity of agricultural production is the important, almost indispensable role of an immobile input, land. There is also a wider scope for the substitutability between labor and capital in agriculture as compared to manufacturing. The differences in factor endowments and input choices point to the different factor intensities of agricultural production across the world (See Kawagoe, et al, 1985). In land abundant countries like the US, agricultural production is relatively capital intensive while in labor abundant countries in Asia, it is relatively labor intensive.

In assessing the comparative advantage of a particular country in agriculture, Abbot and Thomson (1987) considered a three-factor model that explicitly includes land. A practical application of the theoretical exercise is to allow for the determination of the shadow price of land. This information is valuable in a situation where the land market is almost nonexistent, or market failures exist that prevent actual prices from reflecting its real productive value ${ }^{6}$. Thus, the shadow price of the land may be higher or lower than the actual or observed price in the contract.

Another characteristic of agricultural production that is often the source of agricultural price volatility is its dependence on weather conditions, a stochastic variable that is outside the control of the individual. It is also dependent on a natural production process that implies a lag period from planting, when input decisions are made to product maturation. This may

\footnotetext{
${ }^{5}$ This follows from the Heckscher-Ohlin theorem of international trade. See also Williamson (2002).

${ }^{6}$ In this case, the shadow price of the land is the marginal physical product of the land multiplied by the international price of the agricultural good.
} 
range from a few months to a few years (Abbot and Thomson, 1987). In order to maximize output from land, which is a scarce resource, and cope with output variability in the face of risks, societies have developed institutions to address these issues (Hayami and Ruttan, 1985).

\section{Yield gap and the role of institutions}

Institutions as pertained to here refer to the rules, both formal and informal that facilitate coordination among individuals and help form expectations with regards to the behavior of others when faced with different circumstances. It is widely documented that agricultural institutions can facilitate or serve as a major obstacle to agricultural modernization and development ${ }^{7}$.

Poor institutions, along with the lack of access to capital and technolo$\mathrm{gy}^{8}$ can also explain why some countries that are endowed with suitable and available arable land for agriculture have actual output that is far below their respective potential. According to the Deininger, et al (2011), most of these countries that exhibit high yield gap are from sub-Saharan Africa which includes Rwanda, Malawi, Mozambique, Sudan and Zambia. Among these countries, only 25 percent of actual potential have been attained. The same study pointed out that the attainment of output potential will help solve food security issues at home and help in smoothing international price volatility in food.

The next question to ask is, to what extent are poor institutions, specifically legal rules the cause of this output gap? What are the specific institutional and legal setup and characteristics that hinder these countries?

\section{Property rights in land}

Property rights in land is one of the most important institutions in agriculture as it establishes the user rights in land and determines how the gains will be distributed (See for instance, Ellickson, 1993) ${ }^{9}$. User rights in land

\footnotetext{
${ }^{7}$ See for instance Hayami and Ruttan (1985). We adopt their broad definition of institutions. See also Feder and Feeny (1991) for the relationship between property rights and development.

${ }^{8}$ See for instance Adesina (2010) for other factors that serve as obstacles to agricultural development in Africa.

${ }^{9}$ Ellickson explored the different land regimes and derived conditions under which individual ownership of land is preferable over group ownership given transaction costs, organization costs, and formal and informal institutions.
} 
range from the right to manage the resource and determine its use, the right to exclude others and the right to sell (Ostrom and Schlager, 1992) ${ }^{10}$.

Among the hierarchy of property rights claim, a land title is the most concrete and unambiguous form of ownership that is recognized by the government and enforceable by the court. There are many benefits of a land title. (1) It reduces enforcement costs by providing clear boundaries of ownership. (2) As it ensures security of tenure, it encourages individuals to engage in long term improvements in the land and conserve it as a resource. (3) Ownership of a land title can also be used as collateral and allows its owners to gain access to credit. (4) It also facilitates transferability and exchange and permits allocative efficiency. (5) Land titles also increase the value of the land and increases its price (Feder and Nishio, 1999). Empirical evidence in Asia and Latin America also supports the link between tenure security in the form of land titling and higher investment (See for instance Alston, et al, 1996 and Feder and Onchan, 1987).

However, empirical evidence from Africa, the host of some of the largest agricultural FDI have shown little or negligible effect of formal land tenure security on farm investment (See for instance Braselle, et al, 2001; Gavian and Fafchamps, 1996; and Jacoby and Minten, 2007). The absence of a formal credit market as well as the existence of customary rights make the net benefit of land titling less attractive (Feder and Nishio, 1999). According to Atwood (1990) while most of the land in Africa are owned by households and families, and conditions of tenure permit heritability and land transfers, there are two main characteristics that distinguish it from the rest of the world. First, the user rights are informally recognized and sanctioned but bear no legal status. Second is that they are conditioned by group rights and secondary rights to grazing for instance. Apart from other transaction costs ${ }^{11}$, the existence of informal institutions that can serve as cheap institutional alternatives to guarantee security of tenure makes the costs of formal land titling relatively too high (Atwood, 1990).

Atwood argues that in this case, land titling may not be a prerequisite towards attaining an efficient resource allocation or development. On the other hand, Feder and Nishio (1999) recognized that while customary rights, through the existence of informal rule and order may be may be able to serve this function, it may lose its particular advantages as the size of the economy grows and impersonal transactions and exchange in agriculture become more important.

The discussion above poses potential problems with the entry of large scale foreign investment with respect to: (1) land valuation, and (2) the identification of the proper owners of the land and those who have recog-

\footnotetext{
${ }^{10}$ See also Alchian and Demsetz (1973) for a general discussion of property rights.

${ }^{11}$ The transaction costs of formalization of land rights involve the determination of boundaries which requires, land surveying and other enforcement costs.
} 
nized user rights but cannot sell it. There is ambiguity whether the latter are legally entitled to some form of compensation on the contested land. It also poses problems with regards to (3) dispute settlement ${ }^{12}$. If not handled correctly, then issues of unfair valuing of the land and unjust displacement may arise. Cooter and Schaefer (2011) had emphasized the role of voluntary transfers as opposed to coercive transfers as crucial in spelling the success or failure of changes in the land tenure system.

In case the land is considered to belong to the state or owned by a community headed by a leader, then this creates potential agency problems, especially if the incentives of the agent representing their principal are not properly aligned. There is more room for corrupt transactions and rentseeking opportunities in the land deal.

What these points at is the need to conduct more empirical studies to understand the relationship between the existing range of user and property rights in the host country and how the introduction of large scale agricultural investment changes or impacts these existing property relations and to what extent it raises agricultural productivity.

\section{Optimal farm size: Scale economies and returns to scale}

Since one of the main issues raised about the agricultural FDI is its size, it should also be examined to what extent scale economies exist in agricultural production. According to Eastwood, et al (2010), countries with higher income have larger farm size. However, there is a divergence in the pattern with how farm size changed in the $20^{\text {th }}$ century. In advanced countries, it increased while in Asia and Africa, the reverse occurred. Regardless of the differences, family labor is still the main source of employment, even among developed countries where a high degree of mechanization is observed. There appears to be no significant variance across countries.

According to Eastwood et al (2010), the family as a main source of employment in agriculture has become the equilibrium setup mainly because it is able to minimize the cost of labor supervision. Unlike hired labor, the family is the residual claimant. In a context where monitoring becomes complicated and where production is exposed to a number of risks, the family has the proper incentive to exert the optimal effort (See for instance, Hayami, 2010). Among the range of agricultural activities that make monitoring complicated are crop management, crop rotation and crop-livestock combination (See Otsuka, et al, 1992; and Hayami and Ruttan, 1985). Since the right to land is hereditary, the sustainability and

${ }^{12}$ For a discussion of role of courts and justice in economic development, see Feld and Voigt (2009). 
preservation of the land's productivity is also considered for future generations.

An empirical study by Kawagoe, et al (1985) shows that agricultural production in developed countries exhibits increasing returns to scale while it is scale neutral in least developed countries. The difference lies in the choice of agricultural technology. In developed countries, the agricultural labor force went down as wage rose in the industrial sector, which was accompanied by an increase in mechanization. On the other hand, in less-developed countries where labor is relatively less expensive than capital, the adoption of machines to save labor did not occur. Instead, the kind of technology that was adopted were land-substituting inputs such as fertilizer and high yielding varieties, that are typical of the green revolution period and that are very divisible. In both cases, the agricultural production choice reflects the relative scarcity of factors.

\section{Plantation agriculture or family managed and owned farm?}

The question therefore arises whether or not plantation agriculture, characterized by centralized planning and production, usually of a monocrop and employing hired labor enjoys some advantages over family-run or owned farms. Since most FDIs share the same characteristics as the plantation agriculture, it would be useful to review the debate in the literature (Hayami, 2010). The traditional notion is that the former is superior because of mechanization. However, more recent literature, backed by empirical evidence pointed out that the latter is rational and under certain cases, is more efficient with respect to resource allocation (See for instance Otsuka, et al, 1992).

Scale economies in agriculture usually stems from the existence of indivisible factor inputs that leads to lower average production cost as the farm size increases (Deilinger and Feder, 2001). However at the farm level of production, there is no wide scope for economies of scale. According to Hayami (2010), it plays greater role at the post-harvest processing and marketing stage. Within these stages, the plantation setup has its advantages. The importance of post-harvest facilities, and marketing and distribution depends on crop varieties. Sugar, tea and banana for instance are good examples. Sugar, apart from the need to process sugarcane, also needs tight coordination at the planting and harvesting stage. On the other hand, banana is easily perishable. Thus, it is for this reason that plantation agriculture is mostly concentrated on the production of cash crops and seldom for crops like rice for instance.

Historically, the plantation setup had been used mainly to open up frontier lands in colonial countries (Hayami, 2010). As it requires the use of 
heavy machinery and construction of facilities such as roads where none existed before, then scale economies exist. However, where there is already an existing settlement, the colonial rulers usually relied on a setup where a part of the agricultural produce is collected like a huge tax to the government while leaving the family as the basic unit of production (Hayami, 2010).

Thus, whether or not the large scale FDI is welfare enhancing should weigh the benefits and costs associated with the transformation of the family owned or managed farm to a plantation. Apart from the efficiency considerations, it should also be considered that massive centralized production is socially more intrusive when the land is already settled. In such a situation, then it may be explored whether there are other institutional arrangements that may be more efficient and at the same time, least socially costly that increase agricultural productivity. For instance, arrangements that take advantage of the advantages of a family owned or managed farm while taking advantage of scale economies existing in certain stages of production ${ }^{13}$. It is also important to consider if the technology that is adopted was based on factor input efficiency and not due to politicoeconomic considerations.

\section{Conclusion}

The aim of this paper is to work towards a greater understanding of the relationship between food security and the large scale FDI, an important question raised by the preceding paper. In particular, we looked at the factors that led to its emergence and focused on two of two aspects that generate controversy - the implications of its size and the weak institutions in the host country. By having a clearer understanding of the agricultural price transmission process and the complex real and institutional issues surrounding it, we are in a better position to weigh the normative aspects.

The land grab is partly a reaction to the price volatility in world agricultural prices. On the one hand, it provided incentives for firms with relative capital abundance to invest in countries which are relatively abundant in land. On the other hand, it is also a matter of a particular transactional choice, that of large scale FDI in the form of land sale or lease contract with centralized production and hired labor akin to plantation agriculture. Seen this way, then it appears that it is one way for firms to bypass the world agricultural spot market and directly engaging in production. There are however, advantages and disadvantages with this transactional structure and there may be other ways of expanding agricultural production,

\footnotetext{
${ }^{13}$ For instance, Hayami proposes contract growing schemes.
} 
both at the international and at the national that may be more efficient and generates less social harm and displacement. For instance, information gathering and sharing among countries is crucial in managing uncertainty brought by weather disturbances or shifting demand ${ }^{14}$.

Another aspect of the problem is how to increase agricultural production in poor countries, especially where there is a high output yield gap. This will solve the twin problem of raising agricultural production and solving the country and social group specific aspects of undernourishment. It appears that one of the reasons for this lag is the poor quality of institutions. The challenge is that while capital is needed to increase output, poor institutions in countries where land is relatively abundant and where the agricultural output gap is wide, depress the rental rate of land and lead to poor contract terms. How to solve this dilemma is again another challenge. The most immediate that one can do is to at least ensure that all stakeholders, not just those with formal property rights but all those who have user rights in customary law to be included in the bargaining process in order to determine the value of the land and allocate its use efficiently. In the medium term, the need to build institutions to sustain agricultural development should be prioritized.

Ensuring food security is an imperative goal for society but the difficult and challenging aspect is how to successfully address it, both at the national and international level. It should be underscored that crucial to a successful policy is a deep understanding of the issues surrounding it: the international agricultural price transmission mechanism, the relative scarcity of factors of production and the formal and informal institutions that contribute or hinder development in agriculture.

Finally, a positive analysis of land grab is incomplete without examining the politico economic situation. Land is not just a factor of production in most developing countries. It is the main source of livelihood for a large percentage of the population in poor countries as well the source of social and political power among different social or multiethnic groups.

${ }^{14}$ See for instance FAO, IFAD, IMF, OECD, UNCTAD, WFP, the World Bank, the WTO, IFPRI and the UN HLTF Interagency Report (2011) for the G20. 
Table 1: Large scale foreign investment in agriculture: 100,000 has. and above

\begin{tabular}{|c|c|c|c|c|c|}
\hline $\begin{array}{l}\text { Host } \\
\text { Country }\end{array}$ & $\begin{array}{l}\text { Investor } \\
\text { Home } \\
\text { Country }\end{array}$ & $\begin{array}{l}\text { Land } \\
\text { Area } \\
\text { (in has.) }\end{array}$ & Land Use & $\begin{array}{l}\text { Business } \\
\text { Status }\end{array}$ & $\begin{array}{l}\text { Property } \\
\text { Rights } \\
\text { Index } \\
(\mathbf{2 0 1 2})\end{array}$ \\
\hline \multirow[t]{2}{*}{ Ethiopia } & $\begin{array}{l}\text { NBC/ Israel, } \\
\text { Germany, US }\end{array}$ & 190,000 & $\begin{array}{l}\text { Jatropha } \\
\text { and other } \\
\text { Agrofuels }\end{array}$ & $\begin{array}{l}\text { Signed or } \\
\text { under } \\
\text { negotiation }\end{array}$ & \multirow[t]{2}{*}{4.5} \\
\hline & LHB/ Israel & 100,000 & Jatropha & & \\
\hline Liberia & $\begin{array}{l}\text { EBF-EPO/ } \\
\text { UK }\end{array}$ & 169,000 & Palm Oil & Signed & -- \\
\hline \multirow[t]{8}{*}{ Madagascar } & $\begin{array}{l}\text { Sime Darby/ } \\
\text { Malaysia }\end{array}$ & 220,000 & $\begin{array}{l}\text { Palm oil } \\
\text { and rubber }\end{array}$ & Signed & \multirow[t]{8}{*}{4.1} \\
\hline & $\begin{array}{l}\text { Daewoo/ } \\
\text { Korea }\end{array}$ & $1,300,000$ & $\begin{array}{l}\text { Maize and } \\
\text { palm oil }\end{array}$ & Discontinued & \\
\hline & $\begin{array}{l}\text { Global Agro- } \\
\text { fuel/ } \\
\text { Lebanon }\end{array}$ & 100,000 & Jatropha & & \\
\hline & $\begin{array}{l}\text { Bio Energy } \\
\text { Limited/ } \\
\text { Madagascar, } \\
\text { Australian }\end{array}$ & 120,000 & Jatropha & & \\
\hline & $\begin{array}{l}\text { GEM } \\
\text { Biofuels }\end{array}$ & 120,000 & Jatropha & & \\
\hline & $\begin{array}{l}\text { Osho Group/ } \\
\text { South Africa }\end{array}$ & 100,000 & $\begin{array}{l}\text { Sugarcane } \\
\text { for ethanol }\end{array}$ & & \\
\hline & $\begin{array}{l}\text { Tozzi } \\
\text { Renewable } \\
\text { Energy/ Italy }\end{array}$ & 100,000 & Jatropha & & \\
\hline & $\begin{array}{l}\text { Unitech and } \\
\text { United } \\
\text { Technologies } \\
\text { Group/ US }\end{array}$ & 150,000 & $\begin{array}{l}\text { Sunflower } \\
\text { for oil } \\
\text { production }\end{array}$ & & \\
\hline \multirow[t]{2}{*}{ Mali } & $\begin{array}{l}\text { Project } \\
\text { Malibya; } \\
\text { LAP/ Libya }\end{array}$ & 100,000 & Rice & Signed & \multirow[t]{2}{*}{4.9} \\
\hline & $\begin{array}{l}\text { A1 Korayev/ } \\
\text { Saudi Arabia }\end{array}$ & 100,000 & Unknown & Planned & \\
\hline Mozambique & $\begin{array}{l}\text { Sekab/ } \\
\text { Sweden }\end{array}$ & 100,000 & $\begin{array}{l}\text { Agrofuel } \\
\text { crops }\end{array}$ & $\begin{array}{l}\text { Under } \\
\text { negotiation }\end{array}$ & 4.6 \\
\hline
\end{tabular}


Table 1: $\quad$ Continued

\begin{tabular}{|c|c|c|c|c|c|}
\hline $\begin{array}{l}\text { Host } \\
\text { Country }\end{array}$ & $\begin{array}{l}\text { Investor } \\
\text { Home } \\
\text { Country }\end{array}$ & $\begin{array}{l}\text { Land Area } \\
\text { (in has.) }\end{array}$ & Land Use & $\begin{array}{l}\text { Business } \\
\text { Status }\end{array}$ & $\begin{array}{l}\text { Property } \\
\text { Rights } \\
\text { Index } \\
(\mathbf{2 0 1 2})\end{array}$ \\
\hline $\begin{array}{l}\text { Republic of } \\
\text { the Congo }\end{array}$ & $\begin{array}{l}\text { Agri SA/ } \\
\text { South } \\
\text { Africa }\end{array}$ & 200,000 & Unknown & $\begin{array}{l}\text { Planned but } \\
\text { delayed }\end{array}$ & -- \\
\hline \multirow[t]{5}{*}{ Sudan } & $\begin{array}{l}\text { South } \\
\text { Korea }\end{array}$ & 690,000 & Wheat & Signed & \multirow[t]{5}{*}{--} \\
\hline & UAE & 378,000 & Unknown & Implemented & \\
\hline & $\begin{array}{l}\text { Saudi } \\
\text { Arabia }\end{array}$ & 500,000 & Unknown & Requested & \\
\hline & $\begin{array}{l}\text { Jarch } \\
\text { Capital/ } \\
\text { US }\end{array}$ & 400,000 & Unknown & Signed & \\
\hline & $\begin{array}{l}\text { Citadel } \\
\text { capital/ } \\
\text { Egypt }\end{array}$ & 210,000 & $\begin{array}{l}\text { Sugarcane, } \\
\text { corn, wheat }\end{array}$ & Signed & \\
\hline \multirow[t]{2}{*}{ Tanzania } & $\begin{array}{l}\text { China/ Intl } \\
\text { Water and } \\
\text { Electric } \\
\text { Corp }\end{array}$ & 101,000 & Corn & $\begin{array}{l}\text { Rights of use } \\
\text { received }\end{array}$ & \multirow[t]{2}{*}{5} \\
\hline & $\begin{array}{l}\text { South } \\
\text { Korea }\end{array}$ & 100,000 & $\begin{array}{l}\text { Food } \\
\text { production } \\
\text { and } \\
\text { processing }\end{array}$ & $\begin{array}{l}\text { Under } \\
\text { negotiation }\end{array}$ & \\
\hline Uganda & Egypt & 840,000 & Unknown & Planned & 4.9 \\
\hline Zambia & China & $2,000,000$ & Jatropha & Requested & 4.7 \\
\hline Zimbabwe & $\begin{array}{l}\text { China/ Intl } \\
\text { Water and } \\
\text { Electric } \\
\text { Corp }\end{array}$ & 101,000 & Corn & $\begin{array}{l}\text { Rights of use } \\
\text { received }\end{array}$ & 3.7 \\
\hline
\end{tabular}

Source: Görgen, et al (2009) and International Property Rights Index (http://internationalpropertyrightsindex.org/ranking) 


\section{Bibliography}

Abbott, P. C. and R. L. Thompson. 1987. Changing agricultural comparative advantage. Agricultural Economics 1 (2): 97-112.

Adesina, A. 2010. Conditioning trends shaping the agricultural and rural landscape in Africa. Agricultural Economics 41 (1): 73-82.

Alchian, A. A. and H. Demsetz. 1973. "The Property Rights Paradigm." Journal of Economic History 33 (1): 16-27.

Alston, L. J., G. D. Libecap and R. Schneider. 1996. The determinants and impact of property rights: Land titles on the Brazilian frontier. Journal of Law Economics and Organization 12 (1): 25-61.

Atwood, D. 1990. Land Registration in Africa: The Impact on Agricultural Production World Development 18 (5): 659-671.

Brasselle, A.-S., F. Gaspart, and J.-P. Platteau. 2001. Land tenure security and investment incentives: puzzling evidence from Burkina Faso. Journal of Development Economics 67 (2): 373-418.

Cooter, R. D. and H.-B. Schaefer. 2011. Solomon's Knot: How law can end the poverty of nations. New Jersey: Princeton University Press.

Cotula, L. 2011. Land deals in Africa: What is in the contracts? London: IIED.

Cotula, L., S. Vermeulen, R. Leonard and J. Keeley. 2009. Land grab or development opportunity? Agricultural investment and international land deals in Africa. London: IIED.

Deininger, K. and H. Feder. 2001. Land institutions and land markets. In Handbook of Agricultural Economics Vol 1, edited by B. L. Gardner and G. C. Rausser (ed.), 288 331. Amsterdam: Elsevier.

Deininger, K., D. Byerlee, J. Lindsay, A. Norton, H. Selod, and M. Stickler. 2011. Rising global interest in farmland: Can it yield sustainable and equitable benefits? Washington, D.C.: World Bank.

Dorward, A. 2012. The short and medium term impacts of rises in staple food prices Working Paper, Centre for Development Environment and Policy School of Oriental and African Studies, University of London

Eastwood, R., M. Lipton, and A. T. Newell. 2010. Farm Size In Handbook of Agricultural Economics, Vol. 4, edited by Prabhu Pingali and Robert Evenson, 3323-3397. Amsterdam: Elsevier.

Ellickson, R. C. 1993. Property in land. Yale Law Journal 102 (6): 1315-1400.

$F A O$. 2003. Trade Reforms and Food Security: Conceptualizing the linkages. Rome: FAO.

FAO. 2011. The state of food insecurity in the world: How does international price volatility affect domestic economies and food security? Rome: FAO.

FAO, IFAD, IMF, OECD, UNCTAD, WFP, the World Bank, the WTO, IFPRI and the UN HLTFFAO. 2011. Price Volatility in Food and Agricultural Markets: Policy Responses Interagency Report for the G20 Summit 2010. Available: http://www.worldbank.o $\mathrm{rg} /$ foodcrisis/pdf/Interagency_Report_to_the_G20_on_Food_Price_Volatility.pdf

Feder, G. and A. Nishio. 1999. The benefits of land registration and titling: economic and social perspectives. Land Use Policy 15(1): 25-43.

Feder, G. and T. Onchan. 1987. Land Ownership Security and Farm Investment in Thailand. American Journal of Agricultural Economics 69 (2): 311-320.

Feld, L. and S. Voigt. 2009. Economic growth and judicial independence: cross-country evidence using a new set of indicators. European Journal of Political Economy 19 (3): 497-527. 
Gavian, S. and M. Fafchamps. 1996. Tenure and allocative efficiency in Niger. American Journal of Agricultural Economics 78 (2): 460-471.

Görgen, M., B. Rudloff, J. Simons, A. Üllenberg, S. Väth, and L. Wimmer. 2009. Foreign Direct Investment (FDI) in Land in Developing Countries. Eschborn: Deutsche Gesellschaft für Technische Zusammenarbeit (GTZ).

Hayami, Y. 2010. Plantations agriculture. In Handbook of Agricultural Economics, Vol. 4, edited by Prabhu Pingali and Robert Evenson, 3305-3322. Amsterdam: Elsevier.

Hayami, Y. and V. W. Ruttan. 1985. Agricultural development: An international perspective. Baltimore, MD: Johns Hopkins University Press.

Headey, D. and S. Fan. 2008. Anatomy of a crisis: the causes and consequences of surging food prices. Agricultural Economics 39 (1): 375-391.

Ivanic, M. and W. Martin. 2008. Implications of higher global food prices for poverty in low-income countries World Bank Policy Research Working Paper 4594.

Jacoby, H. and B. Minten. 2007. Is land titling in Sub-Saharan Africa cost-effective? Evidence from Madagascar. World Bank Economic Review 21(3): 461-486.

Johnson, O. E. G. 1972. Economic Analysis, the Legal Framework and Land Tenure Systems. Journal of Law and Economics 15 (1): 259-276.

Kawagoe, T., Y. Hayami and V. Ruttan. 1985. The intercountry agricultural production function and productivity differences among countries. Journal of Development Economics 19 (1-2): 113-132.

Ostrom, E. and E. Schlager. 1992. Property-Rights Regimes and Natural Resources: A Conceptual Analysis. Land Economics 68 (3): 249-262.

Otsuka, K., H. Chuma and Y. Hayami. 1992. Land and Labor Contracts in Agrarian Economies: Theories and Facts. Journal of Economic Literature 30 (4): 1965-2018.

Williamson, J. 2002. Land, labor and globalization in the Third World, 1870 1940. Journal of Economic History 62 (1): 55-85. 



\section{Discussion on Christian Häberli}

summarized by

\section{Johannes Schwarze}

This discussion shows diverging perceptions of reality between the economic and legal profession. While both agree that with respect to agricultural issues in least developed countries lies in productive efficiency, economists tend to approach Large-Scale Agricultural Investments from the theoretically consistent neoclassical concept of functioning markets. For them, allocative efficiency is key. Legal scholars, on the other hand, highlight the incompleteness of markets and concentrate on issues of distributive justice.

Before starting the open discussion, Christian Häberli thanks and generally agrees with the economic analysis of the discussant (Laarni Escresa) but remarks on three points: First, although one might understand land as the limiting factor in agricultural production, it has to be pointed out that available arable land is underused in most LDCs. Therefore, increasing agricultural production is rather an issue of the productivity of the used land than an issue of extending the input factor land. Structural problems like climate change and cyclical problems like changing weather are affecting harvests the most. Second, he points out that especially new market-based risk management can work fine in well-developed and free market countries. However, such market structures do not exist in poor LDCs especially to address the cyclical problems. Third, Häberli emphasizes that agricultural markets, especially in LDCs, are far from perfect (what mainstream economists falsely assume). Most importantly, structural obstacles have to be overcome to significantly decrease the cyclical risk in LDCs' agricultural production. Here lies the main difference between rich and poor countries.

Opening the discussion, Eyal Benvenisti annotates that in addition to food security and land property rights, the water aspect is similarly urging. The particularity with water is that third-party neighboring countries also have water claims, as most water is trans-boundary. It has been shown that international water norms and laws can discipline states to refrain from unsustainable water use. This knowledge may be beneficial to approach the 
international legal regime regarding the land grabbing issue in that host states might refrain from inequitable and unsustainable land use. However, Benvenisti questions that home-state liability is the appropriate means to approach a global risk.

Regarding Escresa's economic analysis, Wolfgang Weigel remarks that to the best of his knowledge, productivity increases in agriculture are so high that they outweigh land as a limiting factor. Thus, the scarcity of land should not be an important constraint. Weigel questions whether the allocative efficiency of land use in the host LDCs is different for investors and farmers. Finally he conjectures that according to Buchanan, the single, unified foreign investor is better organized and thus stronger than the dispersed farmers. This dramatic imbalance in bargaining power between the parties makes the application of the Coase Theorem impossible. To overcome this problem (to institutionalize Coasian bargaining), small landholders would have to unify into one bargaining party strong enough to face the investor.

Stefan Oeter is fascinated by the topic and recognizes the urgent ordering problem of the international community. However, the question of how to resolve this problem still remains open also after Häberli's contribution. Oeter points out that one could reflect about strengthening the international legal regime in the classical way, by strengthening supervision duties of home states over their investors. However, that leads to the conflict of high monitoring costs for home states without the necessary incentives for home states to undertake this task (little to win and imposing costs on important stake holders is risky). This is similar to the problem which had been discussed during the previous day regarding private military companies. Consequently, international standards might remain ineffective. Finally, Oeter questions whether another hybrid organism defining codes of conduct might not be more effective.

In response to the above remarks, Häberli acknowledges that interstate water questions are very important in relation to agricultural issues. Some can be resolved by adequate property rights regimes and technology however, both rather exist in developed countries. Moreover, energy prices affect agricultural production up to three times more than any other economic activity. Not only on-farm and farm-to-market transportation costs, but also fertilizer costs, depend on the oil price. Property rights are crucial in order to improve the LDCs' farmers' position. Even though property rights might exist de jure in some cases they cannot be implemented de facto in the weak institutional frameworks.

Regarding home-state risk management, Häberli does not think that this is superior to the host states' risk management. But home states have state guaranties and ODA that significantly decrease risk and improve the foreign investor's situation over the domestic investor's situation. Further- 
more, Häberli agrees to Weigelt's point that productivity increases can outweigh land as a scarce input factor. He also points out the severe postharvest losses in many developing countries. Addressing these huge problems would be very beneficial for the agricultural production in LDCs. However, Häberli accentuates that agricultural investments in weak states are not for "Sunday School Children". Investors need to be big (China) or seconded by the World Bank in order to undertake such investments. To attract investors, at least a $20 \%$ return on investment is necessary. Moreover, extraterritoriality is necessary to insure responsible investor behavior and avoid corruption. The danger of liability at home effectively disciplines investors. However, proving corruption is a most challenging endeavor.

Furthermore, it is important to understand that competing with China makes ethical behavior difficult if not impossible for investors. But one strong incentive to control home governments stems from migration. The disastrous situations in LDCs resulting from agricultural investments will trigger migration that investor home countries will then have to deal with. In addition, Häberli agrees with the problem of independent monitoring and monitoring costs but points to already existing hybrid regimes and accompanying international instruments and codes. Soft law can help in this context so that hard law is not absolutely necessary. Finally, Häberli raises the question of what a welfare increase means in the context of land grabbing: one would have to weigh a global and national food security increase against the food security decrease for the affected local farmers.

Reopening the discussion, Thilo Marauhn indicates that, regarding Afri$\mathrm{ca}$, the discourse on sustainable land use is strongly fragmented between five disciplines. Although the topic is the same, environmental, cultural, economic, legal, and political discourses lack interconnection. Remarkably, the law and economics discourse is more interdisciplinary, although it traditionally concentrates on land reform. However, Marauhn is optimistic that the discourses will become more intertwined in the future. For Marauhn the main problem lies, first, in the lack of national institutions. He emphasizes the unfairly unequal treatment of domestic and privileged foreign investors. The interplay between customary law and other forms of property rights is a big issue. For Marauhn, the lack of cadastre and the resulting uncertainty pose the main problem. He is skeptical that international agreements, i.e., BITs, can solve the national property rights deficiency. However, he is confident that informal law can help.

Michael Fehling brings Sen's capability approach into play. Sen's approach might be more helpful as land grabbing is rather more a distributional problem than a classical economic efficiency problem. Second, he questions whether multilateral agreements really can solve the enforcement and abuse-of-power issues. 
Haksoo Ko demands the translation of the more intuitive concepts of $\mathrm{Hu}-$ man Rights and Food Security into the language of mainstream economics, to itemize and quantify it. Also, for him, the concept of public interest and public order with regards to land grabbing remained unclear during the presentation.

Christopher Drahozal again emphasizes the problem of food security in the host country. He questions whether arbitration lawyers do really deal with issues of public policy, a point already controversially debated in the academic discourse. Who would be the plaintiff?

Stefan Voigt comes back to Escresa's economic analysis feeling that several points need being highlighting or recapitulation. First, he points to the price decrease after the 2007-2008 food crisis. For Voigt, this shows the successful market reaction to the food crisis. He argues that if productivity is the main problem for agricultural efficiency and the security of property rights is key for increasing productivity, and if further the insecurity about property rights is substantial in many of the host countries, then FDI could not only be a way to increase the security of property rights but also to substantially increase food productivity in the world. Voigt is aware that he argues in terms of allocative efficiency and not in terms of distribution, despite the fact that during the discussion, productivity was identified as the crucial component in efficiency in production,

Voigt points out that first the arable land has to be extended before the productivity can increase on that land. This follows the logic that the cake has to be baked before it can be distributed. As a second point, Voigt reiterates that not property rights per se are important but their enforcement. For this, national or international codes do not suffice but an independent judiciary is indispensable. Since the domestic creation of such a judiciary takes long to build, in order to have quick results, Voigt recommends turning to an already existing judiciary, i.e., international courts. As an example he refers to the former British colonies that successfully attracted investment by dismantling their traditional committee of public counsel. Lastly, he points out that the differences in technology available to farmers of developed and developing countries are exactly arguments in favor of agricultural FDI, since it is these investments that will bring technology.

Replying to the second open discussion, Häberli first straightens out that his research deals with the international aspects of FDI and food security and not with the often disastrous national food situations in host countries. Although he agrees with all conference participants that the latter are more directly causing famine, he hopes to have convinced the audience that a severe problem also persists on the international level. He calls attention to the fact that the situation is not black or white: even without independent judiciaries and corrupt governments, the free press and internationally supported NGOs might serve as effective means to discipline 
governments and investors via public pressure (although these players might sometimes overdo it in keeping out any type of FDI). On the other hand, even if international codes exist they might not be practiced (e.g., regarding child labor) or not even respected. With regards to Sen's capability approach, Häberli states that the international character of the problem is difficult to tackle with Sen's approach focusing on the national level.

On the subject of enforcement and abuse of power in a multilateral framework, Häberli suggests making more use of the existing instruments (e.g., the subsidies discipline in the WTO, the TRIMS agreement - however, these instruments could be expanded and improved). The problem lies in the tension of a trade liberalization tendency (now on the regional, no longer only on the multilateral level) against the food security challenge: reductions of tariffs and subsidies increase competition which may be fine in the long run - however, in the short run, trade liberalization exposes small subsistence farmers to bigger threats. Häberli passes on the question on mainstream economics quantification to his co-speaker.

Häberli disagrees that the ordre publique is not defined in the literature. An according exception is included in all international agreements - however it might be difficult to be invoked, especially in an arbitration dispute. With respect to the question whether arbitration can respect public policy issues, Häberli concedes that no official convention or code exists here. Still, he hopes that international arbitrators will respect the do-no-harmapproach.

Regarding the falling in food prices after the 2007-2008 price bubble, Häberli explains that this was due to good weather in Australia and the US, where production could be increased. US farmers invested heavily in silos to stock their harvest as they expected further price rises in the future. Häberli agrees that FDI could increase productivity - however only for the foreign, not the domestic investor. Still, it might lead to economic growth and affect global food security positively - even if cash crops are exported and perhaps even via biofuel which serves as a floor price for foodproducts. Nonetheless, neither national nor household food security is guaranteed through FDI. Häberli concludes that an independent impact assessment of large-scale agricultural investments is necessary - and feasible since investors often have to rely on their home governments for ODA, subsidies, or protection. At this point, home governments could easily bring in their monitoring.

Closing the discussion, Escresa turns to the counterfactual and asks what would have happened in Africa without FDI. She stresses how difficult it is for example to define a fair price for land rent in LDCs. Actually, the lease price which is now paid by the foreign investor is not lower than the estimated price a local investor would have paid. Agreeing with every- 
body in the room that alleviating poverty and famine is key - the urging question remains: how? 


\section{Short Biographies}

BENVENISTI, EYAL (Prof. Dr.): Eyal Benvenisti, LLB (Jerusalem) 1984, LLM (Yale) 1988, JSD (Yale) 1990, is Anny and Paul Yanowicz Professor of Human Rights at Tel Aviv University Faculty of Law. He is Global Visiting Professor at New York University School of Law (since 2003) and Associate Member of the Institut de Droit international (2011). He is the recipient, most recently, of the European Research Council Advanced Grant for research on 'Sovereigns as Trustees of Humanity: The Obligations of Nations in an Era of Global interdependence' (GlobalTrust) (2013-2018).

DRAHOZAL, CHRISTOPHER R. (Prof. Dr.): Christopher R. Drahozal is the John M. Rounds Professor of Law and Associate Dean for Research and Faculty Development at the University of Kansas School of Law. He has written extensively on the law and economics of arbitration, and has made presentations on arbitration law and practice throughout the United States, Canada, Europe, and Asia. Professor Drahozal is an Associate Reporter for the Restatement (Third) of the U.S. Law on International Commercial Arbitration, and is serving as a Special Advisor to the U.S. Consumer Financial Protection Bureau, assisting with its study of arbitration clauses in consumer financial services contracts.

EGER, THOMAS (Prof. Dr. rer. pol.): Since 2001 Professor of Law and Economics, Faculty of Law, University of Hamburg, Germany. Diploma in Economics (University of Marburg), Ph.D. (Dr. rer. pol.) in Economics (University of Paderborn), Habilitation in Economics (University in Kassel). Director at the Institute of Law and Economics, Program Director of the "European Master of Law and Economics (EMLE)" Program, Director of the DFG-Graduiertenkolleg "The Economics of the Internationalisation of the Law", Vice-Dean for Research and International Affairs. Guest lectures in Mumbai, Bangalore, Beijing, Shanghai, Haifa, Tel Aviv and Cairo. Current research interests: Economic Analysis of Copyright Law, Law and Economics of European Integration, The Economics of Private Enforcement of AntitrustLaw.

ESCRESA, LAARNI (Dr.): Laarni Escresa earned her Ph.D. in Law and Economics at the University of Bologna and Erasmus University Rotterdam and MA in Law and Economics at the University of Hamburg and Ghent University. She was a postdoc fellow at the Institute of Law and Economics, University of Hamburg and a Jean Monnet Fellow at the Robert Schuman Center for Advanced Studies, European University Institute in Florence. 
FEHLING, MICHAEL (Prof. Dr.): Prof. Dr. Michael Fehling is Professor at Bucerius Law School in Hamburg, where he has held the Chair of Public Law and Comparative Law since 2001. Previously he taught Public Law at the University of Freiburg/Breisgau. His research interests include Economic Regulation and Administrative Law from a European perspective (particularly the reform of public services and the regulation of network-industries), Environmental Law, Media Law, Freedom of Science and University Organization, Comparative Public Law (USA) and the Economic Analysis of Administrative Law. Together with Matthias Ruffert he edited a comprehensive work on the legal perspectives on regulation.

FELDTMANN, BIRGIT (Associate professor, Dr. jur.): German law degree and Dr. jur. in 2002 from the University of Bremen (Germany). Employment in scientific and teaching positions at University of Bremen (Germany), Aarhus University (Denmark) and University of Southern Denmark, where she since 2007 holds a position as associate professor. She is International Coordinator at the Department of Law and with her research connected both to the Department of Law and the multidisciplinary Center for War Studies at the University of Southern Denmark. She is leading a research group dealing with maritime security, law enforcement at sea and maritime piracy, and currently finalizing the project "Private armed guards on Danish vessels - legal frame work, legal challenges and specific strategies", cofunded by Den Danske Maritime Fond. She has been guest lecturer/examiner at different Universities and institutions of higher education, such as the Royal Danish Officers Academy and at institutions in Germany, Lithuania, Latvia, USA, Netherlands, and Norway. She has been a legal advisor for different maritime stakeholders and the Danish Ministry for Foreign Affairs, and is connected to WG2 of the Contact Group on Piracy off the Coast of Somalia (CCPCS).

GÖSSLER, MAX (Dipl. Vw.): Max Gössler is a doctoral student at the Graduate Center of the German Institut for Economic Research (DIW) in Berlin. He studied Economics at the Ludwig-Maximilians-University Munich and at the University of British Columbia, Vancouver, Canada. From 2010 to 2012 he has worked as a research associate in the Development and Security department at the DIW. As part of the "PiraT" project, which was funded by the Federal Ministry of Education and Research (BMBF), he primarily focused his research on the economic aspects of piracy and maritime terrorism.

HÄBERLI, CHRISTIAN (Dr.): Christian Häberli is a Senior Research Fellow at the World Trade Institute of Bern University (Switzerland). Main research on trade and investment regulation and policies relating to food security. Professional career in development, trade and agriculture, with postings in Madagascar, Thailand, Nepal and Switzerland. From 1978 to 1982 he worked for the International Labour Organisation (ILO) and from 1983 to 
2007 for the Swiss Government. He completed his legal studies with a Ph.D. on the subject of African Investment Law (1979); he also obtained a degree at the Institut Universitaire d'Etudes du Développement in Geneva (1975) and in theology (Bern 2009). In WTO, he chaired the Committee on Agriculture (Regular Session) and he has served in fifteen dispute settlement panels, namely EC - Bananas III, Japan - Apples, EC - Biotech (GMO), China Trading Rights (Audiovisual Services) and United States - Country of Origin Labelling (COOL).

JESSBERGER, FLORIAN (Prof. Dr.): Florian Jessberger is Professor of Criminal Law at the University of Hamburg where he holds the Chair in Criminal Law, Criminal Procedure, International Criminal Law and Modern Legal History and where he serves as the Director of the Criminal Law Department and as a Vice-Dean of the Faculty of Law. Before joining Hamburg University, Jessberger was the Lichtenberg Professor of International and Comparative Law at Humboldt-University Berlin where he still is a co-director of the Franz-von-Liszt-Institute of International Criminal Justice. Jessberger is a co-editor of the Journal of International Criminal Justice (Oxford University Press) and published extensively in the fields of German criminal law, international criminal law and comparative criminal law. Jessberger was a visiting scholar or lecturer, inter alia, at the University of California, Berkeley, (United States), the University of Western Cape (South Africa), the China University of Political Science and Law (China), and the University of Naples Federico II (Italy).

KIRCHNER, CHRISTIAN (Prof. Dr. iur. Dr. rer. pol. Dr. h.c.): Christian Kirchner is Senior Professor at Humboldt Universitaet, Berlin; he is a member of the Managing Board of Wittenberg Center for Global Ethics e.V. He is member of the American Law Institute. He has served as visiting professor at various universities worldwide (e.g., Mexico City, Pyongyang, St. Gallen, and Shanghai). His research interests include competition law, corporate law, law and economics, institutional economics and business ethics. In 2013, he was awarded the Hayek medal.

KO, HAKSOO (Prof. Dr.): Haksoo Ko is Professor at Seoul National University School of Law in Seoul, Korea. He holds a B.A. in Economics from Seoul National University, and received both a J.D. (law) degree and a $\mathrm{Ph} . \mathrm{D}$. degree in Economics from Columbia University in New York, USA. His research interests include privacy and data protection; technology and communications; and contract negotiation. He has teaching experiences at Columbia University, National University of Singapore, and University of Hamburg. He also practiced law with large law firms in the USA and in Korea.

LEWISCH, PETER (Prof. Dr.iur. et Dr. rer.soc.oec.): Since 2011, Professor of Criminal Law, University of Vienna, Austria. Director of the Center for Business and Financial Crime. He is also a practicing lawyer. 
Current research interests in the economic analysis of law: Experimental economics, economics and psychology, economic analysis of procedural law, regulatory and competition law.

MARAUHN, THILO (Prof. Dr.): Thilo Marauhn is Professor of Public Law, International and European Law at Justus Liebig University, Giessen, Germany. He is a permanent Visiting Professor of Constitutional Theory at the University of Lucerne. Marauhn is a member of the Advisory Board on United Nations Issues of the German Federal Foreign Office, a member of the German National Advisory Committee on International Humanitarian Law and a member of the International Humanitarian Fact-Finding Commission. He has published widely on the law of international security and, among other functions, is a member of the editorial board of the Journal of Conflict and Security Law (Oxford University Press).

OETER, STEFAN (Prof. Dr. jur.): Since 1999 Professor for German and Comparative Public Law and Public International Law, Faculty of Law, University of Hamburg. Law degree at the university of Heidelberg; 19871997 research fellow at the Max Planck Institute for Comparative Public and Public International Law, Heidelberg; 1990 Dr. iur. utr. (Heidelberg); 1997 Habilitation in Public Law and International Law (University of Heidelberg). Chairman (since 2006) of the Independent Committee of Experts of the European Charter for Regional or Minority Languages (Council of Europe); Member of the Scientific Advisory Board of the Federal Ministry of Transport; President of the Historical Commission, International Society for Military Law and the Laws of War; Member of the Permanent Court of Arbitration. Current research interests: Comparative federalism, minority protection and human rights law, humanitarian law, European and international economic law, theory of international law and international relations, Global Constitutionalism.

SCHMIDTCHEN, DIETER (Prof. em. Dr.): Department of Economics, Saarland University; Director of the Center for the Study of Law and Economics, Saarland University. Research interests: Antitrust, New Institutional Economics of International Transactions, Strategic Power Index.

VOIGT, STEFAN (Prof. Dr.): Stefan Voigt is director at the Institute of Law \& Economics at Hamburg University and is a fellow with CESifo (Munich). Previous positions include chairs at the Universities of Marburg, Kassel and Ruhr-University Bochum. Voigt has been a fellow at the Institutes for Advanced Study in Berlin, Greifswald and Notre Dame. His research focuses on the economic effects of constitutions. Voigt is editor of Constitutional Political Economy and a member of various boards including those of Public Choice and the International Review of Law \& Economics. Voigt has consulting experience with both the public and the private sector. He has worked with the World Bank, the European Commission and the OECD but also with the European Round Table of Industrialists (ERT). The 
German newspaper Handelsblatt ranks Voigt among the Top-100 German speaking economists according to quality-weighted research output.

VON WANGENHEIM, GEORG (Prof. Dr.): Georg von Wangenheim is professor for foundations of law, private law and the economic analysis of law at the university of Kassel. He holds a diploma in economics (University of the Saarland, Saarbrücken) and passed the First State Exam in Law at Freiburg in Breisgau. He received his doctorate in economics at the University of Freiburg in Breisgau and got his habilitation from the University of Hamburg. Before coming to Kassel he worked as senior research fellow at the Max-Planck-Institute of Economics at Jena. He was visiting scholar at UC Berkeley and visiting professor at Pompeu Fabra University at Barcelona. Current research interests are economics of tort, contract, public procedural and property law as well as the co-evolution of law and social institutions. 



\section{Index}

$\mathrm{a} / \mathrm{b}$ tests 77

Adaptation costs 263, 275

Agency costs 248, 255, 257, 260, 274

Agreement on the European Economic Area 80

Agronomists 288

Allocative efficiency $311,321 \mathrm{f}$, 324

Anti-suit injunction $148 \mathrm{f}, 151 \mathrm{f}$, 154 ff, 159, 161, 163, 167, 171

APEC 79, 95

Arbitration $148 \mathrm{f}, 151,157,159 \mathrm{f}$, 164, 300, $324 \mathrm{f}, 327$

Behavioural regularity 4, $6 \mathrm{f}, 10 \mathrm{f}$, 14, 16, 23, 25, $28 \mathrm{f}$

Best Management Practices (BMP) 175,203

Bilateral governance 40

Bounded rationality 104, 106, $113,117,250$

Breach of law 17

Budget constraints $210 \mathrm{f}$

'California Effect' 111

'Capability approach' $101 \mathrm{f}, 113$, 323,325

Case-Zablocki Act 34, 47, 51

Centralisation 248

Child labour 289

Choice-of-law $92 \mathrm{f}$

Closed-economy 85

Coase Theorem 322

Coasian bargaining 322

Code of Conduct $134 \mathrm{ff}, 139,145$

Codes of Privacy $110 \mathrm{f}$

Cognitive patterns 16

Comity $8 \mathrm{f}, 36 \mathrm{f}, 147 \mathrm{ff}$
Compound administration 112

'Conflict of law rule' 182

Constitution-building $253 \mathrm{ff}, 273 \mathrm{f}$

Constitutional economics $249 \mathrm{ff}$, $253 \mathrm{ff}, 263$

Constitutional longevity 281

Constitutional revisions 250, 258, 274

Consuetudo 7, 23 ff, 29

'Consumer Privacy Bill of Rights' 82

Consumer surplus 85

Cookies 72 ff, 81, 109

Coordination game $1,4,18 \mathrm{f}$, $23 \mathrm{ff}, 29,31,41 \mathrm{f}, 62,203$

Council of Europe Convention 95

Counter-piracy enforcement 174, 177, $180 \mathrm{ff}, 185 \mathrm{ff}, 189,193$, 195,200

Cournot Nash equilibrium 208

Cost-benefit analysis 102

'Credible commitment theory' 232

Criminal law 2, 182, 189 f, 215 , 218 f, 226, 228 f, 238, 244, 329

Customary International Law (CIL) $2 \mathrm{ff}, 8,12 \mathrm{f}, 16 \mathrm{ff}, 23 \mathrm{ff}$, $28 \mathrm{ff}, 31 \mathrm{f}, 37$

Customary law 3, 5 ff, 12, 15 ff, $29,31,134,315,323$

Customary rights 311

Data availability 77

Data controllers 70, $78 \mathrm{f}, 82 \mathrm{ff}$

Data privacy issues $69,71,80 \mathrm{ff}$, $89 \mathrm{f}, 93,96$

Data privacy law 80,92 
Data Protection Directive 79 f, 95 , 107, 118

Data Protection Commissioner 112

Data protection law 108, 112

Data protection $88 \mathrm{f}, 93,95,99$, $101 \mathrm{f}, 104,106 \mathrm{ff}, 118,329$

Data subjects $70,83 \mathrm{ff}$

Decentralisation 248

Decision making costs $253 \mathrm{ff}$, 259, 261, 265, $273 \mathrm{ff}$

De facto 96, 126 f, 268, 322

De jure 322

Delegated management 289

Development aid 213

Dilemma game $23 \mathrm{ff}$

Domestic contestation 238

Domestic law 36, 55 f, 94, 127 f, 192

'Do-Not-Track' (DNT) mechanism 82

Dworkinian principle 165

Ejidos 287

Enforcement costs 38, 94, 311

'Enhanced cooperation' 253, 267, $275 \mathrm{f}, 279,281$

e-Privacy Directive 80

European Commission 80, 82, 86, 95, 112, 247, 268, 276, 330

European Constitutional Group 248

'European Constitutional impossibility theorem' 249

European Court of Justice $148 \mathrm{f}$, 161, 267, 277, 281

European Data Protection Board 82

European Union (EU) $101 \mathrm{ff}$, $111 \mathrm{f}, 150,192,239,247 \mathrm{ff}$, $251 \mathrm{ff}, 258,263 \mathrm{f}, 266 \mathrm{ff}$, 274 ff, 279 f, 296

Exclusive Economic Zone (EEZ) 178
Executive agreements 34, 36, 63, $67 \mathrm{f}$

Export restrictions 288, 296

Externality 88, 94

Exit costs 39

'Fair price' 290, 325

Federal Trade Commission 81

Fiscal Pact 267

Folk Theorem $25 \mathrm{f}$

Food and Agriculture Organization (FAO) 285 f, 288

Food security 283 ff, 293, 295 ff, $305 \mathrm{ff}, 310,314 \mathrm{f}, 321,323 \mathrm{f}$

Food security issues 298, 305, 310

Framing effect 104, 106

Game theory 4, 23, 25, 30, 41, $147,152,171$

General Agreement on Tariffs and Trade (GATT) 257

General and consistent practice 14

General custom 14

German Federal Constitutional Court 258, $265 \mathrm{f}$

'Global land rush' 292

Global food price stability 308

Global Privacy Policies $110 \mathrm{f}$

Global security environment 122

Grim trigger strategy 26

'Group4Securior' 123

'Hague Model' 184

Hard law 52, 58, 67 f, 135, 137 ff, 323

Human rights 119, $123 \mathrm{f}, 129 \mathrm{ff}$, 132 f, 186, 194, 200, 231, 238, 244, $293 \mathrm{ff}, 297 \mathrm{ff}, 324$

Human rights law 124, 129 f, 133, 135, 139, 186, 295, 305

Human Rights Council 123, 132

Human rights violation 130 f, 299

Hybrid constitutions 257, 267, $273 \mathrm{f}$

Impossibility theorem 247, 249, 266, 268, 273, 279 
Impunity $223 \mathrm{f}, 229,232$

'Inalienability concept' 289

Individual welfare 100, 103

Informal international law $33 \mathrm{ff}$ Informal law 35, $38 \mathrm{f}, 41 \mathrm{ff}, 50 \mathrm{f}$, $54 \mathrm{ff}, 323$

Informality $35 \mathrm{f}$

Information asymmetry $70,78 \mathrm{f}$, 99, $103 \mathrm{ff}, 111 \mathrm{f}, 255 \mathrm{f}, 281$

Institutional economics 35, 45, 103

Inter alia 65,238

Intergovernmental organisations 287, 296, 300

International agreements $35 \mathrm{f}, 38$, $42 \mathrm{f}, 45,47 \mathrm{ff}, 62 \mathrm{ff}, 323,325$

International armed conflict 125 , 127,236

International Committee of the Red Cross (ICRC) 128, 133, 139

International cooperation and harmonization $70 \mathrm{f}, 85,89,92,96$

International Criminal Court (ICC) 217,235

International criminal justice 217 , $228,232,243 \mathrm{f}$

International harmonization 71 , $88,94,96,99,109,111$

International humanitarian law (IHL) 133,236

International Human Rights Law 124, 129 f, 139, 305

International Maritime Bureau (IMB) 175, 202

International Maritime Organisation (IMO) 179

International Military Tribunal (IMT) 217

International Military Tribunal for the Far East (IMTFE) 217

International organizations (IOs)

$2,13,66 \mathrm{f}, 120,145,238,257 \mathrm{f}$
Internet transactions 76, 103

Investor-state arbitration 300

Judicial discretion $277 \mathrm{f}$

Kaldor-Hicks optimum 25

Large-scale land acquisitions 292, 298

Law enforcement $78,130,181$, 201, 213, 224, 328

Least Developed Countries (LDCs) $313,321 \mathrm{ff}$

Legal intervention 24, 79, 226

Legal obligations $11,19,35,133$ f, 237

Legislation $42,56,79,81 \mathrm{f}, 92,94$ ff, $105 \mathrm{f}, 138,173 \mathrm{f}, 179,196$, 200, 244, 275, 283, 289, 293, 299

'Legitimate rule-of-law considerations' 189

Liability rule 145

'Libertarian paternalism' 100 , $105 \mathrm{f}, 117$

'Like product' rules 296

'Limited universality principle' 182

Maritime piracy 173 f, 196, $199 \mathrm{ff}, 210$

Mechanization $312 \mathrm{f}$

Modernity 17

Modification costs 39, 68

Modus operandi 174, 183, 201

Monitoring costs 38, 44, $322 \mathrm{f}$

Montreux Document 133 f, 137, 139

Multilateral agreements 65,252 , 323

Multilateral coordination 4

Municipal law $137 \mathrm{f}$

Mutual trust $149 \mathrm{f}, 156,158 \mathrm{f}, 165$

Nash equilibrium 25, 205, $208 \mathrm{ff}$

National rules 265 f, 274

National sovereignty 251 f, 258, $263 \mathrm{f}$ 
NATO 53, 176, 203

Natural law 7

Negotiation costs 38, 44

New Institutional Economics

(NIE) 37, 61, 168, 249 f, 254

Non-governmental organisations

(NGOs) 47, 58, 218, 221, 286,

$291 \mathrm{f}, 300,324$

Non-international armed conflict

127,236

Norm entrepreneur 18

Normativity 9

Norms 2, 9, 18, 24, 137, 158, 229, 237, 321

Nuremberg Principles 218

One-shot game $3 \mathrm{f}, 8$ f, 23, 153

Opinio iuris 23, 25 f, 29 f, 66, 133

Opinio juris 7, 12, $15 \mathrm{f}$

Opportunity costs 201, 212 f, 215

Opt-in-cases 266

Opt-out cases 266

Optimism bias 117

Ordre public 172

Organisational autonomy 121

'Paradox of control' 91, 104, 117

Peacebuilding strategy 226

Perfect markets 309

Permanent titles 289

Persistent objector 17

Personal data $69,104 \mathrm{ff}$

Personalized services 76

Petrification effect 258 f, 264, 274

'Petrification trap' 259, 267, $275 \mathrm{f}$

Price volatility 288, 309 f, 314

Primum non nocere 299

Principal-agent problems 58, 273

Principal-agent relationship 68

Prisoners' Dilemma 24 f, 29, 41, 147, 153, $164 \mathrm{ff}, 172$

Privacy governance 111

Private military contractor $119 \mathrm{ff}$, 145
Private Military and Security Companies (PMSCs) 132

Private ordering 168

Privacy paradox 91, 104, Privacy policy $72,75,81,86 \mathrm{f}$, 104

Private enforcement 107, 112

Private Security Service Provider 134, 136

Privately Contracted Armed Security Personnel (PCASP) 196

Procedural cooperation 94

Producer surplus 85

Property rights 42, 100 f, 113, 308, $310 \mathrm{ff}, 321 \mathrm{ff}$

Property Rights Index 308, 316 ff

Proprio motu 220

Public international law 2, 4, 8, $34,46,120,158,252,256 \mathrm{ff}$, $260,265,274,280,299,330$

Purchasing behaviour $76 \mathrm{ff}$

Pure strategies 205

'Race to the bottom' 167,308

'Ratification' 36 f, 49, 68, 218, 257, $260 \mathrm{f}, 265 \mathrm{f}, 268,274 \mathrm{f}$, 280

Ratification costs 38

Ratification procedure 265 f, 275

Rational choice model 103

Ratione loci et personae 219

Ratione materiae 219

Ratione temporis 219

Reciprocity 153, 172

Regulatory chill 294

Rent-seeking behaviour 164

Rent-seeking costs 201, 212

Resource allocation 311, 313

'Responsibility to protect' 226 , 299

Revision costs 263, 265

Risk management 134, 288, $321 \mathrm{f}$

'Rule of law' 194, 196 
Rules of Engagement (RoE) 174, 192, 200

'Safe Harbor' framework 86

Schengen Treaty 266

Self-sufficiency 307

Shared Awareness and Deconfliction (SHADE) 202

Social capital $10 \mathrm{f}, 31$

Social dilemma 4, 6, 8, 19, $23 \mathrm{ff}$, 28,30

Soft cooperation 90,92

Soft law 33, 38, 45, $52 \mathrm{f}, 58,61 \mathrm{f}$, $64 \mathrm{ff}, 89,112,119 \mathrm{f}, 132 \mathrm{f}$, $137 \mathrm{ff}, 323$

Sovereign equality 2

'Sovereignty costs' 229

Spot market exchange 64

Stage game $24 \mathrm{ff}$

'Stag hunt' game 153, 164, 166

State behavior 68

State failure 200

State practice $4 \mathrm{f}, 12 \mathrm{f}, 37,127 \mathrm{f}$, $184,189 \mathrm{f}, 236 \mathrm{f}$

Steering effect 138

Stricto sensu 137

SUA Convention 173, 179, $182 \mathrm{ff}$, 190, 200

Substantive law 99

'Supranational union' 257 f, 260 ff, 275

Temporary Steering Committee 136
Terms of trade $167 \mathrm{f}, 306$

Territorial sovereignty 2

Tit-for-tat strategy 26, 153, 172

Tort law 102, 229

Tracking technologies $71 \mathrm{f}, 77 \mathrm{f}$

Trade liberalisation 52, 287

Traditional governance 121

Transaction costs $10 \mathrm{f}, 19,32,38$, $61 \mathrm{f}, 104,106 \mathrm{f}, 109,112,117$, $121,169,245,250,311$

Transaction cost theory $67 \mathrm{f}$

Treaty law 2, 55, 128, 137

Treaty provisions $263,267,290$

Treaty revisions $247 \mathrm{ff}, 263 \mathrm{ff}$, 274

Trilateral governance 40

Unanimity Rule 248 f, 251 f, $253 \mathrm{ff}, 257 \mathrm{ff}, 273 \mathrm{f}$

United Nations Convention on the Laws of the Seas (UNCLOS) 173, 177 f, 179 ff, 200

UN Security Council 53, 185, 218, $220 \mathrm{f}, 230$

Urbanisation 287

User information 72, $75 \mathrm{f}, 81,92$

'Veil of uncertainty' 250, $253 \mathrm{ff}$, $258 \mathrm{f}, 273 \mathrm{f}, 280 \mathrm{f}$

World food spike 307, 309

World Trade Organization (WTO) 252

Zero-sum game 41 